Klaus E. Müller

\title{
Der sechste Sinn
}

\author{
Ethnologische Studien
}

zu Phänomenen

der außersinnlichen

Wahrnehmung 
Klaus E. Müller

Der sechste Sinn 
Klaus E. Müller (Dr. phil.) ist emeritierter Professor für Ethnologie an der Johann Wolfgang Goethe-Universität Frankfurt am Main. Er steht der »Wissenschaftlichen Gesellschaft zur Förderung der Parapsychologie« vor und arbeitet in verschiedenen interdisziplinären Forschungsprojekten mit, u.a. am Kulturwissenschaftlichen Institut Essen und am HanseWissenschaftskolleg Delmenhorst. 
Klaus E. Müller

Der sechste Sinn.

Ethnologische Studien zU Phänomenen

der aussersinnlichen Wahrnehmung

[transcript] $\quad \times \quad T \quad E \quad X \quad T \quad E$ 


\section{Bibliografische Information der Deutschen Bibliothek}

Die Deutsche Bibliothek verzeichnet diese Publikation in der Deutschen Nationalbibliografie; detaillierte bibliografische Daten sind im Internet über http://dnb.ddb.de abrufbar.

(C) 2004 transcript Verlag, Bielefeld

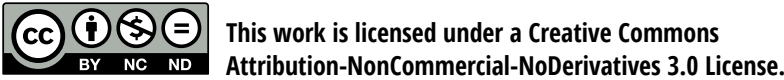

Umschlaggestaltung und Innenlayout: Kordula Röckenhaus, Bielefeld Satz: digitron $\mathrm{GmbH}$, Bielefeld Druck: Majuskel Medienproduktion GmbH, Wetzlar ISBN 3-89942-203-I

Gedruckt auf alterungsbeständigem Papier mit chlorfrei gebleichtem Zellstoff.

Besuchen Sie uns im Internet: http://www.transcript-verlag.de

Bitte fordern Sie unser Gesamtverzeichnis und andere Broschüren an unter: info@transcript-verlag.de 


\section{Inhalt}

\section{Ein Zufall?}

Von der Paradoxie, daß wahrscheinlich ist, was uns zufällt . . 9

\section{Anomalien}

Von der Bedeutung der Zeichen . . . . . . . . . . . 23

\section{Kippfiguren}

Vom Teufel im Detail mit dem Kaleidoskop . . . . . . . . . 40

\section{Der Tod}

Von den verschiedenen Wegen dahinzugehen,

zu bleiben und wiederzukehren oder nicht anzukommen . . . . 54

\section{Hellsehen}

Von der Möglichkeit, die Wirklichkeit zu durchblicken . . . . 66

\section{Geisterglaube}

Vom Umgang mit Engeln, die glücklich, und Teufeln, die unglücklich machen . . . . . . . . . . 9 I

\section{Telepathie}

Von der Einigkeit, die empfindsam und stark macht . . . . . . IIо

\section{Magie}

Vom Willen, der durch Vorstellungskraft

die Welt bezwingt . . . . . . . . . . . . . . I26 


\section{Schafe und Ziegen}

Von der Mißhandlung der Unvernunft durch die Vernunft . . I50

Io. Die Zweifaltigkeit der Welt

Von der Spiegelung des Festen im Flüssigen . . . . . . . I65

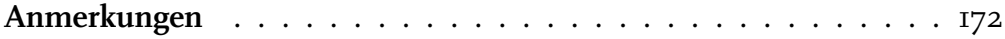

Literatur $\ldots \ldots \ldots \ldots \ldots \ldots \ldots \ldots \ldots$. . . . . . . . . . 
"Willst du die Vollendung sehn,

Mußt ins Breite dich entfalten,

Soll sich dir die Welt gestalten;

In die Tiefe mußt du steigen,

Soll sich dir das Wesen zeigen.

Nur Beharrung führt zum Ziel,

Nur die Fülle führt zur Klarheit,

Und im Abgrund wohnt die Wahrheit.॥

Friedrich von Schiller

Spruch des Konfuzius 



\title{
I. Ein Zufall?
}

\section{Von der Paradoxie, daß wahrscheinlich ist,}

\author{
was uns zufällt
}

\author{
"So tief war ich in Betrübnis \\ versunken, daß ich kaum merkte, \\ wohin ich ging; und der Zufall \\ (oder ein feinerer Sinn, der in uns \\ lebendig ist, doch nur führt, \\ wenn das Gehirn außer Kraft \\ gesetzt ist), lenkte meine Schritte \\ zu einem Teil der Insel, wo..॥ \\ Robert Louis Stevenson'
}

Was ist schon dabei, wenn man stolpert und sich gleich wieder fängt? Stürzt man zu Boden und beschmutzt sich die Hose, entschlüpft einem vielleicht ein »zu dumm!« Befindet man sich gerade auf dem Weg nach Hause, bleibt es bei dem gedämpften Verdruß, da sich der Schmutz ja daheim leicht abbürsten läßt. Es konnte, mußte aber nicht so sein. Schüler vor einer wichtigen Klassenarbeit oder Prüfung, Schauspieler vor der Premiere oder Arbeitsuchende vor einem Bewerbungsgespräch wären dagegen eher versucht, dem Vorfall Bedeutung beizumessen. Konnte, oder mußte es so sein?

Dergleichen geschieht jeden Tag viele Male. Der Schreibstift entgleitet unserer Hand, wir stoßen ein Glas um, treten in eine Pfütze, greifen neben den Lichtschalter oder verlegen irgendeinen Gegenstand. Meist nehmen wir das alles nicht eigentlich wahr - und schon gar nicht, daß wir mit jedem Schritt, den wir tun, das Leben unzähliger unsichtbar kleiner Organismen auslöschen. Was wir nicht sehen, zählt für uns nicht. Je geringfügiger ein Ereignis oder »Zufall«, desto eher ignoriert oder bagatellisiert, desto rascher vergißt man ihn. Er zeigt keine Wirkung, bleibt spurenlos. Das Bewußtsein würdigt ihn, sofern es ihn überhaupt regi- 
striert, nur einer flüchtigen Beachtung. Zufallsphänomene umspielen den Horizont der Aufmerksamkeit; ihr Medium bildet die »Halbwelt«, deren Schatten sie zur Unschärfe verurteilt. Darum ist man sich auch niemals gewiß, ob man nicht einer Sinnestäuschung erlag. Zufallsrealitäten geraten ins Zwielicht. Ihre Bedeutung verschwimmt. Was zählt schon ein einzelnes Sandkorn? Seine Existenz erscheint uns sinnlos.

Die schwache Aufmerksamkeit, die den vielen geringfügigen Zufällen zuteil wird, vermittelt den Eindruck, als träten sie einmalig oder selten auf, so daß sie gewissermaßen para-normal (von griechisch para, »neben«) erscheinen. Dabei stolpert man doch häufiger mal oder läßt etwas fallen. Vorhersehbar ist das nicht - eben weil weder zwischen Zufall und Situation noch den Zufällen selbst ein notwendiger Zusammenhang zu bestehen scheint, der die Grundlage für Prognosen böte. Und doch handelt es sich um einen Trugschluß, der aus der Art unserer Aufmerksamkeit und Optik herrührt.

Verfolgen wir vergleichbare Zufallsereignisse über einen längeren Zeitraum hin, so »streckt sich « gewissermaßen ihre Unbestimmtheit zu einer Art Regelabfolge. Wird eine (unverfälschte) Münze $n$-mal hochgeworfen, ergibt sich als mathematischer Wahrscheinlichkeits- oder »Grenzwert «, daß Kopf oder Zahl nach oben zu liegen kommen, immer einhalb (I/2). Es existiert kein erfolgreiches Spielsystem, daß dieses Ergebnis erschüttern könnte. Physiker bezeichnen diese gewisse Ohnmacht wider die Regel als »Prinzip der Impotenz«; Mathematiker sprechen von einem »Axiom für Zufälligkeit ${ }^{2}{ }^{2}$ Beim Roulette bleibt die Kugel im Verlauf einer längeren Serie von Spielen mit hoher Wahrscheinlichkeit bei jeweils 37 einmal im Gewinnfeld Zero liegen. Gewöhnlich wird ein Mensch von einem Hund nur selten gebissen, noch seltener so empfindlich, daß der Fall den Behörden angezeigt wird. In einer Millionenstadt wie New York geschah das I955 pro Tag immerhin in 75,3 Fällen. In den folgenden Jahren belief sich die Rate I956 auf 73,6, I957 auf 73,5, I958 auf 74,5 und I959 auf 72,6 Anzeigen. Analog verhält es sich mit der Zahl der jährlich zu beklagenden Unfalltoten und Verletzten auf bundesdeutschen Straßen. Jeder einzelne fällt scheinbar einem Zufall zum Opfer. Hätte er die Fahrt nur ein wenig später angetreten, eine andere Route gewählt oder unterwegs eine Pause eingelegt, wäre ihm vermutlich nichts geschehen. Dennoch schwanken die Zahlen, in Relation zur Zulassungsrate beziehungsweise Verkehrsdichte, in etwa immer um den gleichen Wert; Anfang der achtziger Jahre handelte es sich dabei in Westdeutschland um rund I5.000 Tote und 80.000 Verletzte. ${ }^{3}$

Ereignisse, die im einzelnen rein zufällig und unvorhersehbar erscheinen, zeigen, mengenmäßig verstärkt, offensichtlich ein sehr stabiles »Durchschnittsverhalten «. ${ }^{4}$ Erfahrung, Erinnerung und Geschichte folgen einer ähnlichen Regel. Einzelne Vorkommnisse, Entdeckungen, Fehlschläge, selbst »Wunder« (Heilungen z.B.) ordnen sich, längerhin 
aufsummiert, zu Struktur- und Verlaufstypen, wie etwa im Fall des Gefolgschaftswesens oder bei Überschichtungsprozessen.

Es macht also einen entscheidenden Unterschied, ob man ein scheinbar - singuläres Ereignis oder eine Fülle vermeintlicher Einzelfälle ins Auge faßt. Wahrscheinlichkeiten treten erst bei Berücksichtigung größerer Häufigkeiten beziehungsweise längerer Reihungen auf und implizieren die Voraussicht, »daß bei beliebiger Verlängerung einer solchen statistischen Reihe die relative Häufigkeit eines bestimmten Ereignisses gegen einen Grenzwert konvergiert«, der eben die Wahrscheinlichkeit des Ereignisses angibt. ${ }^{5}$ Weicht aber etwas vom Wahrscheinlichkeits- oder Durchschnittswert ab, so wirkt es vereinzelt, einem Irrläufer gleich, und entsteht, paradoxerweise, der Eindruck, daß es sich nunmehr um ein zufälliges, paranormales Ereignis handle. »Die Wahrscheinlichkeitstheorie ist«, wie Arthur Koestler griffig formuliert, »der Sprößling des Paradoxen, das sich mit der Mathematik vermählt hat. ${ }^{6}$ Gleichwohl darf, wie daraus hervorgeht, als ebenso gewiß wie der Durschschnittswert gelten, daß Zufälle oder Anomalien optisch als Horizont- oder Grenzphänomene gegenüber der massiven, »robusten« Dichtewelt im Zentrum erscheinen.

Grenzbereiche bilden Übergangszonen zwischen stabil strukturierten Zentralarealen: Sie gleichen verwilderten Gärten, in denen vielfältige Blumen des Zufalls erblühen. Die verstärkte Wechselwirkung an den Rändern der einander berührenden, durchdringenden und überlagernden Systeme gefestigter Ordnung hat stete Instabilität zur Folge, die immer wieder, wie die Bläschen in einem Glas Mineralwasser, Unvorhersehbares auftreibt. Es gibt dort »keine zwei Augenblicke, die einander äquivalent wären «.7 Je mehr Ordnungsstrukturen bestehen, desto vielfältiger fluktuiert Ungewißheit in ihren gleichsam »überschüssigen« Grenzbereichen. Entgegen dem menschlichen Vermeinen, das sich am »Durchschnittsverhalten« orientiert, überwiegt in der Natur daher »Chaos«.

Doch nicht als Dauerzustand. Immer wieder nämlich kommt es in diesem Brodeln dazu, daß flüchtige, häufig geringstfügige Schwankungen, wie der Schlag eines Schmetterlingsflügels, einander verstärken und "genau im >richtigen< Augenblick einen Reaktionsweg aus einer Reihe von weiteren, ebenso möglichen Wegen« einschlagen, ein Prozeß, der als »Selbstorganisation « bezeichnet wird: Aus der Oszillation der Möglichkeiten entwickelt sich ein Regelverlauf, der sich beobachtbar manifestiert und unter Umständen, wie im Fall des inzwischen schon sprichwörtlichen »Schmetterlingseffekts«, ein verheerendes Unwetter auslöst. Es herrscht also, wie Ilya Prigogine (I9I7-2003, Nobelpreis I977) sagt, dem wir diese Einsichten vor allem verdanken, »unter gleichgewichtsfernen Bedingungen ein delikates Wechselspiel zwischen Zufall und Notwendigkeit, zwischen Schwankungen und deterministischen Gesetzen«. ${ }^{8}$ Das Verständnis dieser Zusammenhänge erlaube es, »die Kluft zwischen Sein 
und Werden«, das heißt zwischen Zufallsfluktuationen am Anfang und Prozessen der Selbstorganisation hin $\mathrm{zu}$ definiten, regelgeleiteten Systemen, zu »überbrücken «. $?$

Selbstorganisation wie Wahrscheinlichkeit, beschrieben von der »Theorie dynamischer Systeme« (»Chaostheorie«), bauen »belanglose« Zufälle in deterministische Ordnungen ein, in denen Notwendigkeit herrscht. Mikroskopische Ereignisse bündeln sich und treten, durch wechselwirkende Agglomeration, makroskopisch in Erscheinung. Mutationen - »essentielle Zufälle« in der Terminologie Jacques Monods (I9ıoI976, Nobelpreis I965) ${ }^{\text {IO }}$ - lösen evolutive Prozesse aus und führen $\mathrm{zu}$ neuen biologischen Formen. Paranormales tritt als solches aus dem fluktuierenden Wechselspiel der Horizontphänomene als »Zufall« hervor, bewegt sich unter steter Abschwächung, gebremst und gebrochen beim Durchgang durch die Strukturen der »Mittelwelt«, optisch ins Zentrum der Aufmerksamkeit und kommt dort zur Ruhe, das heißt nimmt, gleich der Roulettekugel im Gewinnfeld, die Position ein, die ihm die Wahrscheinlichkeit, das erwartete »Durchschnittsverhalten«, zuschreibt; es gerinnt sozusagen zur Normalität. Seine Dynamik läßt sich als kurvilineare Bewegung zwischen zwei Extremen beschreiben: Sie setzt ein im Mikrobereich der Potentialitäten mit dem punktartig, quasi explosiven »Aufleuchten« zu Beginn, seinem »Anfangszustand «, verliert dann durch die fortwährende »Symmetriebrechung« auf dem Weg durch die Strukturen im Mittelfeld an Geschwindigkeit, um zuletzt, angezogen von den Kräften des Gleichgewichts, eingefangen zu werden im makroskopischen Zentralsystem, wo es seinen »Endzustand « erreicht.

Offensichtlich haben wir es mit fundamentalen Zusammenhängen zu tun. Der Zufall, so belehren uns die Quantenphysiker, stellt ein »grundlegendes Element « der Natur dar; von ihm scheinen auf atomarer und molekularer Ebene praktisch alle Prozesse, wie beispielsweise der radioaktive Zerfall oder die Bewegungen der Gasmoleküle in einem geschlossenen Behältnis, abzuhängen. ${ }^{\text {II }}$ »Teilchen « können ebenso korpuskular wie wellenförmig in Erscheinung treten. Ihr Ort und Impuls lassen sich niemals gleichzeitig mit eindeutiger Bestimmtheit angeben (»Unschärferelation«). Einzelereignisse, das heißt potentielle Anfangszustände oder »Zufälle«, sind insofern nicht mehr präzise prognostizierbar, weder praktisch noch dem Prinzip nach. ${ }^{\text {I2 }}$ Jeder Zustand eines Systems kann ebensogut der Beginn (»Impuls«) wie das Ende einer Entwicklung (»Ort«) sein; er enthält potentiell, wie im letzteren Fall, die Vergangenheit, im ersteren die Zukunft des Systems. ${ }^{\text {I3 }}$ Alles fluktuiert, so daß an die Stelle deterministischer, »klassischer« wiederum statistische, also Wahrscheinlichkeitsaussagen treten, die sich auf »Mittelwerte« (sog. »makroskopische Observablen «) - etwa Dichte, Druck oder Temperatur eines Gases beziehen, und als solche langfristig sehr wohl vorhersagen lassen. ${ }^{\text {I4 Vom }}$ End- läßt sich auf den Anfangszustand (die »Geschichte« des Systems) zurückschließen, der selbst aber prinzipiell unbestimmt bleibt - wie der 
»Urknall«, dem das Universum seine Entstehung verdankt: Erst als sich das anfängliche Plasma zum »neutralen« Gas zerdehnte, konnte es zu Dichteschwankungen und »Symmetriebrechungen« kommen, in deren Folge sich galaktische Makrostrukturen zu bilden begannen, deren »Verhalten « dann den heute bekannten physikalischen Gesetzen gehorchte.

Und wie hätte sich wohl die Physik entwickelt, wenn das schwächliche Siebenmonatskind Isaac Newton (I643-I727) nicht am Leben geblieben wäre? Ein Zufall, wenn man so will, ein paranormales Ereignis wollten es so. Mit seiner Geburt war eine Anfangsbedingung gegeben, aus der sich auf dem Weg über gewisse Wahrscheinlichkeiten schließlich mit Notwendigkeit eine folgenreiche Entwicklung ergab. Newtons Gravitationsgesetz stellt, auch wenn es später modifiziert werden sollte, eine einmalige, extreme Leistung dar, ebenso außergewöhnlich wie Newtons Geburt.

Ethnologie und Geschichte könnten dafür beliebig viele weitere Bespiele anführen. Niemand vermag vorauszusagen, wie sich ein Bauer beim Frühstück genau verhalten, was er im einzelnen sagen wird. Sehr wahrscheinlich jedoch ist, daß er sich anschließend mit Proviantbeutel und Gerät aufs Feld begibt - wie das sein Vater und seine Vorfahren zu dieser Jahreszeit schon immer taten. Und ganz sicher wird die Familie im Sommer die Ernte einbringen. Wie das geschieht und daß es mit bestimmten Ritualen bis hin zum abschließenden Erntefest verknüpft ist, folgt überlieferungsbedingten, das heißt deterministischen Verhaltensvorschriften, die im Kern alle traditionellen Agrargesellschaften teilen. Träte jedoch während des Frühstücks ein unerwartetes, paranormales Ereignis auf, schriee zum Beispiel über dem Haus ein bestimmter, eigentlich nachtaktiver Vogel, würde sich der Bauer die Hand verbrennen oder erlitte er auf dem Weg zum Feld einen tödlichen Unfall, könnte das alles ändern: Es hätte sich eine unvorhergesehene Anfangsbedingung mit entsprechenden Verhaltensanforderungen und Konsequenzen eingestellt. Der Bauer würde vielleicht, um das unheilverkündende Vorzeichen gleichsam zu »hintergehen«, seinen Aufbruch verschieben, der Leichnam des Verunglückten müßte geborgen und zurücktransportiert und rituell gereinigt, schließlich irgendwo weit draußen im Busch flüchtig verscharrt werden, da ein Unfall immer als »Schlimmer Tod « gilt, der ein schweres Vergehen zur Voraussetzung hat und insofern eine »ordentliche« Bestattung verbietet (um der Seele den Zutritt zum Ahnenreich zu verlegen). Vom - scheinbar zufälligen - auslösenden Ereignis zu Beginn bis zum Einscharren der Leiche gewönne also das Geschehen wiederum zunehmend an Wahrscheinlichkeit, um sich zuletzt zur Notwendigkeit der unzeremoniellen Beisetzung im Busch zu verfestigen. Alle Prozesse in Natur wie Kultur und Geschichte gehorchen offenbar dem Dreisatz: fluktuierende Unbestimmtheit - Wahrscheinlichkeit - Notwendigkeit, und zwar undulierend, in allen Richtungen hin und her und immer wieder aufs neue, das heißt im Mikro- ebenso wie im Makrobereich. 
Kleine Zufälle stehlen sich, gleich zwielichtigen Elementen, vom Rand her durch die Gitter der zentralen Ordnungsstrukturen und treten, wenn sie »anecken« und der Lichtstrahl der Aufmerksamkeit sie trifft, unerwartet, unter Umständen wie »blitzartig« auf, das heißt erscheinen zunächst charakterisiert durch die Eigenschaften der Unzugehörigkeit (Fremdheit) und Plötzlichkeit. Niklas Luhmann (I927-I998) faßte das in die Formel: »Für ein System sind Ereignisse zufällig, wenn sie nicht im Hinblick auf das System produziert werden. «5 Damit läßt sich ihnen, nach den Kriterien der »pragmatischen Informationstheorie«, als dritte Eigenschaft Erstmaligkeit addizieren: Sie enthalten eine neue Information ${ }^{\mathrm{I} 6}$ - die uns, anfangs zumindest, befremdet, weil wir sie (noch) nicht verstehen.

Deckt sich Erst- mit Einmaligkeit, verstärkt sich die Annahme, daß es sich um einen »echten« Zufall gehandelt hat. Doch wäre dies keine essentielle, notwendige Eigenschaft, da »Zufälle« sich durchaus wiederholen können. Wer »Glück« hat, würfelt beim Spielen häufiger die Sechs oder fährt mehrmals in Folge gute Ernten ein. Geschieht das, schwindet der Eindruck der Zufälligkeit mit der Anzahl der Wiederholungen dahin. ${ }^{17}$ Die Ereignisse »bestätigen « einander; die Wahrscheinlichkeit anhaltender Affirmationen wächst. Bereits »die Zweitmaligkeit gibt der Erstmaligkeit Realität «. ${ }^{\mathrm{I} 8}$

Kleine Zufälle zeichnen des weiteren Geringfügigkeit und Nichtlokalität aus; das heißt muten »sinnlos« an und erscheinen nicht zwingend an bestimmte Umstände - Orte, Zeiten, Situationen, Zustände - gebunden, anders etwa als Unfälle, die immer wieder an ein und derselben Kurve vorkommen, als Gespenster, denen man nur in einem bestimmten Schloß oder Waldstück und allein um Mitternacht begegnen kann, oder Krisensituationen und Dämmerzustände, in denen es häufiger als sonst zu außersinnlichen Wahrnehmungen kommt.

Doch immer handelt es sich, schon aufgrund der Nichtlokalität, um Grenzphänomene »neben« (para) der Normalität - eine weitere typische Eigenschaft zufälliger Ereignisse. Das bedeutet indes strukturspezifisch, daß sie von einem angenommenen Mittelpunkt im Zentrum der Ordnung aus wahrgenommen und definiert werden: Zufälle stellen periphere Feldgrößen dar. Denkt man sich dort einen menschlichen Betrachter, indem man die Situation ethnologisch sozusagen »humanisiert«, gewinnen sie nach den Kriterien der anthropo- oder ethnozentrischen Optik Bedeutung, die in geringfügigen Fällen freilich bei Null liegt.

Anders aber, wenn es sich um robuste Ereignisse handelt. Ihre Eigenschaft des plötzlichen Auftretens schlägt dann um in Bedrohung, erscheint als Gefahr, die Furcht, Angst oder Entsetzen weckt, und zwar proportional zum Maß der Annäherung und Geschwindigkeit in Richtung auf den Beobachter hin: Das Empfinden erreicht seinen Höhepunkt im Moment der Berührung und kann dann unter Umständen zum Ableben führen. ${ }^{19}$ 
Robuste Zufälle treten seltener auf. Der gelinde oder massive Schock, den sie auslösen, prägt sich jedoch dem Bewußtsein deutlicher ein, bleibt in der Erinnerung haften, so daß es so scheint, als kämen sie häufiger vor. Insofern ist man eher geneigt, eine Verbindung zwischen ihnen herzustellen, so daß sich nunmehr der Eindruck aufdrängt, als wiederholten sie sich, als läge ihnen eine gemeinsame Bedingung zugrunde, wie im Falle der Krisentelepathie unter Engstangehörigen. Das läßt es dann begründet erscheinen, sie seriell zu reihen und ihnen Wahrscheinlichkeit zuzusprechen. Man erwartet sie schon, wie die Weiße Frau, die mitternächtlicherweile durch schottische Schlösser schwebt.

In traditionellen Gesellschaften herrschte der Glaube, daß plötzlich Hereinbrechendes die Betroffenen krankmache, in härteren Fällen töte. ${ }^{20}$ Die Buschmänner (Südafrika) hielten anfangs das Erscheinen von Sputnik I für den Vorboten einer drohenden Katastrophe; als nichts geschah und sich die Erscheinungen mehrten, die Erstmaligkeit also erlosch, gewöhnte man sich daran und maß dem Phänomen keine Bedeutung mehr bei. $^{21}$ Unfälle mit Todesfolge wurden generell als »Schlimme Tode« verstanden, das heißt, man sah sie durch Unheilskräfte - ein schweres Vergehen, einen Geisteranschlag oder Zauber - verursacht. Die Toten stellten eine Bedrohung für die Gemeinschaft dar; man bestattete sie daher nicht rituell, sondern verscharrte sie flüchtig im Busch, damit ihre Seelen keinen Zugang zum Ahnendorf in der Unterwelt fanden. ${ }^{22}$ Kleine Zufälle affizieren nur kaum die Aufmerksamkeit; gewinnen sie größere Dimensionen und treten ein in die Makrowelt, wird aus der Gleichgültigkeit Betroffenheit.

Die Situation verlangt nunmehr nach einer Erklärung; man muß ihr Bedeutung verleihen, um sich mit ihr auseinandersetzen, angemessen reagieren, etwas tun $\mathrm{zu}$ können. Beispielsweise entgleitet einem eine kostbare Vase, fällt zu Boden und zerbricht, während man einen schwerkranken Angehörigen betreut. Bei vielen stellt sich gleich ein ungutes Gefühl ein. Es könnte sich um ein Vorzeichen handeln, das bedeutet, daß der Kranke in Kürze stirbt. Oder ein Mann begegnet nachts auf dem Nachhauseweg im Wald einem schwarzen Schwein, das einige Schritte vor ihm herläuft und dann wieder verschwindet. Kurz darauf erfährt er, daß zur gleichen Stunde sein Vater verstarb. Irischem Volksglauben nach bestand zwischen beidem eine Verbindung ${ }^{23}$ : Die Plötzlichkeit der Erscheinung, die Person des »Betroffenen« und die Farbe des Tieres deuteten auf den Tod eines nahen Angehörigen hin. Für Carl Gustav Jung (I875-I961) hätte es sich um ein typisch »synchronistisches«, das heißt keinesfalls zufälliges Ereignis gehandelt, wobei er jedoch weniger, wie der Begriff das eigentlich ausdrückt, an einen gleichzeitigen, und schon gar nicht an einen kausalen, sondern einen »gleichsinnigen « Zusammenhang dachte. ${ }^{24}$ Ein weiteres Beispiel beträfe den Fall, daß ein Baum während eines Unwetters umstürzt und auf ein - »zufällig« - vorbeifahrendes 
Auto fällt, dabei den Fahrer tötet, nicht aber seinen kleinen Sohn, der im Fond sitzt. Auch hier stellt sich den Angehörigen die Frage nach dem Warum.

Gewicht und Betroffenheit derartiger Ereignisse lassen kaum jemanden kalt. Man gerät ins Grübeln. »Wenn wir«, geht Alfred Schütz (I899I959) dem Gedanken nach, »in unserer Erfahrung auf etwas stoßen, was uns zuvor nicht bekannt war und daher außerhalb unseres gewöhnlichen Kenntniszusammenhangs steht, reagieren wir mit einem Erkundungsprozeß. Zunächst definieren wir das neue Faktum und versuchen, seine Bedeutung zu erfassen; dann modifizieren wir Schritt für Schritt unser Deutungsschema der Welt, bis das Fremdphänomen mit allen anderen unserer Erfahrungsbestände und ihrer Bedeutung kompatibel und konsistent erscheint [...] So wird es zuletzt zu einem ergänzenden Element unseres verbürgten Wissens. « ${ }^{25}$ Man stellt im Rahmen eines bestimmten Anschauungssystems zwischen zwei (oder mehreren) Ereignissen einen Kausalzusammenhang oder eine akausale Korrelation her, die sich nach den Prämissen anderer, beispielsweise wissenschaftlicher Theorien verböte. Zerbricht im Beziehungskontinuum zweier Engstangehöriger, deren einer sich in einem kritischen Zustand befindet, dem anderen eine Vase, entspricht das dem »Zerbruch« des Gefährdeten - er stirbt. Traditionellen Vorstellungen nach würde der Baum den Fahrer erschlagen haben, weil er ein schweres Vergehen beging, das heißt eine Regel, ein Tabu »brach« oder auch einem Zauberanschlag zum Opfer fiel ${ }^{26}$, während das Kind »Glück« hatte und verschont blieb, weil es schuldlos, vielleicht auch für etwas Bestimmtes ausersehen oder seine Zeit einfach noch nicht gekommen war.

Das befremdliche oder bestürzende Ereignis wird auf dem Schütz'schen Wege entschärft und dem System integriert. Dies verleiht ihm Lokalität; seine Dynamik erscheint als Wiederholung. Doch bezöge sich das zunächst nur auf seine formale Zuordnung. Da es in den genannten Fällen jedoch ein reflektierendes Bewußtsein betraf, entspricht die Positionierung im System einer bestimmten Bedeutung, die als solche nur plausibel erscheint, wenn sie »Sinn macht«. Diese letztere Bedingung erfüllen allein normative, insbesondere religiöse Anschauungssysteme: Die kontingente Erfahrung, die jemandem »zustößt«, wird »bewältigt« durch den Bezug auf eine »letzte Wirklichkeit « ${ }^{27}$, konkreter: auf übergeordnete, transzendente Drittinstanzen (Ahnen, Geister, Götter), deren Handeln eine »höhere « Absicht leitet. ${ }^{28}$ Erst dadurch springt die formale Systemverträglichkeit um in »hochgradig signifikante Koinzidenz « ${ }^{29}$ und gewinnt Sinn. Ein Fazit der Literaturwissenschaftlerin Renate Lachmann: »Wenn die Vorfälle, Zwischenfälle und Unglücksfälle nicht mehr Zufälle, sondern sinnvolle Ereignisse und die unerklärlichen Erscheinungen keine Trugbilder, sondern natürliche Phänomene oder übernatürliche Zeichen einer höheren Intelligenz sind, dann erhält die Sinnzuweisung, das Verkehren von unbekannt in bekannt, von unerklärlich in erklärlich einen 
soteriologischen Aspekt. ${ }^{30}$ Es handelt sich nun nicht mehr um ein rätselhaftes Psi-Phänomen oder Zufall, sondern teleologische Notwendigkeit.

Doch damit ist das Problem erst lokalisiert, nicht gelöst. Legitim erscheint diese Deutung allein unter der Voraussetzung, daß sich alles Geschehen auf den Betrachter und sein persönliches Umfeld bezieht, das heißt den Kriterien der anthropozentrischen, konkreter der ego-, allgemeiner der nostrozentrischen (oder ethnozentrischen) Optik folgt. Ein vermeintlicher Zufall stellt dann eine »Botschaft« dar; er erscheint gesteuert und bedeutet entweder eine Warnung (Omen), eine Züchtigung, einen Hinweis, etwas Bestimmtes zu tun, oder einen schadensmagischen Anschlag. In jedem Fall liegt die Ursache, der Impuls dazu, bei transzendenten »Intelligenzen«, auch beim Zauber, da man annimmt, daß dieser letztlich immer auf Anstiftung geistiger Mächte zurückgeht.

Die teleologische Deutung hat somit eine dualistische Kosmologie, die Annahme einer jenseitigen Gegenwelt zur Voraussetzung. Traditioneller Anschauung nach wird ihr Verhältnis zur diesseitigen bestimmt durch Inversion. Alles ist dort »ganz anders«, läßt sich allein mit Hilfe von Negationen beschreiben: Es gibt dort weder Raum noch Zeit; das Jenseits entspricht einer Art Vakuum, durch das sich masselose, rein spirituelle Existenzen nicht eigentlich »bewegen«, da sie aufgrund der herrschenden Nichtlokalität überall und nirgends gleichzeitig und sozusagen »von Ewigkeit zu Ewigkeit« sind. Die Extreme beider Welten bilden auf der einen Seite kompakte, leblose Materie, auf der anderen die unsterblichen Götter, an der Spitze der unendlich ferne Deus otiosus, der vor Zeiten den Kosmos erschuf. Beide stellen füreinander Horizontphänomene dar, erscheinen wechselseitig extrem paranormal.

Doch berühren und durchdringen sie einander. Und wo das der Fall ist, muß es aufgrund des herrschenden Inversionsverhältnisses notwendig $\mathrm{zu}$ unerwarteten, »exotischen « Reaktionen kommen, die meist sicherlich so geringfügig ausfallen, daß sie nur schwach oder gar nicht wahrgenommen werden, gelegentlich aber auch »robuster« Natur sind.

Bleibt man bei der teleologischen oder, wenn man so will, »animistischen« Deutung, läßt sich am Konzept des kosmologischen Dualismus schwerlich vorbeidenken. Das schlösse dann auch, wie für die Anschauungen traditioneller Gesellschaften ganz gewöhnlich, ja selbstverständlich, die Konsequenzen mit ein:

I. Ungewöhnliche Erfahrungen und Ereignisse sind grenzbereichsgebunden; wo sie auftreten, herrschen Übergangszustände.

2. Infolge des gegebenen, unveränderlichen Inversionsverhältnisses beider Welten zueinander sollte bei Wechselwirkungen gewissermaßen im Untergrund ein »Feld « entstehen, das zumindest im groben gleichbleibend einheitlich strukturiert ist und daher den Ereignissen im Wahrnehmungsbereich ähnliche, seltener übereinstimmende Züge verleiht (wie z.B. bei Geistererscheinungen). 
3. Da für die Gegenwelt Nichtlokalität, Atemporalität und Spiritualität gelten, sollten sich bei Wechselwirkungen diesseitige Lokalität, Temporalität und Körperlichkeit »verwischen«, das heißt an präziser Bestimmbarkeit verlieren. Die Horizonte falten sich gleichsam ineinander ein. Es entstehen Dämmer- und Entrückungszustände; Visionen, Gesichte, Träume, Eingebungen stellen sich ein; scheinbar wandelt sich die Wahrnehmungsfähigkeit des Bewußtseins. In lebenden Organismen besteht die Verfaltung in Form des Leib-Seele-Dualismus in Permanenz; sie sind potentiell daher immer offen für transzendente, sogenannte »außersinnliche« Wahrnehmungen; es bedarf nur entsprechender Voraussetzungen, einer spezifischen »Grenzsituation«, die eine massivere Wechselwirkung möglich und spürbar macht.

4. Die spirituelle Welt stellt, erstmals sich aktualisierend während der Schöpfungszeit, als der »Geist Gottes« mittels Gedankenkraft den amorphen Urbrei zu gestalten begann, den bewegenden, dynamischen Gegengrund der materiellen dar, auch im Menschen: Mens agitat molem (Vergil: Aeneis VI 727). Die unterschiedlich dicht gepackte Masse der letzteren läßt Impulse von »drüben« unmittelbar freilich nur dort durch, wo sie durchlässiger ist, beziehungsweise Offenstellen, gleichsam »Fenster « zum Jenseits bestehen, wie im Falle von Brunnen, Höhlen, Teichen, um Mitternacht, zu Neujahr oder während persönlicher Krisenzustände, in denen der Verbund von Leib und Seele sich lockert. Unter diesen Bedingungen strömt spirituelle Energie widerstandsfreier durch und löst entsprechend robuste Effekte aus: Hellsichtigkeit und Wahrträume stellen sich ein, Ahnen und Geister erscheinen. Im Extremfall schlägt die antiweltliche Kraft so stark durch, daß sie Materielles auslöscht: Der Organismus eines Menschen kollabiert, seine Lebenskraft, die Vitalseele, löst sich auf und verstrahlt, seine - unsterbliche - Freiseele wird von der Transzendenz gleichsam aufgesogen, sie geht, nunmehr entschlackt und reine Energie, ins Jenseits über. Impulswellen dagegen, die auf dichter gefügte Materie treffen, werden gebeugt und gestreut; sie lösen lediglich schwache Effekte oder Wechselwirkungen aus, die zu ungewohnten Verbindungen, zu »Korrelationen « führen und, falls sie überhaupt wahrgenommen werden, als geringfügige »Zufälle« in Erscheinung treten.

Die anthropozentrische Optik mißt, wie gesagt, nur robusten Ereignissen Bedeutung zu. Sie erscheinen als persönliche »Botschaften«, die den Empfänger unmittelbar und nur wenig gebrochen, gleichsam per E-Mail von »drüben« erreichen. Sie enthalten Informationen, denen ein »höherer Wille«, eine Absicht des Senders zugrunde liegt. Die Ahnen lassen ein Kind erkranken, um dem Vater zu verstehen zu geben, daß er seine außerehelichen Eskapaden einstellen soll. Das heißt: In derartigen starken Fällen wird Kausalität, eine causa efficiens, vorausgesetzt, während man in 
schwachen eher von Korrelationen ausgeht, wie sie typisch für betrachterferne, fluktuierende Grenzbereichsphänomene erscheinen. Nach Kant kann es auch nur so sein. Nach ihm nämlich folgt der Begriff der Kausalität bekanntlich nicht der Erfahrung, sondern geht ihr bereits voraus, als Kategorie a priori oder angeborene Vorstellungsregel. Psychologische Experimente haben gezeigt, »daß Gewißheit, die sich auf eine klare Kenntnis der kognitiven Strukturen gründet und das Geschehen im Umfeld vorauszusagen erlaubt, generell erwünscht ist«, das Gegenteil entsprechend Unbehagen auslöst. ${ }^{3 \mathrm{I}}$ Starke Anomalien erscheinen daher notwendig, da sie anthropozentrisch wahrgenommen und gedeutet werden, kausal bestimmt; schwache fernhin am Horizont können auch auf Korrelationen beruhen.

Tut man so, als könne man sich aus der Anthropozentrik lösen, und versucht, einen gleichsam säkularen, »objektiv-wissenschaftlichen « Standpunkt einzunehmen, ändert sich im Grunde nicht viel. Man geht aus von der vertrauten, erfahrungsgesättigten »klassischen « Welt, in der das Geschehen bestimmten Gesetzmäßigkeiten und Regeln gehorcht und sich daher voraussagen läßt. Zufälle erscheinen wie aufplatzende Blasen über fluktuierend bewegtem sumpfigem Grund in gleichgewichtsfernen Bereichen am Rand des in Kultur genommenen Landes. Wir bezeichnen sie so, weil wir, wie die Physiker uns versichern, ihre Ursachen nur (noch) nicht kennen, die aber gleichwohl vorauszusetzen sind, da es, so Friedrich Hund (1896-1997), »keine ursachlosen Ereignisse gibt. Das wäre«, setzt er erläuternd hinzu, »wie eine Erschaffung der Welt aus dem Nichts. « ${ }^{32}$ Mit jeder Erweiterung der Erkenntnis fällt Licht ins Dunkel des Unbekannten und legt den morastigen Grund für Zufälle trocken. Staunen und Verwunderung schwinden, wie schon Aristoteles (384-322 v. Chr.) lehrte, mit wachsendem Wissen dahin. Wäre uns alles bekannt, könnte es keine Zufälle mehr geben.

Doch wissen wir, daß dies Illusion bleibt; es überschritte unsere Erkenntniskapazitäten. Dies bedenkend, sah der Philosoph Eduard von Hartmann (I842-I906) den gebotenen Kompromiß in Wahrscheinlichkeitsaussagen. ${ }^{33}$ Wie schon ausgeführt, werden diese jedoch mittels statistischer Regeln gewonnen und beziehen sich auf Korrelationen, die selbst, um es mit Gerhard Vollmer zu sagen, auf verschiedenen unbekannten Auslösefaktoren oder »Koinzidenzen unabhängiger Kausalketten « beruhen, für die nach einer Erklärung zu suchen, ihm »sinnlos« erscheint. ${ }^{34}$ Denn das würde die Kenntnis kausaler Zusammenhänge erfordern, die uns allein in den Stand setzten, Antworten auf die Frage nach dem Warum, nicht lediglich nach dem Wie von Koinzidenzen, Korrelationen oder Funktionen zu finden.

Will man sich damit nicht bescheiden, ist man bekanntlich genötigt, sozusagen am Grund ein - eben noch nicht vollends erhelltes - universal gültiges Bezugssystem der Laplaceschen Fiktion vorauszusetzen. Eine probate Hilfskonstruktion stellt die Annahme einer »dunklen« Gegen- oder 
»Antiwelt« dar, deren Strukturen und dynamische Gesetzmäßigkeiten durch stete Impulse das Geschehen in der empirischen »Lichtwelt« untergründig bestimmen ${ }^{35}$ - »schwach« durch Fluktuationen und ihrer Erscheinung nach immer erstmalige Zufallsereignisse in gleichgewichtsfernen Grenzbereichen, die sich gegebenenfalls selbstorganisieren und zu neuartigen Entwicklungen führen können, »stark « dagegen durch wiederholte Prozesse im gleichgewichtsnahen zentralen, »klassischen« Erfahrungsraum, wo sie zunächst Wahrscheinlichkeits-, dann Gesetzescharakter annehmen und das gesichert Gewußte nur immer wieder aufs neue bestätigen. In der Ethnologie entspräche dem das Linton-Kluckhohnsche Konzept von der covert und overt culture. Unter der ersteren verstand Ralph Linton (1893-I953) die basic personality structure, Clyde Kluckhohn (1905I960) die grundlegenden patterns einer Gesellschaft, das heißt beider Auffassung nach die strukturierte Summe der allgemeineren Geltungskriterien der Welt- und Lebensanschauung, des Sozialerhalts, der Moral und Ästhetik, die in der »offenbaren« Kultur, vermittelt über die Sozialisation, als manifeste configurations, das heißt habituelle Stereotypen und Institutionen erscheinen und durch repetitive responses der Individuen untereinander, also fortwährende Bestätigung, stabilerhalten werden. ${ }^{36}$

Sich mit dem, was sich ständig wiederholt und bestätigt, zu beschäftigen, mag auf die Dauer langweilig erscheinen. Früher gebot das die Orthodoxie, deren Autorität jedoch seit Beginn der »Neuzeit« zunehmenden Erosionskräften ausgesetzt ist. In der Gegenwart - diesen Begriff einmal sehr elastisch verstanden - rührt sich gewissermaßen das Erkenntnisinteresse, traut Stabilitätserklärungen nicht mehr und läßt sich reizen von »Grenzzuständen«, in denen das Gleichgewicht schwankt, »anything goes«, wie Paul Feyerabend (1924-I994) deklarierte, in trügerischen Nischen Geheimnisse lauern, exotische Erscheinungen vorüberziehen, Schamanen tanzen, »der Fremde« uns anblickt und zur Selbstreflexion aufruft, Informationen wellenförmig fließen oder korpuskularartig von Gegenständen ausgehen, Ethnologen, dem geschmeidig sich fügend, in »dialogische Diskurse « eintreten und »polyphone« Stammesmonographien schreiben und, dies nicht zuletzt, Kreativität blüht.

Doch bei aller Fluktuation multikultureller »Optionen« stellt sich, das Ganze wieder über den Kamm der Langfristigkeit geschoren, immer wieder die Regel ein. Diffundierende Identitäten zum Beispiel ziehen sich regional immer wieder zusammen und formieren sich neu. Ein Vorstellungs- und Verhaltensrepertoire bildet sich aus, das nur im Oberflächenbereich, nicht aber seiner inneren Aufbaustruktur nach vom Altvertrauten abweicht. ${ }^{37}$

Die patterns bleiben. Da die »Anfangsbedingungen« einer Entwicklung indes unbestimmt, wenn man so will dem Zufall überlassen sind, läßt sich der Verlauf zunächst nur mit einer gewissen Wahrscheinlichkeit voraussagen; je länger er im Gang ist, desto mehr Regelcharakter gewinnt er jedoch. Ein künstlerischer Einfall wächst sich zum »Stil« aus, der 
bestimmten Kriterien gehorcht, so daß ein Literatur-, Kunst- oder Musikhistoriker rasch erkennt, welcher Schriftsteller, Maler oder Komponist der "Schule« verpflichtet war. Analog halten geschichtliche »Schlüsselereignisse«, Mutationen, wissenschaftliche Erkenntnisse oder politische Entscheidungen die Schöpfung fortwährend in Gang. Am Ende, das heißt im Augenblick der Betrachtung, stehen eine Art, eine Theorie oder »Schule«, ein Staat, eine Verfassung.

Analytisch ist demzufolge zwischen peripheren Ereignissen, Zufällen oder Anfangsbedingungen und geronnener Regel in der zentralen Gleichgewichtswelt zu scheiden. »Tatsächlich hat sich«, wie Henning Genz das für die Physik bestätigt, »die Methode der Trennung von Anfangsbedingungen, die allein für die Zufälle des Wirklichen verantwortlich sind, und symmetrischen Naturgesetzen glänzend bewährt. « ${ }^{38}$

Nicht bewährt allerdings hat sich die Annahme, wir könnten eine dezentrale, »objektive« Betrachterposition beziehen. Jeder glaubt sich in einem gleichgewichtsnahen Zustand zu befinden, in einer regelgeleiteten Welt zu leben und nimmt Ungewöhnliches, das Norm und Gesetze beugt oder bricht, als Horizontphänomen wahr. Als lebendige Menschen, als Angehörige sozial verschlüsselter Gruppen, können wir den magischen Kreis der anthropo- oder soziozentrischen Weltwahrnehmung vielleicht gedanklich, nicht aber realiter verlassen. Wir messen diesem Bedeutung, das heißt einen Sinn in unserem Lebenszusammenhang zu und vernachlässigen oder ignorieren jenes. Beider Verhältnis begreifen wir dynamisch als Entwicklung: von Anfangsbedingungen zum Regelsystem, von einfachen zu komplexen Formen, von der Barbarei zur Zivilisation, ob nun im anagenetischen oder evolutionären Sinn. Die »Trennung «, von der Genz spricht, ist lediglich ein analytisches Hilfsmittel; denn Ursprung und Ende bilden einen Zusammenhang, zunächst anscheinend eine Korrelation, dann, im Sog der anthropozentrischen Optik, einen kausal, ob nun teleonomisch oder teleologisch determinierten Pozeß, der zuletzt, oben auf der zeitlich stillgestellten Betrachterebene, als komplementäre Beziehung erscheint: Die verdeckte »dunkle« Kultur steht mit der offenbaren »lichten « ganz ebenso in einem derartigen Zusammenhang39 wie die Mikro- und Makrowelt oder der dunkle und der helle Kosmos.

Es gibt kein Entweder-Oder. Zwischen Zufall und Notwendigkeit besteht eine unaufhebbare Beziehung. Selbst wenn wir sie nur konstruieren, folgen wir damit wieder einer Notwendigkeit, die sich aus der Anthropozentrik ergibt. Wir müssen der Welt Bedeutung verleihen, um uns orientieren und überleben zu können. Unbewußt oder kryptisch lauert Teleologie auch im Hintergrund säkular gestimmter Köpfe. Für Ameisen oder Pferde stellt sich das Problem vermutlich nicht.

Läßt sich der »Urknall« als Zufall verstehen? Falls ja, müßte er laut Hund und anderen eine Ursache haben - und wäre ein Scheinzufall. Das würde bedeuten, daß auch danach bis in alle Zukunft hin Scheinzufälle möglich waren und sind. Im Grunde verschöbe dies das Problem nur 
hinter den Urknall zurück. Verdankt das Universum indes seine Entstehung nicht einem Zufall, sondern der Absicht einer wie auch immer gearteten »höheren Intelligenz«, könnten auch alle späteren Ereignisse, die uns als Zufälle erscheinen, in Wahrheit keine sein; sie müßten allesamt der Schöpfungsabsicht folgen, also irgendwie Sinn machen. Wie immer einen das persönlich anmuten mag - und mir selbst widerstrebt es zutiefst: als geborenen Anthropozentrikern bleibt uns eigentlich keine andere Wahl, als der letzteren, sagen wir »animistischen « Alternative den Vorrang einzuräumen. Vielleicht sind wir ja doch alle wie Kerzen im Atem Gottes. 


\section{Anomalien}

\section{Von der Bedeutung der Zeichen*}

Warum verfehlt der vollkommen gearbeitete Pfeil eines erfahrenen, treffsicheren Jägers sein Ziel? Wie kommt es, daß eine Pinie das eine Jahr reichlich, im nächsten jedoch keinerlei Zapfen trägt? Wieso wird nur einer von zwei Männern, die gemeinsam reisen, von einer Infektionskrankheit befallen? Möglicherweise lag es an einem Versehen, einer Unachtsamkeit, einer Ursache, die im dunkeln blieb, oder purem »Zufall«. Jedenfalls sähen wir keinen Anlaß, uns deswegen den Kopf zu zerbrechen und nach einer Erklärung zu suchen. Wir sind weder vom Jagdglück noch einer gesicherten Pinienkern-Ernte abhängig und können, wenn wir erkranken, die Arbeit auch einmal ruhen lassen, ohne gleich um unsere Existenz bangen zu müssen.

Anders stellte sich das in traditionellen Gesellschaften dar. Jagdpech wie Ernteausfälle und die längerfristige Arbeitsunfähigkeit eines Angehörigen konnten für eine Familie, unter Umständen die gesamte Gruppe, nicht nur Hunger bedeuten, sondern das Überleben aufs Spiel setzen. Man mußte für derartige Unbilden plausible Erklärungen parat haben, um entsprechend wirksam, das heißt mit probater Erfolgsaussicht reagieren zu können.

Gewöhnlich erreichen die Handelskanus der Wogeo-Insulaner die nahegelegene Nordküste Neuguineas problemlos. Mitunter jedoch kentert eines und die Mannschaft ertrinkt. Da die Überfahrt an sich keine Risiken birgt und die Leute hinreichend Erfahrung besitzen, kann da nur etwas »nicht mit rechten Dingen zugegangen « sein - man vermutet, daß Zauber im Spiel war, wie analog etwa auch bei Schlangenbissen oder Verletzungen durch Wildschweinattacken. In allen Fällen handelt es sich um selte-

* Das folgende Kapitel beruht auf einem - hier leicht überarbeiteten - älteren Text, der erstmals unter dem Titel »Reguläre Anomalien im Schnittbereich zweier Welten« in der Zeitschrift für Parapsychologie und Grenzgebiete der Psychologie 34, I-2 (I992): 33-49, erschienen ist. 
ne, eigentlich auch ungewöhnliche Vorkommnisse. ${ }^{\text {I }}$ Ein weiterer Grund könnte ein Vergehen, ein Tabubruch sein. Diese Erklärung führen Ngadju Dayak auf Borneo ins Feld, wenn jemand auf einem morschen Floß einbricht. $^{2}$ Von den Lovedu in Transvaal berichten Eileem J. und Jacob D. Krige den folgenden Fall: Auf einem Feld steht ein alter, abgestorbener Baum, dessen Geäst aber immerhin noch einigen Schatten spendet. Daher ruhen sich die Leute gern unter ihm aus, wenn sie bei der Feldarbeit eine Pause machen. Eines Tages sitzen zwei Kinder zu seinen Füßen und da geschieht es: Er stürzt um und erschlägt das eine von ihnen. Jahrelang hatte er standgehalten; warum nicht noch einen Tag oder nur wenige Stunden länger? Wieso wurde das eine der Kinder und nicht das andere getötet? Niemand zweifelte, daß »Hexerei« die Ursache war. ${ }^{3}$ Monica Wilson diskutierte das Problem in bezug auf Erkrankungen durch »Ansteckung « mit einem Lehrer der Pondo (Transkei). »Ich verstehe schon«, hielt der ihr entgegen, »daß Typhus von Läusen übertragen wird - nur: Wer sandte die infizierte Laus? Warum biß sie gerade A und nicht seinen Bruder B?« Mit Malaria sei es das gleiche. Wenn eine Krankheit lediglich die Leute eines Gehöftes vernichte, könne sie nur »gesandt « sein, von wem und aus welchem Grund auch immer. ${ }^{4}$ Gewißheit erlangt man dann durch Divination, beispielsweise indem man ein Orakel befragt.

Überraschende Mißgeschicke müssen, wie alles andere Geschehen auch, ihre ganz bestimmten Ursachen haben. Da sie die traditionelle Lebensordnung stören, können sie nur Folge einer Verletzung ihrer Voraussetzungen sein. In härteren Fällen kommen dafür zwei Möglichkeiten in Betracht: Entweder haben die Betroffenen wider eine wichtige Norm, beziehungsweise ein starkes Tabu verstoßen und werden dafür von Ahnen und Göttern bestraft, oder die Heimsuchungen gehen auf das Übelwollen anderer, etwa den Bösen Blick, vor allem aber auf Schadenszauber zurück. In diesem Fall ist gleichsam weiter zurück mit einer vorgelagerten verdeckten Veranlassung zu rechnen: Der Wille, Böses zu wirken, muß seinerseits eine Ursache haben, die im Verhalten des Opfers selbst (Unfreundlichkeit, Mißgunst, Geiz) oder einem früheren Vergehen des Unheilstifters liegen kann, das ihn schwächte und anfällig für »Einflüsterungen« bösartiger Geistmächte machte. Geringere Widrigkeiten dagegen ein Abkommen vom Weg im Wald, ein Stolpern, bei dem man sich den Fuß verstaucht, eine ungeschickte Bewegung beim Töpfern, die das Tonmodell zerstört - werden auf unmittelbare Eingriffe von Geistern zurückgeführt, die man vielleicht aus ihrer Ruhe aufgeschreckt oder durch ein unbedachtes Wort verärgert hat oder denen es, wie vielen von ihnen, ganz einfach Spaß macht, den Menschen eins auszuwischen.

In traditionellen Anschauungssystemen finden also zwar »Anomalien«, das heißt ungewöhnliche Vorkommnisse, Platz, nicht aber Zufälle: Es gibt für alles eine Erklärung. Hat man keine zur Hand, geht man - wie beispielsweise die G/wi-Buschmänner in Botswana - davon aus, daß es sich um eine Kombination von Wirkursachen handelt, deren einige sich 
der Kenntnis der Menschen entziehen'; die Überzeugung von der Determiniertheit allen Geschehens weist dann lediglich einen kleinen weißen Fleck auf; es wäre nur eine Frage der Mühewaltung, das Muster am Grund der Ereignisse deutlich zu machen. Andernfalls bliebe es eben einfach im dunkeln. ${ }^{6}$

Die Welt im engeren, eigentlichen Sinne, das heißt die je eigenethnische Endosphäre, stellte traditioneller Anschauung nach ein klarkonturiertes, festgefügtes System idealer Ordnung dar. Bestimmte Verhaltensgebote sicherten seinen Bestand. Eines der wichtigsten bildete die Verpflichtung zur Reziprozität: Eine Gabe mußte durch eine wertadäquate Gegengabe, eine Leistung durch eine entsprechende Gegenleistung, Zuwendung durch Zuwendung vergolten werden. »Wechselseitige Hilfe«, beobachtete die südafrikanische Ethnologin Monica Wilson bei indigenen Bevölkerungen ihrer Heimat, »ist eine conditio sine qua non des sozialen Zusammenlebens. « Jede Austauschbeziehung enthielt überdies die Botschaft, daß die Beteiligten zusammengehören, Mitglieder einer Gemeinschaft sind. ${ }^{8}$ Im Gegenzug konnten ein niedergebranntes Haus wiederaufgebaut, eine durch Tabubruch verursachte Krankheit durch Sühne geheilt, ein Vergehen geahndet werden. Es handelte sich, im Sinne eben der Reziprozität, um prinzipiell reversible Prozesse, um Erhaltungsregeln, die den Kraftfluß im Innern banden und die gesellschaftliche Homöostase gewährleisteten - jedenfalls dem Ideal nach, wie es George Silberbauer selbst für die G/wi-Buschmänner, die er aufgrund jahrzehntelanger Erfahrung bestens kannte, beschreibt, also Sammlerinnen und Jäger, bei denen man es sonst eher lax mit Konventionen und Verhaltensregeln hält: »Die G/wi betrachten ihre Umgebung, die der Wahrnehmung zugängliche >Mittelwelt<, als ein klar geordnetes Ganzes. Seinsformen, Ereignisse und Tatbestände erscheinen de facto oder potentiell erklärbar vermöge ihrer kausalen Wechselbeziehungen mit anderen Seinsformen usw. Diese Verknüpfungen sind weder chaotisch noch zufälliger Art, sondern regelbestimmt, das heißt unterliegen steter Repetition. Unvorhergesehene Wendungen und Irregularitäten stellen durchaus vertraute Komplikationen dar; man begreift sie jedoch als Umstellungen in der Kombination der Faktoren, die eine Beziehung bestimmen, nicht aber als Abweichungen von der Ordnung oder gar deren Auflösung. «9 Entsprechend mehr noch gilt das für seßhafte, also bereits deutlicher differenzierte Gesellschaften. Bei ihnen verstärkt sich der Ordnungsdruck sichtbar zu den zentralen Dichte- und Repräsentationsbereichen hin, wo die Ältesten öffentlich auftreten, Ratsversammlungen und Gericht auf dem Dorfplatz halten, das Männerhaus steht und die großen Kulte, die den Fortbestand der Gruppe zum Gegenstand haben, gestelzt und feierlich prunkvoll in Szene gesetzt werden. Verletzungen der Tradition hätten hier, im Kernbereich des Systems, zu explosionsartigen Konsequenzen führen müssen. Zwar kamen Krankheiten, Unfälle, Konflikte oder Wetterkatastrophen, die den Bestand der Gesellschaft bedrohten, immer wieder mal vor; sie ließen 
sich jedoch in der Regel durch entsprechende Sühnemaßnahmen rückgängig machen. Dem Tod eines Angehörigen folgte die Reinkarnation eines verstorbenen Gruppenmitglieds. Schweren Mißgeschicken lag stets ein gravierendes Fehlverhalten hienieden zugrunde: Ahnen, Sippen- und Dorfschutzgeister, unter Umständen die Götter selbst, suchten zur Warnung oder mit strafender Hand die Frevler heim, um die erschütterte Ordnung wieder zurechtzurücken. Die diesseitige hatte so zwingend die Existenz einer jenseitigen, unsichtbaren, transzendenten »Antiwelt« zur Voraussetzung, aus kausalen oder, wenn man so will, aus Gründen der Strukturkonsistenz des Ganzen. Beide bildeten einen komplementären Verbund.

Entsprechend wurde die jenseitige Welt als inverses Gegenbild zur diesseitigen begriffen, noch deutlich konturiert im erdnahen, dichter mit Stoff durchsetzten Bereich, dann zunehmend gestaltlos im fernen Kosmos, wo alles sich auflöst und vollends umkehrt in raumzeitlose Geistigkeit. Ersteres galt für die Totenwelt. Auf dem Weg dahin mußte die leibunabhängige, rein spirituelle »Freiseele«, nachdem sie ihre körperliche Umhüllung abgestreift hatte, zunächst die öden und wüsten Weiten der irdisch-geographischen Exosphäre durchziehen, wo die Schrecken zunehmend wuchsen und sie garstige Geister und gargantuanische Ungeheuer bedrohten, bis sie zuletzt an den Rand der Erde gelangte. Dort hatte sie schwimmend, in einem Nachen oder über eine haarnadelschmale Brücke die Wasser des Urozeans, der verbreiteter Anschauung nach stromförmig die Erdscheibe rings umkreiste, zu überqueren, um dann zuletzt, »drüben« in der Unterwelt angekommen, auf der Gegenseite, also den Kopf nach unten auf antipodische Weise, den Weg zurück bis zum Ahnendorf unmittelbar unter der Siedlung der Lebenden zu gehen. Dort traf sie die Dinge zwar im Grunde nicht anders an, als sie auf Erden waren, nur verhielt sich hier eben alles invers zu den Verhältnissen oben: Dem Tag oder Sommer (Regenzeit) im Diesseits entsprechen im Totenreich Nacht und Winter (Trockenzeit). Infolgedessen wachen und arbeiten die Verstorbenen, wenn die Lebenden schlafen. Die Sonne geht bei ihnen im Westen auf und im Osten unter, oder es scheint statt ihrer überhaupt nur der Mond. Die Flüsse, Entsprechungen jener auf Erden, fließen in gegenläufiger Richtung. Rechts verkehrt sich in der Unterwelt in Links. Begriffe werden in der Gegenbedeutung, also etwa »süß« für »bitter« oder »stehen « für »liegen«, verwandt. Männer verwandeln sich mitunter zu Frauen, diese zu Männern. Im Alter Dahingeschiedene entwickeln sich zu Kindern zurück, Frühverstorbene reifen zu Erwachsenen und Alten heran. Ihre Hütten betreten die Toten von hinten, und natürlich bewegen sie sich weiterhin »kopfüber«, mit den Sohlen gegen die Unterseite der Erde. Nicht anders sitzen sie etwa auch in den Booten, die entsprechend kieloben über das Wasser gleiten. Ebenso weisen Dachfirste und Baumkronen - aus irdischer Sicht - nach »unten«. Eine betagte Zulu (Südafrika) demonstrierte einem Europäer die Gegenweltlichkeit in der Weise, daß 
sie auf den Rücken ihrer Hand wies und erklärte: »So leben wir«, darauf die Hand umkehrte und, auf die Innenfläche deutend, hinzusetzte: »So leben die Ahnen. « ${ }^{\mathrm{IO}}$ Märchenhelden, die - etwa durch einen Brunnen noch zu Lebzeiten in die Unterwelt geraten, fallen beim Grenzübertritt nicht selten in tiefen Schlaf, also einen todähnlichen Zustand. Wachen sie »drüben« wieder auf, stellen sie staunend fest, daß dort statt der Männer die Frauen zur Jagd gehen und Initiationen und Feste ausrichten, wie zum Beispiel bei den Mek in Neuguinea. ${ }^{\text {II }}$ Vordem einfache Leute fahren, europäischen Märchen zufolge, in goldenen Wagen, während einstige Könige in Lumpen gehen und Schweine hüten. ${ }^{\mathrm{I} 2}$ Unansehnliche Geschenke wie Dreckklumpen, Steine oder Mist, die ihnen die Jenseitigen machen, verwandeln sich nach ihrer Rückkehr in Gold. ${ }^{\mathrm{I} 3}$

Und eines Tages kehren die Toten, sich reinkarnierend, wieder ins Leben zurück, während andere sterben und in die Gemeinschaft der Ahnen eingehen. Da eine Gesellschaft, vorausgesetzt, daß ihre Mitglieder sich penibel an die altüberlieferten Vorschriften hielten, einen gleichbleibenden Bestand an Freiseelen besaß und insofern auch nur zu überleben vermochte $^{\mathrm{I} 4}$, wog sich das Verhältnis der Lebenden zu den Toten, wie die Wassersäulen in kommunizierenden Röhren, gegeneinander auf. Stieg die Dorfbevölkerung überstark an, starb nach Überzeugung der Asmat in Irian Jaya (Westneuguinea) prompt der »Überschuß «ab; geschah dasselbe bei den Toten, reinkarnierten sich mehr als gewöhnlich. ${ }^{15}$ War es zu vielen schwereren Vergehen gekommen und starben die Schuldigen oder Angehörige von ihnen dafür eines Schlimmen Todes, so daß ihre Seelen nicht ins Ahnenland fanden und der Bestand bedrohlich sank, begaben sich die Schamanen in vielen Teilen der Welt entweder in die Oberwelt zu Gott, der dort eine Art Seelen-Pool unterhielt, und baten ihn um Ersatz ${ }^{16}$ - oder stahlen ganz einfach Seelen bei benachbarten Gruppen. ${ }^{\text {I7 }}$ Dabei konnte es sich allerdings immer nur um eine Notlösung handeln; denn normalerweise duldete man keine »Fremdseele« in seiner Mitte. Daher war auch Intimkontakt mit Gruppenfremden strengstens verpönt. Entstand aus einer derartigen Beziehung ein Kind, wurde es entweder abgetrieben oder sofort nach der Geburt getötet.

Wachsend mit der Entfernung zur erdnahen Verschränkung von Diesseits und Jenseits weitete letzteres sich zunehmend aus. Raum und Zeit verloren sich vollends. Zuletzt herrschte ubiquitäre Unendlichkeit, »von Ewigkeit zu Ewigkeit«. Die Wesen dort essen und altern nicht, sind körperlos, rein spirituell, unsterblich wie die leibunabhängige Freiseele des Menschen. Sie bilden »Antiexistenzen« zu den Geschöpfen auf Erden, denen einige von ihnen aber doch immerhin noch insofern verbunden bleiben, als sie gewisse »Ressortfunktionen« - als Jagd-, Wetter-, Meeresoder Erdgottheiten (bzw. Heilige) - wahrnehmen, das heißt sich vernehmlich bemerkbar machen, angerufen und versöhnt werden können und Opfer entgegennehmen. Allem schließlich extrem entrückt, residiert der Schöpfer- und Hochgott in den äußersten Sphären des Alls. Er existierte 
bereits vor der Erschaffung des Kosmos, wie er auch nach seinem Untergang noch sein wird: so ungeworden wie unvergänglich, allgegenwärtig, allwissend, allmächtig; ein »Deus otiosus«, der die Welt kaum mehr wahrnimmt, ein »Deus absconditus«, der aller Zuwendung unerreichbar bleibt ${ }^{18}$ - die absolute Inversion seiner menschlichen Kreatur. Das Jenseits entspricht der »Traumzeit« der australischen Aborigines, wie sie ebenso aber auch andere Völker kennen, in der zeitlose Ewigkeit herrscht und man entsprechend die Schöpfermächte noch schauen und in die Vergangenheit zurück- wie in die Zukunft vorausblicken kann. ${ }^{\text {I9 }}$

Gleichwohl sind Diesseits und Jenseits, Götter und Menschen ohne einander nicht denkbar. Auch Gott »lebt« nur im Bewußtsein seiner Geschöpfe. Zwischen beiden Welten webt wechselwirksame Abhängigkeit. Doch besitzen die höheren jenseitigen Mächte, schon aufgrund ihrer Vorgängigkeit, ihrer »Seniorität«, ein gewisses Übergewicht. Während Gott sich universalem Glauben zufolge nach der Erschaffung der Welt, beziehungsweise dem Sündenfall, der den Menschen die Sterblichkeit eintrug, das heißt sie vollends materialisierte, »zurückzog«, segnen die Götter und noch unmittelbarer die Ahnen sie, spenden Fruchtbarkeit und Prosperität und strafen, wenn die Sterblichen fehlgehen. Sie allein verursachen in letzter Instanz alles Geschehen auf Erden. Die Traumzeitwelt ist den Australiern so der stete Kraftquell, aus dem Mensch und Natur die existenzerhaltenden Energien zufließen. ${ }^{20}$ Enger im personalen Sinne jedoch verknüpft das dichteste Band Menschen und Ahnen. Die Verstorbenen vor allem tragen die Verantwortung für die Fruchtbarkeit und die Überlebensfähigkeit der Ihren auf Erden. Die Nyakyusa in Tansania glaubten sogar, daß sie aus diesem Besorgen heraus bei jedem Fortpflanzungsakt zugegen wären. ${ }^{2 \mathrm{I}}$

Nicht minder wichtig für das Interdependenzverhältnis war auch der Informationstransfer zwischen den Welten. Dafür kam auf seiten der Lebenden einzig die Freiseele in Betracht, weil sie selber geistiger Art war. Doch mußte sie sich dazu aus ihrer Leibeinkörperung lösen, da diese ihr gleichsam die Sicht verstellte und ihre Wahrnehmung trübte. Auf die nächstliegende Weise geschah das im Traum, wenn die Physis weitgehend deaktiviert war und »ruhte«. Dann verließ die Seele oftmals den Leib, »stieg aus « und bewegte sich fort, unternahm einen »Ausflug«. Was sie dabei sah und erlebte, bildete den Inhalt ihrer Traumgesichte. Allerdings verlor sie nie ganz die Verbindung zum Körper - andernfalls wäre der Mensch gestorben. Es blieb ein Maß an »Befangenheit«; der Träumende kam kaum über den Grenzbereich zwischen den Welten hinaus. Deutlicher konnte er nur unlängst Verstorbene aus seiner engeren Verwandtschaft sehen, die ihm noch »nahe« waren. ${ }^{22}$ Alles andere nahm er gewöhnlich nur schemenhaft, in verfließenden Konturen, ja manchmal bizarr verformt wahr. Die »Eindrücke« von »drüben« streuten gewissermaßen beim Aufprall auf die Diesseitigkeit; die Bilder erschienen daher wie »verschmiert«. Wurde der Schlaf dann flacher, das heißt trat die Seele 
wieder in die stoffliche Verfangenheit ein, wuchs entsprechend der »Beugungseffekt « der Gesichte. Das Geschaute verwirrte sich mehr und mehr. Sprach der Träumende dabei, geschah es auf kaum verständliche Weise, wie auch Propheten, Besessene oder Schamanen »in Zungen reden«, stammeln oder ihre »Botschaften « in scheinbar unzusammenhängenden Wortkaskaden und Satzfetzen herausschreien. Es bedurfte dann erfahrener Exegeten, um die überbrachten Informationen gewissermaßen zu »dekodieren«, das Muster, nach dem die »Streuung« erfolgte, klarzulegen.

Trance entspricht gleichermaßen dem Schlafzustand, wie der Tod, der eintritt, wenn sich die Seele vollends vom Körper löst und für längere Zeit ins Jenseits überwechselt. Analog berichten auch Märchen immer wieder davon, daß Menschen, die vorübergehend in die »Anderswelt« gelangen, während des Übertritts in eine Art Dämmerzustand oder einen tiefen Schlaf verfallen. ${ }^{23}$ Für sogenannte spontane außersinnliche Wahrnehmungen (im Fachjargon ASW) scheinen ähnliche Voraussetzungen zu gelten. Fast die Hälfte wird Träumen zugeschrieben. ${ }^{24}$ ASW-Gesichte sind zwar »meist anschaulich-visueller Natur, aber lückenhaft, undeutlich, instabil und insgesamt am ehesten dem Traumerleben vergleichbar «. ${ }^{25}$ Parapsychologen halten es infolgedessen für gesichert, »daß ein Zustand herabgesetzter Bewußtseinstätigkeit in unterschiedlichen Ausprägungsformen die Aufnahme parapsychisch übermittelter Eindrücke und Informationen begünstigt «. ${ }^{26}$

Eine weitere Gunstbedingung stellen offenbar auch schwere persönliche Krisen mit entsprechend hochsensibilisierten Gemütszuständen dar, wie sie durch eine lebensgefährliche Krankheit, den drohenden Tod eines Angehörigen oder den Verlust eines Partners verursacht sein können. ${ }^{27}$ In traditionellen Gesellschaften hatte man eine plausible Erklärung dafür. Durch Askese Geschwächte, delirierende Kranke oder Sterbende verfielen in einen Dämmerzustand, schliefen viel oder verloren das Bewußtsein, weil ihre Freiseele den Körper fast schon verlassen hatte und so in einen steten Traumzustand überging. Dabei gewann sie Hellsichtigkeit.

Gewöhnlich übertrug sich ein bedrohlicher Leidenszustand durch Telepathie auf die nähere Umgebung. Man nahm an, daß zwischen Engstangehörigen eine Art sympathetischer Empfindungsgemeinschaft bestand. Erkrankte einer, litten andere spürbar mit. Brach jemand ein Tabu, wurden die Angehörigen von den Folgen mitaffiziert; sie konnten dann gleichfalls von einem Leiden oder Unheil betroffen werden. Befanden sich die Männer weit fort auf der Jagd, beim Fischfang auf hoher See oder auf dem Kriegspfad, hing der Erfolg, ja ihr Leben wesentlich mit vom Verhalten der Ihren daheim ab. Ein Vergehen dort hätte ihnen zum Verhängnis ausschlagen können. Und das würde sich wiederum den Angehörigen mitteilen - etwa durch einen plötzlichen Schmerz, das Zerspringen eines Gefäßes oder im Traum. ${ }^{28}$ Die Freiseelen naher Verwandter und Gatten blieben, auch über größere, ja eigentlich beliebige Entfernungen hinweg, 
in Verbindung; sie »wußten « immer irgendwie »voneinander « - wie die kosmischen Quanten-»Teilchen«, die irgendwann einmal in enger Wechselwirkung standen und auch später noch weiterhin, wie durch eine geheimnisvolle, »quasi-telepathische« Beziehung, verbunden scheinen. ${ }^{29}$ Die Parapsychologie kann auf analoge Phänomene verweisen. In über 80 Prozent der Fälle haben spontane, stark affektgeladene ASW-Gesichte mit nahestehenden Personen zu tun, die sich in einer kritischen, oft lebensbedrohlichen Situation befinden. ${ }^{30}$

Die meisten »Botschaften «, die man in traditionellen Gesellschaften aus der jenseitigen Welt empfing, waren weniger dramatischer Art. Es handelte sich um Omina oder »Zeichen«, wie sie jedermann täglich widerfahren konnten, im strengeren Fall um ungewöhnliche Erscheinungen. Die »Botschaft« betraf in der Regel den, der sie wahrnahm. Sie setzte eine Beziehung zwischen ihm und einer bestimmten Geistmacht, wie seinem persönlichen Schutzgeist, voraus oder kam ihm von seinen Ahnen zu. Den Anlaß bildete eine Verfehlung, die er im verborgenen begangen hatte, so daß die Öffentlichkeit nichts davon wußte und darauf reagieren konnte, oder eine Gefahr, die ihm bevorstand. Sie stellte also in jedem Fall eine Warnung dar. Es kam darauf an, sie »richtig« zu lesen - nach Maßgabe des Koordinatensystems, das die Weltanschauung der Gruppe dafür vorgab. Ein bestimmter Vogel, der ihn bei Tag von links überflog, kündigte ihm eine potentielle Bedrohung, ein Käuzchen, das um Mitternacht nahe beim Haus schrie, eine akute Gefahr, gewöhnlich den Tod eines Angehörigen, wenn nicht seinen eigenen an. Ein schweres Unwetter, das alle betraf, wies warnend auf ein Kollektivverschulden hin. ${ }^{\text {I }}$

Solche »Zeichen« konnten an sich jederzeit und überall in Erscheinung treten. Der doppelweltliche Kosmos wurde indes nicht im Sinne einer festen, fensterlosen Burg begriffen, die rings in säuberlicher $\mathrm{Ab}$ scheidung das gestaltlose Jenseits umgab. Die Raumzeit besaß im Gegenteil eine ungleichmäßige Verteilung. An manchen Stellen »dünnte« sich die Materialität gleichsam »aus« oder riß vollends auf, so daß offene Zonen entstanden, durch die der Informationsfluß widerstandsfreier, rascher und unmittelbarer strömen, an denen Geistmächte schwereloser ein- und austreten, das heißt sich »Spukphänomene« und »Zeichen« deutlicher, auch häufiger zeigen konnten. In räumlicher Hinsicht waren das zum Beispiel Erdspalten, Höhlen, Brunnen, Teiche und hochaufragende Bergregionen, in zeitlicher alle bedeutenderen biographischen, gesellschaftlichen und kosmischen Wendezeiten, wie die Geburt, ein Unglück, der Tod, die Nacht, vor allem die Mitternacht, und der Jahres(zeiten)wechsel mit der Neujahrsnacht als der »Jahresmitternacht«. Wo beide in Deckungsgleiche gerieten, beispielsweise in einer Höhle während der Neujahrsnacht, durfte man fast sicher mit Ahnen- und Geisterbegegnungen rechnen und bestanden optimale Divinationsmöglichkeiten. Wer ein dringliches Anliegen hatte, suchte unter diesen Bedingungen den 
Kontakt zu Ahnen und Göttern; wichtige Rituale wurden bevorzugt während derartiger raumzeitlicher Kongruenzsituationen vollzogen.

Doch selbst, was man unter derartigen Gunstbedingungen erfuhr, traf die Wahrnehmung noch gebeugt. Abgesehen vom Durchgang der spirituellen Botschaft durch die Flucht der materialen Erscheinungen, unterlag der Informationstransfer unvermeidlich dem Inversionsverhältnis zwischen Diesseits und Jenseits. Das bedeutete beispielsweise auch, daß Menschen und Geister einander nicht sehen können, es sei denn in Grenzsituationen, wie kurz vor dem Tod oder wenn jene es bewußt darauf anlegen und jemandem in körperlicher Gestalt erscheinen, um ihn vor einer Gefahr zu warnen oder ins Unheil zu ziehen. Von sich aus waren nur Menschen dazu imstande, die zuvor, wie Schamanen, eine spezielle Initiation durchlaufen und eine Doppelnatur erworben hatten, die ihnen erlaubte, bedarfsweise mal als Menschen, mal als Geistwesen zu agieren. ${ }^{32}$ Da aber beide einander, auf jeden Fall jedoch die Menschen die Geister, nicht sehen konnten, bestand immer die Möglichkeit, daß sie sich zufällig - seitens der Geister vielleicht auch mit Absicht - berührten. In diesem Fall löschten sie, einer verbreiteten Anschauung nach, entweder einander oder der Geist den Menschen aus: Legte ein Toter einem Lebenden die Hand auf die Schulter, tötete er ihn; unternahm ein Märchenheld eine Reise in die Unterwelt und streifte dort jemanden flüchtig, starb dieser im gleichen Augenblick. ${ }^{33}$ Menschen und Geister besaßen aufgrund ihrer Antiweltlichkeit gleichsam eine »umgekehrte Ladung«; sie verhielten sich extrem unverträglich zueinander. Wie Teilchen und Antiteilchen in der Physik hoben sie einander beim Zusammenstoß auf.

Gleichzeitig bedingten sie aber einander. Beide verband eine sichtlich fundamentale Komplementaritätsbeziehung: Die Toten wären ohne die Lebenden, das Diesseits ohne das Jenseits nicht denkbar gewesen. Menschen existieren vermöge der Hilfe ihrer Ahnen. Stürbe ein Geschlecht indessen aus, würden, einem universalen Glauben zufolge, auch die Totenseelen gewissermaßen »verlöschen «.

Der kosmologische Dualismus ist die konsequente Folge der Schöpfung. Den Mythen nach erfüllte zu Urbeginn eine breiig-gestaltlose, unbewegt »träge« Masse, wenn man so will: ein einheitliches vollsymmetrisches Plasma, die Welt. Über ihm schwebte, vogelgestaltig, der uranfängliche Gott. Er »langweilte sich«, wie es immer wieder heißt, da absolut nichts geschah. Er beschloß, etwas zu tun. Funkengleich übertrug sich sein schöpferischer Wille auf den ruhenden Urbrei, »zündete« gleichsam und löste Bewegung aus. Teils kraft seines gebieterischen Wortes, teils durch gestaltenden Zugriff schied er das Feste vom Flüssigen und formte den aus den Wassern geschöpften Stoff. Nach der Erschaffung »belebter« Körper, wie Sonne, Mond, Wind, Wolken, fließende Gewässer, Pflanzen, Tiere und Menschen, die sich im Raum bewegen, trat die Zeit in Erscheinung - oder richtiger: war die Raumzeit entstanden. Und jetzt erst, nach- 
dem die stoffliche Welt ihre feste - notwendig endliche und begrenzte Gestalt gewonnen hatte, hob sich von ihr auch das »Jenseits « als immaterielle »dunkle«, raumzeitlose Antiwelt deutlich ab. Ein »Phasensprung« hatte stattgefunden und zwei zwar komplementär verbundene, durch die inverse Struktur ihrer Symmetrien aber klar voneinander geschiedene Welten entstehen lassen.

Innerweltlich fand der Prozeß dann seine Fortsetzung mit der weiteren Differenzierung der Formen bis zum Ende der Schöpfungszeit. Den letzten »Phasensprung « verursachten die Menschen selbst durch den »Sündenfall«. Ursprünglich hatten sie noch im Paradies, einem Übergangsbereich zwischen Diesseits und Jenseits mit offenen Grenzen zu beiden hin, mit den Göttern zusammengelebt. Nach dem Fall sahen sie sich unsanft auf die Erde inmitten des Diesseits versetzt, mußten ihr Dasein mit ihrer Hände Arbeit fristen, litten, erkrankten und starben. Doch hatten die Götter ein gewisses Erbarmen gezeigt und ihnen die »Kulturheroen « gesandt, die sie in der Fortpflanzung, geordnetem sozialem Verhalten, der Jagd, dem Bodenbau, der Gerätefertigung und allem, was sie sonst zum Leben bedurften, unterwiesen. Sie vermehrten sich und wanderten ab; kleinere »Phasensprünge« ließen verschiedene Kulturen mit je eigenen Ordnungsstrukturen oder Partialsymmetrien entstehen. Die Götter aber, und der Schöpfer zumal, waren in unerreichbare Ferne gerückt, oder anders gesagt: Mit der zunehmenden Verfangenheit der Menschen in die Materialität der diesseitigen Welt nach der Vertreibung aus dem himmlischen Garten wurden ihre Lider gleichsam schwer; die Verdichtung des Stofflichen mit der Vielfalt seiner Formen und »Symmetriebrechungen « verstellte ihnen den Blick und verdüsterte ihre einstige Klarsicht. Am Ende schienen ihnen die Götter unsichtbar geworden; die Kommunikation mit ihnen war nur mehr gebrochen möglich.

Die eigene Anschauung spiegelte wider, was sich im großen vollzogen und verfestigt hatte. Das Weltbild traditioneller Gesellschaften gründete sich auf das Basiskonzept eines dualistischen Zwei-Sphären-Systems: Die eigenweltliche Endosphäre, in der allein aufgrund der ethnozentrischen Optik das Dasein optimal verwirklicht erscheint, wird rings von der fremdweltlichen Exosphäre umschlossen, die mit fortschreitender Ausdehnung zunehmend mehr ihr negatives Kontrastbild darstellt. Was im Innern gerade Konturen und geordnete Strukturen besitzt, muß draußen entsprechend verbogen, krumm, gebrochen, im Extremfall chaotisch anmuten.

Auch dies liegt in der Schöpfung begründet. Ihr Meisterwerk hatten die Götter nämlich erst zuletzt mit der Erschaffung der endosphärischen Binnenwelt und des Urahnen der je eigenen Gruppe vollbracht. Davor war ihnen mangels Erfahrung noch manches mißlungen. Das Trümmerfeld mit den Fossilien und Überlebseln dieser ersten, noch tastenden Versuche bildet die exosphärische Außenwelt - mit Rückständen der noch ungeschiedenen Ursubstanz, wie Mooren und Sümpfen, mit gleichsam 
halbfertigen, bizarr gestalteten Landschaften, wilden Menschen und monströsen Kreaturen, den Abkömmlingen der mißratenen oder auch einfach nur abgebrochenen Schöpfungsansätze. Ihnen bleibt ein »gerades« Fortkommen von Natur aus versagt, zumal der Boden, auf dem sie sich bewegen, schwankend und schlüpfrig ist. Das läßt sie entweder absinken in stumpfe Stagnation oder treibt sie auf schiefe Bahnen. Berührungen mit ihnen, wie mit der exosphärischen Außenwelt überhaupt, mußten als gefährlich aufgefaßt werden; man fürchtete, sich auf jeden Fall zu verunreinigen, eigentlich aber irgendeine Art von Versehrung davonzutragen, zu erkranken, den Verstand, ja das Leben zu verlieren - eben vernichtet zu werden durch den Kontakt mit dem »absolut Anderen«.

Jenseits der Grenzen des territorialen »Kulturlands«, in Wildnis, Einöden, Busch und Wald, Wüsteneien und unwegsamen Bergregionen, hatte man mit »Verkehrtem« zu rechnen, drohte Verkrümmung an Leib und Seele, lauerte Unkalkulierbares - wie im Schmutz, den man von draußen ins Haus trug und der einer verbreiteten Vorstellung nach verborgen Geistergeschmeiß in sich birgt. Man fegte daher häufiger gründlich aus und lud den Kehricht am Rand oder außerhalb des Dorfes ab. ${ }^{34}$

Mit »verkrümmten« Existenzen im eigenen Innern verfuhr man genauso. Überführte Verbrecher, deren Vergehen so schwer waren, daß eine Resozialisierung, eine »Begradigung « ihrer Verkrümmung, aussichtslos schien, wurden entweder gewaltsam »hin-gerichtet « oder exkommuniziert und der exosphärischen Außenwelt überantwortet, der sie wesensmäßig entsprachen. Dort fristeten sie vielleicht noch eine Zeitlang als Wegelagerer und Räuber ein Schattendasein, hatten aber, als »Vogelfreie«, nur geringe Überlebenschancen. Eines »Schlimmen Todes« Verstorbenen, das heißt Menschen, die sich unerkannt aufs schwerste vergangen hatten und dafür von den Ahnen mit einem tödlichen Unfall, einem plötzlichen Tod »aus heiterem Himmel« oder durch Ermordung bestraft worden waren, erging es nicht anders. Wie schon erwähnt, bestattete man sie nicht auf die übliche zeremonielle Weise, sondern verscharrte sie flüchtig und formlos irgendwo draußen im Busch, warf sie in Sümpfe oder legte sie in einsamen Berggegenden ab. ${ }^{35}$ Ihre Seelen konnten so nicht ins Totenreich finden, das heißt sich niemals mehr reinkarnieren. Sie irrten fortan friedlos im Grenzbereich zwischen Diesseits und Jenseits umher, gingen ein in das Heer der exosphärischen Unheilsgeister und lauerten den Menschen an typischen »Schnittstellen« wie an Wegkreuzungen im Wald $^{36}$, in Ruinen verlassener Ortschaften, an einsam gelegenen Seen usw., auf, gleichsam verzehrt von dem Wunsch, sich für ihre Unseligkeit an den Lebenden zu rächen.

Der Weg über die Gemarkungsgrenzen hinaus in die »Grauzone« von Busch und Wald galt früher daher, wofür in Europa noch die Märchen anschauliche Beispiele liefern, stets als riskantes Unterfangen. Man mußte gewärtigen, von Räubern überfallen oder von Nixen in die Tiefe eines Sees gezogen zu werden, Zauberern, Hexen und kannibalischen Riesen 
ins Netz zu gehen. Jenseits der endosphärischen Lebenswelt begann »rechte« Ordnung allmählich »unrechter« Gegenordnung zu weichen. Es herrschte die für Übergangszonen typische Zustandsinstabilität; jederzeit konnte einem Unerwartetes, Außergewöhnliches widerfahren.

Dennoch mußte man nahezu täglich Streifzüge zumindest in die nähere Umgebung unternehmen, die insofern auch besser bekannt und weniger gefürchtet war. Busch und Wald lieferten nicht allein wichtige Rohstoffe wie Holz, Tone, Sand, Steine usw.; sie bildeten auch Reservoire unverzichtbarer Nahrungsgüter: Man jagte und fischte dort, sammelte Honig, Vogeleier, Kleingetier, Beeren, Nüsse, Pilze, Wildgemüse und Heilkräuter. Vor den bestehenden Risiken konnte man sich immerhin durch magische Abwehrmaßnahmen zu schützen suchen. Und auf der anderen Seite bot die grenzbereichstypische Destabilisierung immer auch ein dynamisch-kreatives Potential ${ }^{37}$. Wie schon erwähnt, verwischt sich die klarkonturierte Materialität hier durch das Auseinandertreten der Ordnungen, »dünnt sich« gewissermaßen »aus«, so daß Hintergründiges sichtbarer und Hellsichtigkeit wie Erscheinungen leichter möglich werden. Propheten treten in aller Welt bevorzugt im peripheren Bereich der Gesellschaft auf, ihrer Botschaft wie dem Äußeren nach der Konvention widerstrebend, mit langen, ungepflegten Haaren und Bärten, in schmutzige, abgetragene Felle gekleidet, nacktfüßig und apokalyptische Zerstörung verheißend ${ }^{3}$, falls die Ihren nicht zur Umkehr bereit sind und zurückfinden zur Tradition ihrer Väter. Auch die Gottesmutter pflegt sich eher Randständigen, wie Hirtenkindern und armen Bergbäuerinnen, als Kirchenfürsten $\mathrm{zu}$ offenbaren und ihre überraschendsten Wunder unter charakteristischen Grenzbereichsbedingungen zu wirken. ${ }^{39}$

Im Grunde kannte man in traditionellen Kulturen keine eigentlichen »Anomalien«, sondern lediglich ungewöhnliche, seltener glückverheißende, häufiger bedrohliche Vorkommnisse unterschiedlichen »Härtegrads«. Menetekel, von den eigenen Ahnen verhängt, trugen zum Erhalt, Schadenszauber, Hexerei und Geisteranschläge, ins Werk gesetzt von gemeinschaftsfeindlichen Kräften, zur Zersetzung der Gesellschaft bei. Alle aber waren letztlich transzendenten Ursprungs. Doch was immer im einzelnen auch geschah - es blieb systemkonsistent, konnte plausibel begründet, gegebenenfalls integriert oder auch korrigiert, beziehungsweise rückgängig gemacht werden.

Außerhalb aber in der dunklen exosphärischen Antiwelt brodelte ständig Unwägbares, lauerten und drohten Gefahren, vor denen man sich schützen oder auch zurückziehen konnte, über die man jedoch nur kaum Kontrolle besaß. Und dort vollzog sich, nachdem die Entstehung der Archaischen Hochkulturen im 4. Jahrtausend v. Chr. bereits den Boden dazu bereitet hatte, im 6. Jahrhundert v. Chr. im alten Griechenland, fernab also am Rand der Eigenwelt bei den »Wilden«, eine Entwicklung, die den »vorklassischen« Kulturen eines bösen Tages zum vernichtenden Verhängnis ausschlagen sollte: Dreiste Geister begannen dort, die Unan- 
tastbarkeit der altüberlieferten Traditionen in Zweifel zu ziehen und unorthodoxe Fragen zu stellen. Seitdem zählt der Zweifel - wenn auch nicht unbedingt an den eigenen, so doch den Auffassungen anderer - zu den solidesten Säulen des Szientismus.

Die Gründerheroen der Wissenschaften erschufen eine schöne neue Welt mit eigenen Regeln, die sich schon bald auf ihre eigenen Ahnen berufen konnte, ihre eigene Kultur und Götter besaß. Abermals wurden Licht und Dunkel geschieden; vor dem Glanz der Erkenntnis und den Leuchtfeuern, die ringsum hochschlugen, schien die Restwelt in der Finsternis der Unwissenheit zu versinken. Die dortigen »Wilden« dachten verquer »prälogisch«, glaubten an Zauber und Geister und besaßen in ihrer krausen Verkrümmtheit schockierende Ähnlichkeit mit Zwangsneurotikern, Schizophrenen und Paranoikern.

Ganz anders der Geistesadel in den Männerhäusern der neuzeitlichen Hochkulturen. Das Denken dort orientiert sich an geradlinig ableitbaren exakten Erklärungen, die ihrerseits paßförmig eingebaut sind in spezifische theoretische Rahmensysteme. Um diese nicht der Gefahr auszusetzen, durch Unwissen und Aberglaube »verunreinigt« zu werden, ging man in Seklusion und schirmte sich vor der Welt der Uneingeweihten draußen $\mathrm{ab}$ - durch eine eigene Sprache, eigene Konventionen, einen eigenen Ehrenkodex und die Verpflichtung zur Rechtgläubigkeit. Neues mußte integriert werden, damit das Ideal der »Vereinheitlichung « aller Glaubenssätze keine Verletzung litt. Aristoteles, einer der Gründerahnen, hatte die Losung vorgegeben: »Jede Wissenschaft hat zu ihrem Gegenstand das, was immer oder doch in den meisten Fällen stattfindet [...] Es muß also immer oder als in der Regel stattfindend bestimmt sein. $^{4}$ Wer im Dorf bleiben wollte, hatte sich an die Traditionen zu halten, um nicht des Normbruchs geziehen und am Ende gar exkommuniziert zu werden. Doch konnte er in dem Fall immerhin, sofern er die Mittel besaß, ein Tochterdorf gründen.

Auch dort aber hätten Gesetze den Bestand des Systems bestimmt. Wir »erkennen« ihr Walten, so der österreichische Zoologe Robert Kaspar, »aber nur dadurch«, daß es »sich millionen- und milliardenfach wiederholt $\ll{ }^{4 \mathrm{I}}$ Es erscheint reproduzierbar. Der Wissenschaftler, fordert der Physiker Wolfgang Pauli (I900-I958, Nobelpreis I945), sollte sich daher auch einzig auf »das beschränken, was reproduzierbar ist «. ${ }^{42}$

In dieser geometrisch klarstrukturierten Regelwelt erscheint alles, dem klassischen Verständnis nach jedenfalls, streng determiniert - wie in den alten Dorfkulturen. Der Fall eines Steines, erläutert der Evolutionstheoretiker George G. Simpson, wird generell von der Schwerkraft, speziell »in bezug auf die Zeit, den Ort und die Bedingungen durch die gesamte vorausgegangene Geschichte der Materie in diesem Stein « bestimmt. ${ }^{43}$ Die radikalste Fassung dieser Sicht der Dinge stammt bekanntlich von Pierre Simon de Laplace (I749-I827): »Wir müssen den gegenwärtigen Zustand des Universums als die Auswirkung des vorgehenden Zustands 
betrachten und als die Ursache dessen, was folgen wird.« Wo etwas unbestimmt bleibt, kennen wir nur die entsprechenden Antezedenzbedingungen noch nicht. ${ }^{44}$ Neuere, wie der Chemiker Hanns Sachsse (I906-I992) zum Beispiel, konzedieren immerhin, daß uns manches vielleicht aufgrund unseres begrenzten Erkenntnisvermögens verborgen bleibt. »Es mag sein «, so sein Bedenken, daß selbst das Einmalige »in gewissem Umfang, ja vielleicht bis in die letzten Einzelheiten im Zusammenhang unseres Universums bedingt ist, aber da unser Verstand endlich ist, können wir den Zusammenhang nur bis zu einer gewissen Grenze durchschauen, und das Durchschaubare ist eben erklärbar und begründbar [...] und das nicht Durchschaubare müssen wir eben als Gegebenheit, als das, was uns zufällt, hinnehmen.« Derartige »Zufälle« schlössen jedoch »einen Gesamtplan keineswegs aus «. ${ }^{45}$

Dafür hatte die Evolutionsbiologie bereits ein Konzept entwickelt, das allerdings nur für den spezielleren Fall biotischer Systeme galt: Zufällige »Mutationen « geraten ins Räderwerk der Anpassungs- und Selektionsmühlen und werden, wie Jacques Monod formulierte, »nachdem der Replikationsmechanismus sie eingefangen und reproduziert hat, durch die Auslese festgehalten ${ }^{4}{ }^{46}$ In der Folge schließen sich im Prinzip auf ähnliche, jedoch zunehmend mehr determinierte Weise einzelne zu immer komplexeren Systemen zusammen. ${ }^{47}$ Inzwischen hat die Quantenphysik die allgemeineren theoretischen Grundlagen für den Sachsseschen »Gesamtplan « geliefert, indem sie den »Zufall« als mathematisch-statistische Größe voll ins Kalkül zog. Ihr Geltungsanspruch umfaßt die gesamte, auch die biotische Natur. Ihren Vertretern zufolge stellt sie »heute die umfassendste abgeschlossene Theorie dar. $^{48} \mathrm{Ihr}$ genügen, der Schätzung Carl Friedrich von Weizsäckers nach, »eine Milliarde von heute bekannten einzelnen Erfahrungstatsachen, und keine einzige Erfahrung ist bekanntgeworden, die in überzeugender Weise den Eindruck erweckt hätte, sie widerspreche der Quantentheorie ${ }^{49}$

Das naturwissenschaftliche Weltbild baut sich sonach auf dem Basiskonzept eines dualistischen Zwei-Sphären-Systems auf: Die endosphärische Makrowelt, erfahrbar, weitgehend determiniert und geregelt nach den Gesetzen der Reproduktion, wird rings von einer empirisch nicht unmittelbar zugänglichen indeterminierten, mikrokosmischen, den Zuschreibungen nach »exotischen «»Grund- und Randwelt« umschlossen, die mit fortschreitender »Entfernung « zunehmend mehr die kontrastiven Züge einer »Antiwelt« annimmt. Beide sind alles andere als scharf voneinander geschieden, sondern durchdringen sich auf vielfältigste Weise, bilden gemeinsam ein komplementäres Ganzes..$^{50}$ Probleme werfen indes die Übergänge im Grenzbereich auf ${ }^{\text {II }}$, hier kann es immer wieder zu unvorhergesehenen, überraschenden, fremdartigen Erscheinungen kommen.

Begründet liegt die Doppelnatur der Welt in der »Schöpfung«. Nach der Initialzündung durch den »Urknall« bestand das Universum nach weithin übereinstimmender Meinung zunächst »aus einer Art Quanten- 
brei«, wie die Physiker sich ausdrücken. ${ }^{52}$ Noch ungeschieden und gestaltlos, befand sich diese - anfangs unvorstellbar heiße - Ursubstanz »in einem Zustand perfekter Symmetrie«. Im Zuge der Expansion kühlte sie sich dann zunehmend ab und durchlief dabei eine Reihe abrupter »Phasenübergänge«, die zu Symmetriebrechungen und in der Folge zur Ausbildung verschiedener Strukturen, Formen und Systeme, wie der Galaxien zum Beispiel, im Endergebnis zur besagten Doppelnatur der Welt führten. ${ }^{53}$

In dieser schönen Gewißheit wiegen sich freilich nur Köpfe, die sich damit bescheiden, den Zusammenhang zwischen Elementarteilchen- und sinnlich erfahrbarer Makrowelt theoretisch zwingend begründet $\mathrm{zu}$ wissen und der Versuchung erliegen, die Regeln der quantitativen Wahrscheinlichkeit, eben weil sie grundlegend sind und die allgemeinere theoretische Valenz besitzen, für bedeutsamer zu halten als ihre spezielleren Konsequenzen in der - immer kulturell gedeuteten, das heißt mit qualitativen Eigenschaften ausgestatteten - makrokosmischen Lebenswirklichkeit.

Wir tragen noch immer am Erbe unserer vermeintlich »unaufgeklärten« Altvorderen. Denn nunmehr haben wir es de facto mit zwei Doppelwelten zu tun, die sich ebenengleich überschneiden und sichtlich analogen Vorstellungsprinzipien genügen - da beide ihre Entstehung menschlichem Denken verdanken. Doch nur die zweite (historisch gesehen wäre es die erste), die Diesseits und Jenseits umfaßt, erfüllt die Bedingungen eines Sinnsystems, das Orientierung gewährt, das Handeln leitet und Ziele setzt, deren Begründungen aus der gelebten, geschichtlichen Vergangenheit schöpfen, verläßliche Vorgaben für die Gegenwart liefern und Wege in die unsichere Zukunft weisen. ${ }^{54}$

Das wird deutlich beim Auftreten von »Anomalien«. Niemand wird sich ernstlich betroffen fühlen, wenn es bei atomaren Zertrümmerungsprozessen im Teilchenbeschleuniger $\mathrm{zu}$ unvorhergesehenen »Ereignissen« kommt. Möglicherweise muß eine theoretische Annahme modifiziert, korrigiert oder erweitert werden. Doch erkrankt jemand, der uns nahesteht, lebensgefährlich oder erliegt einem tödlichen Unfall, »greift« uns das spürbar »an«. Fragen nach möglichen Versäumnissen, nach dem persönlichen Verschulden entstehen, das unter Umständen gesühnt werden, für das man »bezahlen« muß. Man macht sich Gedanken über das »Schicksal«, das scheinbar »blindlings zuschlägt« oder in dem sich ein »höherer Wille« kundgibt, das vielleicht eine »Prüfung« bedeuten könnte. Man sucht nach Gründen in der eigenen Biographie und im Zusammenleben mit anderen, das heißt greift auf die Vergangenheit zurück, um eine Erklärung für das gegenwärtige Geschehen zu finden, auch, um es in Zukunft anders, besser zu machen und der - vermeintlich - kontingenten Erfahrung Sinn zu verleihen. Das Begründungsbemühen wächst auf die Weise immer über den einzelnen hinaus und gewinnt damit der überzeugenden These Thomas Luckmanns zufolge religiösen Charakter: »Das Transzendieren der biologischen Natur durch den menschlichen 
Organismus« stellt seiner Auffassung nach ebenso eine "grundlegende anthropologische Tatsache« wie ein »religiöses Phänomen« dar. Subjektives Erleben wird durch den Austausch in der Begegnung mit anderen, um überhaupt kommunikabel zu sein, »synchronisiert « und gewinnt dadurch überindividuelle, »objektive« Bedeutung. So entstehen über gesellschaftliches Übereinkommen (oder durch »Konstruktion«) »symbolische Universa« jenseits der alltäglichen Wirklichkeit, die den Bezugsgrund des Sinnverständnisses und damit die Bedingung für ein »gesellschaftlich geordnetes Zusammenleben « bilden. ${ }^{55}$

Hier bleiben Kontingenzen ein Problem, so aufgeklärt immer der Betroffene sich dünkt, weil sie die »Kohärenzfiktion ${ }^{56}$ der Gesellschaft, das grundlegende Postulat einer jeden konsistenten Identitätsideologie, und damit geltende Sinnsysteme zu erschüttern drohen. Es hilft da nicht viel, wenn man ihnen, wie die Philosophen Eduard von Hartmann (I842I906) und Hans Vaihinger (I852-1933), das Irritierende meint nehmen zu können, indem man, unter Rückgriff auf den ebenso gängigen wie naiven Grundsatz, erklärt, es handle sich stets um bloße Fiktionen, »weil unsere Wissenschaft nicht alle Ursachen umfaßt, welche in einem Falle wirken; denn sonst gäbe es [...] nur Gewißheit.« Da diese unerreichbar für Menschen sei, müsse man sich schon mit dem Zufall abfinden - als einer unentbehrlichen Fiktion. ${ }^{57}$ Fraglos eine schwache »Erklärung «, da ihr Bedeutungsgehalt praktisch gleich Null ist und sie daher wenig Sinn macht. Auch Kontingenz zum Kalkül statistischer Wahrscheinlichkeitsregeln zu deklarieren, würde kaum jemandem die Beunruhigung nehmen, die unerwartet Auftretendes mit schwer abschätzbaren Konsequenzen auszulösen pflegt.

Die »Aufklärung « hat Kontingenzen (»Zufällen«) keinesfalls den Boden entzogen noch die Aussicht genährt, sie ließen sich tatsächlich einmal ganz aus der Welt schaffen; im Gegenteil: Mit der Verdopplung der dualistischen Kosmologie sind vier »Welten « mit entsprechend mehr Schnittflächen entstanden; mit der verstärkten Komplexität in allen - gesellschaftlichen, ökonomischen, technischen, wissenschaftlichen usw. Bereichen hat sich eine Vielzahl neuer Systeme mit einer vermehrten Menge von Grenz- und Übergangszonen samt Hintergründen oder »Transzendenzen« gebildet - Regionen also, an denen es strukturbedingt $\mathrm{zu}$ »Symmetriebrechungen« oder Anomalien kommt. Mit ihnen schwindet die Reproduzierbarkeit und wächst die Verunsicherung, in Fällen persönlicher Betroffenheit das Leidensbewußtsein. Die Orientierung verliert an Boden, während das Kreativitätspotential, das unter den Bedingungen verstärkter Instabilität, in Prigoginescher »Gleichgewichtsferne«, besonders gedeiht, sich gleichsam »entfesselt«: Die Differenzierungsprozesse beschleunigen sich; das Bemühen, Kontingenzen einzufangen, zu deuten und den Systemen zu integrieren (sie zu »erklären«) oder sie auszulöschen, sieht sich einer Vielzahl von »Angeboten« einer Vielzahl von »Sinnlieferanten« gegenüber. Man kann sie auf Spuk, Sinnestäuschung, 
den Willen Gottes, eine Regelverletzung, einen Fehler im Theoriensystem, Genialität, mangelndes ganzheitliches Bewußtsein oder psychotische Wahnvorstellungen zurückführen.

Die Menschen werden auch fürderhin, unbeschadet der Quantentheorie und aller Wahrscheinlichkeitsregeln, mit Kontingenzen zu kämpfen haben, in der Wissenschaft wie im »wirklichen Leben«. Doch läßt sich durchaus unter ihnen scheiden und qualifizieren - nicht indem man bei den Differenzierungen ansetzt und sich in »heillosem « Relativismus verliert, sondern durch den transkulturellen Vergleich von Gesellschaften, die über einen bestimmten Zeitraum hin traditionsbestimmt lebten und insofern ein stabiles Identitätsbewußtsein mit entsprechend konsistenten Weltanschauungen und Sinnsystemen auszubilden in der Lage gewesen waren und, wie die Analyse zeigt, in der Tat eine Vielzahl grundlegender, also sichtlich bewährter Übereinstimmungen (»Universalien«) aufweisen. Aus diesem Erfahrungserbe ließe sich lernen, welches die Bedingungen dafür sind, daß Menschen sowohl untereinander als auch mit anderen in komplexen - berufsständischen, geschichteten, multikulturellen usw. Sozialsystemen auskömmlich und erfolgreich zusammenleben können. Die Komplexität hat die Probleme, das heißt die Anomalien, »Zufälle« und Kontingenzen, vermehrt; doch sind sie strukturell gleich geblieben. Ihren Voraussetzungen und Eigenschaften, also Grenzsituationen und den »exotischen« Erscheinungen, die ihre Ausgeburt sind, verstärkte Aufmerksamkeit zu schenken, sollte sich lohnen. Wie sagte schon Justus von Liebig (1803-1873): »Die Wissenschaft fängt eigentlich erst da an interessant zu werden, wo sie aufhört. $«^{58}$ 


\section{Kippfiguren}

\section{Vom Teufel im Detail mit dem Kaleidoskop*}

Die europäische Hauskatze (Felis domestica) gehört der Ordnung der Raubtiere (Carnivora) und absteigend in der Systematik genauer der Familie der Katzenartigen (Felidae), der Unterfamilie der Echten Katzen (Felinae), der Gattung der Kleinkatzen (Felini), der Art der Wildkatzen (Felis silvestris) und schließlich der Unterart der Nubischen Falbkatzen (Felis lybica) an, deren domestizierte Form sie darstellt - wiewohl dem Laien gelegentlich Zweifel kommen, ob er das Tier, das wohlig schnurrend und scheinbar Zuwendung suchend seine Beine umstreicht, tatsächlich als »gezähmt« betrachten darf; es gibt Fälle, die einen anderen Eindruck erwecken.

Trägt dies jemand öffentlich vor, sind sich auch diejenigen, die ihm nicht ins Gesicht sehen, sicher, daß er die Lippen, in geringerem Maß auch den Unterkiefer bewegt. Die ersteren drücken, in bestimmten Zusammenhängen, wieder auch Zuwendung aus, letzterer eher in Ausnahmefällen. Mit ihm hat es eine ernstere Bewandtnis, von der noch die Rede sein wird. Jedenfalls aber ist man sich einig, daß er ein Teilelement des Mandibularbogens, dieser selbst einen Teil des Viscerocraniums, das heißt des Kiefern- oder Gesichtsschädels bildet.

Aus Feststellungen wie diesen schöpfen wir die Gewißheit, daß alles in der Natur Bestandteil eines Systems ist, in dem ihm Genese, Form, Eigenschaften, Funktion usw. seine bestimmte Stelle, Bewegungsweise und Wechselwirkung mit anderen zuweisen. Je besser das verstanden und je eindeutiger es definiert ist, desto verläßlicher läßt sich damit umgehen, auch in prognostischer Hinsicht. Inwieweit es sich dabei um »Natur « oder menschliche Setzung handelt, mag vorläufig dahingestellt bleiben.

* Das folgende Kapitel stellt die überarbeitete und erweiterte Fassung eines Textes dar, der erstmals unter dem Titel »Der Teufel im Detail. Systemfragen der Anomalistik« in der Zeitschrift für Parapsychologie und Grenzgebiete der Psychologie 36, 3-4 (I994): I63-I75, erschien. 
Doch liegen in Fällen wie den genannten unstreitig idealisierende Simplifizierungen vor, typische Beispiele des für manche anrüchigen reduktionistischen Zuschliffs, der Katze und Kinnlade wie »eingefroren« erscheinen läßt. Unter gewissen Bedingungen indes weichen die harten Konturen auf. Eine Katze ist sowohl Haus- wie Raubtier, während die Mandibula je nach Form und Ausmaß im Verhältnis zum restlichen Gesichtsschädel schön oder abstoßend anmuten, ja im Rahmen eines Boxkampfs ein gesuchtes Angriffsziel darstellen kann. Kein Vorstellungsgegenstand existiert, der nicht immer auch Teil anderer, ja mehrerer Ordnungssysteme wäre und diese dadurch miteinander verbindet, bis hinauf zu kaum noch bewußt wahrgenommenen Zusammenhängen. In allen kommt er vor - aber unter verschiedenen, wenn man so will »optischen« Aspekten, die ihm seine je konkrete Positionierung im System verleihen.

Richtet ein Zahnmediziner sein Auge auf den Unterkiefer eines Patienten, folgt er (gewöhnlich) seinen professionellen Interessen; mögliche ästhetische oder sportliche Gesichtspunkte treten dabei in den Hintergrund, ja sinken vielleicht vollends unter den Horizont seiner Aufmerksamkeit ab in die »Transzendenz« des Augenblicks. Dort existieren sie potentiell fort. Verläßt der Arzt die Praxis und tritt daheim seiner Frau gegenüber, können sie, je nach Verhältnis und Stimmungslage beider, gleichsam »schlagartig« aktuell werden, während gleichzeitig die professionellen Aspekte verblassen.

Ein Patient würde es für befremdlich halten, wenn sich sein Zahnarzt, während er mit gemischten Gefühlen im Behandlungsstuhl liegt, nicht für den schmerzenden Zahn, sondern die Proportionen seines Unterkiefers im Verhältnis etwa zur Nase oder Augenpartie des Gesichtsfeldes interessierte. Katzenbesitzer in städtischen Milieus zeigen sich irritiert, wenn ihre verschmusten Tiere erbeutete Mäuse mit scheinbar sadistischem Behagen langsam zu Tode quälen. Doch würde es sich in beiden Fällen immerhin noch um sanfte Anomalien handeln. Auch der Zahnarzt ist »nur ein Mensch«, und eigentlich weiß man ja, daß Katzen auch Raubtiere sind. Die betroffenen Zuordnungssysteme zählen noch zur Welt des Vertrauten. Der kurze Schock entstand dadurch, daß sich eine der gegebenen latenten, das heißt für den Augenblick »transzendenten « Potentialitäten überraschend aktualisierte, weil sich der Geschockte noch in einem Zusammenhang wähnte, in dem sie gewöhnlich nicht in Erscheinung treten. Zwei Systeme überschnitten einander.

Ein Extremfall wäre gegeben, wenn sich etwas ereignete, das offensichtlich einem dem Betroffenen völlig unbekannten Bedeutungszusammenhang, sozusagen einer fernen »Transzendenz«, entstammte und daher »exotisch«, wenn nicht stark schockierend erschiene. Man stelle sich beispielsweise vor, jemand sucht einen Zahnarzt auf und bemerkt, daß er eine polierte und kunstfertig mit Einritzungen ornamentierte menschliche Mandibula um den Hals trägt. Auf den fragenden Blick des Patienten hin erläutert der Arzt nicht ohne Stolz, es handle sich um die 
Kinnlade eines Kollegen, den er erschlagen und aus dessen Schädel er die Knochenpartie gelöst und entsprechend bearbeitet habe, um sie fortan als Trophäe seines Triumphes zu tragen.

Dies hat es tatsächlich gegeben. Es war in nicht wenigen traditionellen Kulturen, und namentlich unter Kopfjägern, Brauch. ${ }^{\text {I }}$ Denn mehr noch als der Schädel galt speziell der Unterkiefer des Menschen als im höchsten Maße lebenskrafthaltig, ja gelegentlich als Sitz des Lebens selbst ${ }^{2}$ - ihm entsproßen die ersten Zähne und später, bei Männern, teils auch älteren Frauen nach Eintritt der Menopause, das Barthaar: beide ihrerseits hochpotenzierte Lebenskraftträger. Man ließ ihm daher schon seit den ältesten Zeiten, hinaufreichend bis zu den Neandertalern, bei Bestattungen oftmals eine Sonderbehandlung zuteil werden ${ }^{3}$ oder trug die besonders hergerichteten - Kinnladen seiner Vorangegangenen lebenslang am Leib ${ }^{4}$, nicht eigentlich aus Pietät, sondern mehr als magisches Stärkungs- und Schutzmittel, also als Talisman wie Amulett.

Der behandelnde Arzt hätte das Brauchtum während eines »aktiven Abenteuerurlaubs« liebgewinnen und mitgebracht haben können. Dem Patienten müßte der Anblick, falls er nicht gerade Ethnologe wäre, als eine robuste Anomalie erscheinen, zumal ihre Reproduzierbarkeit zumindest in Frage stünde. Erst durch die Erläuterung gewänne das ungewöhnliche Schmuckstück, wenngleich nur gedanklich in seinen ursprünglichen Zusammenhang zurückversetzt, den Anschein von Normalität.

Es hätte also in diesem Fall noch eine Möglichkeit des Verständniszugangs bestanden. »Robust anomal« mutet ein Phänomen an, wenn es am transzendenznahen Horizont des Vertrauten, wie in traditionellen Kulturen, deren Begründungszusammenhänge nicht hinreichend bekannt sind, gesichtet oder von dort in die eigene Bedeutungs- und Sinnwelt versetzt wird, in die es nicht paßt. Allerdings ist der Effekt in der Regel befristet. Anomalien stören und stoßen auf eine geringe Toleranzbereitschaft. Naivlinge und Gelehrte beginnen, beide auf ihre Weise, erbarmunglos am Räderwerk der Integrationsmaschinerie zu drehen. Vermutungen werden laut, Skepsis regt sich, Erklärungen fräsen die kantigen Konturen des unwillkommenen Sperrguts weich, schmelzen es unter Umständen gar den bekannten Gußformen ein.

Doch ist der Prozeß nicht risikofrei. Auf dem Weg vom bizarren Halsschmuck zum schieren ethnographischen »Kulturelement « aus fernen Breiten, zum Museumsstück oder Gegenstand der vergleichenden Anatomie durchläuft der Knochen eine Übergangsphase der Unbestimmtheit, in der er voll weder das eine noch schon das andere ist: Er durchbricht die Grenzen gleich mehrerer Zuordnungssysteme. Die ursprünglichen Bindungen lösen sich, gleich Sehnen; der Gewebskörper »schwimmt« wie auf Wellen, getrieben von wechselnden Strömungsimpulsen, »eckt« verschiedentlich »an«, wobei dann latente Eigenschaften oder »Aspekte« plötzlich quasi »aufleuchten« können, um gleich darauf wieder ins Dunkel zurückzutreten. Andere Zusammenhänge kommen ins 
Spiel, werden gewissermaßen »abgetastet«. Mal erscheint das Objekt als unappetitliches Knochenfragment eines längst vermoderten Leichnams, mal als Amulett, Reliquie oder eine Art »Fetisch«, mal als Besonderheit des »Kopfjagdkomplexes « primitiver Agrarkulturen. Die Katze, eben noch verschmust und possierlich, enthüllt unerwartet ihre Raubtiernatur oder springt plötzlich aufs Fensterbrett, wölbt fauchend den Buckel und nimmt, als schwarze Silhouette bedrohlich sich abhebend vor dem im Licht des Vollmonds fahl strahlenden Nachthimmel, unversehens die Verkörperungsform einer Hexe an. Beim Passieren derartiger sogenannter quasi-chaotischer »Phasenräume « ${ }^{5}$ ständig gebrochener Wellenfelder von Bedeutungszuweisungen beginnen die Phänomene semantisch $z u$ »oszillieren«. Eindeutige Zuordnungen oder gar Prognosen erscheinen da kaum mehr möglich. ${ }^{6}$ Katzen und Kinnladen werden beim Deutungsdurchlauf verbogen, geknickt und gebrochen, wie Licht, das ein durchlässiges Medium passiert. Ihre verschiedenen potentiellen, dabei abwechselnd »aufleuchtenden « Eigenschaften »zersplittern sich« gleichsam ${ }^{7} \mathrm{im}$ Prisma der Interpretation, verselbständigen sich teils und streben dann singulären Zuständen $\mathrm{zu}$ - das heißt werden zu robusten Anomalien.

Den großen Erwartungen, die vielfaltsfreudige Jünger postmoderner Weltoffenheit daraus schöpfen könnten, hat die Natur jedoch Grenzen gesetzt. Sicherlich bewegen wir alle uns mehr in Phasenräumen, als uns lieb sein kann. Ein ganz gewöhnlicher Hochschullehrer mittleren Alters kann sich zum Beispiel auf seinem Weg von der Wohnung zum Hörsaal vom Gatten und Vater zum Verkehrsteilnehmer, Unfallopfer, Käufer, »Prof«, Idol oder Langweiler, zum »Chauvi«, Entertainer oder (bei Anfängerveranstaltungen) gar zum »Grufti« verwandeln - und das vielfach unvorhersehbar, je nach Wetter, Verkehrssituation, dem eigenen Befinden, der Zusammensetzung der studentischen Hörerschaft usw. mehr. Doch wo Unwägbarkeit verunsichernd waltet, »wächst«, wie Hölderlin weiland hoffnungsvoll sang, »das Rettende auch«: Gesicherter wissenschaftlicher Erkenntnis nach streben auch chaotische Zustände gewöhnlich »einem stabilen Gleichgewicht zu«. ${ }^{8}$ Der Mensch lebt ungern mit Widersprüchen, zumal als Gelehrter. Der Ethnologe dezidiert, die »im Feld« dem Wilden entwendete Kinnlade als Reliquie oder Trophäe einzustufen. Sie ist darauf wieder zur Ruhe gekommen; Gleichgewicht hält sie im Lot. Sie hat einen festen Platz in einem von mehreren möglichen Systemen gewonnen. Hier läßt sie Schlußfolgerungen, ja selbst Prognosen zu. Aus alledem sollte sich ableiten lassen:

I. Besonders ungewöhnlich, »exotisch« anmutende Phänomene entstammen fernen Zusammenhängen. Auf dem Weg der Erklärung verlieren sie an Fremdartigkeit, weil sie mit fortschreitender Annäherung immer bekanntere Sinnsysteme durchlaufen; ihre »Brechungen« flachen gewissermaßen ab, bis sie zuletzt eingepaßt und Teil der Endowelt sind - oder umgekehrt: Ein Phänomen gewinnt mit wachsen- 
der Entfernung, proportional zur Anzahl der passierten Systeme und entsprechend den zunehmenden Brechungseffekten, an Fremdartigkeit; es strebt dem Zustand der Singularität, also extremer Anomalität $\mathrm{zu}$.

2. Während des Durchlaufs im »Phasenraum« destabilisieren sich die Strukturen, können unerwartet - und entsprechend kaum prognostizierbar - wechselnde Aspekte der Phänomene ins Licht treten, flüchtig und fließend, wie schwingend auf unsichtbaren interferierenden Wellen.

3. Die Instabilität der Übergangsphase und damit die stete Möglichkeit überraschend auftretender »Ereignisse « wächst mit der Zahl der miteinander verschränkten Systeme. Theoretisch könnten es beliebig viele sein, in der Breite ebenso vielfältig vernetzt wie vertikal verschachtelt bis in unergründliche Höhen und Tiefen. Und in den zahllosen Verwinkelungen und Nischen dazwischen nisten die trickreichen Teufelchen, die Zweifel und Widersprüche säen und der Gelehrtenschaft mit Regelabweichungen und Anomalien, spukhaften Zufällen, paradoxen Erfahrungen, Wahrträumen, Visionen und dergleichen mehr Schauder einflößen.

4. Sind die betroffenen Systeme weitgehend bekannt, lassen sich die aberrierenden Phänomene, beziehungsweise die Beugungseffekte, denen sie unterlagen, über kurz oder lang identifizieren, das heißt »befriedigend« erklären.

5. Treten extrem fremdartige Phänomene, also absolute Anomalien, auf, liegt die Annahme nahe, daß sie sowohl sehr fernen als auch ganz und gar unbekannten »Hintergrundsystemen« oder Transzendenzen entstammen, entweder, räumlich-metaphorisch gedacht, von jenseits des Horizonts, aus unvorstellbaren Höhen oder unergründlichen Tiefen herrührend, sowie, dies vielleicht die wichtigste Voraussetzung, daß sie ungebeugt die Systemfluchten passierten, also gleichsam »masselos«, das heißt psychischer, beziehungsweise spiritueller Natur sind.

Letzteres dürfte der seltenere, wenn nicht der Ausnahmefall sein. Er setzt einen Zustand voraus, in dem zumindest das Wachbewußtsein, das von Erfahrungen, Wahrnehmungen und Vorstellungen gleich einer Abstellkammer vollgestellt ist, sozusagen im Schatten liegt und nur wenig Licht hat. Denn wäre es anders, könnten extreme Fremdphänomene als solche gerade nicht in Erscheinung treten, da die Vielzahl der Brechungen auf dem Weg bis zur Wahrnehmung sie bereits zugeschliffen und ihnen das absolut Unvertraute genommen hätte. So gesehen, ließe sich annehmen, daß uns durchaus »Signale« aus sehr »fernen « und unbekannten Systemzusammenhängen erreichen könnten, die wir aber aufgrund unserer spätestens seit der Neuzeit vielleicht zu einseitig fixierten und verengten Sicht- und Erkenntnisorientierung als solche gar nicht (mehr) wahrzunehmen imstande sind. 
»Robuste« Anomalien hingegen entziehen sich auch unserem Wachbewußtsein nicht, im Gegenteil: Sie rühren es auf, jagen uns unter Umständen Entsetzen ein. Sie besitzen zwar extrem ungewöhnliche, das heißt annähernd singuläre Eigenschaften, aber doch nur annähernd, weil sie, wie Psi-Phänomene zum Beispiel, durchaus wiederholt auftreten können - was im übrigen für ihre systemische Herkunft spricht und eine Erklärung, auf welchem Wege auch immer, theoretisch denkbar erscheinen läßt. Vergegenwärtigt man sich die Fülle möglicher Systemfelder in der Natur - und jedes, auch ein bloß imaginiertes Phänomen, gehört, wie schon gesagt, irgendeinem Ordnungszusammenhang an - darf vorausgesetzt werden, daß es auch absolute Anomalien geben muß: Nicht dies, sondern die gegenteilige Annahme wäre extrem unwahrscheinlich. Sie treten, als Fremdphänomene eben, »spontan« in einem vertrauten Ordnungszusammenhang auf und gehen hier entsprechend »exotische« Korrelationen ein, das heißt lösen Wechselwirkungsprozesse aus, die sich konventionellen Erklärungsmustern konsequentermaßen entziehen. ${ }^{9}$

Fassen wir noch einmal den Unterkiefer ins Auge und folgen ihm in Gedanken auf seinem Weg vom anonymen Skelettelement des Mandibularbogens der Vertebraten bis ins Dämmerlicht eines melanesischen Männerhauses an die haarige Brust eines ehrwürdigen Alten: Absinkend gleichsam aus der Stratosphäre des Allgemeinen, hat er durch fortschreitende Differenzierung (oder »Beugung«) zuletzt seine konkrete Gestalt und Bedeutung als Ahnenreliquie gewonnen; er ist vielleicht schöner, aber auch irgendwie »kleiner« geworden. Eine Katze sind wir gewohnt, zusammengerollt auf dem Sofa liegen zu sehen. Doch ließe sich immerhin vorstellen, daß sie sich gähnend reckt, erhebt und aufsteigt über alle Schranken der zoologischen Taxonomie hinaus bis ins Reich der Raubtiere. Sie hätte damit makroskopische Dimensionen gewonnen, würde irgendwie »größer« erscheinen.

Derartige Systemdurchläufe, verfolgt von einem ruhenden Betrachtungspunkt aus, lassen sich daher entweder, in Richtung auf den Beobachter zu, als fortschreitende Differenzierungs-, unter Umständen auch Sezierungsprozesse oder, vom Betrachter fort, als stetige, durch Kombination und Vervielfältigung angetriebene Weiterungen begreifen. Wir könnten, unserer leidenschaftlichen Erkenntnissucht nachgebend, die Kinnlade auch bis in letzte, kleinste Partikel zerschlagen und die Katze immer weiter aufblasen zum Wirbeltier, Lebewesen, Stoff usw., bis sie zuletzt aufginge im Universum. Doch würden dabei, Schritt um Schritt, wichtige Zusammenhänge und Eigenschaften verlorengehen. Mit der Konzentration auf den letzten Knochensplitter unter dem Mikroskop sänke die Mandibula als Ganzes, mehr noch die Bedeutung, die sie etwa als Reliquie oder Trophäe besitzt, unvermeidlich unter den Horizont der Wahrnehmung ab, wie der erweiterte Blickwinkel, der die »Katzenartigen « (Felidae) anvisierte, die konkrete Katze auf dem Schoß zum Verschwinden brächte. ${ }^{\text {Io }}$ Einigermaßen gestaltscharf und verläßlich nehmen wir allein unsere 
eigene vertraute, »mesokosmische« Endowelt, das heißt immer nur begrenzte Bereiche »mittlerer Dimensionen « wahr. ${ }^{\text {II }}$ Jeder »Fort-Schritt«, der darüber hinaus führt, läßt hinter uns Land zurück, dessen Konturen sich in der Erinnerung allmählich verlieren, das eines Tages vielleicht vollends in Vergessenheit gerät. Schritte man rüstig bis ans Ende, gelangte man zuletzt entweder zum Kleinsten oder Größten schlechthin: Ratlos, unter Umständen zutiefst durchgraut, sähe man sich echten Singularitäten, das heißt absoluten Anomalien gegenüber, die als solche wahrhaft unfaßbar sind.

Der Weg führte jeweils vom wohlfühlig Vertrauten mittlerer Dimensionalität in die Kälte des Unbekannten. Und wer immer ihn geht, verwandelt sich, durchläuft eine Metamorphose schrittweiser Inversion: Er schrumpft oder wächst, wird krank oder gesund, zum Wilden oder Zivilisierten, je nachdem, welche Richtung er einschlägt. In beiden Fällen stößt er in zunehmendem Maß auf Anomalien, breitet sich fluktuierende »Unbestimmtheit« aus, erwarten ihn am Ende Singularitäten.

Doch die Reise hielte noch eine weitere Merkwürdigkeit bereit. Zwischen den einzigartigen Eckgrößen des Kleinsten und Größten besteht eine Beziehung. Ersteres scheint immer »unter« oder »hinter « uns, letzteres »vor« uns zu liegen. Elementarteilchen verbinden sich zu Atomen, die sich zu chemischen Elementen und Molekülen zusammenschließen. Aus Einzellern wurden in Jahrmillionen hochkomplexe Organismen; den primordialen »Urhorden « winkte schon in der Wiege das Los, eines Tages in Stammes- und Stadt-, schließlich in staatlichen Großgesellschaften aufzugehen. Zwei als solche unerklärliche Singularitäten am Anfang und Ende der Wegstrecke verbindet eine erklärtermaßen qualitative Beziehung - die Fiktion der Evolution, kein Natur-, sondern ein Kulturprodukt, entstanden in der mesokosmischen Anschauungswelt.

Eine mögliche Erklärung könnte im Wechsel der Optik liegen. Mikround Makrobereichen ist gemeinsam, daß sie scheinbar an der Peripherie des Betrachtungskreises liegen; in beiden gedeihen Anomalien und verhärten sich zu Singularitäten. Doch ist ebendies genauso auch für intermediäre »Phasenräume« typisch. Der Gedanke liegt daher nahe, daß beide, strukturell, von gleicher Art, das heißt die vermeintlich peripheren ebenfalls Zwischenbereiche sind. Das sollte zumindest aus den Überlegungen folgen:

I. Alle - ob materielle oder ideelle - Größen gehören irgendwelchen Zusammenhängen an; also wäre das auch für Singularitäten zu fordern. Nur solange sie vereinzelt erscheinen, muten sie extrem exotisch an; zum Vergleich: »Ein vollständig isoliertes Molekül zeigt nur quantenmechanische Eigenschaften. Ein den Umgebungseinfluß partiell integrierendes Quasimolekül zeigt auch klassisches Verhalten. «2

2. Kein System existiert per definitionem allein; es besitzt immer eine Umwelt anderer Systeme, deren Einflüssen es mit unterliegt. ${ }^{\mathrm{I} 3}$ Aller- 
dings ließe sich aus methodischen Gründen seine quasi hermetische Geschlossenheit fingieren, um ihm »klassisches «, das heißt durch Replikation bestimmtes Regelverhalten zu verleihen und verläßliche Prognosen möglich zu machen. Doch strömte auch dann noch in die »kontrollierten Bereiche stets Unbekanntes ein«, wie der Physiker Henning Genz nicht ohne Bedauern konstatiert. ${ }^{\text {I4 }}$

Nur die Ferne also läßt sozusagen »normale« Übergangsanomalien als quasi-periphere Singularitäten erscheinen und entrückt sie der Erklärung - nicht bloß vorderhand, sondern, mit wachsender Distanz, unter Umständen auch auf immerdar, weil unser Fassungsvermögen eben begrenzt bleibt. So halten es, abermals zum Vergleich, auch Astronomen für wenig wahrscheinlich, »daß wir je all die vielen Faktoren kennen und verstehen lernen, welche die Geschwindigkeit der Erde relativ zu fernen Galaxien bestimmen «. ${ }^{15}$ Doch können wir immerhin verstehen, warum das so ist.

Ungewöhnliches wächst proportional zur Entfernung. Früher dachte man sich die Randzone der Welt mit bizarren Misch- und Monstergeschöpfen bevölkert, mit Ziegenfüßigen, Zentauren, Halbseitigen, Brustgesichtigen, Mundlosen und »Fußschattnern«, die ihre über die Maßen breiten entenartigen Füße, bequem auf dem Rücken liegend, als Sonnenschirm benutzten. Doch sind Ferne und Fremdartigkeit relative Begriffe, zwei komplementäre Aspekte ein und desselben: Sie bedingen einander. Nur in Grenzfällen wird Distanz als räumliche Größe begriffen. Fern kann einem auch der Nächste erscheinen, »so-fern « er sich nur, nach des Betrachters Bedünken, auffallend ungewöhnlich verhält. Erwachsene stehen oft ratlos den Vorstellungen und Verhaltensweisen von Kindern gegenüber und hoffen, daß sie ihnen eines Tages, wenn sie »klüger« geworden und "gereifter « sind, näherkommen werden. Jemandem, der sein Dasein mit seiner Hände Arbeit bestreitet, mag, was Philosophen umtreibt, reichlich absonderlich, wenn nicht abwegig erscheinen; aber er könnte bei ihnen in die Lehre gehen (oder auch umgekehrt). Gläubige betrachten hoffnungslos Ungläubige als bedauernswerte Geschöpfe, die entweder nicht imstand oder willens sind, die Wahrheit zu begreifen; sie stehen ihnen »ferner« als Glaubensbrüder in einem anderen Land; gäbe man sich Mühe, könnte man sie vielleicht noch »bekehren«. Angehörige traditioneller Kulturen hielten die Weißen anfangs teils für Erscheinungen aus dem Jenseits (zumal wenn sie über das Meer kamen), teils schlichtweg für verrückt.

Derartige Einstellungen haben allesamt eine deutlich abwehrende Distanzierungstendenz gemein. Und das erklärt sich daraus, daß sie Folge der allgegenwärtigen identitätsideologischen Optik sind, einer Konstante im menschlichen Gruppenverhalten. Sozietäten von überschaubarer Größe mit gewachsenem, stabilem Identitätsbewußtsein, wie das idealtypisch für traditionelle Dorfgesellschaften gilt, tendieren nämlich dazu, die eigene überkommene Lebensweise zu verabsolutieren. Sie pflegen sie beharrlich 
für das Nonplusultra menschenmöglicher Daseinsverwirklichung, das heißt für höchstmäßig entwickelt, optimal bewährt, richtig, gut und wahr zu halten. Daraus folgt, daß alles, was nicht der Eigenordnung entspricht, was andersartig, »abweichend « und fremdartig erscheint, also grundsätzlich »Auswärtiges«, nur als minderartig aufgefaßt werden kann, und zwar proportional zum Maß der Deviation (oder »Entfernung«) - bis hin zur totalen Inversion: Fern und fremdartig Lebende werden als tiernahe Wilde eingestuft, Kreaturen am Rand der Welt als mißgestaltige Abkömmlinge verunglückter Schöpfungsversuche begriffen. Während im Innern der eigenethnischen mesokosmischen Welt, wo die eigentlichen, »wahren« Menschen wohnen, alles seine geradegefügte, geometrisch klar strukturierte, regelgeleitete Ordnung besitzt, muß das Geschehen jenseits davon, in der außenweltlichen Fremd- oder »Exosphäre«, wie gebogen, verkrümmt, asymmetrisch, regellos, ja chaotisch und gleichsam übersät mit »Blasen« von Anomalien erscheinen. ${ }^{16}$ Das erklärt auch die genannte Evolutionsfiktion: »Hinter« uns, in der »Urzeit«, waberte noch alles in wogendem Wechsel, bildeten sich Strukturen und Formen erst allmählich heraus; »hier und heute« befinden wir uns auf dem Höhepunkt der Entwicklung; »fern « in der Zukunft dräut uns der Untergang, Ragnarök und das Jüngste Gericht, wenn alle Ordnung sich auflöst, Sterne vom Himmel fallen, die Sonne erlischt, das heißt die Schöpfung sich umkehrt, die Welt wieder im uranfänglichen Chaos versinkt - und nichts als Anomalien, bezeichnend für die Antiwelt, das Geschehen beherrschen.

Dabei handelt es sich, vom Anbeginn bis zum Weltuntergang, um dynamische Inversionsprozesse, die über Äonen von Weltzeitaltern hin irreversibel und darum nur anfangs für die Menschen heilsverheißend, ab der Wende aber verhängnisvoll sind. Zwischen den Welten jedoch besteht statisch strukturierte Inversion mit gleichsam »regulären« Anomalien in den Übergangs- und Horizontbereichen. Jeder kann sich davon überzeugen - im Traum, während einer ekstatischen Seelenreise, im Delirium oder zu mitternächtlicher Stunde an Neujahr, wenn die Wasser kurzfristig stillestehen, die Tiere wie Menschen sprechen, Bäume sich auf den Weg machen und einander besuchen und sich der Himmel öffnet, so daß man bis tief hineinsehen und unter Umständen selbst die Herrlichkeit Gottes schauen kann. ${ }^{\text {I7 }}$

Außergewöhnliche Erscheinungen waren den Menschen früher nicht fremd; unter bestimmten Voraussetzungen erwartete man sie geradezu. Insofern besaßen sie auch kaum kontingenten Charakter. Man verstand sie zu deuten und konnte mit ihnen umgehen. Ja unter Umständen suchte man solche Erfahrungen auch ganz bewußt. Dazu war erforderlich, daß man durch rigoroses Fasten und andere Kasteiungen, durch rhythmisches Wiegen, Rezitieren gewisser Formeln, Singen und Tanzen, oft auch den Genuß »bewußtseinsverändernder« Drogen den Körper gleichsam »einschläferte«, das heißt sich in Trance versetzte, um der Freiseele den eksta- 
tischen »Ausstieg« zu erleichtern. Das Paradigma dafür lieferte der Schlaf, die Vorbedingung zum - hier allerdings ungesuchten - Träumen.

Derartige mit voller Absicht ins Werk gesetzte Seelenreisen waren nicht ohne Risiko. Die Betreffenden mußten die »Technik« beherrschen, wie das Schamanen vermochten, und bereit sein, die systemwechselbedingten »Beugungen« bis hin zur Inversion auf sich zu nehmen. Die Seele dematerialisierte, »entschlackte « sich beim Übertritt in die ganz andere Welt der Transzendenz, löste sich von der »trägen Masse« ihres Leibes und sah sich konsequentermaßen außergewöhnlichen Erfahrungen ausgesetzt. Dazu zählte vor allem ein verändertes Zeiterleben: Mit dem Verlassen der stoffgebundenen Räumlichkeit verflüchtigte sich auch die Zeit, um allmählich in den »Fernen« des Alls in Ewigkeit überzugehen. Schamanen, Märchenhelden, Propheten und Heilige in Entrückungszuständen machen bei ihren Besuchen im Jenseits überall auf der Welt dieselbe Erfahrung: Während sie dort meinten, sich nur für wenige Stunden oder höchstens Tage aufgehalten zu haben, stellen sie bei ihrer Rückkehr fest, daß auf Erden inzwischen eine ganze Nacht, oft Monate und Jahre, ja manchmal Jahrhunderte vergangen sind. ${ }^{18}$ Verwandte und Freunde treten ihnen hochbetagt gegenüber oder verstarben bereits vor langer Zeit, so daß sich kaum noch jemand an ihre Namen erinnert. Sie selbst dagegen scheinen nur kaum gealtert: Die Zerdehnung und zunehmende Verflüchtigung der Zeit im Jenseits verlangsamt - entsprechend dem Dilatationseffekt der Einsteinschen Relativitätstheorie, demzufolge die Uhren im All »langsamer gehen« - den Alterungsprozeß, bis er zuletzt, bei den ewigen Göttern, vollends zum Stillstand kommt. ${ }^{\text {I9 }}$

Wer damit und den Gesichten, die er hatte, nicht fertigwird, verliert, wenn er zurückkehrt, den Verstand. Geübte wie Schamanen wissen kontrolliert damit umzugehen. Sie wechseln die Grenzen nach Belieben und immer nur kurz, so daß kaum etwas von ihrer Verwandlung »haften« bleibt. Während sie »drüben« sind, können sie, wie Ahnen und Götter, rückwirkend auf die diesseitige Welt Außergewöhnliches, unter Umständen Wunder, wirken - beispielsweise unfruchtbaren Frauen zu Kindern verhelfen oder Todkranke heilen. Hexen und Schadenszauberer aber besitzen die Fähigkeit, die Verkrümmung beim Wiedereintritt ins Diesseits zu glätten, nur begrenzt. Sie nehmen zunächst die Gestalt spezifischer Tiere an. Hexen erscheinen bekanntlich - und nicht allein in Europa - bevorzugt als schwarze Katzen, Zauberer verkörpern sich in größeren Raubtieren, in Wölfen, Tigern und Jaguaren, oder treten ihren Opfern, wie auf dem melanesischen Eiland Sabarl, als theriomorphe Monster mit langem filzigem Haar, spitzen Krallen und lappig hängenden Ohren gegenüber. ${ }^{20}$ Denn anders als die Schamanen können sie ihr außergewöhnliches Wirkvermögen nur von diesseits der Grenze her entfalten. Die Nacht ist die geeignete Zeit dazu. Darin entsprechen sie den erdnahen Unheilsgeistern. Auch diese materialisieren sich, wenn sie auf Menschen aus sind, 
entweder in vorgetäuschter Schönheit als »berückend « verführerische Männer und Frauen (wie Nixen z.B.) oder mal als furchterregende Tiere, mal in seltsam verformter, mißwüchsig-monströser Gestalt: als bucklige Wurzelzwerge mit feuersprühendem Blick, grobschlächtige kannibalische Riesen und alte, gebückte, runzelhäutige und hakennasige Frauen von abstoßender Häßlichkeit, die langgezogenen ledernen Brüste über die Schultern geschlagen.

Götter dagegen zeigen sich den Menschen sichtbar nur kaum mehr, vielleicht noch im Traum. Tun sie es bei Tag, dann inkognito. Ihrer Nähe wird man sich gewöhnlich erst nachträglich bewußt, wenn der Begegnung mit einem notleidenden Unbekannten, dem man Beistand gewährte, eine unerwartete Segnung, beziehungsweise, wenn man ihn abwies, ein Schicksalsschlag folgte.

Heute, in unserer »entzauberten « Zeit, wandeln weder Geister noch Götter unter den Menschen. Die Irdischen sind unter sich. Alles geschieht nachvollziehbar »rational«, Gutes wie Böses. Die Gründe für beides liegen auf der Hand; man kann sie benennen und das Geschehene entsprechend belobigen oder verurteilen und bestrafen. So begibt sich zum Beispiel, daß reingläubige Gelehrte ihr Flammenauge auf Parapsychologen richten, die sich im Grenzbereich der geklärten Wissenschaftswelt mit »Irrationalem« befassen. Doch ihr Los scheint besiegelt. Echte Endzeitstimmung greift um sich. Denn jene nahen mit erhobenem Schwert, um zu richten; einige milder Gestimmte vielleicht auch, um aufzuklären und heimzuführen, die umzudenken bereit sind. Ihrer eschatologischen Selbstbestimmung gemäß bedürfen die Heilsträger des Fortschritts der Vermummung nicht mehr. Anders als Götter offenbaren sie sich unmittelbar. Anomalien, die ihrem szientifisch gestählten Besen widerstreben, werden, wie Kehricht, dem Orkus der Unwissenheit übergeben.

Aber es bleibt trotz allem der weiche Boden in den Grenzgründen der vielfältig verschachtelten Systemaufbauten, in dem $\mathrm{zu}$ forschen wie $\mathrm{zu}$ richten schwerer fällt; zumal, wenn man nur von einer Ordnungsetage aus seine Grundgesetze erläßt. Teils halten auch Parapsychologen dort noch einen Fuß in der Tür, nur zu gern bereit, mit den Konventionalisten drinnen zu koalieren. Doch dann schlüge die Tür hinter ihnen zu - und ihre schillernde Suite aus Medien, Wahrträumern, Zwiegesichtigen, Geistheilern und »Sensitiven « würde mit dem Aufzug in die Tiefe stürzen. Denen aber, die sich oben hielten, in der Hoffnung, mit eingelassen zu werden, widerführe unter Umständen Analoges. Langjährige Erfahrung lehrt jedenfalls, daß »Paragnosten« in genau dem Maße, in dem sie sich mit ihrer »professionellen « Rolle identifizieren, die Gabe zu spontanen »außersinnlichen Wahrnehmungen« einbüßen. Die Routine führt »zum Verlust ihrer wie immer auch gearteten paranormalen Sensitivität «. ${ }^{2 I}$

Anomalien sind Grenzbereichs-, also Übergangsphänomene. Jede Art von Festlegung kann ihnen daher qualitativ nur konträr sein; Versuche, 
sie $\mathrm{zu}$ »routinisieren«, müssen sie konsequentermaßen auslöschen. Es bleibt nur die Möglichkeit, sie bei der eigenen Wurzel zu packen, das heißt den Verständniszugang über ihre grundsätzlich unbestimmte und instabile, polysystemisch oszillierende, fluktuierende Grenzbereichsnatur zu suchen.

Systeme stellen artifizielle Gebilde dar; sie verdanken ihre Entstehung menschlicher Setzung. Ihre Schöpfer schreiben ihnen klarkonturierte, feste Grenzen zu, wie sie die Natur nicht kennt. ${ }^{22}$ Das impliziert Momente kultureller, speziell situativer Bedingtheit: Ich kann mein Gegenüber als Vater oder Fußballfreund, einen Knochen als Teil des Mandibularbogens oder Reliquie betrachten. Derartige Festlegungen dienen der besseren Orientierung im System und dem verläßlicheren Umgang mit Natur, Kultur und Gesellschaft. Systemmarkierungen entsprechen gewissermaßen der Inbesitznahme und Kultivierung von Territorien. Sie grenzen »jungfräuliches « Land aus der Umwelt aus und konstituieren dort Regeln, nach denen sich fürderhin das Zusammenleben bestimmen und demgemäß probate Voraussagen für die Zukunft treffen lassen. ${ }^{23}$ Das gilt gleichermaßen für das Alltagsverhalten als auch die Wissenschaft, die es nur um einiges genauer damit nimmt. ${ }^{24}$

Mit jeder Systemsetzung aber wird nicht nur anderes ausgegrenzt, sondern auch kreiert. Ob durch Teilung oder Vervielfältigung: stets entstehen im Umfeld neue Systeme mikro- wie makroskopischer Dimensionierung. ${ }^{25}$ Das verursacht uns mitunter gemischte Gefühle: Der Blick nach »draußen« verwirrt; das Bedürfnis wächst, sich um so sicherer im Innern einzuhausen, indem man alles ordentlich zurechtrückt, die Orientierungskonturen härtet, Regeln schmiedet und die Mauern höher zieht. Je weniger Störendes durchdringt, desto wohlfühliger das Behaustheitsempfinden. Man versteht, was sich in der eigenen »dörflichen« Endowelt vollzieht; die Dinge wiederholen sich, es herrschen Verhältnisse, die rational nachvollziehbaren Kriterien folgen. Ungewöhnliches wird entsprechend auf exogene Impulse oder Nachlässigkeiten bei der Systemkonstituierung zurückgeführt. Ordnungshärte tilgt Anomalien aus.

Die nähere Umwelt trägt demgegenüber bereits irritierend »schillernde« Züge; doch mutet das meiste durchaus noch vertraut an. Man darf annehmen, daß die im eigenen Innern das Geschehen regulierenden Gesetze auch dort ihre Gültigkeit besitzen. Newtons Entdeckungen »erweckten den Anschein, als könnte alles in mathematischen oder mechanischen Begriffen beschrieben werden $\ll .{ }^{26}$ Wo sich Unebenheiten zeigen, greift die Wissenschaft ein, korrigiert, schleift ab, hobelt, richtet gerade oder löscht aus, nimmt Brachland in Kultur, gewinnt dem gerodeten Boden des eigenen neue, koloniale Territorien hinzu. »Die Urteile der Naturwissenschaften«, räumt einer ihrer renommiertesten Vertreter, der Physiker Hans Primas, bemerkenswert selbstkritisch ein, »klingen rational, weil ihre irrationalen Elemente nicht erwähnt werden. Nur indem sie 
das >Irrationale als nicht dazu gehörend deklariert< und aus den öffentlichen Diskussionen ausschließt, kann die Naturwissenschaft die Realität rationalisieren. $\ll^{27}$

Was weiterab liegt, entzieht sich, zunächst jedenfalls, noch dem Zauberstab der Naturwissenschaften. Schweift unser bieder-bäuerliches Auge einmal über die Feldflur hinaus, dorthin, wo Busch und Wald beginnen, rückt zunehmend Unvertrautes ins Blickfeld. Da es anderen Zusammenhängen entstammt, läßt es sich schwerlich zur eigenen Ordnungswelt »kausak in Bezug setzen - es sei denn, man böge es eben paßförmig zurecht. ${ }^{28}$ Wenn ethnische Einheiten in Händel miteinander geraten, entscheiden über den Sieg nicht nur die besseren Waffen, List und eherner Mannesmut, sondern auch die Götter zu Häupten der Kämpfer. Die triumphierende Gruppe bestimmt in ihrem Namen, wie die Welt fortan $\mathrm{zu}$ verstehen, wie die Pontius Pilatus-Frage allein zu beantworten ist.

Tragen die Kreuzritter der neuzeitlichen Gelehrtenschaft, die sich kompromißlos den klinischen Idealen der »Wissenschaftshygiene« verschrieben haben, den Sieg über die Ungläubigen davon, breitet sich »Aufklärung« aus - die Strahlen allerdings gebündelt nach dem Linsenschliff der szientifischen Okulare. Denn auch Gelehrte eines Fachs, einer Disziplin oder »Schule« bilden eine Art Population, die der gut ethnozentrischen Neigung erliegt, ihre Errungenschaften zu generalisieren. Dies monierte bereits Plutarch (ca. 46-I2O n. Chr.) bei den Geographen seiner Zeit. Sie pflegten, führt er im Theseus (c. I) aus, auf ihren »Erddarstellungen das, was sich ihrer Kenntnis entzieht, an den äußersten Rand ihrer Karten zu drängen und Erklärungen hinzuzufügen wie: >was jenseits davon liegt, ist Sandwüste und voll wilder Tiere oder >unzugänglicher Morast oder >skythisches Schneegefilde«". Der japanische Epistemologe Magoroh Maruyama prägte für diese Art Optik den Terminus »Akademozentrismus «. ${ }^{29}$ Hans Albert, Wissenschaftstheoretiker und Vertreter des Kritischen Rationalismus, ist (ethno- wie ethologisch begründetermaßen) überzeugt, das hänge »ohne Zweifel mit der Institutionalisierung wissenschaftlicher Disziplinen zusammen«, die zu einer Art »Revierverhalten« führe und die Intention zur Folge habe, »jeden Versuch, mit den Ideen und Methoden einer anderen Disziplin in dieses >Revier< einzubrechen, von vornherein als Anmaßung zu beurteilen und daher zurückzuweisen $\ll^{3 \circ}$ - oder auch, wie man erfahrungsgemäß ergänzen darf, als »unwissenschaftlich « zu brandmarken. In Übersichtswerken zur Geschichte des eigenen Fachs wird gelegentlich der Erfolg der gerade »tonangebenden « Schule (sofern ihr jedenfalls der Verfasser selbst angehört) gewissermaßen als Sieg der Kinder des Lichts über die Kinder der Finsternis beschrieben..$^{3 \mathrm{I}}$ Gestandenen Rittern des Rationalismus können dann Geistergesichte und psychokinetische Effekte gleichsam als bloße Luftspiegelungen über skythischem Schneegefilde erscheinen.

Richtet man seine Aufmerksamkeit konzentriert auf nur einen Zusammenhang, wird man für anderes außerhalb blind; seine Konturen 
verschwimmen, es sinkt ab ins Dunkel der Unkenntlichkeit. Doch was man nach der einen Seite hin fortbläst, trägt einem der Wind unter Umständen von der anderen wieder zu. Die Setzung von Systemen konstituiert mit Notwendigkeit nicht nur andere seitlich wie ober- und unterhalb, sondern läßt in den Grenzbereichen dazwischen immer auch Raum für Widergewöhnliches, für »Anomalien «, seien es »Scheinsingularitäten « ${ }^{22}$ oder exotische »Abstrusitäten« wie Unterkiefer als magische Kraftreservoire, Poltergeister und Hexen, die nächtlicherweile in Gestalt schwarzer Katzen friedlich Schlafenden das Leben entziehen.

Je mehr Systeme, desto reicher die Ernte. Auf der einen Seite seilen wir uns gleichsam ab in die Nanostrukturen der Mikrowelt, in der hinter jeder der zahllosen Ecken und Biegungen boshafte Teufelchen lauern, um uns in die Irre, in die dunklen Fluchten immer neuer labyrinthischer Zaubergärten zu locken. Auf der anderen Seite zwingt uns die Annahme, daß sich das Weltall insgesamt aus wechselwirkender Materie zusammensetzt, zu der Schlußfolgerung, daß es sozusagen ein »Umsystem« geben muß, das entsprechend immaterieller Natur ist, das heißt die Inversion des empirisch wahrnehmbaren Universums darstellt - jene Welt, wo der allwissende und allmächtige Gott wohnt, gleichsam die Apotheose des Irrationalen. 


\section{Der Tod}

\section{Von den verschiedenen Wegen dahinzugehen, zu bleiben und wiederzukehren oder nicht anzukommen}

Unter den immer wiederkehrenden, »regulären Anomalien« stellt der Tod den Extremfall dar, ob er nun als Folge einer anderen ungewöhnlichen Begebenheit, wie einer Geistererscheinung oder eines Blitzschlags, oder auf friedliche Weise eintritt; denn ursprünglich war er in der Schöpfung nicht vorgesehen.

Seine Entstehung wird unterschiedlich begründet. Universaler Anschauung nach führten die Menschen zu Anbeginn ein paradiesisches Dasein. An allem herrschte Überfluß. Doch ernährte man sich allein von Früchten, das heißt, es wurden weder Pflanzen »gewaltsam« ausgegraben oder geschnitten noch Tiere getötet. Gott wandelte noch unter seinen Geschöpfen und pflog ungezwungen Umgang mit ihnen. Niemand erkrankte, alterte oder starb.

Doch trugen sie den Stachel der Sterblichkeit bereits in sich. Sie waren, anders als Gott, Erschaffene, verbunden aus den an sich unverträglichen Bestandteilen Geist (Seele) und Leib (Stoff). Das machte sie anfällig - falls sie ein schädigender Impuls traf. Man sollte meinen, daß sich unter den Bedingungen des paradiesischen Daseins dafür kein Anlaß bot. Aber das Fleisch war eben schwach. Mit der Zeit trieben Sorglosigkeit und Leichtsinn die Menschen in den Übermut. Die Korongo, eine Gruppe der Nuba im Sudan, verfielen zum Beispiel auf die Idee, rein zur Kurzweil »Bestattung « zu spielen. In feierlicher Prozession trugen sie einen Baumstamm - den sie dazu also eigens gefällt hatten - zu Grabe und setzten ihn unter rituellem Gepränge bei. Den Schöpfer indes verdroß die respektlose Posse. Zur Strafe schlug er sie allesamt mit Krankheit und Tod. ${ }^{\text {I }}$ In anderen Erzählungen ist die Rede davon, daß fleischliches Gelüst in den Menschen erwachte und sie begannen, mehr zu essen, als ihnen guttat, Inzest begingen, ja auch Gewalt widereinander übten, wann ihnen gerade der Sinn danach stand. ${ }^{2}$ Der paradiesische Friede geriet in Ge- 
fahr. Argwöhnisch geworden, gab Gott ihnen nach einer Mythe von Sulawesi (Indonesien) eine letzte Chance. Er ließ einen Strick aus dem Himmel herab, an dem ein Stein und eine Banane befestigt waren. Statt nach dem ersteren, der ihnen die Unvergänglichkeit gesichert hätte, griffen sie in ihrer Gier nach der Frucht - um sich damit deren Los einzuhandeln: zu keimen, aufzuwachsen, Früchte zu tragen und zu vergehen, erneut $\mathrm{zu}$ erstehen und wieder zu sterben, immer so fort. ${ }^{3}$

Der Schöpfer, am Ende bitter enttäuscht, mochte die Verhöhnung seiner Autorität nicht länger leiden. Er vertrieb die Menschen aus dem himmlischen Garten, nahm ihnen die Unsterblichkeit, ja übergoß sie oftmals noch zusätzlich mit einer gewaltigen Flut, die nur wenige überlebten. ${ }^{4}$

Neben diesen gibt es aber auch andere Mythen, die den Ursprung des Todes den zerstörerischen Intentionen eines bösen göttlichen Wesens zuschreiben, das ebenfalls unerschaffen schon von Anbeginn an existierte. Mal tritt es als erklärter Widerpart Gottes, mal als verschlagener »Trickster«, mal unverhohlen als Personifizierung des Todes selbst auf. Dieser »Gegengott« begleitet entweder den Schöpfer bereits vom ersten Augenblick an oder taucht urplötzlich aus dem dunklen Umfeld des von Gott geschaffenen Weltordnungssystems, sozusagen »wie aus dem Nichts « auf und versucht, die guten Absichten des Schöpfers zu durchkreuzen, indem er ihm heuchlerische Ratschläge erteilt oder (meist hinter seinem Rücken) ins Handwerk pfuscht - woraus sich die Unzulänglichkeiten der Schöpfung, das heißt alle unerwünschten Anomalien erklären.

Dieser »Vater aller bösartigen Überraschungen« hat es vor allem auf den Menschen abgesehen, in dessen Erschaffung er immer wieder einzugreifen bemüht ist, so daß am Ende eben ein unvollkommenes und anfülliges Geschöpf herauskam, anders, als es den ursprünglichen Absichten Gottes entsprach. Nach einer dafür sehr typischen Mythe der Wogulen in Westsibirien hatte der Schöpfer den Leib des ersten Menschen mit einer dicken Hornhaut überzogen. Als er sich dann in den Himmel begab, um die Seele zu holen und den Torso damit zu beleben, nutzte der Böse die Chance und kratzte soviel von der Schutzhülle ab, als er konnte, so daß schließlich nur mehr ein Rest davon an Finger- und Fußspitzen übrigblieb. Seitdem besitzen die Menschen ihre weiche, verletzliche Haut, die sie angreifbar macht und oft auch zu ihrem Tod führt. ${ }^{5}$

Trickster, Tod und Teufel sind nicht von ungefähr mit der Finsternis verbunden, die der Schöpfer gleichsam abtat, als er das Licht vom Dunkel schied und die Welt »ertagen« ließ. Manchen Mythen zufolge hatte er die abgeschiedene Finsternis zunächst in einem Sack oder Gefäß eingeschlossen. Irgendwann unterlief dann jemandem die Unachtsamkeit, das Behältnis zu öffnen, womit die Nacht Zugang zur Welt erhielt. Oder ein anderer beging eine Missetat, die den Schöpfer derart erzürnte, daß er die Finsternis wieder heraufholte und die gesamte Welt damit überzog. Sein Zorn verrauchte jedoch mit der Zeit. Noch einmal schied er das Licht vom 
Dunkel, ließ nunmehr beide jedoch nebeneinander bestehen, in der Art, daß eines periodisch dem anderen folgte, in stetem Wechsel und gewissermaßen zur bleibenden Warnung der Menschen. Gelegentlich, wenn Sorglosigkeit und Sünde sträflich überhand zu nehmen drohen, greift Gott dann mit beiden Händen in die Büchse der Finsternis und sucht die Verworfenen mit dem unzeitgemäßen Dunkel einer Sonnenfinsternis heim, um ihnen vor Augen zu rücken, daß er sie leicht in die Urnacht zurückstürzen und allesamt wieder auslöschen könnte. ${ }^{6}$

Mit dem Dunkel hat auch die Macht des Bösen an Einfluß über die Welt gewonnen. Jedesmal, wenn die Dämmerung fällt, setzt die Zeit der Unheilsgeister ein, denen nahe zu kommen, tödlich sein kann - denn in der Nacht ist auch der Tod unterwegs. Im Grunde ist sie bereits seit Urbeginn seine Welt. Nach einer Mythe der Samojeden in Sibirien erhielt Gott am Abend des ersten Schöpfungstages, als die Nacht gerade hereinzubrechen begann, Besuch von einem geheimnisvollen Alten, der ihn bat, bei ihm nächtigen zu dürfen. Gott war das nicht so recht, da er eigentlich wünschte, daß niemand etwas von der Erschaffung der Erde wissen sollte. Doch sagte er zu. Am Morgen indes, als es hell wurde, war der Fremde schon wieder verschwunden; er hatte sich gleichsam in das Nichts aufgelöst, aus dem er gekommen schien. Als die Schöpfung jedoch vollendet war, trat er erneut in Erscheinung. Diesmal ersuchte er Gott um eine Dauerwohnstatt auf Erden. Der Schöpfer aber hatte ein ungutes Gefühl und wies ihn ab. Darauf beschwor ihn sein Besucher, es würde ihm schon ein winziger Fleck, nicht größer als die Einstichstelle eines Stockes, genügen. Da dies nicht unbillig schien, gewährte der Schöpfer es ihm, wenn auch widerstrebend - zu Recht, wie sich zeigen sollte. Jener stieß nun mit einem Stab ein Loch in die Erde und verschwand darin mit den höhnischen Worten: »Gut, jetzt bin ich unter der Erde, aber ich werde [heraufkommen und] Menschen rauben « - der Tod hatte seinen Fuß in die Welt gesetzt.7

Doch gehört er ihr, wie die Mythen bekunden, nicht eigentlich an. Wie von nirgendwoher erschlich er sich gleichsam hinterrücks Zutritt, ein düsterer Gott, unbesiegbar und von gespenstischer Unangreifbarkeit, der, während der Schöpfer sich längst von der Welt zurückzog, unter den Menschen verblieb und, wenn ihre Stunde geschlagen hat, lautlos aus dem Dunkel hinter sie tritt, mit einem Mal da ist und sie hinwegrafft, um sich gleich wieder, wie nebelartig von der Finsternis aufgesogen, im Nirgendwo zu verlieren.

Vielfach wurde er daher auch als Fremder begriffen und schon insofern als bedrohlich aufgefaßt. Seine Absichten konnten nur gegen die Interessen der Gruppe, gegen das Leben ihrer Mitglieder gerichtet sein. ${ }^{8}$ In Erzählungen tritt er, wenn eine junge Frau sein beabsichtigtes Opfer ist, in der Gestalt eines gutaussehenden, scheinbar wohlhabenden Unbekannten, wie bei den Agni in der Republik Elfenbeinküste etwa' ${ }^{9}$, sonst 
eher, wie in europäischen Märchen, als hagerer, finsterblickender unheimlicher Gast auf. ${ }^{\text {IO }}$

Fürchten mußten ihn allerdings nur jene, die ein schweres Vergehen begangen und mit einem »Schlimmen Tod « zu rechnen hatten. Denn wer traditionsgemäß lebte und sich und die Seinen frei von Schuld wußte, durfte sich in der Gewißheit wiegen, eines Tages eines »natürlichen«, das heißt gewaltlosen Todes zu sterben und überdies nach etwa drei bis fünf Generationen wiedergeboren zu werden.

Wessen Tage gezählt waren, der welkte wie das Herbstlaub dahin. Seine Kräfte verließen ihn. Von Schwäche zunehmend ausgezehrt, dämmerte er mehr und mehr vor sich hin, delirierte oder verlor das Bewußtsein: Seine Freiseele vermochte sich müheloser, wie im Schlaf, aus der leiblichen Halterung zu lösen; sie schickte sich zum »Heimgang« an. Der Sterbende verfiel in einen typischen Übergangszustand, das heißt wurde empfänglich und offen für »außersinnliche Wahrnehmungen« (ASW): Er hatte »Gesichte« - oder »Nahtodeserfahrungen«, wie sie neuerlich zunehmend auch in modernen Gesellschaften wieder von Menschen berichtet werden, die, schwer erkrankt oder verletzt, gewissermaßen »auf der Schwelle zum Tod « standen. Fast übereinstimmend erinnern sie sich, wie ihre Seele den Körper verließ, sich bis zur Zimmerdecke erhob und von dort das Geschehen unten am Krankenbett beobachtete. Oder es war ihnen, als seien sie durch eine Art Tunnel »ausgestiegen«, um sich »drüben « auf blumenreichen Auen, umflutet von einem überhellen, gleichzeitig beglückenden Licht und einer wundersamen »Sphärenmusik«, seltener auch in wahren Schreckenslandschaften wiederzufinden, bevölkert von »Dämonen und anderen finsteren Figuren«, die sie bedrohten oder auch angriffen ${ }^{\mathrm{II}}$, bis ihnen schließlich »eine Stimme« gebot, wieder umzukehren, da ihre Zeit noch nicht gekommen sei. ${ }^{\text {I2 }}$

Übereinstimmende Erlebnisse werden auch von beherzten Märchenhelden berichtet, die bei wachem Bewußtsein durch Höhlen, Brunnen und Teiche in die Unterwelt ab-, beziehungsweise an Lianen, Bohnenranken und Bäumen in die Oberwelt aufsteigen, oder anderen, die dorthin entrückt werden, nachdem sie sich irgendwo draußen im Wald niedergelegt haben, um auszuruhen, und dabei in einen Dämmerzustand versunken oder auch unversehens eingeschlafen sind. Manche sehen sich auch von bösen Stiefmüttern oder Zauberern, die ihre guten Absichten vereiteln wollen, vor schier unlösbare Aufgaben gestellt. Schon meinen sie, verzweifeln zu müssen, da erscheint ihnen plötzlich eine freundliche alte Frau, beruhigt und fordert sie auf, sich schlafenzulegen. Und wenn sie am darauffolgenden Morgen erwachen, stellen sie zu ihrer Verwunderung fest, daß tatsächlich alles auftragsgemäß erledigt ist $!^{13}$

Oft geht bei Grenzübertritten von der einen in die andere Welt die Erinnerung an die jeweils verlassene verloren. Kinder vergessen ihre Eltern, Boten ihren Auftrag, Prinzen ihre vornehme Herkunft, ja selbst 
ihr Erlösungsversprechen, das sie einer verwunschenen Königstochter »drüben« gaben. Geisterfrauen, die einen Menschen heiraten, behalten nur mehr eine dunkle Erinnerung an ihr vormaliges Dasein. ${ }^{\mathrm{I}}$ Es ist in der Tat wie im Traum, in dem sich, wie Heraklit sagt, »der Geist in uns von der Verbindung mit dem Umgebenden trennt « und infolgedessen »die Gedächtniskraft, die er vorher besaß, verliert «. ${ }^{15}$ Einer altgriechischen mythischen Überlieferung zufolge ist der »Schlaf« (Hypnos) der Zwillingsbruder des »Todes« (Thanatos), und beide sind Kinder der $» N a \operatorname{cht} \ll(N \gamma x){ }^{.6}$

Naturwissenschaftler und Ärzte wissen nicht so recht, was sie von den Nahtodeserfahrungen halten sollen, da sich derartige Gesichte ihrem Verständnis entziehen. Es $m u ß$, wie sie meinen, eine »andere« (die »richtige«!) Erklärung geben. Was läge näher, als die Ursache in der organischen Basis des Bewußtseins zu suchen. Neurophysiologen vertreten die These, daß die Todesangst im Gehirn eine »Katastrophenreaktion « auslöse, die zu gewissen »Überfunktionen«, namentlich aber zur Freisetzung übermäßiger Mengen körpereigener Opiate (Endorphine) führe - was nicht zuletzt »den friedlichen Gesichtsausdruck vieler Toter erklären« könnte. ${ }^{17}$

Möglich immerhin, daß dies für einige Fälle gilt. In traditionellen Gesellschaften jedoch verlief der »natürliche« Tod auf eine Weise, die weder geeignet war, Todesangst noch Katastrophenstimmung aufkommen zu lassen. Der Sterbende war von seinen Angehörigen umgeben, die ihn immer wieder berührten, stützten, ja umarmten. Keinen Augenblick wurde er allein gelassen. Und er wußte überdies, daß seine Stunde gekommen war und er Würde bewahren mußte, wie es die Tradition gebot und die Seinen das von ihm erwarteten. ${ }^{18}$ Zudem blieb ihm noch Wichtiges zu tun. Er mahnte die Anwesenden etwa, langjährige Zwistigkeiten, die Unfrieden unter ihnen gestiftet hatten und die Solidarität der Gruppe bedrohten, endgültig zu begraben, entschied in strittigen Erbschaftsfragen und segnete seine Kinder und Kindeskinder. ${ }^{19}$ Was er in dieser letzten Stunde, da er sich schon auf der Schwelle zum Ahnendasein befand, sprach, verfügte und prophezeite, besaß einen hohen Wahrheitsgehalt und erforderte entsprechende Berücksichtigung. ${ }^{20}$

Zum Schluß aber, wenn die Seele nur mehr wie an einem dünnen Faden mit dem Körper verbunden war, wurde der Sterbende hellsichtig; er sah über die Grenze hinaus. Man merkte ihm das auch an. Seine Augen waren weit in die Ferne gerichtet. »Er ist schon ein Mensch von Nzambi« (Gott), pflegten die Yansi im westlichen Kongogebiet zu sagen. ${ }^{2 \mathrm{I}}$ Vor allem aber gewahrte er einer universal verbreiteten Vorstellung nach seine verstorbenen Verwandten, die gekommen waren, ihn abzuholen und sicher »heimzugeleiten«. Meist bleiben sie in einer bestimmten Distanz $\mathrm{zu}$ ihm stehen und warten, bis er zum Aufbruch bereit ist ${ }^{22}$, in einigen Fällen treten sie aber auch näher, wie bei den Apinayé in Ostbrasilien, versammeln sich um sein Lager und speisen mit ihm, um ihn willkom- 
men zu heißen und in ihrer Mitte aufzunehmen. ${ }^{23}$ Und wieder berichten auch viele Europäer und Amerikaner mit Nahtodeserfahrungen, daß ihnen nach dem »Ausstieg« verstorbene Angehörige und Freunde erschienen seien, um sie »drüben « in Empfang zu nehmen. ${ }^{24}$

Der Sterbende »entschlief«; doch nicht für immer. Die »Zwillingsbrüder« wechselten die Rolle. Der Tiefschlaf des Toten markierte seinen Übertritt in die »andere Welt«. Dort wurde er gemäß dem Inversionsverhältnis zwischen Diesseits und Jenseits wiedergeboren - der gängigen Vorstellung nach auf rituelle Weise: Die Ahnen reinigten ihn, um die Restschlacken seines irdischen Daseins von ihm abzutun, frisierten, bemalten und kleideten ihn neu ein und feierten abschließend seine Heimkehr und »Auferstehung « in einem großen gemeinsamen Fest. ${ }^{25}$ »Nach unserem Tod«, sagt Paracelsus, »wird die Seele geboren. $\ll^{26}$ Fortan führte der Dahingegangene im Kreise seiner Verwandten »drüben« ein Leben analog dem auf Erden - nur eben seiten- und zeitenverkehrt. Und war dann dort seine Stunde gekommen, entschlief und »starb« er abermals und kehrte zu seinen Verwandten »oben « zurück. ${ }^{27}$

Das ist der Grund, warum Säuglinge anfangs, wie Sterbende zuletzt, soviel schlafen: Sie befinden sich noch im Dämmerzustand des Übergangs von der einen zur anderen Welt. Man glaubte, daß ihre Seele sich zurücksehne nach ihren Hinterbliebenen »drüben«, zumal ihre Angehörigen dort um sie trauerten und sie zur Umkehr zu bewegen versuchten. Sie wechselte gewissermaßen noch unentschlossen hin und her. Weilte sie gerade bei ihren Lieben im Totenreich, lächelte das Kind im Schlaf; weinte es, rechnete man das seinem Schmerz zu, Abschied nehmen zu müssen. $^{28}$ Niemals sollte einem Kind daher Anlaß gegeben werden zu erschrecken, weil das seine Seele hätte zurücktreiben können. Vielmehr galt es, ihr behutsam und liebevoll zu begegnen, um sie für das Dasein auf Erden ausgesprochenermaßen $\mathrm{zu}$ »gewinnen«. Ließe man es an der notwendigen Zuwendung fehlen, waren die Menomini in Nordamerika überzeugt, gewänne sehr rasch die Sehnsucht nach der kaum erst verlassenen jenseitigen Welt die Oberhand und an die Stelle des Schlafes träte wieder der Tod. ${ }^{29}$ Um ein übriges zu tun, zog man häufig auch sanft, aber nachdrücklich an Händen, Füßen, Fingern und Zehen, Knie- und Armgelenken, beugte sie hin und her, das heißt bemühte sich, den Körper aus seiner quasi embryonalen »Schlafhaltung « zu lösen. ${ }^{30}$

$\mathrm{Zu}$ Anfang standen die Seelen der Kinder also noch unmittelbar in Kontakt mit den Ahnen. Und das machte sie, gleich Sterbenden wieder, hellsichtig. So konnten sie etwa auch Geister noch sehen. ${ }^{3 \mathrm{I}}$ Da sie ihre Gesichte indes sprachlich noch nicht zu vermitteln vermochten, suchte man den Zugang dazu über die Ausdeutung ihres Verhaltens, dem insofern Zeichenbedeutung zukam. Fegte ein Kleinkind zum Beispiel spontan den Hof, nahm man bei den Suaheli in Ostafrika an, daß der Besuch eines Fremden bevorstehe. ${ }^{32}$

War die erste, kritische Phase im Leben des Kindes komplikationslos 
überstanden, das heißt, hatte sich seine Freiseele offenbar mit der Einkörperung abgefunden, suchte man den Verbund durch verschiedene Rituale weiter zu festigen. Besondere Bedeutung kam dabei der Namengebung zu, und zwar aus zweierlei Gründen. Zum einen war dies ein entscheidender Schritt auf dem langen Weg der Sozialisierung des Kindes: Wer einen Namen besaß, wurde unmittelbar kommunikationsfähig; er konnte persönlich angesprochen, gerufen, getadelt, lobend gegenüber anderen erwähnt und bei Bittgebeten genannt werden. Zum anderen diente die Zeremonie sehr häufig dazu, den Ahnen, der sich in dem Kind verkörpert hatte, zu identifizieren. Das geschah in der Regel so, daß man die Namen der in Betracht kommenden, das heißt der vor etwa drei bis fünf Generationen verstorbenen näheren Verwandten der Reihe nach rezitierte. Reagierte das Kind dann bei einem von ihnen in besonderer Weise, indem es etwa abrupt aufhörte $\mathrm{zu}$ weinen, die Brust seiner Mutter suchte oder lächelte, war man überzeugt, den richtigen getroffen zu haben. ${ }^{33}$ Hatte man die Zeichen falsch gedeutet und der Name »paßte nicht«, zeigte sich das Kind in der Folge auffallend unruhig und mißgestimmt, schrie fortgesetzt oder begann zu kränkeln. Dann mußte man die Prozedur wiederholen - bis das Kind sich beruhigte und genas. ${ }^{34}$ Danach gingen sowohl die Erinnerung an das Totenreich als auch die Hellsichtigkeit verloren ${ }^{35}-$ außer bei Kindern, die unter ganz bestimmten Bedingungen geboren waren, wovon später noch die Rede sein wird.

Starb ein Säugling noch vor der Namengebung, also etwa während der ersten zwölf bis sechzehn Monate, fand man sich rasch damit ab, da ja nie so ganz sicher war, ob sich die Seele zum Bleiben entschließen würde; man mußte eigentlich stets damit rechnen. Da es sich bei den kleinen Toten teils noch um Ahnen, teils erst um unvollkommene Menschen handelte - weshalb man die Kinder in dieser Zeit auch, wie bei den Thonga in Südafrika zum Beispiel, als »unfertiges Wesen « (khuna) oder »Ding « $(\text { shilo })^{36}$, als $\gg$ Affe $\ll(m a s ̌)$, wie bei den Chamula in Mexiko (Chiapas) ${ }^{37}$, oder schlichtweg als »Kind « bezeichnete - bestattete man sie auch nicht auf die übliche rituelle Weise, sondern vergrub sie im Hof beziehungsweise unweit vom Haus oder hing die Särge, wie in Ostsibirien zum Beispiel, in nahestehende Bäume. Der Gedanke war, daß man die offensichtlich noch schwankende Seele dadurch zum Bleiben bewegen und ihr den nächsten Versuch erleichtern könnte. ${ }^{38}$

In alter Zeit hatte man auch die erwachsenen Toten nahebei, das heißt unter dem Haus oder im Hof, auf jeden Fall aber im Dorfareal bestattet $^{39}$, um sie unmittelbar bei sich zu behalten, die Beziehung zu ihnen besser wahren zu können und die Voraussetzung dafür zu schaffen, daß sie später ungehindert und auf kürzestem Wege wieder zurück ins Leben fanden. Doch bedeutete der Tod eines Erwachsenen etwas ganz anderes als das Dahinscheiden eines noch kaum ins Dasein getretenen Kindes. Der Verstorbene würde für längere Zeit seinen bestimmten Platz unter den Ahnen einnehmen, trug Verantwortung für die Seinen »oben« 
und durchlief während seines jenseitigen »Winters « eine Metamorphose wie im Leben - von der »Geburt« bei der Ankunft bis zum »Tod«, das heißt seiner Reinkarnation. Dazu mußte er aber auch sicher im Totendorf ankommen. Und dies zu gewährleisten, war Aufgabe der Beisetzungsriten.

Zunächst jedoch löste das Ableben eines Gruppenmitglieds eine Umbruchsituation aus: die notwendige Voraussetzung für den Übertritt von dieser in die »andere « Welt. Dem trugen die Trauernden Rechnung durch verschiedene Formen korrespondierenden Verhaltens, teils um dem Toten stützend zur Seite zu stehen, teils mit dem Ziel, den kritischen, instabilen, potentiell chaotischen Zustand durch rituelle Objektivierung besser unter Kontrolle halten zu können. Man ließ die Arbeit zum Beispiel ruhen, das heißt kehrte die Alltagsverhältnisse um, stellte die körperliche Hygiene ein, ging nackt oder in schmutzigen Lumpen und mißachtete ungestraft selbst strenge Tabus. Bei den Zulu in Südafrika verrichtete man mit der linken Hand, was man sonst mit der rechten tat; im Haus übernahmen die Frauen die Männerseite (rechts), die Männer die Frauenhälfte (links). ${ }^{40}$ Während der Bestattungsfeierlichkeit selbst wurde reichlich gegessen und gezecht, es fanden Maskentänze und Scheinkämpfe statt (beides szenische Veranschaulichungen der zugegenen Geistmächte), die Geschlechter tauschten die Kleider, oft kam es zu orgiastischen Ausschweifungen, die auch nicht Halt vor der Inzestschranke machten. ${ }^{4 \mathrm{I}}$ Starb gar ein bedeutender Mann oder König, steigerte sich das Ganze zum tage-, manchmal monatewährenden Tohuwabohu der sogenannten »rituellen Anarchie«.

Zur Beisetzung trug man den Leichnam nicht durch die Tür, sondern, mit den Füßen voran, den Hintereingang hinaus, schob ihn durch ein Fenster oder auch ein eigens dazu in die Wand geschlagenes Loch, das anschließend wieder geschlossen wurde. ${ }^{42}$ Manchmal beschädigte man Teile des Hauses, wie zum Beispiel das Dach. ${ }^{43}$ Die Beigaben, die man dem Toten mitgab oder auf seiner letzten Ruhestätte deponierte, wurden oftmals zerschlagen, der Schlitten, auf dem man ihn - wie bei den Tungusen in Sibirien zum Beispiel - transportiert hatte, mit den Kufen nach oben aufs Grab gelegt. Anschließend begab man sich rückwärts schreitend zurück oder wählte einen »verkehrten« Weg. Das geschah alles weniger, wie man oft liest, um den Toten zu täuschen und in die Irre zu führen, sollte er den Wunsch haben, wieder zurückzukehren; denn das hätte nicht nur eine Ungebührlichkeit wider den Verstorbenen bedeutet, sondern auch im Widerspruch zum Zweck der Bestattungsriten gestanden, ihm den Weg ins Totenreich zu weisen. Vielmehr sollte das Ganze der Seele signalisieren, daß sie sich nunmehr in einer Welt zurechtfinden mußte, in der alles »verkehrtherum « war. ${ }^{44} \mathrm{Um}$ des Dahingegangenen willen, vor allem aber auch, damit er sich später würde wiederverkörpern können und imstande war, seinen Beitrag zum Erhalt der Gruppe zu leisten, mußte alles darangesetzt werden, daß er auch sicher in der Ah- 
nenwelt ankam. Versäumte man auch nur eine Kleinigkeit, riskierte man schon, daß er womöglich sein Ziel verfehlte. ${ }^{45}$ Darum erschienen auch die Toten, um ihn zu geleiten, oder war ihm der Schamane als »Psychopompos« (»Seelenführer«) behilflich dabei.

Während der anschließenden Trauerzeit sollten die Hinterbliebenen ihrem Schmerz niemals allzusehr Ausdruck verleihen - wiederum, weil sonst zu befürchten stand, daß der Verstorbene gehalten wurde und nicht zügig auf dem Weg, den er nun mal gehen mußte, vorankam. Erzählungen berichten mahnend, daß manche Tote in derartigen Fällen zurückkehrten und die Trauernden, die ihren Kummer nicht zu bezwingen vermochten, mit sich ins Grab zogen. ${ }^{46}$ Aus dem gleichen Grund vermied man meist auch, die Namen Verstorbener auszusprechen. ${ }^{47}$ Vor allem Kindern, deren Seelen sich ja freiwillig zur Umkehr entschlossen hatten, glaubte man auf diese Weise ausgesprochene Qualen zu verursachen. Das klingt etwa auch in europäischen Märchen noch nach, in denen Kinder im Grab keine Ruhe finden können, weil ihre Mutter ohne Unterlaß um sie weint. Im Grimmschen Märchen Das Totenhemdchen (Nr. I09) erscheint schließlich der verstorbene Liebling seiner Mutter und bittet sie inständig: »Ach Mutter, höre doch auf zu weinen, sonst kann ich in meinem Sarge nicht einschlafen, denn mein Totenhemdchen wird nicht trocken von deinen Tränen, die alle darauffallen. $\ll^{48}$

Eigentlich bestand auch zu übertriebenem Kummer kein Anlaß. Denn die Dahingegangenen existierten ja fort, auf der anderen, den Lebenden nicht sichtbaren Seite des Daseins in der metakosmischen Welt. Man hielt ständig Kontakt miteinander, auch und gerade, um das weitere Fortleben aller zu sichern. Das geschah ganz selbstverständlich, in einer ungezwungenen Weise, für die den heutigen Menschen durch die moderne Entwicklung das Verständnis verstellt und verlorengegangen ist. Bei den täglichen Mahlzeiten und vor allem bei Festlichkeiten gedachte man der Verstorbenen, opferte ihnen Speise und Trank, dankte ihnen für empfangene Segnungen und hielt die Erinnerung an sie in Erzählungen und Lobliedern aufrecht. Diese ihrerseits behielten die Nachlebenden »oben« immer im Auge, nahmen besorgt und liebevoll Anteil an ihrem Geschick, unablässig bemüht, sie gesund und glücklich zu sehen. Wenn Kummer und Sorge drückten, wandte man sich daher vertrauensvoll an seine Ahnen, überzeugt, daß man auf ihre Hilfe zählen konnte - sofern man sich jedenfalls untadelig benahm. Nicht selten erschienen sie den Ihren auch im Traum, rieten ihnen, erteilten ihnen den einen oder anderen wichtigen Hinweis und warnten sie, falls Gefahren drohten. Auf der anderen Seite aber zürnten sie auch, wenn die Lebenden ihre Pflichten verletzten, die Traditionen mißachteten und geheiligte Vorschriften brachen. Je nach der Schwere des Falls erhoben sie dann strafend die Hand wider die Frevler und suchten sie mit Krankheiten, Mißernten, Unglück und anderem Ungemach heim. Jeder verstand das, es war notwendig; denn andernfalls hätte die Überlebensfähigkeit der Gesellschaft, jetzt wie in der Zukunft, 
auf dem Spiel gestanden. Einmal im Jahr, gewöhnlich nach Einbringen der Ernte, lud man die Abgeschiedenen zu einem gemeinsamen großen Fest, dem »Allerseelen«, ein, speiste und trank mit ihnen, unterhielt sie mit Tanz und Musik, pries sie in Reden und Liedern und verabschiedete sie zuletzt, reich mit Opfergaben bedacht.

Doch war dies im Grunde nur dem Ideal nach die Regel. Denn da nur wenige Menschen wirklich in hohem Alter friedlich entschliefen, bildete der »natürliche« Tod genaugenommen die Ausnahme. Viele starben bereits in frühen Jahren, später an den Folgen einer Krankheit, einer Hungersnot, eines Unfalls oder durch Kriegseinwirkung. Sicherlich ging es auch dabei, wie man überzeugt war, niemals mit rechten Dingen zu. ${ }^{49}$ Doch handelte es sich noch nicht um »Schlimme Tode«. Die Verfehlungen, die der Grund dafür waren, das heißt die Ahnen zu der entsprechenden Heimsuchung veranlaßt hatten, ließen sich meist durch Sühnemaßnahmen wiedergutmachen - anders wäre das Totendorf bald entvölkert und die Gesellschaft am Ende gewesen.

Einen Schlimmen Tod sui generis erkannte man daran, daß er plötzlich, auf scheinbar ungewöhnliche und oft auch gewaltsame Weise eintrat: Die Betreffenden fielen einem Mord, Blitzschlag oder Raubtier zum Opfer, ertranken, stürzten von einem Baum, einer Klippe usw. ${ }^{5}$; neuerlich zählen auch Autounfälle dazu..$^{5 \mathrm{I}}$ Die Ursachen bildeten besonders schwere Vergehen, wie Inzest, Kindesschändung, Bruder- und Elternmord, Todeszauber, Hexerei und Verletzungen religiöser Gebote, die sich mit nichts mehr sühnen ließen. Die Täter waren gesamtkonstitutionell so »verbogen«, daß sie von den Jenseitigen nur mehr »hin-gerichtet« werden konnten.

Das Urteil der Ahnen (bzw. Götter) band auch die Menschen. Derart Gezeichneten wurde keine Regelbestattung zuteil; man entäußerte sich ihrer, indem man sie weitab im Busch entweder ablegte und den Tieren zum Fraß überließ oder nur notdürftig verscharrte. Und das hatte eben, wie schon gesagt, die wahrhaft vernichtende Folge, daß ihre Seelen nicht den Weg ins Totenreich fanden, sich niemals mehr reinkarnieren konnten, das heißt für alle Ewigkeit exkommuniziert blieben und fortan als »Untote« im Grenzbereich zwischen Diesseits und Jenseits ein Antidasein im Schattenheer der Unheilsgeister und »Verlorenen Seelen« führten, immer darauf aus, den Lebenden aufzulauern und sich für ihr Los an ihnen zu rächen - vor allem aber: ihnen den Weg zum Totenreich zu verlegen.

Ihre Bindung an die Ihren blieb unmittelbarer, wenn auch unwillkommen. Starben sie, ohne daß ihre Angehörigen davon erfuhren, erschienen sie ihnen entweder im Augenblick des Todes oder während der ersten Stunden und Tage danach, um sich ihnen irgendwie mitzuteilen. Der isländische Psychologe Erlendur Haraldsson ging derartigen Erlebnisberichten in seiner Heimat nach. In etwa der Hälfte der Fälle erschienen die Toten Verwandten oder Bekannten. Überwiegend geschah das, 
während sich sich ausruhten oder in Dämmer- beziehungsweise Übergangszuständen kurz vor dem Einschlafen oder Erwachen befanden. Und auffallend häufig waren die Personen, die den Kontakt zu den Ihren suchten, eines gewaltsamen Todes - durch Unfall, Mord oder Selbstmord gestorben. In knapp einem Viertel der Fälle wurden die Aussagen des Berichterstatters durch einen zweiten Anwesenden bestätigt. ${ }^{52}$

Unter christlichem Einfluß erhielten die Verlorenen Seelen die Chance, ihre Schuld durch Bußübungen abzutragen, teils auch wiedergutzumachen. In den Alpenregionen erinnerten sich ältere Leute noch bis in die ersten Jahrzehnte des letzten Jahrhunderts daran, Prozessionen sündiger Untoter selbst gesehen zu haben. Sie zogen stets auf den gleichen Wegen um Mitternacht vor bestimmten kirchlichen Festen jammernd und klagend dahin, geißelten sich, sprachen Gebete und murmelten immer wieder »in Ewigkeit amen «.53 Im Märchen Der gestohlene Heller der Brüder Grimm (Nr. 154) wird erzählt, wie ein Mann, der bei einer befreundeten Familie zu Besuch weilt, genau zur Mittagszeit, da es gerade zwölf Uhr schlägt und man gemeinsam bei Tisch sitzt, die Tür aufgehen und ein »schneeweiß gekleidetes, ganz blasses Kindlein hereinkommen« sieht. »Es blickte sich nicht um und sprach auch nichts, sondern ging geradezu in die Kammer nebenan. Bald darauf kam es zurück und ging ebenso still wieder zur Türe hinaus.« Doch niemand außer dem Gast hatte die Erscheinung wahrgenommen. Als sich dasselbe an den folgenden Tagen wiederholte, ging der Besucher dem Kind schließlich nach und sah es in der Kammer nebenan auf dem Boden sitzen »und emsig mit den Fingern in den Dielenritzen graben und wühlen«. Dann gewahrte es jedoch den Fremden und verschwand auf der Stelle. Als der erzählte, was er gesehen hatte, wurde der Mutter klar, daß es sich um ihr eigenes Kind handeln müsse, das vor vier Wochen gestorben sei. Daraufhin brach man die Dielen auf und fand zwei Heller darunter, die das Kind von der Mutter erhalten hatte, um sie einem Armen zu geben, was es jedoch unterlassen hatte, um das Geld für sich zu behalten. Deshalb konnte es im Grab keine Ruhe finden und mußte alle Mittage nach den Hellern suchen. Die Eltern gaben nunmehr das Geld einem Bedürftigen - worauf das Kind nie wieder gesehen wurde.

Das Märchen ist das Evangelium der Armen. In ihm können selbst jene Verdammten, die eines Schlimmen Todes gestorben sind, noch auf Errettung hoffen. Durch bösen Zauber oder zur Strafe in einen Gegenstand gebannt, oft auch zu einer qualvollen Tätigkeit verurteilt, büßen sie irgendwo im Grenzbereich zwischen Diesseits und Jenseits, etwa in einem wilden Schloß in tiefem Wald, ihre Schuld, bis eines Tages der Held des Märchens zu ihnen findet, die Mächte, die sie in ihrer Gewalt haben, bezwingt und sie nicht nur erlöst, sondern auch ins Leben zurückführt lange vor Anbruch des Jüngsten Gerichts.

Tod und Leben waren nicht scharf geschieden. Sie bildeten zwei Möglichkeiten oder Aspekte des Daseins, die immerzu um die Grenz- 
scheide zwischen den Welten wie Wellen, die sie gleichsam brach, oszillierten, um unter bestimmten Umständen mal hier, mal da festere, »korpuskulare« Gestalt anzunehmen. Das verbindende Element dabei stellte die Seele dar. 


\section{Hellsehen}

\section{Von der Möglichkeit, die Wirklichkeit zu durchblicken}

Nachts, wenn der Schlaf, der Zwillingsbruder des Todes, Macht über den Tag gewinnt und ihn auslöscht, werden der Leib und die Lider schwer; die Bewegung erlischt, das Auge fällt zu, Dunkel dämpft die Wahrnehmung ab. Tag und Nacht sind nicht scharf geschieden. Die Seele verbindet sie, da sie an beiden teilhat. Während der Körper ruht, löst sie sich aus der gelockerten, »korpuskularen« Verankerung und bewegt sich wie wellenförmig fort, zunächst noch schwerfällig und bedrückt von der Last der Erinnerungen des am Tage Erlebten, dann leichter und freier, aufsteigend in die überirdische Lichtwelt der Transzendenz. Es ist, als erwache sie aufs neue in einer anderen Welt. Anfangs hat sie Mühe, sich zurechtzufinden. Alles erscheint ihr seltsam verformt. Gestalten treten schemenhaft auf und verlieren sich wieder, andere dagegen gewinnen rasch scharfe Konturen; manche geleiten die Seele, warnen sie vor Gefahren, erteilen ihr Ratschläge und weisen sie auf Künftiges hin, andere treten ihr drohend in den Weg, bedrängen sie und versuchen, ihr Gewalt anzutun. Oft hat sie das Empfinden, als werde ihr eine Botschaft übermittelt, die sie nur nicht versteht. Die Gesichte sind selten klar, weil sich der Träumende in der Übergangszone zu einer ihm unvertrauten Welt bewegt; sie bedürfen der Dekodierung.

Die jenseitige bildet den Ur- und Umgrund der diesseitigen Welt. In ihr liegt begründet und wird angestoßen, was sich im Diesseits vollzieht, generell kraft der Schöpfung, speziell vermöge der Führung der Menschen durch Ahnen, Geister und Götter. Der Zugang zur Transzendenz in Gedanken und Träumen, durch Deuten des Erfahrungsgeschehens, während der Besessenheit oder in der Ekstase - bot insofern die besondere Möglichkeit zu »höherem « Erkenntnis- und Wissensgewinn. Traditionelle Gesellschaften maßen daher der Traumexegese eine eminente Bedeutung bei. ${ }^{\text {I }}$ Zum einen konnte es um wichtige »Botschaften « der Jenseitigen gehen, die es unbedingt zu entschlüsseln galt, zum andern lieferte sie 
Hinweise auf die Ursachen etwa von Krankheiten, wiederholtem Mißerfolg oder einem sonstwie bedrohlichen Geschehen.

Konsequentermaßen wechselten die Gesichte mit der Entfernung der Seele von ihrem Wohnsitz. Im allgemeinen lassen sich sechs Arten von Wahrgenommenem unterscheiden:

I. Solange sich die Seele noch nicht vollends vom Körper gelöst hat, das heißt während des »flachen« Schlafs zu Beginn und kurz vor dem Wiedereintritt (dem Erwachen), beherrschen Geschehnisse der nahen Vergangenheit, die dem Menschen besonders zu schaffen machten, das Traumerleben.

2. Bewegt sich die Seele noch in der näheren Umgebung des Schlafenden, nimmt sie die Dinge »realistisch«, wie bei Tag, wahr, sieht aber gleichwohl »weiter«, entdeckt Verborgenes oder erkennt eine drohende Gefahr. Mitunter macht sie eine Stelle aus, an der ein Schatz vergraben liegt ${ }^{2}$, oder erblickt ein Raubtier, das sich der Ortschaft nähert, so daß tags darauf jedermann gewarnt ist und niemand die Siedlung verläßt. ${ }^{3}$ Der (noch) vertrauten Umwelt wegen läßt sich das gelegentlich sogar überprüfen. Einer verbreiteten Vorstellung zufolge verläßt die Seele den schlafenden Körper in der Gestalt eines kleinen Tieres - meist einer Maus, einer Eidechse oder eines Käfers - durch den Mund. Ist gerade jemand zugegen, kann er die Bewegungen des Tieres verfolgen, ja gewissermaßen Experimente mit ihm anstellen und später mit dem, was der Träumer nach dem Erwachen von seinem Erleben berichtet, vergleichen und gegebenenfalls bestätigen. Beispielsweise sieht er das Tier an einen Bach gelangen, über den es offensichtlich hinüberwill. Der Beobachter legt dann einen Stab darüber, den es als Brücke benutzt, um am anderen Ufer durch ein Loch in einen Hügel zu kriechen. Wieder aufgewacht, erzählt sein Begleiter, er habe geträumt, einen großen Strom auf einer hölzernen Brücke überquert, darauf in eine Berghöhle eingedrungen und dort einen Schatz gefunden zu haben. ${ }^{4}$

3. Passiert die Seele die Grenze zum Jenseits und gerät in die Nähe zum Totenreich, suchen Ahnen, und zwar besonders, wenn ihre Nachlebenden sich in einer kritischen Situation befinden, den Kontakt zu ihr und erteilen ihr praktische Ratschläge, die etwa die Verschiebung der Aussaat oder die Behandlung eines Kranken betreffen, und warnen sie vor Gefahren wie Überfällen, Unwettern und Hungersnöten. Gegebenenfalls beklagen sie sich auch, daß ihnen zu wenig Aufmerksamkeit zuteil wird. ${ }^{5}$ Manchmal inspirieren Verstorbene, der persönliche Schutzgeist, ja selbst eine Gottheit die Träumenden sogar auch zu neuen Tanzschritten, Liedern und ornamentalen Motiven in der Stikkerei und Schnitzkunst. ${ }^{6}$ Empfing ein Oberhaupt oder Priester auf diese Weise die Idee zu einer Innovation mit weiterreichenden sozia- 
len und politischen Konsequenzen, trat beispielsweise auf Foueda, einer Insel der Salomonen-Gruppe, der Ältestenrat zusammen und prüfte, ob die Eingebung als echt zu betrachten oder der Betreffende einer Täuschung erlegen $\mathrm{sei}^{7}$ - in dem Falle ging es eben um mehr. Generell nahm man ernst, was die Geistmächte im Traum geboten oder verhießen, und hütete sich, den Weisungen nicht Folge zu leisten. $^{8}$ Ein amerikanischer Offizier präsentierte sich eines Tages den Mohawk stolz in einer nagelneuen, scharlachroten Uniform. Kurz darauf bedeutete ihm ein Mann des Stammes, mit dem er gut stand, im Traum den Rock von ihm zum Geschenk erhalten zu haben. Der Offizier kannte sich in der Kultur der Irokesen aus und händigte seinem Freund die Uniform aus. Nicht auf den Kopf gefallen, offenbarte er ihm wenige Tage später, er habe ihm im Traum 500 Morgen guten Ackerlandes vermacht. Dem Mohawk blieb keine Wahl; er mußte sich in das Gebot der Jenseitigen schicken. Doch war ihm die Ironie der Glaubensverpflichtung bewußt; er bemerkte: »Mit dir werde ich niemals wieder träumen. «9

4. Tiefer im Jenseits tauchte die Seele in die Geisterwelt ein, wo es gewöhnlich wenig geheuer war. Die Wesen dort - übellaunige, garstige Geister, die Seelen von Hexen, die nächtlicherweile auf Beutefang gingen, und das Heer der eines Schlimmen Todes verstorbenen »Verlorenen Seelen« - standen den Menschen feindselig und haßerfüllt gegenüber; sie verfolgten und jagten sie förmlich, um ihnen irgendein Leids anzutun. Geriet eine Traumseele in ihre Gewalt, quälten sie entweder ihr Opfer, was universalem Glauben nach Alpträume auslöste, oder suchten sie in die Irre zu führen, was ebenso verbreiteter Vorstellung zufolge zu Psychosen, unter Umständen zum Tod führte. $^{\text {Io }}$

5. Je weiter die Seele in die Tiefen des Jenseits vordrang, desto näher kam sie dem Ursprung der Dinge. Sie gelangte in die »Traumzeit« der australischen Aborigines und konnte die Urzeitwesen und Geistmächte, die an der Schöpfung beteiligt gewesen waren, schauen - ähnlich modernen Astronomen, deren Blick mit Hilfe von Hochleistungsteleskopen bis fast an den Rand des Universums reicht und dort auf die Verhältnisse trifft, wie sie zu Beginn des Kosmos herrschten, weil die Strahlung (das »Licht«), die davon kündet, uns erst heute erreicht. Die Seelen der Alten bedurften der Technik nicht. Körperfrei, wie sie waren, sahen sie unmittelbar, was sich anschickte, auf Erden ins Geschehen zu treten, oder erfuhren von den dortigen Geistmächten, was sie zu tun beabsichtigten. Wer besonders »tief « schlief - ein Zeichen dafür, daß seine Seele weit entrückt war - hatte verbreiteter Überzeugung nach prophetische Träume; er konnte Kommendes voraussehen. ${ }^{\text {II }}$ Mal gewahrte er, was bevorstand, gleichsam ungeschminkt. Mit Früchten überladene Bananenstauden deuteten für die Dafla im Nordosten Indiens auf reichen Kindersegen ${ }^{\text {I2 }}$, klares Wasser 
für die Lakher im südlichen Assam auf gute Gesundheit ${ }^{13}$, ein Kampf, in dem viele Gegner fielen, für die Jibaro in Ekuador auf den sicheren Sieg in einem zu erwartenden Scharmützel hin. ${ }^{\text {I4 }}$ Oft aber teilte sich Träumenden Bevorstehendes in bestimmten Bildern mit, deren Bedeutung man kannte oder sich von Kundigen »übersetzen« ließ. Träumte man beispielsweise vom Verlust eines Zahnes, war man sich bei Naga-Völkern in Assam wie in Schottland (und auch sonst häufig) sicher, in naher Zukunft mit dem Tod eines Angehörigen rechnen zu müssen; Vorderzähne betrafen nahe, Backenzähne entferntere Verwandte. ${ }^{15}$ Wie das Knochengerüst generell, stand das Gebiß im engeren Sinne, aus Gründen, die mit den traditionellen (universal übereinstimmenden) Zeugungsvorstellungen zu tun haben, für die patrilineare Abstammungsverwandtschaft.

6. Aufgrund des Inversionsverhältnisses zwischen Diesseits und Jenseits nahmen Seelen, und solche vor allem, die sich »weit draußen« befanden, die Dinge, die auf Zukünftiges deuteten, häufig - nach Auffassung der Samojeden in Sibirien sogar immer - »verkehrt« wahr. ${ }^{{ }^{-6}}$ Iglulik-Eskimo erklärten Knud Rasmussen, man habe sich das so vorzustellen, daß die Seele den Körper »upside down« verlasse, so daß sie »mit dem Kopf nach unten (head downwards) hänge «. ${ }^{17} \mathrm{Um}$ die Bilder richtig zu verstehen, mußte man sie also »rückübersetzen«. In komplizierteren Fällen bedurfte das entsprechender Übung. Derartige, scheinbar »falsche« Botschaften waren nach Überzeugung der Muria Gond in Bastar (Zentralindien) nur die erfahrenen, »weisen« alten Männer imstande, korrekt $\mathrm{zu}$ »entziffern «. ${ }^{18}$ Meistens handelte es sich jedoch um gängige Bilder, die jedermann verstand. Belustigende Träume bedeuteten etwa, daß einem Trauriges bevorstand. ${ }^{\text {I9 }}$ Träumte jemand bei den schon genannten Lakher davon, daß er den Bau eines neuen Hauses in Angriff nahm, hatte er mit seinem alsbaldigen Ableben $\mathrm{zu}$ rechnen. ${ }^{20}$ Trug ein Ao Naga im Traum einen schweren Leichnam auf den Schultern, durfte er hoffen, eine reiche Ernte einzufahren. $^{2 \mathrm{I}}$

Traditioneller Anschauung nach handelten Träume, ob in »theorematischer « Klarheit ${ }^{22}$ geschaut, durch Geister verfälscht oder metaphorisch verschlüsselt, immer von Wahrem - vor allem, wenn sie Zukünftiges betrafen. ${ }^{23}$ Man begriff sie, wie die Batek Dè, als »Teil der normalen Wirklichkeit«. ${ }^{24}$ Ja nach Überzeugung der Jibaro (Ekuador) offenbart sich die wahre Wirklichkeit (true reality) den Menschen allein in Träumen. Die gewohnte, bewußte Wahrnehmung bei Tage, glaubten sie, sei pure Blendung (delusion), voller Täuschung, falschen Informationen und Lügen; sie verdiene daher nur wenig Vertrauen. »Only the dream unveils us the real essence of things [...] In the dream all men whom we meet, even our foes, invariably tell us the truth [...] for here it is the souls that meet, freed from the bonds of the corporeal existence. $\ll^{25}$ Wer die Wahrheit über gegenwärtiges wie zu- 
künftiges Geschehen zu wissen begehre, solle sich daher schlafen legen und träumen. ${ }^{26}$

Seelenreisen waren nicht unproblematisch. Vor allem unkundige, noch weniger erfahrene Seelen Jüngerer konnten in die Irre gehen und den Rückweg verfehlen oder abgefangen werden. Daß dies seltener geschah, als man angesichts der zahlreichen übelsinnigen Geister eigentlich annehmen sollte, lag daran, daß die Seele einer weit verbreiteten Anschauung nach während des Träumens mit dem Körper verbunden blieb. Es herrschte die Vorstellung, daß sich der »Ausstieg « nach Art einer strahlenförmigen Emanation vollzog, das heißt Leib und Seele ein unsichtbarer, manchmal - allerdings nur hellsichtigen Menschen erkennbarer - leuchtender, farbiger Faden oder auch ein ganzes Strahlenbündel verband, das sich gummizugartig mehr und mehr dehnte, um bei der Umkehr gleichsam »zurückzuschnellen « ${ }^{27}$ Tungusen in Sibirien veranschaulichten dem russischen Ethnologen Waldemar Bogoras den Vorgang mit dem Bild vielzähliger »Seelenarme«, die eine beliebige Länge annehmen und nach Wunsch jeden Punkt im Universum erreichen können. ${ }^{28}$ Analog stellte man sich auch den (bewußten) »Gedankenflug « vor. ${ }^{29}$

Denn auch im Wachzustand bleibt die Freiseele imstande, über ihre »Fühler« Kontakt zur Transzendenz aufzunehmen, und offen für Wahrnehmungen der »anderen Art«. Spielt der bewußte Wille dabei eine führende Rolle, steht ihr die Gebundenheit an die erinnerte oder gelebte Wirklichkeit gleichsam im Weg; sie muß sie, um weiterzukommen, regelrecht »hintergehen«, ja überwinden. Leichter gelang das wieder in Übergangszuständen zwischen konzentriertem Erleben und Schlaf, wenn an die Stelle der Zwillingsbrüder und Söhne der Nacht gewissermaßen ihr Halbbruder trat, der die zwielichtige Dämmerung beherrscht, die Tagträumerei weckt und der Phantasie Flügel verleiht.

Menschen, die sich die Zeit nehmen, untätig in einem bequemen Sessel zu sitzen, auf dem Sofa oder bemoostem Waldboden zu liegen und auszuruhen, »entspannen« sich fühlbar. Ihre leiblichen Empfindungen klingen ab; sie »dämmern « vor sich hin, versinken in einen wohligen Zustand schläfrigen »Dösens«. Ihre Gedanken »gleiten hinweg« - und mit einem Mal »fällt« ihnen etwas »ein«, auf das sie sonst nicht so ohne weiteres gekommen wären, sie haben eine »Eingebung«, eine Idee (von griechisch idea, ursprünglich »Gesicht«, »Erscheinung«), eine Intuition oder Inspiration, ja unter Umständen eine Vision. Sie erkennen und sehen etwas, das ihnen zuvor verborgen blieb, wie umstellt war vom Zubehör ihrer geschichtlichen und kulturellen Erfahrungswelt. Säuglinge sind davon erst kaum angerührt. Wie schon erwähnt wurde, wechselt ihre Seele zunächst noch immer wieder zwischen Diesseits und Jenseits; sie befinden sich in einem elementaren Übergangszustand. Daher schlafen sie viel und dämmern und plappern wie abwesend vor sich hin: Ihre visionären Gesichte überwiegen bei weitem die Wahrnehmung ihrer unmittelbaren Umgebung. Man ist überzeugt, daß sie hellsichtig sind ${ }^{30}$ - wie Ster- 
bende, die langsam hinwegdämmern und, »entschlafend«, ihre Ahnen kommen sehen, um sie abzuholen.

Doch muß Hellsichtigkeit nicht an derartige akute Zustandswechselprozesse gebunden sein. Bestimmte, besonders empfindsame Menschen, sogenannte »Sensitive« im Parapsychologenjargon, deren gleichsam »dünnhäutige« Physis durchlässiger für spirituelle Wahrnehmungen ist, spüren die Vibrationen, die eine nahende Gefahr, eine sich aufbauende Übergangsfront, auslöst, vorweg. Die amerikanische Ethnologin Ruth Landes, die in den dreißiger Jahren des vergangenen Jahrhunderts unter den Ojibwa im westlichen Ontario arbeitete, berichtet von einer jungen Frau, die eines Tages plötzlich die Vision eines Überfalls der benachbarten Sioux hatte. Sie informierte sogleich ihren Vater, der umgehend Verteidigungsmaßnahmen in die Wege zu leiten versuchte, bei den Männern der Siedlung jedoch nur auf taube Ohren stieß - niemand traute dem Gesicht, da keiner der renommierten Seher eine entsprechende Botschaft empfangen hatte. Gleichwohl erwies sich die Prophezeiung als wahr. ${ }^{3 \mathrm{I}}$ Auf Mangaia in Polynesien überkam eine Frau ganz plötzlich die Vision eines Schiffsunglücks, bei dem ihr Mann, der zu der Zeit gerade zur See fuhr, den Tod fand. Nicht lange danach erhielt sie die Bestätigung dafür. ${ }^{22}$

Auch Europäer machen - häufiger, als das gemeinhin bekannt ist derartige Erfahrungen. Nur trauen sie sich nicht, davon zu berichten, wenn sie befürchten müssen, belächelt oder des Aberglaubens bezichtigt zu werden. Eine Ausnahme bilden lediglich Marienerscheinungen, weil sie sich noch, wenn auch nur am Rand, im Bereich des gebilligten Glaubens bewegen. Ältere Volksüberlieferungen jedoch, und zumal aus entlegeneren Gebieten, die das Licht der »Aufklärung « nur erst spärlich aufgehellt hat, sind voll von Berichten über visionäre Gesichte und Geistererscheinungen. Unweit von Brig am Fuß der Figinenalpe im Kanton Wallis wurde früher Bergbau betrieben. Eines Tages erblickte ein Knappe hoch oben über der Stollenöffnung ein »Bergmännlein«, das ihm durch Zeichen $\mathrm{zu}$ verstehen gab, er solle seinen Meister informieren, daß der Schacht auf der Stelle geräumt werden müsse. Der Meister nahm die Aufforderung ernst. Und kaum hatten die Bergleute die Grube verlassen, da stürzte der Schacht auch schon unter Beben und donnerndem Getöse ein - das »Bergmännlein « hatte ihnen das Leben gerettet! ${ }^{33}$

Gewissermaßen im Vorfeld möglicher Gefahren bewegen sich Menschen, die weit draußen in der Wildnis unterwegs sind, wo die vollkommen erschaffene, wohlgeordnete Welt des heimischen Territoriums mehr und mehr übergeht in die noch weniger geschiedenen Verhältnisse, wie sie zu Beginn der Schöpfung herrschten und sich in diesen abgelegenen, peripheren Bereichen erhalten haben. Hier ist Jenseitiges dem Diesseits gleichsam noch enger »eingefaltet«, so daß beides einander vielfältig grenzübergreifend durchdringt. Wen es, aus welchen Gründen auch immer, in derartige Regionen verschlägt, dem kann geschehen, daß ihm Geister erscheinen - bucklige Zwerge, die ihn aus dem Wurzelgestrüpp 
eines Baumriesen tückischen Auges belauern, garstige kannibalische Unholde mit Zwiebelkopf, das Gebiß schon gierig gebleckt, oder verführerisch schöne Nixen, die ihn mit Sirenengesang in die Tiefe eines schattigen Waldsees zu ziehen versuchen. Derartige Begegnungen sind nach Auffassung der Runa im Osten Ekuadors ein untrügliches Anzeichen dafür, daß man »die Grenze zur mythischen Traumzeit überschritten hat $\ll .34$

Doch muß einem dort nicht nur Bedrohliches widerfahren. Gelegentlich beglücken auch Götter die Menschen mit ihrer Erscheinung. Diese Gnade wurde zum Beispiel manchen Apinayé im Norden des ostbrasilianischen Bundesstaates Goiás zuteil, wenn sie sich allein und weitab ihrer Siedlung auf der Jagd befanden..$^{35}$ Der deutsch-brasilianische Ethnologe Curt Nimuendajú gibt den Fall eines Mannes wieder, dem sich kein Geringerer als der Schöpfer selbst (der Sonnengott) offenbarte. Er erzählte ihm: »Mit einem Mal sah ich ihn unter den herabhängenden Zweigen eines großen Baums in der Steppe stehen. Seine Keule war neben ihm in den Boden gerammt, seine Hand umspannte den Griff. Er war hochgewachsen und von heller Hautfarbe; sein Haar wallte hinter ihm bis fast auf den Boden herab. Er war am ganzen Körper bemalt, die Außenseiten seiner Beine überzogen breite rote Streifen. Ich wußte sofort, daß er es war. Mein Mut verließ mich, das Haar stand mir zu Berge, und meine Knie begannen zu zittern. Ich legte das Gewehr ab, da ich meinte, ihn ansprechen zu müssen, doch ich konnte keinen Laut herausbringen, weil er mich unverwandt ansah. Ich senkte dann meinen Kopf, um meine Fassung zurückzugewinnen. Als ich etwas ruhiger geworden war, blickte ich wieder auf - er stand nach wie vor da und sah mich an. Nunmehr nahm ich all meinen Mut zusammen und trat einige Schritte auf ihn zu, kam aber nicht weiter, da meine Knie mir den Dienst versagten. Abermals blieb ich lange Zeit stehen, den Kopf gesenkt und bemüht, mich zu beruhigen. Als ich dann die Augen wieder erhob, hatte er sich bereits abgewandt und schritt langsam durch die Steppe davon. $\times^{36}$ Begegnungen mit Geistmächten lösen, wie unschwer begreiflich, starke Gemütsbewegungen aus, eine tiefe »Erschütterung«, die den Verbund von Leib und Seele lockert, so daß der betroffene Mensch partiell oder auch gänzlich die Kontrolle über seinen Körper verliert: Die Sprache versagt ihm, die Beine knicken unter ihm ab, oder er steht da wie gelähmt. Treten ihm bösartige Geister gegenüber, kann der Schock so groß sein, daß er die Sprache für immer verliert, bleibende Lähmungen davonträgt oder ihn gar der Schlag rührt. Im Fall des Apinayé löste die Erscheinung zwar eine entsprechende Erschütterung aus, doch war es weder tödlicher Schreck noch Entsetzen, was ihm in die Glieder fuhr und ihn »außer sich « brachte, sondern das beglückende, »überwältigende Bewußtsein, seinem Gott und Schöpfer gegenüberzustehen «. 37

Da man wußte, unter welchen Voraussetzungen man am ehesten mit Visionen rechnen durfte, konnte man sie, wenn man einen Rat oder Hilfe 
brauchte, auch willentlich herbeizuführen suchen. Man begab sich weit fort in die Wildnis - tief in den Wald, in die Wüste oder auf einen hohen Berg - und bemühte sich dort in der selbstgewählten Seklusion der Einsamkeit, seine Physis durch Fasten, ständiges Wachen und andere Kasteiungen, durch Gebete und Meditationsübungen gleichsam »abzutöten«, um seine Seele ganz für »außersinnliche« Wahrnehmungen freizumachen. Diesen Weg gingen in vielen traditionellen Kulturen, namentlich aber bei Indianern Nordamerikas, beispielsweise Jugendliche, um ihres persönlichen Schutzgeistes ansichtig zu werden. Am Ende völlig erschöpft, nervlich überreizt und hoch sensibilisiert, glitten sie in einen tranceähnlichen Dämmerzustand über, in dem ihnen schließlich die ersehnte Vision zuteil wurde - der Geist offenbarte sich ihnen. Gewöhnlich erschien er in der Gestalt eines mythischen Wesens (etwa des »Donnervogels«) oder bestimmten Tieres und unterwies sie in geheimen Rezepturen heilkräftiger Medizinen, in magischen Formeln und Techniken, Gebeten, Liedern und mancherlei praktischen Kenntnissen, die etwa die Jagd, handwerkliche und künstlerische Fertigungsweisen betrafen. Der Schutzgeist stand seinem Schützling zeit seines Lebens bei, erschien ihm aber nur in besonders bedrohlichen Situationen, um ihn zu warnen und zu beraten, sowie ein letztes Mal, wenn sein Ende bevorstand, um ihm dies anzuzeigen und ihn darauf vorzubereiten. ${ }^{38}$

Das erinnert an die Propheten der altorientalischen Königskulturen. Auch von ihnen ist überliefert, daß sie sich in die dämmrige Abgeschiedenheit der Tempel, in die Wüste, in eine Höhle oder auf einen Berg zurückzogen, der »Welt draußen « den Rücken kehrten und durch Fasten, Beten und Kontemplation »Einkehr « hielten, das heißt sich in ihre Seele, die Transzendenz in ihnen, »versenkten «, um die stoffliche Umhüllung gleichsam zu »durchtunneln « und sich dem Jenseits zu öffnen. War die Gottheit bereit, sich ihnen zu offenbaren, hörten sie entweder nur ihre Stimme oder sie erschien ihnen auch, etwa in Gestalt eines brennenden Dornbuschs oder einer Staubsäule, die bis zum Himmel reichte. In anderen Fällen sandte sie einen Boten, einen »Engel des Herrn«. Da es den Propheten nicht um eigene Anliegen, sondern die Sorgen vieler, um allgemeine Mißstände ging, galten die Offenbarungen ihrem Volk insgesamt, nicht ihnen persönlich.

Ihre Zahl stieg in den altvorderasiatischen Hochkulturen zeitweilig sprunghaft an - mit der zunehmenden Komplexität der städtischen Gesellschaften wuchsen die sozialen Probleme. Die Bibel unterscheidet zwischen Sehern und Propheten. ${ }^{39}$ Allein die letzteren galten als die eigentlichen, das heißt von Jahwe selbst berufenen Übermittler des göttlichen Wortes. ${ }^{40}$ Sie waren überall in eigenen, »berufsständischen « Vereinigungen organisiert und unterhielten sogar entsprechende Ausbildungseinrichtungen, die von besonders renommierten Prophetenmeistern geleitet wurden.$^{4 \mathrm{I}}$ In Israel gewannen sie ihre besondere historische Bedeutung mit dem Beginn des politischen Niedergangs um die Mitte des 
I. Jahrtausends v. Chr. und vollends nach der Zerstörung Jerusalems und der Vertreibung ins babylonische Exil. Die Knechtung des »auserwählten Volkes« verlangte ebenso nach einer plausiblen Erklärung wie, falls man tat, was Gott durch die Propheten gebot, nach der Aussicht auf die letztendliche Erlösung. ${ }^{42}$

Im Westen waren besonders die Etrusker für ihre Wahrsagekunst berühmt. ${ }^{43}$ Die Tradition setzte sich noch unter den Römern fort. ${ }^{44}$ Cicero indes mißbilligte sie; er kritisierte ihren Mangel an Präzision und das »Dunkle« (obscurum) ihrer Bedeutung. ${ }^{45}$ Doch dafür gab es gediegene Gründe. Botschaften aus dem Jenseits wurden beim Durchgang durch die stofflichen Fluchten des Diesseits und zuletzt die kulturspezifische Weltanschauung der empfangenden Medien »gebrochen«; sie mußten schwer verständlich, dunkel, ja absurd erscheinen. Im alten Griechenland waren den Seherinnen - es handelte sich überwiegend um Frauen - daher Priester zur Seite gestellt, sogenannte »Propheten« (prophetai), denen die Aufgabe zukam, die verworrenen und wie bruchstückartig gestammelten Weissagungen in verständliches Griechisch zu »übersetzen«. Solcher Heiligtümer, an denen weibliche Medien und »Propheten« gemeinsam Dienst taten, gab es viele - unter anderem in Dodona (Epeiros), Abai (Phokis), Thegyra (bei Orchomenos), Theben, bei Akraiphia (Böotien) sowie weitere auch im westlichen Kleinasien, zum Beispiel in Didymoi bei Milet. ${ }^{46}$ Man suchte sie auf, wenn man in einer Sache nicht weiterwußte oder sich sonst in einer kritischen Lage befand, und dringend eines Rates, wenn nicht konkreter Hilfe bedurfte. Die Medien versetzten sich dann auf verschiedene Weise - etwa durch den Genuß von Wasser aus einer heiligen Quelle ${ }^{47}$ oder Opferblut ${ }^{48}$ - in Trance, empfingen und überbrachten, »in Zungen«, die Antwort der Gottheit.

Die berühmteste aller altgriechischen Weissagungsstätten befand sich in Delphi (Phokis) am Fuß des Parnaß. Das Allerheiligste des Tempels lag über einer Erdspalte, der offenbar toxische Dämpfe entströmten. Ursprünglich soll hier nur ein einziges Medium, »eine Jungfrau in der Blüte der Jahre « ${ }^{49}$, Dienst getan haben; später, als der Ruhm des »Orakels« wuchs und die Nachfrage stieg, waren es ihrer zwei bis drei, die einander ablösten. Als namhaftester »Prophet« wirkte um die Wende vom I. zum 2. Jahrhundert n. Chr. gut zwanzig Jahre lang kein Geringerer als der Platoniker Plutarch (ca. 46-I20 n. Chr.) in Delphi. Er lebte im etwa eine Tagereise entfernten Chaironeia, wo er ebenfalls als Priester, zeitweilig auch als Leiter des Baureferats und sogar Bürgermeister tätig war. Einmal im Monat begab er sich nach Delphi, um dort seines Prophetenamtes zu walten. Die »Pythia« (das Medium) unterzog sich dazu einer gründlichen Reinigung, legte ein langes Gewand an und krönte ihr Haupt mit einem goldenen Haarputz. Im Tempel trank sie aus einer Quelle, nahm Lorbeerblätter in den Mund, kaute sie und bestieg dann den großen, vergoldeten Dreifuß, der genau über der Erdspalte aufgestellt war. Der »Prophet« stand neben ihr und teilte ihr die Anfragen der Ratsuchenden mit. 
Vermutlich vor allem durch das Einatmen der Dünste geriet sie allmählich in Trance und offenbarte, was ihr der Gott - hier wie auch an den meisten anderen genannten Orakelstätten Apollo - an Auskünften und Prophezeiungen eingab. Der »Prophet «übertrug dann die unzusammenhängend hervorgestoßenen Worte in verständliche Sprache - gewöhnlich in Versform..$^{\circ}$ Plutarch, nicht nur altgläubiger Philosoph, sondern auch bedeutendster Religionstheoretiker der Antike, ließ es sich mit seinem priesterlichen Dienst nicht genügen; er suchte nach einer Erklärung für den Vorgang. Seine These, dargelegt in der Schrift Über den Verfall des Orakelwesens, lautet: Offenbar lieferten halbschlafähnliche Dämmerzustände, in denen, wie namentlich während der Trance, das wache, auf die Wahrnehmung sinnlicher Eindrücke und Erfahrungen konzentrierte Bewußtsein außer Kraft gesetzt sei, besonders günstige Voraussetzungen zur prophetischen Schau..$^{5}$ Es entstünde da »in der Seele eine ungewohnte, seltsame Verfassung «, die sich nur ungenau beschreiben lasse. Denkbar sei, »daß infolge der Durchflutung mit Wärme bestimmte Öffnungen für das Eindringen von Vorstellungen des Zukünftigen sich auftun, wie der verdunstende Wein neben vielen anderen Regungen, die er hervorruft, abgelegene, verborgene Gedanken enthüllt«. Es sehe so aus, als gehe die Seele dabei »mit dem prophetischen Hauch « (to mantikon pneuma), der an den Orakelstätten aufsteige, »eine Verbindung und Verschmelzung von der Art ein wie das Auge mit dem ihm wesensverwandten Licht. Denn obschon das Auge die Kraft zu sehen hat, so ist es doch zu nichts nütze ohne das Licht, und die prophetische Kraft der Seele bedarf wie das Auge einer verwandten Kraft, die sie entzündet und schärft. « ${ }^{22}$ In Dämmerzuständen lockert sich der Verbund von Seele und Leib; er wird durchlässiger und läßt den Empfang jenseitiger »Lichtpulse« zu, die in der Seele zünden und als Wahrnehmungen oder Botschaften transzendenter Mächte Gestalt annehmen. Ihre Übermittlung in der rein diesseitigen Erfahrungen angepaßten Sprache bereitet kaum überwindliche Schwierigkeiten. Das Medium ist in seinem intermediären Übergangszustand dazu nicht in der Lage. Wo der Gott durch eine Priesterin sprach, klang das, wie nach dem Zeugnis Herodots (II 57) in Dodona, in den Ohren der Menschen nicht selten, als handle es sich um eine fremde Sprache, ja wie Vogelgezwitscher.

Derartige Fälle kommen der Besessenheit nahe, die zwar auch an bestimmte Heiligtümer und Zeiten gebunden, also institutionalisiert sein kann, ebenso häufig aber spontan auftritt. Sie stellte ein weiteres Mittel dar, durch den unmittelbaren Kontakt zu transzendenten Mächten Zugang zum jenseitigen Wissensgrund zu gewinnen. In traditionellen Dorfgesellschaften waren es gewöhnlich die Ahnen, die von irgend jemandem aus ihrer Nachkommenschaft Besitz ergriffen, nur in selteneren Fällen auch Götter - dann handelte es sich wieder im eigentlichen Sinne um Prophetie. Durch die plötzliche und gleichsam gewaltsame Einkörperung, die Verbindung also zweier an sich antithetischer Existenzen, deren 
Berührung sonst zur gegenseitigen Vernichtung führen konnte, hier aber durch die Seele, die unmittelbar betroffen und von gleicher Art wie die Geistmacht war, abgemildert wurde, kam es zu heftiger leiblicher »Erschütterung«. Der Körper verkrümmte sich, die Motorik geriet außer Kontrolle, die Gesichtszüge verzerrten sich, gewannen den Ausdruck, wie ihn so häufig Masken zeigen, die Geister darstellen. Doch wählte der Ahne diesen Weg wieder nur, wenn er meinte, eingreifen zu müssen, weil die Seinen sich in einer heillosen Situation befanden oder ihnen Gefahr drohte. Jemand war beispielsweise schwer erkrankt, ein Unwetter hatte die Felder verwüstet, oder es herrschte Unfriede in der Gesellschaft, weil einige einem Zauber zum Opfer gefallen oder Gebrauchsgüter, Schmuck und Talismane gestohlen worden waren. Der Ahne benannte dann die Ursachen des Desasters, riet, was zu tun, welche Opfer zu bringen seien, entlarvte die Schuldigen und sagte bevorstehendes Unheil - Viehseuchen, Wetterkatastrophen, einen Überfall usw. - voraus. Rührten die Ahnen sich nicht, obwohl man sie dringend brauchte, konnte man ihnen den Zutritt erleichtern, indem man Drogen nahm oder durch Tanz und Gesang seinerseits Trancezustände herbeiführte. ${ }^{53}$

Viele Völker warteten nicht erst, bis sie in Bedrängnis gerieten. Sie nutzten die großen Festlichkeiten, die Ahnen, die man dabei ja immer zugegen glaubte, zur Einkörperung zu bewegen. Und so kam es bei derartigen Gelegenheiten häufig denn auch verstärkt zu Besessenheitsfällen. Gleich mehrere fielen in Trance und konnten entsprechend befragt werden oder prophezeiten spontan, was ihnen die Geistmächte eingaben. ${ }^{54}$ Auch dann bedurfte es anderer, entsprechend erfahrener Leute, die nur schwer verständlich artikulierten Weissagungen zu deuten.

In manchen Teilen der Welt, die unter massivem Hochkultureinfluß standen, bildeten sich ausgesprochene Besessenheitskulte heraus, die sich mit der Zeit zu eigenen Religionsgemeinschaften entwickelten, wie namentlich im Sudan (z.B. der Z $\bar{a}$ ) und in Mittel- und Südamerika (z.B. der Candomblê). Die Medien - in der überwiegenden Mehrheit Frauen - sind gemeinschaftlich organisiert. Die Besessenheiten finden zu vorgegebener Zeit in kultischem Rahmen im Heiligtum und unter Leitung erfahrener Meisterinnen (bzw. »Priesterinnen«) statt und dienen auch weniger der Prophetie als der Selbsttherapie. Nicht Ahnen, sondern Geister und mehr noch Götter ergreifen Besitz von den Medien. Die Séancen haben mit Problemen der Frauen, ihrer Familien und Gesellschaft zu tun; die Begegnung mit der Geistmacht trägt $\mathrm{zu}$ ihrer Bewußtwerdung und Präzisierung bei; der Gott gibt Hinweise, wie sie sich bewältigen lassen könnten.

Es gibt Fälle, in denen die Geistmächte von den Menschen, deren Seelen sie in Besitz genommen haben, nicht mehr lassen. Die Folge ist lebenslängliches »Irresein«. Die Betroffenen erscheinen als eine Art lebendiger Idole. In vielen Kulturen schrieb man Geisteskranken daher prophetische Gaben zu, auch im abendländischen Mittelalter; in islamischen Ländern noch heute. ${ }^{55}$ Manche können, wie bei den Nyakyusa im 
südlichen Tansania zum Beispiel, Hexen erkennen. ${ }^{56}$ Man begegnet ihnen mit einer gewissen scheuen Achtung, fürchtet sie aber auch, da man niemals ganz sicher sein kann, ob nun ein guter oder ein böser Geist, ein Engel oder der Teufel aus ihnen spricht. ${ }^{57}$

Nach christlichem Verständnis ist alles Wesentliche bereits durch die Schrift offenbart und durch Engel und Propheten vorausgesagt worden..$^{8}$ Vollends nach dem Erscheinen Christi bestand keinerlei Anlaß mehr zu prophetischen Weissagungen. Gleichwohl gab es zu Anfang immer noch Menschen, über die in Augenblicken intensivsten religiösen Erlebens »der Heilige Geist kam« und deren Mund dann überfloß von der Fülle dessen, was sie empfunden und geschaut hatten. In der Regel geschah das allerdings in den gottesdienstlichen Versammlungen. Neben der üblichen lehrhaften entwickelte sich so während des ersten Jahrhunderts als zweite Form der Verkündigung die »charismatische« Predigt. Doch konnte sie, wie gesagt, eigentlich Neues nicht mehr enthalten. Sie trug eher zur zusätzlichen Ermutigung, Erbauung und Festigung der Heilszuversicht bei. Laut Epheser 3:5 bildeten die Charismatiker mit den Aposteln die Hauptstützen der Gemeinden. In den Geschichts- und Lehrbüchern des Neuen Testaments werden sie dennoch durchweg als »Propheten« (prophetai) bezeichnet. Und sichtlich waren sie nicht nur zum Empfang von Eingebungen und visionären Gesichten, sondern auch ekstatischen Entrückungserlebnissen imstande. ${ }^{59}$ Zur Stärkung ihrer seherischen Kraft pflegten auch sie ihre Physis wieder durch Enthaltsamkeitsübungen (insbesondere Fasten) $\mathrm{zu}$ »desensualisieren $\aleph^{60}$ Gabe wie Institution verloren sich dann allerdings gegen Ende des zweiten Jahrhunderts - zu ebender Zeit, als sich die Verhältnisse der Kirche allmählich zu stabilisieren begannen. ${ }^{6 \mathrm{I}}$

Hellsehen und Prophetie blühen auf, wenn Dunkel über die Menschen kommt und es eines »zweiten Gesichts« bedarf, um die Finsternis zu durchdringen. Lebenskrisen und Katastrophen machen die gewohnte Welt wanken; Risse entstehen im Mauerwerk, die ungewohnte Perspektiven eröffnen und die Augen auftun für eine veränderte Wahrnehmung unter neuartigen Blickwinkeln. Das Beben läßt vieles verfließend, flexibel, »durchsichtig « und in wechselnden Kombinationsmöglichkeiten erscheinen. Der Phantasie und Kreativität wachsen Flügel. Sichtlich bilden persönliche wie gesellschaftliche Erschütterungen die genuine Voraussetzung für Visionen und den Durchbruch zur Transzendenz.

Daher erwacht die Prophetengabe, aller Theologie zum Trotz, immer wieder aufs neue, sobald nur tiefgreifende »Kontingenzeinbrüche« zu schweren existentiellen Krisen führen. Unter Umständen gewinnen besonders charismatische - Propheten derart an Einfluß, daß neue, »häretische« Glaubensgemeinschaften, ja Religionen entstehen. Die Apostel oder »Gesandten« bedürfen dann allerdings gewichtiger »Zeichen« und Berufungserweise, um überzeugend legitimiert erscheinen zu können. Die Stifter und Propheten der verschiedenen apostolischen und neuapo- 
stolischen Kirchen - die ihren Aufstieg einschneidenden wirtschaftlichen und sozialen Umbrüchen in Europa verdankten - behaupteten so etwa, ihren Auftrag von Jesus Christus oder Gott selbst erhalten zu haben. ${ }^{62} \mathrm{Im}$ Falle Muhammads löste eine persönliche Lebenskrise die prophetische Gabe aus. Seinen Anspruch, vom Allerhöchsten »gesandt « zu sein, mußte er sowohl gegenüber Juden und Christen in Arabien als auch den mächtigen altgläubigen Patrizierklanen in Mekka verteidigen. Dazu konnte er sich nur in der Nachfolge Christi zum letzten, dem »Siegel« der Propheten und Beauftragten des arabischen Himmelsgotts Allah erklären.

Später traten Gottgesandte und Propheten vor allem während des neuzeitlichen Kolonialismus in den »Bruchzonen « der unmittelbaren Pressionen zwischen indigenen und europäischen Interessen auf. Sie wiesen sich teils zwar als Berufene Gottes, Allahs oder Christi, vor allem aber der Ahnen aus. In der Folge entstand abermals eine Vielzahl - häufig nur kurzlebiger - nativistischer, messianistischer und anderer Arten von »Heilserwartungsbewegungen«, praktisch überall in der Welt.

Die Berufung auf vor- und übergeordnete, jenseitige Autoritäten setzt, wie der Anspruch auf transmundane, »paranormale« Erkenntniszugänge, den kosmologischen Dualismus voraus. Beide Welten sind jedoch, wie schon gesagt, nicht streng voneinander geschieden, sondern aufs engste verbunden durch ein komplementäres Wechselverhältnis. Sie gehen, schon aufgrund der ungleichen Masseverteilung im Diesseits, mannigfaltige, mal mehr, mal weniger dichte Verschränkungen ein. Manchmal erscheint Transzendenz dem Stofflichen wie eingeschlagen oder als blasiger Einschluß in ihm enthalten; an Stellen, an denen annähernd »Vakuumbedingungen « herrschen, strömt sie nahezu ungehindert zu.

Menschen sind Erdgebundene. Sie können nicht ohne weiteres in die spirituelle Umwelt überwechseln und umstandslos mit den Jenseitsmächten kommunizieren. Diese dagegen sind dazu jederzeit imstande, da sie dem Diesseits essentiell wie raumzeitlich »vorausexistieren «, seinen Ursprungsgrund bilden und seine Geschicke bestimmen. Allerdings fließt die Information nur in ganz seltenen Fällen unmittelbar - manchmal im Traum, eher aber, wenn der Mensch sich durch Askese und Konzentration soweit seiner Physis entäußert hat, daß er allein noch bewußt mit der Seele, der beweglichen Achse, die beide Welten verbindet, wahrnimmt, oder in den »hellen « Momenten, wie sie Aufenthalte an Stellen hoher stofflicher Auflösung, Wendezeiten auf dem Höhepunkt, einschneidende Übergangszustände und schwere, »erschütternde« Krisen hervorrufen können. In allen anderen Fällen kommen die Geistmächte nicht umhin, sich materialer Medien zu bedienen, um sich den Menschen mitzuteilen. Und das hat eben immer zur Folge, daß die Informationen, infolge des »Welle-Teilchen-Dualismus« von Seele und Substanz, gebrochen, fragmentiert oder zumindest gebeugt die sinnliche Wahrnehmung erreichen.

Im Grunde bildet diese Art Botschaftsübermittlung den Regelfall. 
Abgesehen von Extremsituationen, bietet sich Ahnen und Göttern auch sonst vielerlei Anlaß, den Menschen etwa einen hilfreichen Hinweis, einen Rat oder einen mahnenden Wink zu geben, von einer Unbotmäßigkeit, zu der sie sich vielleicht gedankenlos anschicken, Abstand zu nehmen, oder sie vor einer drohenden Gefahr zu warnen. Dazu bedienen sie sich vielfältiger »Zeichen« oder Ereignisse, die allerdings häufig übersehen, manchmal auch nicht hinreichend ernstgenommen werden. Man erkennt sie an gewissen Veränderungen im Erscheinungsbild der Natur, die sich gleich einem fließenden Vorhang zwischen Diesseits und Jenseits verstehen ließe, der sich bewegt, verformt und ausbeult, wenn ihn Impulse von »drüben« treffen. Da sich an der Ausdrucksweise der Jenseitigen selbst seit Urzeiten nichts geändert hat, kennt man die Zeichen und weiß, was sie bedeuten. ${ }^{6} 3$ Wer genau achthat auf seine Umwelt, vermag gleichsam im »Buch der Natur « zu lesen; er versteht, wie Vincenzo Petrullo die Überzeugung der Yaruro in Venezuela wiedergibt, »perfekt die Welt, in der er lebt«. Die Yaruro »suchen des Nachts den Himmel nach Zeichen ihrer Götter ab. Jede Nacht lesen sie ein neues Kapitel in einem großen Buch voller Geschichten. Tagsüber haben ihnen die Winde, die Wolken und die Sonne viel zu erzählen, und sie schauen und lauschen mit äußerster Aufmerksamkeit. « ${ }^{64}$

Anders als in gewöhnlichen Büchern steht der »Text« nicht für alle Zeit fest; er bewegt und verändert sich, wie in der gesprochenen, lebendigen Sprache, immerzu. Mal erscheint die Schrift schwach-, dann mit einem Mal fettgedruckt; in bestimmten Fällen flammt sie feuergleich auf, wie die Unheilsverkündung an der Wand im Festsaal Belsazars. Und selbst, wenn sich nichts verändert, also kein Zeichen aufscheint, bedeutet das etwas: nichts Geringeres nämlich als die beruhigende Botschaft, daß die Menschen sich folgsam an die altüberlieferten Verhaltensvorgaben halten, in Eintracht mit Ahnen und Göttern leben und ihnen insofern keinerlei Unheil droht.

Doch ist das leidvollerweise nur äußerst selten der Fall. Irgend jemand verletzt immer mal eine Regel, so daß sich das Verhältnis zwischen den Menschen und ihren jenseitigen Aufsichtsmächten »spannt« und letztere sich zu einem mahnenden Hinweis veranlaßt sehen. Meist handelt es sich, entsprechend den überwiegend harmlosen Vergehen, um einen milden Fingerzeig. Ein Informant Thomas O. Beidelmans bei den Kaguru im Norden Tansanias verglich ihn mit einem »Brief« (letter), der lediglich auf ein mögliches Ungemach hinweise. Dem stünden Zeichen von »extrem ungewöhnlichem Vorkommen« gegenüber, die immer ein sehr ernstes und unmittelbar bevorstehendes Unheil ankündigten und insofern als »Telegramme « verstanden werden könnten. ${ }^{65}$

Beim Empfang derartiger »Expreßbotschaften« war höchste Aufmerksamkeit geboten. Handeln konnte es sich dabei nur um bewegliche Zeichen, wie eine auffallende Himmelserscheinung ${ }^{66}$, etwa ein Meteoriteneinschlag und ganz besonders Mond- und Sonnenfinsternisse, oder 
das ungewöhnliche Verhalten von Menschen und Tieren. Oft erweckten schon Personen, die ein zurückgezogenes, eigenbrötlerisches Leben führten, argwöhnische Wachsamkeit. Begegnete man einem derartigen Sonderling nachts in der Nähe seines Hauses, bedeutete dies im alten Rußland, daß man mit einem Unglück zu rechnen hatte. ${ }^{67}$ Generell wurde eigentlich alles, was einem unerwartet und zumal an Ungewöhnlichem widerfuhr, als umgehend deutungsbedürftige »Botschaft« begriffen, insbesondere, wenn man dabei in eine kritische Situation geriet; das konnte ebenso eine Verwundung wie eine Mißernte sein. ${ }^{68}$

Vor allem aber schienen Tiere als »Botengänger « geeignet. Sie standen zum einen den Menschen unter allen Lebewesen - auch der Schöpfung nach - am nächsten und besaßen offenbar unmittelbarer Zugang zum Jenseits: Sie vermochten sich auf dem Boden wie in der Luft, auf dem Land wie im Wasser und sowohl in wie auch auf der Erde zu bewegen, das heißt konnten den Himmel wie durch Höhlen und am Grund von Gewässern die Unterwelt erreichen. Atypisches Verhalten galt in ihrem Falle daher immer als »Zeichen«; je ungewöhnlicher, desto dringlicher mußte die Botschaft sein. Maulwürfe zeigen sich zum Beispiel so gut wie nie um die Mittagszeit außerhalb ihrer Höhle. Geschieht das, drohte nach Auffassung der Ila in Sambia wie der Lakher in Assam dem, der das sah, ein tödlicher Unfall oder er mußte befürchten, daß statt seiner ein Mitglied seiner Familie starb. ${ }^{69}$ Oft nahm man auch an, daß es sich nicht eigentlich um ein Tier, sondern einen Ahnen, eine Geistmacht oder eine Hexe beziehungsweise einen Zauberer im »Tiergewand « handelte. In den ersteren Fällen konnte das Gutes, in den letzteren nur Unheil bedeuten..$^{\circ}$

War man sich über die Bedeutung eines Zeichens nicht ganz im klaren, konnte man ein Orakel befragen. Dafür stand eine Vielzahl von Möglichkeiten bereit. Im ganzen liefen sie auf dreierlei Verfahrensweisen hinaus: Man stellte seine Frage, warf dann irgendwelche »Würfel « kleine Knochen, Steine, Stäbchen, Muscheln und anderes dergleichen aus und entnahm ihrer Lage nach dem Wurf, ob die Antwort »ja « oder »nein « lautete. Oder man deutete die Bewegung eines kleinen Tieres eines Insekts, einer Schnecke, einer Maus usw. - in einem abgesteckten Feld, die Risse und Sprünge in einem erhitzten Knochen oder die Rinnsale, die eine ausgegossene Flüssigkeit im Erdreich (Sand) hinterließ, entsprechend aus. Und schließlich konnte man sich auch, wie im Falle der griechischen »Orakel«, direkt an ein Medium wenden. In allen Fällen fragte man bei der jenseitigen Instanz, die das Zeichen gegeben oder zu einer Unternehmung aufgefordert hatte, nach, womit man zu rechnen haben würde. Bei einem geplanten Vorhaben mußte der Anfrage allerdings nicht unbedingt ein Zeichen vorausgegangen sein; man erkundigte sich einfach, um Aufschluß über den zu erwartenden Ausgang des Unternehmens zu erhalten - wie Caesar vor Beginn einer jeden Schlacht. Orakel setzten voraus, daß allezeit eine unmittelbare Kommunikation mit 
den Mächten im Jenseits möglich war, sofern man sich nur geeigneter Mittel bediente.

Neben den unheilvollen gab es, allerdings seltener, wie die nüchterne Lebenseinschätzung lehrte, auch glückverheißende Omina. Sie unterschieden sich von den ersteren nicht der Art der Erscheinung, sondern den Umständen nach, unter denen sie auftraten. In der Regel hatten sie mit dem Beginn einer wichtigen Unternehmung, eines Lebens- und Zeitabschnitts zu tun: Wurde ein Kind zum Beispiel mit einer »Glückshaube« (der festen Eihaut nach ausgebliebenem Blasensprung) geboren, bedeutete das gemeinhin, daß es zu Großem, in Sibirien etwa zu einem außergewöhnlichen Schamanen ${ }^{71}$, bestimmt war. Zum Zeichen dafür, daß die Geburt eines bedeutenden Propheten, Heilsbringers oder Königs bevorstand, erschien über seiner Geburtsstätte häufig ein ungewöhnlich hell leuchtender Stern - wie im Falle Abrahams, Johannes des Täufers, Jesu Christi, Mithradates VI. Eupator von Pontos (reg. I20-63 v. Chr.) und anderer, beispielsweise polynesischer Könige. ${ }^{72}$

Bei aller kulturspezifischen Variabilität - in bezug auf Auswahl, Zuordnung und Gewichtung - liegen der Zeichendeutung doch stets bestimmte, weltweit übereinstimmende Kriterien zugrunde, die zusammengenommen so etwas wie ihr elementares semantisches Koordinatensystem bilden. Im folgenden seinen die wichtigsten genannt.

I. Generell schenkt man vor allem Omina während einschneidender Initialphasen - bei Schwangerschaft, Geburt und Taufe ${ }^{73}$, an Neujahr, vor der Aussaat, während einer Amtsübernahme (Inthronisation), zu Beginn einer Unternehmung - besondere Aufmerksamkeit, da sie Hinweise auf die Folgeentwicklung enthalten. ${ }^{74}$ Thomas O. Beidelman gibt zwei typische Beispiele von den Kaguru. Täglich treffen sie im Dorf oder auf dem Weg zum Feld auf alle möglichen Leute, ohne dem irgendeine Bedeutung beizumessen. Doch treten sie eine Reise an, achten sie ganz genau auf Anzahl und Geschlecht der Personen, die ihnen begegnen, weil sie meinen, daraus Rückschlüsse auf den Ausgang der Unternehmung ziehen zu können. Spechten schenken sie gewöhnlich keine Beachtung, es sei denn, sie nehmen gerade eine wichtige Aufgabe in Angriff; denn dann ist es von besonderer Bedeutung, wenn der Vogel sich einem zeigt. ${ }^{75}$ Analoges gilt überall auf der Welt für Jäger, die sich auf dem Angang befinden. ${ }^{76}$

2. Je seltener und ungewöhnlicher eine Erscheinung, desto größer und gewichtiger die Bedeutung der Botschaft, die sie enthält.. ${ }^{77}$ Eine Sonnenfinsternis kündigt zum Beispiel den drohenden Untergang der Welt an. Man unternimmt daher alles Mögliche - schlägt beispielsweise Lärm, um das Ungeheuer, das sich anschickt, die Sonne zu verschlingen, abzuschrecken, tut Buße, sucht die erzürnten Götter durch Opfer zu versöhnen - um die Apokalypse noch einmal abzuwenden ${ }^{78}$ (bisher noch immer mit gutem Erfolg!). 
3. Art und Erscheinung eines Zeichens entsprechen dem, was es anzeigt: Benutzt man eine Schere und läßt sie offen liegen, steht Streit bevor. ${ }^{79}$ Zerbricht man etwas, wird jemand alsbald das Haus verlassen. ${ }^{80}$ Leckt der Topf mit dem Wasser, mit dem man das Neugeborene wäscht, droht ihm der Tod durch Ertrinken. ${ }^{8 \mathrm{I}}$ Erleidet jemand bei der Arbeit einen Unfall oder verletzt sich schwer, hat er mit dem Ableben eines nahen Angehörigen $\mathrm{zu}$ rechnen. ${ }^{82}$ Ebenso weiß bei den Gurunsi (Burkina Faso, Westsudan) ein König, dessen bester Freund, Hofbarde oder Lieblingsfrau stirbt, daß ihm sein eigener Tod bevorsteht. $^{83}$

4. Ungewöhnliche Naturerscheinungen, die von mehreren oder gar allen Mitgliedern einer Gruppe wahrgenommen werden - am Himmel Kometen, ein hell aufleuchtender Stern, eine Mond- und Sonnenfinsternis, auf Erden ein Wirbelwind, eine Luft- oder Wasserhose, eine Fata morgana oder ein Erdbeben - deuten auf Glücks- wie Unglücksfälle größeren Ausmaßes hin.

5. Als besonders prädisponiert zur Botschaftsübermittlung gelten Tiere, und namentlich solche, die nachtaktiv sind und, vielleicht sogar gleichzeitig noch, eine »Doppelnatur« besitzen, beispielsweise Schakale, Eulenvögel, Fledermäuse, Wasserschildkröten, Kröten, Maulwürfe, Amphibien, Schlangen und Spinnen. ${ }^{84}$

6. Wesentlich für die Bedeutung eines Zeichens ist immer auch die Raumstelle, an der es sich zeigt: ob am Himmel, im Osten oder Westen, auf einem Berg, im Wald, über der Siedlung, einem Heiligtum, dem eigenen Haus, ob rechts (günstig) oder links (ungünstig). ${ }^{85}$

7. Gleichfalls spielt eine Rolle, zu welcher Zeit sich ein Ereignis zuträgt, das Zeichenbedeutung besitzt, ob bei Tag (günstig) oder Nacht (ungünstig), am Morgen oder Abend, an Neujahr oder sonst während eines Phasenwechsels (Mitternacht, bei Aufnahme einer Arbeit oder Amtsübernahme, während der Hochzeitsfeier). ${ }^{86}$ Nach rumänischem Volksglauben kündigte zum Beispiel ein Erdbeben am Tage Gewinne, in der Nacht Verluste an. ${ }^{87}$

8. Für akut bedrohlich werden Erscheinungen gehalten, die zum einen höchst ungewöhnlicher Art sind - eine Henne kräht wie ein Hahn ${ }^{88}$, ein Eber deckt eine Ziege ${ }^{89}$ - und sich zum andern rasch und unmittelbar auf den Beobachter zu bewegen; sie deuten fast ausnahmslos auf den nahen Tod des Betroffenen oder eines seiner Angehörigen hin $^{90}$ - etwa, wenn sich in Irland Schwäne, und zudem noch in ungerader Zahl, einem Hause nähern ${ }^{9 \mathrm{I}}$ und Eulenvögel nachts nahebei oder, schlimmer noch, auf dem Dach sitzend $»$ rufen ${ }^{9}{ }^{92}$ Die Feuerland-Indianer mußten das Schlimmste befürchten, wenn ein Guanaco aufgerichtet mit klagenden Lauten direkt auf jemanden zuschritt oder ein Hund sich mit ausgestreckten Pfoten kriechend auf einen Mann zu bewegte, der in geselliger Runde vor seiner Hütte saß. ${ }^{93}$ Bei den Kaguru hielt man es für ein Zeichen akuter Bedrohung, wenn 
ein seiner Art nach scheues Wildtier die Siedlung betrat, ja vielleicht in ein bestimmtes Haus eindrang. ${ }^{94}$

9. Für extrem dringlich wird eine Botschaft gehalten, wenn sich ein markant ungewöhnliches Zeichen mehrfach wiederholt (ein bestimmtes Tier sich immer wieder zeigt) oder mehrere, die auf dasselbe hindeuten, gehäuft auftreten. Für den ersteren Fall gibt George Silberbauer ein Beispiel von den G/wi Buschmännern in Südafrika. Eine Gruppe von Männern befand sich, weit entfernt vom Lager, auf der Jagd. Gleich am ersten Abend, während sie zusammensaßen, griff sie ein Löwe an und verletzte einen der Jäger am Bein. Es gelang ihnen zwar, das Tier zu vertreiben, doch kehrte es kurz darauf zurück und attackierte sein Opfer erneut. Daraufhin verlegten die Männer den Rastplatz um einige Kilometer und entfachten dort ein hell loderndes Feuer. Doch auch dort griff sie der Löwe an, und ebenso in der folgenden Nacht, obwohl sie erfolglos gewesen waren und keinerlei Fleisch mit sich führten. Schien das schon auffallend genug, so verstärkte sich der Eindruck des Ungewöhnlichen noch dadurch, daß sie das Tier überhaupt angriff, sich zuvor nicht durch Knurren und Brüllen bemerkbar machte und auch durch das Feuer nicht abgeschreckt wurde, was alles dem normalen Löwenverhalten widersprach. Nach der vierten Attacke zweifelten sie nicht mehr, daß er "gesandt« sein mußte - in diesem Fall offenbar von G//amama, der Trickster-Gottheit - und ihnen bedeutet werden sollte, ihr Jagdunternehmen abzubrechen, was sie dann auch taten. ${ }^{95}$

Ausschlaggebend für die Deutung waren also vor allem die Situation derer, denen ein Zeichen zuteil wurde, der Ort, an dem es in Erscheinung trat, die Zeit, zu der das geschah, das Maß der Abweichung vom Gewohnten, die Dynamik und Richtung, mit der sich das Zeichen durch das Wahrnehmungsfeld bewegte, sowie nicht zuletzt der Adressat, dem es galt, etwa ein schwer Erkrankter oder ein Oberhaupt während der Amtsübernahme. Traten mehrere dieser Kriterien gleichzeitig (in Kombination) auf, besaß die Botschaft eine entsprechend erhöhte Dringlichkeit und Bedeutung.

Doch eigentlich konnten es sich die Menschen zu keiner Zeit leisten, sorglos ihrer Arbeit nachzugehen und darauf zu vertrauen, daß ihnen Ahnen und Götter im Bedarfsfall schon einen Wink geben würden, auf der Hut zu sein und dieses zu tun, jenes aber unter allen Umständen zu lassen. Auch Träume boten keine untrügliche Gewähr, da ihre Deutung oft ungewiß blieb. Vor allem in Sammlerinnen- und Jägerkulturen, in denen der unsteten Lebensweise wegen der Ahnenglaube entweder gar keine oder nur eine rudimentäre Rolle spielte und man außer dem weit entrückten Schöpfer kaum Götter im eigentlichen Sinne kannte, stellte sich das Problem, in kritischen Situationen - bei schweren Erkrankungen, fehlendem Jagdglück, drohenden Überfällen oder einer Naturkatastrophe 
- Aufschluß über die Gründe der bedrohlichen Umstände sowie, mehr noch, Hinweise zu ihrer Überwindung zu erhalten, in besonderer Weise. Eigentlich blieb nur die Möglichkeit, sich gewissermaßen bewußt auf den »Traumpfad« zu begeben und unmittelbar mit den verantwortlichen Mächten im Jenseits in Kontakt zu treten.

Allerdings konnte dazu kaum jeder imstande sein. Die speziellen Gefahren, die aus Gründen des Inversionsverhältnisses zwischen der diesseitigen und der jenseitigen Welt bei direkten Kontakten zwischen Menschen und Geistmächten, und vor allem für die ersteren, bestanden, machten besondere Gaben, viel Übung und Erfahrung erforderlich. Da man derart kundiger und versierter »Grenzgänger« allein um des schieren Überlebens willen allezeit dringend bedurfte, hatte sich offensichtlich schon früh, das heißt mit großer Wahrscheinlichkeit bereits in den Sammlerinnen- und Jägerkulturen des Jungpaläolithikums (ca. 36.0oo8.000 v. Chr.), ein entsprechendes Spezialistentum ausgebildet. Um zu leisten, was ihre Aufgabe war, mußten sie geradezu über die »Technik« gebieten, sich im Bedarfsfall, also jederzeit, in den künstlichen Traumzustand der Ekstase zu versetzen, das heißt »ganz Seele« zu werden, um ins Jenseits übergehen und sich dort bewegen zu können, sowie, was noch wichtiger war, dabei den Vorgang immer bewußt unter Kontrolle zu halten und imstande zu sein, ihn sofort, wenn der Zeitpunkt dafür gekommen schien, wieder abzubrechen.

Diese Spezialisten waren zur Hauptsache die bekannten Schamanen, wie sie in besonders ausgeprägter Form in Sibirien, teils auch in Nordamerika vorkamen und noch heute in Himalayaländern und bei Indianern Südamerikas tätig sind. Um ihren Aufgaben gerecht werden zu können, hatten sie eine wahre Metamorphose zu durchlaufen, die sich in mehreren Stufen vollzog.

In Nordasien setzte der Prozeß - zumindest bei »großen« Schamanen - bereits vor ihrer Geburt ein. »Tierherrinnen«, jene Geistmächte also, die über den Bestand des Jagdwilds wachten, schenkten ihnen zunächst ihr »geistiges« Leben. Besaßen sie Vogelgestalt, brüteten sie die Seelen der künftigen Schamanen in einem Nest hoch oben auf dem Weltbaum (in der Oberwelt) aus; andere, die man sich cervidengestaltig, das heißt als Elch-, Hirsch- oder Renkühe und mit Sitz am Fuß des Weltbaums (in der Unterwelt) dachte, verschlangen die ausersehene Seele, gebaren sie wieder, säugten und zogen sie auf, bis ihre Zeit zur Verkörperung auf Erden gekommen war. Diese Schamanen besaßen so also schon pränatal eine Doppelnatur: im Leben zwar Menschen wie andere auch, waren sie doch gleichzeitig Kinder einer Geistmacht - die im übrigen auch späterhin ihre Geschicke mütterlich sorgend begleitete.

Erreichten sie nach ihrer irdischen Geburt die Pubertät, zeigte sich rasch, daß sie anders als gewöhnliche Sterbliche waren. Sie versanken in anhaltende Grübeleien, schienen wie abwesend, schliefen lange, sprachen im Traum und fühlten sich matt und zerschlagen. Dann plötzlich überfie- 
len sie Fieberanfälle. Wild mit den Augen rollend, stießen sie unartikulierte, quasi tierische Schreie aus und tanzten, bis sie erschöpft zusammenbrachen. Manche suchten die Einsamkeit in der Wildnis, irrten dort ziellos umher, kletterten Bäume hinauf oder verkrochen sich in Höhlen und litten teils qualvoll, bis man sie aufspürte und zurück ins Lager brachte.

Die Erschütterung kam nicht von ungefähr. Den Kandidaten waren Geister erschienen und hatten sie von ihrer Berufung unterrichtet. Dagegen versuchten sie sich zunächst nach Kräften zu wehren, da sie wußten, was ihnen bevorstehen würde. Letzten Endes jedoch blieb ihnen keine Wahl. Verweigerten sie den Ruf, wurden sie mit lebenslangem Wahnsinn geschlagen. Nicht wenige legten daher Hand an sich selbst. Schickten sie sich indes in ihr Los, genasen sie auf der Stelle.

Doch handelte es sich nur um eine begrenzte Erholungsfrist. Über kurz oder lang nach diesem »Berufungserlebnis « erkrankten die Kandidaten aufs neue. Nunmehr sanken sie in tiefe Bewußtlosigkeit, atmeten kaum mehr und schienen wie tot. An ihrem Leib wurden dunkelviolette, blutunterlaufene Druckstellen sichtbar, zeigten sich Blutergüsse, oft auch Ausschlag. An den Gelenken trat Blut aus, ihr Mund sonderte Schaum ab. Die Kräfte verließen sie; es schien, als zehre sie etwas aus. Man kannte die Zeichen. Sie bildeten äußerlich ab, was die Betroffenen während dieser Phase, mit der ihre eigentliche Initiation einsetzte, seelisch durchlebten.

Dieser entscheidende Teil ihres Werdegangs währte in der Regel drei Tage. Die Novizen erlebten in einer Art Traumvision, wie die Geister gewöhnlich dieselben, die sie zuvor berufen hatten - ihren »Leichnam« Stück für Stück auseinandernahmen. Als erstes trennten sie den Kopf ab und deponierten ihn auf einem hoch an der Wand angebrachten Brett, damit er die Möglichkeit hatte, das weitere Geschehen $\mathrm{zu}$ verfolgen. Daraufhin zogen sie mittels eiserner Haken die Gelenke auseinander und lösten das Fleisch von den Knochen, das sie, in kleine, mit dem Blut der Initianden durchtränkte Bissen zerlegt, untereinander verteilten und gemeinsam verzehrten. Danach setzten sie zur »Wiederbelebung« der »Getöteten« an: Die Knochen wurden wieder zusammengelegt, die Gelenke mit Eisenfäden verbunden, das Skelett mit neuem Fleisch umkleidet und zuletzt der Kopf auf den Rumpf gesetzt - die Initianden lebten, gewandelt, erneut wieder auf, wenn auch zunächst im Jenseits. Dort unterwiesen sie die Geister, die dadurch, daß sie von ihrem Fleisch und Blut gegessen hatten, zu ihren »leiblichen « Verwandten geworden waren, zum Abschluß in allem, was sie über die jenseitige Welt wissen mußten, um als Schamanen erfolgreich ihren Aufgaben nachgehen zu können. Vor allem erfuhren sie, welche Geistmächte die verschiedenen Krankheiten auslösten, welche die Verantwortung für die einzelnen Wildtiergattungen trugen, wo genau sie zu finden waren und wie sie mit ihnen umzugehen hatten.

Nach Abschluß der Initiation genas auch der irdische Leib der Kandi- 
daten; die Seele kehrte zurück und verband sich aufs neue mit ihm. Der Werdegang des Schamanen hatte sich mit dem endgültigen Gewinn seiner Doppelnatur vollendet. Fortan war er imstand, gleichsam auf Abruf Reisen ins Jenseits zu unternehmen, um seinen besonderen, grenzgängerischen Aufgaben nachkommen zu können, wobei ihm seine »Hilfs«- und »Schutzgeister«, die ihn berufen und initiiert hatten, als »Blutsverwandte« dazu verpflichtet, getreulich zur Seite standen.

Schamanen hatten vor allem die Aufgabe, schwere Erkrankungen und namentlich Psychosen zu heilen, die man dadurch verursacht glaubte, daß die Freiseele des Patienten sich, wie zumeist im Traum, vom Körper entfernt hatte und nicht mehr zurückfand, weil sie von bösartigen Geistern in die Irre gelockt worden war oder sich auch unmittelbar in ihrer Gewalt befand und von ihnen gequält, beziehungsweise »besessen« wurde. Der Schamane versetzte sich dann - mittels Konzentration, Gesang und Tanz, oft auch durch den Genuß halluzinogener Drogen - in Trance, begab sich ins Jenseits, spürte die verlorene Seele auf und geleitete sie wieder zurück, beziehungsweise suchte sie ihren Peinigern durch geduldiges Verhandeln, Opferversprechen, Gewalt oder List zu entwinden. Weitere Aufgaben bestanden darin, Frauen, die scheinbar nicht empfangen konnten, zu Kinderseelen zu verhelfen, indem er diese aus ihrer jenseitigen Heimstatt entführte, bei bevorstehenden Jagd- und Fischfangunternehmungen auf hoher See die Wetterentwicklung vorauszusagen, die Wildstandorte $\mathrm{zu}$ erkunden und die »Herren« oder »Herrinnen der Tiere«, im letzteren Fall also unter Umständen ihre »Tiermütter«, zu bewegen, den Menschen einige ihrer Schützlinge zur Beute freizugeben. Schließlich hatten Schamanen die Ihren vor den Anschlägen übelwollender Geistmächte zu schützen und geleiteten nicht selten auch die Seelen der Verstorbenen sicher ins Totenreich.

All das vermochten sie allein aufgrund ihrer Doppelnatur, der sie die Gaben der Hellsichtigkeit, Telepathie und Präkognition sowie ihre außergewöhnliche Heilkraft verdankten. Schamanen besaßen gewissermaßen Geisteraugen und konnten so am Tage wie in der Nacht Verstorbene und Geister sehen und mit ihnen verkehren, ohne Schaden zu nehmen. Ihr Erkenntnisvermögen reichte bis tief in die Transzendenz, die Vergangenheit wie die Zukunft hinein.

Analog Begabte kannte man auch in anderen Kulturen. Gemeinsam war ihnen allen, selbst noch »Propheten « neuzeitlicher, christlicher ${ }^{96}$ wie nativistischer »Erweckungs «- und »Heilserwartungsbewegungen « 97 , daß sie zuvor eine Metamorphose durchlaufen hatten, das heißt vermeintlich »gestorben « und nach einer Zeit der Erneuerung und spirituellen Unterweisung durch geistige Mächte im Jenseits als Gewandelte »wiederauferstanden« waren. Bei den Aborigines in Australien erhielt der zum »clever man« Bestimmte von den Geistern, die ihn auserwählt hatten, einen »Ruf« (calling), worauf er sich in die Einsamkeit der Wildnis zurückzog und eine Höhle suchte, vor der er sich niederließ. Alsbald in Schlaf oder 
Trance versunken, »träumte« er, daß die Geister seine Knochen zerlegten, in einen Beutel packten und mit seiner Seele in die himmlische Oberwelt reisten. Dort setzten sie seinen Körper wieder zusammen und führten durch Einschnitte oder ein in die Schädeldecke getriebenes Loch bestimmte magisch wirksame Stoffe, vor allem aber Quarzkristalle, in seinen Leib ein oder entnahmen ihm die Eingeweide, um sie gleichfalls durch derartige »Zauberorgane $\ll \mathrm{zu}$ ersetzen. ${ }^{98}$ In jedem Fall erlangten die derart Gewandelten Hellsichtigkeit und ein dem normalmenschlichen weit überlegenes Erkenntnisvermögen - sie waren gleichsam halbseitig Geistmächte geworden; ihre Seele hatte sich weitgehend aus ihrer physischen Halterung gelöst.

Manchen Menschen konnten derartige Gaben aber auch gleichsam in die Wiege gelegt sein. Die Voraussetzung dafür bildete in der Regel, daß sie - mit oder ohne Zutun von Geistmächten, etwa von Feen - während einer Übergangsphase oder unter bestimmten günstigen Witterungsbedingungen geboren (bzw. gezeugt) worden waren - beispielsweise bei Sonnenaufgang, an Sonntagen oder einem bedeutenden Feiertag, zwischen den Jahren, vor allem aber an Neujahr und bei schönem, sonnigem Wetter. ${ }^{99}$ Wer solchermaßen unter einem »Glücksstern « das Licht der Welt erblickt hatte, besaß weltweit verbreiteter Anschauung nach das »zweite Gesicht« - er sah Todesfälle voraus, konnte Verlorenes wiederfinden und Geister sehen - galt als übergewöhnlich wirk- und heilkräftig und hatte in allem eine »glückliche Hand«, das heißt war erfolgreich und konnte es im Leben zu etwas bringen. ${ }^{\text {Io० }}$

Altorientalischen Überlieferungen nach galten derartige Gunstbedingungen auch für große Propheten, religiöse Erneuerer und Könige. ${ }^{\text {IOI }}$ Ihnen allen war ein zukunftweisendes Leben bestimmt; ihre Entscheidungen und Verheißungen setzten prognostische Weitsicht voraus. Auch Herrschern wurden daher prophetische Gaben zugeschrieben. ${ }^{\text {IO2 }}$ Doch kommen Offenbarungen, wie schon gezeigt wurde, nicht immer verständlich »herüber«. Wie es Gott gewöhnlich vorzieht, seine Botschaften durch einen Engel überbringen zu lassen ${ }^{\mathrm{IO} 3}$, die altgriechischen Orakel geistlicher Interpreten, die ismailitischen Propheten, mit deren Auftreten jeweils eine neue Weltperiode beginnt, zur Verdeutlichung ihrer Offenbarungen eines »Sprechers « bedürfen ${ }^{104}$ und gottbegeisterte Poeten und Sänger häufig einen Rhapsoden zur Seite hatten, der laut und verständlich für alle wiederholte, was ihnen über die Lippen $\mathrm{kam}^{\mathrm{I05}}$, besaßen so auch traditionelle Sakralkönige - in Altvorderasien ${ }^{106}$ und Afrika ${ }^{107}$ wie in Polynesien $^{108}$ - ihre »Speaker«, die bei öffentlichen Auftritten des Herrschers vernehmlich für alle Anwesenden nachsprachen und gegebenenfalls faßlicher formulierten, was dieser nur mit leiser Stimme und gelegentlich dunkel, in apokryphen Anspielungen, verlautbaren ließ.

Was weither von »drüben« kommt und zumal schon vor langer Zeit die Menschen erreichte, kann nur »gebeugt« sein und muß Unkundigen schwer oder unverständlich erscheinen. Doch enthält es gleichwohl wahre 
Informationen. Die Mythen, die von den Gesta der Götter in grauer Vorzeit berichten, galten gemeinhin als schlechthin wahr (true stories), auch wenn das Geschehen noch so kraus und grotesk anmutete und sich dem Verständnis entzog; denn es handelte sich gleichsam um Offenbarungen in Tatgestalt. Darum durften sie auch nur von untadeligen Autoritäten überliefert werden, die dafür bürgten, daß die heiligen Texte in Form und Gehalt unverändert blieben, das heißt ihre Botschaft nicht weiter verfälscht wurde. Anhänger der sogenannten »Weltreligionen« halten es mit ihren Ursprungsmythen nicht anders. Die Texte des Alten und Neuen Testaments entsprechen der Überlieferung nach Offenbarungen Gottes; ihre Verfasser waren, wie Petrus sagt, inspiriert und »getrieben vom Heiligen Geist«. Eingriff durch Deuteln verfälsche sie nur; denn »in der Schrift geschieht keine Weissagung aus eigener Auslegung «. ${ }^{\text {○9 }}$ Legenden und Sagen kam bereits weniger Glaubwürdigkeit zu. Zwar berichteten sie von Heroen, Heiligen und großen Ahnen, auch Wundern, mit denen Geister und Götter in die Geschehnisse eingegriffen hatten, und enthielten insofern wahre Überlieferungen, doch konnten sie im Grunde von jedermann, der sie hinreichend kannte, erzählt und die Texte entsprechend auch freier gehandhabt werden. Viele hatten im Laufe der Zeit schon Hand an sie gelegt. Man traute ihnen daher nur bedingtermaßen. Noch weniger Kredit genossen rein historische Geschichten (stories). Sie hatten die Gesta sterblicher, oft ganz gewöhnlicher Menschen zum Gegenstand, reichten in der Regel nicht allzuweit zurück und konnten von jedem beliebig, auch dem Hörensagen nach, erzählt werden. Meist bezeichnete man alle Überlieferungen, die von nachurzeitlichen Geschehnissen handelten, bei denen der unmittelbare Kontakt $\mathrm{zu}$ den Jenseitsmächten bereits weitgehend verlorengegangen war und man nur mehr in Ausnahmefällen mit echten Offenbarungserlebnissen rechnen konnte, als »unwahre Geschichten« (false stories). ${ }^{\text {IIO }}$

Von bestenfalls äußerst »flachem« und wenig zuverlässigem Wahrheitsgehalt galten schließlich Erzählungen, die Ereignisse der jüngsten Vergangenheit betrafen, wie sie den Gegenstand der täglichen Konversation bildeten. Die Berichte stimmten nur selten überein, da jeder das Geschehene ein wenig anders erlebt, beziehungsweise aus unterschiedlichen Quellen davon erfahren hatte und auch seinerseits bei der Wiedergabe das eine hervorhob und dramatisierte, das andere aber bagatellisierte oder ganz fortließ. Und nicht zuletzt mischten sich auch persönliche Interessen, Neigungen und Klatschsucht mit ein. Die Informationen waren oberflächlicher, flüchtiger Art und »streuten« entsprechend mehr. Sie kamen weder geradlinig und verläßlich geleitet von fern noch aus der Tiefe. Sie entbehrten der Bürgschaft durch transzendente Instanzen.

Daher wußten auch jene mehr und standen der Wahrheit näher, die ein höheres Alter als andere besaßen. Bereits Fünfjährige waren darin Dreijährigen über, Initiierte Nichtinitiierten. Ältere verfügten über ein Mehr an Erfahrung. Sie hatten häufiger Gelegenheit gehabt, Erlebtes zu 
durchdenken, zu überprüfen, mit anderen zu diskutieren und entsprechend verläßlichere Schlüsse daraus zu ziehen. Ihr Wissen wuchs mit den Jahren. Und zudem standen sie zuletzt als Älteste den Ahnen am nächsten, die an Erfahrung noch ihnen überlegen waren, wie diesen die Geister und Götter bis hinauf zum uranfänglichen Schöpfergott, dem ältesten aller, der allein Allwissenheit beanspruchen kann.

Älteste ragen, wie die Gola in Liberia sagen, »mit ihren Köpfen schon in die andere Welt«; ihre Augen tun sich gleichsam auf, sie beginnen Dinge zu sehen, die ihnen im Leben verborgen geblieben waren »Traumdinge, die ihnen in anderer Form als durch Erfahrung zuteil geworden sind «. ${ }^{\text {II }}$ Sie schöpfen nicht nur, wie sich die amerikanische Ethnologin Anne Fuller auch von libanesischen Bauern bestätigen ließ, aus dem, was sie im Leben gelernt und erlebt haben, sondern, wenn auch nur annäherungsweise, aufgrund ihrer Nähe zum Tod auch aus »jenem höheren Wissen, das Gott besitzt «. ${ }^{\text {II2 }}$ Trafen sie eine Entscheidung, konnten sie sich ebenso auf ihre überlegene säkulare Erfahrung wie gegebenenfalls einen Traum berufen, in dem ihnen die Ahnen dazu geraten hatten. Selbst wenn man nicht verstand, was sie meinten, bürgte doch ihre Autorität dafür, daß man ihnen Vertrauen schenken konnte. »Ein einfacher Bauer maßt sich nicht an, die Wahrheit von allem zu wissen [...] Er sinniert nicht darüber, sondern fragt: >Wer war es, der das gesagt hat<, und trifft danach seine Entscheidung, ob er es für richtig halten soll. II3 $^{\mathrm{II}}$ Weisheit und Wahrheitsbewußtsein erreichen im Alter ihren Höhepunkt. Alte Leute, erklärte ein Oberhaupt der Moba in Togo dem deutschen Ethnologen Jürgen Zwernemann, »können nicht lügen «. ${ }^{\text {II4 }}$

Mit der Wahrheit verantwortlich umzugehen, waren auf Erden daher am ehesten die Ältesten, in differenzierteren Gesellschaften mehr noch die Oberhäupter und Könige autorisiert, deren Status sie über die Ahnen hinaus selbst den Göttern naherückte. Ein Häuptling, waren die Mandari im Sudan der Auffassung, trifft grundsätzlich nur richtige Entscheidungen; denn »aus ihm spricht Gott «. ${ }^{\mathrm{II}}$ Die Könige der Kam im Norden Nigerias galten gar selbst als Götter und waren schon insofern, gleich diesen, außerstande, andere $\mathrm{zu}$ täuschen, geschweige denn $\mathrm{zu}$ lügen. ${ }^{\mathrm{I} 6}$ Ramses II. (I290-I224 v. Chr.) wurde mit den Worten gehuldigt: »Der Thron deiner Zunge ist ein Tempel der Wahrheit, und Gott sitzt auf deinen Lippen. «II Und nicht minder sprach auch aus den altisraelitischen Königen Gott. Von David (ca. Io04-965 v. Chr.) rühmt die Heilige Schrift, er komme »an Weisheit dem Engel Gottes gleich, daß er alles weiß, was auf Erden vorgeht «. ${ }^{\text {II8 }}$

Könige sprachen daher, wie Propheten, bisweilen in »dunklen« Worten. Die menschliche Sprache setzte der göttlichen Botschaft Grenzen; sie faßte sie lediglich unvollkommen, bog und brach sie. Schien unverständlich, was der Herrscher sagte, und war kein »Speaker« zugegen, der die Verlautbarung »übersetzte«, zweifelte man dennoch nicht daran, daß er die Wahrheit sprach. »Wenn du mit dem König gehst«, lautete - nicht 
ganz ohne Augenzwinkern - eine Empfehlung der Gola, »und es regnet, achte gut auf seine Worte. Vielleicht sieht er zum Himmel auf und sagt: >Sieh, wie die Sonne scheint und wie klar es ist<. Dann solltest du sagen: >Ja, mein König, die Sonne scheint, und noch nie hat es einen so klaren Tag gegeben $<\ll^{\text {II }}$ Nicht etwa aus purer Botmäßigkeit, sondern weil immer möglich bleibt, daß damit etwas Besonderes, vielleicht eine geheime Wahrheit zum Ausdruck gebracht werden soll, die der metaphorischen Umkleidung bedarf, weil sie nicht für die Ohren aller bestimmt ist oder ihnen unzuträglich wäre.

Allein die Art Wissen, wie man sie aus Träumen und anderen Weisen der außersinnlichen Wahrnehmung gewinnt, entsprach nach Überzeugung der Jibaro in Ecuador (und ebenso vieler anderer Völker) »der wahren Realität« (true reality). Das bewußte Erleben galt ihnen demgegenüber als wenig verläßlicher, allezeit durch Trug und Täuschung verformbarer Sinnenschein. ${ }^{\text {I20 }}$ Die Suku im äquatorialen Zentralafrika schieden begrifflich zwischen »denken« (ku-baanza), das sich der abwägenden Überlegung, Vermutung und Schlußfolgerung bedient, und »wissen« (ku-zaaya), womit das Initiations- und Geheimwissen sowie, als Frucht dieser Kenntnis, magisches Wirkvermögen gemeint war. Nur dieses, neben der Belehrung durch Ältere überwiegend auf »mystische« Weise, durch Visionen, Divinationspraktiken und Seelenreisen gewonnene Wissen wurde als wahrheitsgemäß, als true knowledge begriffen; es konnte nicht rational erschlossen, sondern allein »entdeckt « (discovered) werden, da es eine andere als die dem Menschen unmittelbar vertraute, das heißt die außerlebensweltliche Realität betraf (»it exists objectively outside the Suku«). ${ }^{\mathrm{I2I}}$ Die jenseitige, unsichtbare Welt hinter der sinnlich wahrnehmbaren Flucht der Erscheinungen, einzig sie, »die Welt dessen«, wie der Schweizer Ethnologe Gerhard Baer die entsprechende Auffassung der Matsigenka in Peru wiedergibt, »was man in der alltäglichen Wirklichkeit nicht sieht, das dem gewöhnlichen Auge Verborgene, ist das Wirkliche ${ }_{.}{ }^{\mathrm{I} 2}$ 


\section{Geisterglaube}

\section{Vom Umgang mit Engeln, die glücklich, und Teufeln, die unglücklich machen}

Doch nur kaum in diesem apodiktischen Sinne. Denn offenkundig entsprach nicht alles, was sich dem Augenschein entzog, der true reality oder gar lauterer »Wahrheit«. Daß hätte bedeutet, daß es allein irrende Menschen und infallible Götter, eine irdische und, sauber geschieden von ihr, eine rein transzendente Welt gab. Die tägliche Erfahrung jedoch lehrte nun mal, daß sich dazwischen, vielfältig ineinander verwoben, geschachtelt und abgestuft, mal dichter gedrängt, mal weitläufig auseinandergezogen, der Übergangsbereich zwischen irdischer Binnen- und überirdischer Außenwelt dehnte, der Anteil an beiden hatte und entsprechend von Kreaturen der unterschiedlichsten Übergangsart bevölkert sein mußte.

Menschen in den Zentralarealen der modernen, hochzivilisierten Welt können sich heute, »aufgeklärt«, wie sie sich dünken, kaum mehr vorstellen, daß ihre Vorfahren über Jahrzehntausende hin, ja bis vor verhältnismäßig kurzer Zeit, wie im übrigen noch in der Gegenwart der überwiegende Teil der Menschheit, überzeugt waren, von ganzen Heerscharen von Geistern umgeben zu sein, mit denen sie buchstäblich auf Schritt und Tritt in Berührung gerieten, auch wenn ihnen das nicht immer deutlich zu Bewußtsein kam. Geister waren - und sind, wie gesagt, nach dem Glauben vieler noch immer - allgegenwärtig. Sie folgen dem Menschen »dicht auf den Fersen, blenden seine Sinne, dringen in ihn ein, quälen und betrügen und foltern ihn in tausend wunderlichen und mutwilligen Arten . $^{\mathrm{I}}$ Denn wie anders hätte man sich erklären sollen, daß plötzlich, ohne ersichtlichen Grund, ein Topf vom Wandbord fiel und zerbrach, daß man im Wald über eine Wurzel stolperte und sich den Knöchel verstauchte, daß ein sonst furchtsames Tier nicht auswich, sondern stehenblieb und einen unverwandt ansah, daß man einen Hexenschuß erlitt, der Pfeil das Jagdwild verfehlte oder man unverhofft von einem herabfallenden Tannenzapfen getroffen wurde? Sichtlich waren da 
Kräfte wirksam, die irgendjemand absichtsvoll in Gang gesetzt haben mußte. Denn für »Zufälle« war im Weltbild prämoderner Gesellschaften kein Platz. Häufig machte man den Zauber eines mißgünstigen Zeitgenossen dafür verantwortlich. Doch gab es genügend Fälle, in denen dieser Verdacht nur kaum in Betracht kam. Und dennoch war man sichtlich das Opfer eines Anschlags geworden - dessen Urheber allerdings unsichtbar blieben. Die Vermutung lag daher nahe, daß es sich um Agenzien spiritueller Natur handeln mußte. Da es wenig plausibel schien, daß Götter sich mit derartigen Kleinlichkeiten abgaben, konnten nur nichtgöttliche, niedriger geartete Geistwesen die Hand im Spiel haben. Im Mittelalter, als die Kirche in Europa noch nicht so recht Fuß gefaßt hatte, machten sie selbst vor den Pforten der Klöster nicht Halt. Hier wußte man allerdings, in wessen Sold sie standen. Richalm von Schöntal, Anfang des I3. Jahrhunderts (ca. I2I6-I219) Abt der Zisterze Schöntal (im Jagsttal), belegt das minutiös in seinem Liber revelationum (»Buch der Enthüllungen«). Täglich, ja stündlich sah er sich den Anfechtungen der verschiedensten »Teufel« ausgesetzt, die nicht nur sein Fleisch, sondern auch seinen Geist in Versuchung führten. Erkältungen, Auswurf, Übelkeit, selbst Alterserscheinungen wie Faltenbildung und Muskelschwäche waren seiner Überzeugung nach ihr Werk. An Festtagen mischten sie sich gern unter die Mönche im Refektorium, wenn gewöhnlich ein edlerer Wein als gewöhnlich in den Pokalen funkelte. Und schon bald wurde ihr unseliger Einfluß offenbar, wenn einer der Zecher das heulende Elend bekam, andere nicht mehr Herr ihrer Sprache waren oder unsicheren Schrittes singend und lärmend durch die Halle schwankten. ${ }^{2}$

In traditionellen Gesellschaften hatte sich zudem die Annahme, daß derartige unliebsame Erfahrungen auf ganz konkrete Geistmächte zurückzuführen waren, immer wieder mal dadurch bestätigt, daß sie gelegentlich auch sichtbar in Erscheinung traten, das heißt sich gewissermaßen »materialisierten«. Über ihre Natur sagte das an sich noch nichts aus, da sie ihre Gestalt ganz nach Belieben und Anlaß wählen und jederzeit wandeln konnten. Immerhin bot das - gesetzt, die Erscheinung versetzte einen nicht in lähmenden Schrecken - die Möglichkeit, in angemessener Weise zu reagieren, das heißt bestimmte Schutz- und Abwehrmaßnahmen zu ergreifen oder auch, wie unter Menschen, in Kommunikation mit ihnen zu treten, sei es, um sie versöhnlich zu stimmen oder ihnen Opferangebote und Versprechungen zu machen.

Eigentlich konnten sich die Geister auf jede sichtbare Weise verkörpern; meist handelte es sich jedoch - und das erweckte den Argwohn um seltener vorkommende, ungewöhnliche Erscheinungen: farbige, bizarr gestaltete Steine, Tiere, die man bei Tag nur kaum zu Gesicht bekam, einzeln stehende große Bäume, Flämmchen über sumpfigem Gelände bei Nacht, Sternschnuppen sowie Wind-, Wasser- und Sandhosen. Überwiegend aber traten sie in Tiergestalt auf. Tiere besaßen wie Menschen eine Freiseele, die sie verdrängen, deren Platz sie einnehmen 
konnten - es handelte sich dann sozusagen um »besessene« Tiere. Zwar waren sie imstande, sich jeder Form zu bedienen, doch scheint es, als ob sie bestimmte Tierleiber bevorzugt hätten. Meist traten gutartige Geister als sanftmütige Tiere, etwa als Rehe, Hirsche, Elche, Schwäne, Wiedehopfe, Störche oder Strauße, übelsinnige als Raub- und Kriechtiere, beispielsweise als Schakale, Wölfe, Tiger, Schlangen, Reptilien und Skorpione auf.

Entschieden gefürchteter jedoch waren Geister, die den Menschen in ihrer, aber auch dann zumeist irgendwie abgewandelter Gestalt gegenübertraten. Zwar konnten sie überaus schön und verführerisch erscheinen, doch nur um ihr Opfer um so sicherer in ihre Netze zu locken; oder sie traten in der Maske des Biedermanns auf, ließen aber auch dann irgendwann sozusagen den Bocksfuß unter der Kutte hervorfahren. Schlimmer indes waren jene, die ohne alle Umschweife in Erscheinung traten. Offenbar kannten ihre Phantasie und Erfindungskraft dabei keinerlei Grenzen. Sie zeigten sich in den absonderlichsten - und vor allem möglichst schreckerregenden - Gestalten, halb Mensch, halb Tier, meist dicht behaart, mit Rettigkopf, tellergroßen feurigen Augen, grünem, zottigem Haar, kupfernen Krallen und rückwärts gewandten Füßen, die Frauen mit überlangen, über die Schultern geworfenen Brüsten, mal als bucklige Zwerge mit alten, runzelübersäten Gesichtern, mal als grobschlächtige Riesen mit Hunger auf Menschenfleisch, mal auch in der Form fahler Skelette. Die Iglulik-Eskimo kannten zum Beispiel weibliche Geister, die in großer Zahl an den Meeresküsten lebten. Sie trugen, wie Knud Rasmussen von seinen Gewährsleuten erfuhr, »spitze Kapuzen aus Haut auf dem Kopf, absonderlich kurze Hosen aus Bärenfell, lange, schwarzgemusterte Stiefel und Umhänge aus Robbenleder. Ihre Füße sind nach oben gedreht, so daß es scheint, als gingen sie auf den Fersen. Den Daumen halten sie nach innen über die Handfläche gedrückt, die Arme ständig erhoben, mit den Händen zusammen. Ihr Kopf wackelt fortwährend hin und her. Ruft man sie an, zeigen sie sich stets heiter und fröhlich. Nicht größer als der Arm eines Mannes, gleichen sie süßen kleinen, lebenden Puppen. $\ll^{3}$

Indessen, ob sie sich nun in Steinen, Tieren oder Wasserhosen verkörpern: letzten Endes stehen sie doch den Menschen am nächsten. Sie leben gleich ihnen - sofern sie nicht ein Solitärdasein vorziehen - in Familien, Klanen und Stämmen, heiraten, haben Kinder, zanken sich und feiern rauschende Feste. ${ }^{4}$ Auch besitzen sie eine eigene Sprache, die weltweit übereinstimmend als eine Art Pfeifen beschrieben wird. Doch welche Erscheinungsform sie immer auch wählen, stets kann man sie daran erkennen, daß sie - als gleichsam masselose Wesen - weder einen Schatten werfen noch im Wasser oder auf glänzenden Oberflächen ein Spiegelbild hinterlassen. ${ }^{5}$

Und Geister gehen auch mit der Zeit. In den »entwickelteren« Regionen der Welt, in denen die Maschinen ihre dünnen Stimmen zu über- 
dröhnen und sie zu verdrängen drohen, reagierten sie, kraft ihrer schier unerschöpflichen Verwandlungsfähigkeit, ebenso rasch wie den Gegebenheiten entsprechend. I954 überflog erstmals ein Flugzeug eine Siedlung der Tonga in Sambia. Eine Frau geriet darüber derart in Schrecken, daß sie Hals über Kopf in den Busch floh und nur mühsam wieder zur Rückkehr bewegt werden konnte. Wenig später erschien ihr das Flugzeug im Traum und offenbarte ihr neue Lieder, Tanzschritte und Trommelrhythmen, die alsbald weite Verbreitung fanden. In der Folge träumten auch andere Frauen von Flugzeugen, dann von Traktoren, Motorbooten mit Schleppnetzen, ja selbst Eisenbahnzügen. Die Geister ergriffen von ihnen Besitz und bedienten sich ihrer als Medien. Wer von einem »Traktor« besessen war, rieb sich mit Dieselöl ein und schleifte schwere Ketten über den Tanzplatz. ${ }^{6}$

Geister sind Teil der Wirklichkeit. Sie lassen sich hören und sehen, manchmal auch riechen, und visualisieren sich gegebenenfalls in zeitgemäß adäquater Weise. Man hat immer zumindest die Chance, mit den Schrecken, die ihre Erscheinung auslöst, umzugehen. Oft spürt man ihre Anwesenheit auch nur. Carl Gustav Jung berichtet von einem derartigen Erlebnis, das ihm I9I6, auf dem Höhepunkt einer persönlichen Krise, widerfuhr. Seit Tagen hatte es in seinem Haus gespukt. Eines Sonntagmorgens ging die Türklingel. Er öffnete, sah jedoch niemanden draußen stehen. Er empfand »die Luft« als drückend »dicht«. Er fühlte, daß etwas im Gange war: »Das ganze Haus war angefüllt wie von einer Volksmenge, dicht voll von Geistern. Sie standen bis unter die Tür, und man hatte das Gefühl, kaum atmen zu können. «?

Treten gewöhnliche Geister auch zumeist einzeln in Erscheinung, so werden sie doch überwiegend als Gattungswesen begriffen; anders als Götter also ohne persönliche Züge, Individualität und Namen, aber analog zu den Fremdvölkern, mit denen sie die exosphärische Umwelt teilen. Beide sind viel zu zahlreich und mangels dauerhafter Beziehungen zu ihnen kaum hinreichend bekannt, als daß man sie deutlicher voneinander unterscheiden könnte. Insofern schreibt man auch Geistern einer gegebenen Gattung - Wald-, Erd-, Fluß-, Berggeistern usw. - immer nur Kollektiveigenschaften zu. Gleich Fremdvölkern (»Barbaren«) erscheinen sie artmäßig anomal ${ }^{8}$ und gelten zumindest als launischen, eigentlich aber generell bösartigen Wesens, allezeit mit Bedacht darauf aus, die Menschen $\mathrm{zu}$ ärgern und zu verunsichern, mehr noch zu schädigen und zu quälen, ja sie womöglich vollends ins Verderben zu ziehen.

Geister sind typische Übergangsexistenzen zwischen den geordneten Welten der Götter und Menschen. Daher ihre genuine Instabilität, die sie unausgeglichen erscheinen und ständig die Gestalt wechseln läßt und, da ihnen die Götter unerreichbar sind, hinzieht zu den ihnen näher stehenden Menschen, die sie um ihrer ausgewogenen Geschöpflichkeit willen beneiden, die sie an sich zu binden und zu beherrschen versuchen, um teil an ihrem glücklicheren Dasein zu haben. Meist gelingt ihnen das 
jedoch nicht, so daß sie verärgert werden und sich von ihrer bösartigen Seite zeigen. Kommt es indes zu freundlichen, ja intimen Beziehungen, wie das gelegentlich durchaus der Fall ist, helfen sie ihren Schützlingen, bewahren sie vor Gefahren und bescheren ihnen Glück und Erfolg, gewöhnlich das ganze Leben lang.

Letzten Endes liegt ihr Wesen in ihrer Entstehung begründet. An sich lief ihre Existenz den Intentionen des Schöpfers zuwider. Doch mangelte es ihm anfangs noch an Erfahrung; er achtete nicht genau auf alles, vergaß etwas oder machte Fehler. Geister konnten ihr Dasein so einem Versehen, Mißgriff, auch purem Zufall verdanken. Einem malaiischen Mythos zufolge hielt das Lehmmodell des ersten Menschen nur, weil der Schöpfer ihm eiserne Stützen eingezogen hatte. Allerdings kam er auf diesen Gedanken erst beim zweiten Versuch, da beim ersten der Torso, als er ihm seinen Odem einblies, »explodiert« war. Aus den verkohlten Trümmern, die weithin überall niedergingen, entstanden die Geister Produkte aus Ungeschick und Bruchwerk. Ähnlich unbeholfen stellte sich Gott auch nach einer außerbiblisch-jüdischen Überlieferung an. Hier hatte er zunächst statt der Leiber die Seelen der ersten Menschen erschaffen. Als er nun fortfahren und die Körper bilden wollte, wurde er vom Sabbat überrascht - er hatte nicht bedacht, wie lange genau er brauchen würde. Er unterbrach seine Arbeit und hinterließ unfertige Geschöpfe in Gestalt leibloser Seelen. Handelte er in diesen Fällen sträflich unüberlegt, waren es nach hinduistischem Glauben Empfindungen quälenden Unwohlseins, die ihn gezielt zur Erschaffung bösartiger Geistwesen bewogen. Nachdem er seine Arbeit weitgehend getan hatte, überfielen ihn nämlich Hunger und Durst. Das nahm ihm die Laune. Sein Sinn verfinsterte sich, und er erschuf Wesen, die seiner Stimmung entsprachen: mißgestaltete Kreaturen, hungernd und ausgemergelt, zügellos, grausam und gierig nach Menschenfleisch. Häufiger jedoch hat Gott nicht unmittelbar mit der Entstehung der Geister zu tun. Sie bildeten sich, wie die Mythen vieler Völker berichten, irgendwie von selbst, etwa wie Geschmeiß aus verrottendem Fleisch, aus Asche von Verbranntem oder Restund Abfallstoffen der Schöpfung. ${ }^{9}$ Aber natürlich zeigten sie sich von ihrer unangenehmen Seite und begannen den Menschen zuzusetzen erst nach dem Sündenfall, als Gott sich enttäuscht in die Tiefen des Alls zurückgezogen hatte und nicht mehr allzusehr Interesse an den Geschicken der Menschen nahm. »Sünde«, so beispielsweise der Glaube im alten Mesopotamien, »brachte Dämonenherrschaft mit sich, diese wiederum hatte Krankheit zur Folge. « ${ }^{\text {IO }}$

An Ablagerungsstätten zerfallenden Stoffs, dem Nährboden, aus dem sie einstmals entstanden, ist Geistern auch heute noch am wohlsten. Universaler Vorstellung nach halten sie sich bevorzugt in Kehricht, Schmutz und Unrat, auf Dung- und Abfallhaufen, in Ställen, Latrinen, Mühlen (in denen Korn zermahlen wird und sich viel Staub befindet) und verlassenen, verfallenden Gebäuden (Ruinen) sowie an Orten auf, an 
denen - etwa durch einen Unfall oder Mord - Blut floß und sich zersetzte: dort also, wo Reinheit und Urdnung übergehen in Zerfall und Auflösung. ${ }^{\text {II }}$ Daher die verbreitete Regel, täglich wenigstens einmal Haus und Hof zu kehren, das Geschirr zu reinigen und sich mehrmals, vor allem vor den Mahlzeiten, Hände und Mund zu waschen. ${ }^{\text {I2 }}$

In analogem, erweitertem Sinne finden sich Geister ferner auch besonders an typischen Grenz- und Übergangsstellen zwischen Eigen- und Außenwelt, Kulturland und Wildnis, Diesseits und Jenseits vor: an Kreuzungen, wo sich zwei oder mehrere Grenzlinien topographisch geschiedener Räume schneiden, in Schwellenbereichen, an Flußübergängen und Wasserfällen, in Schluchten, Höhlen, Brunnen und Quellen, auf hohen, karstigen Bergen, an Pässen, auf Friedhöfen, in Sümpfen, Wüsten und einzelnstehenden hochaufragenden Bäumen. ${ }^{\mathrm{I3}}$

Doch sind sie auch dort nicht immer aktiv. Wiederum leben sie gleichsam auf und treibt es sie ganz besonders um zu Übergangszeiten. $\mathrm{Zu}$ hüten hat man sich also an den besagten Stellen vor ihnen namentlich während der Mittagszeit (vgl. die »Mittagshexe« im osteuropäischen Volksglauben), in der Abend- und Morgendämmerung, nachts, vor allem um Mitternacht, und zu - biographischen, sozialen und kosmischen Wendezeiten, wie allen voran zu Neujahr, das heißt in der Zeit »zwischen den Jahren « beziehungsweise Jahreszeiten (Sommer und Winter, Trokken- und Regenzeit).

Als »Internaturen « erscheinen Geister, anders als Götter, nicht nur eher, sondern mehr noch der irdischen Welt zugehörig. Die meisten sind an bestimmte Lokalitäten (Quellen, Sümpfe, Wüsten usw.), einige an die Elemente Erde, Wasser, Feuer und Luft (bzw. den Wind, wie die Windsbraut z.B.) gebunden. Überblickt man den »Befund«, so lassen sie sich insgesamt etwa wie folgt klassifizieren:

\section{Geister nichtmenschlichen Ursprungs}

\section{Gruppengeister}

a) Gutartige Geister: Zu ihnen zählen vor allem persönliche Schutzgeister, die einen bestimmten Menschen sein Leben lang wachsam begleiten, ihm helfend zur Seite stehen, vor drohenden Gefahren erscheinen, um ihn zu warnen, ihm in akuten Fällen beispringen und zuletzt seinen Tod ankündigen ${ }^{\mathrm{I}}$; Hausgeister, meist in Zwergen- (Heinzelmännchen), Koboldoder Schlangengestalt, die unter der Schwelle, dem Herd oder den Dielen des Wohnraums hausen, Haus und Hof vor Schaden, etwa durch Brand oder Blitzschlag, und den Anschlägen bösartiger Geister und Zauberer schützen $^{\mathrm{I5}}$; Familien-, Klan- und Stammesgeister, die Sorge für die Gesundheit, die Fortpflanzung, den wirtschaftlichen Erfolg, den sozialen Frieden und Schutz der ihrer Verantwortung unterstehenden Verwandt- 
schaftsgruppen trugen ${ }^{16}$; Feen (im mediterranen Bereich die Peris), die immer weiblichen Geschlechts und meist auffallend schön sind, betörend zu singen vermögen, häufig hoch in den Bergen in Eis- oder Kristallbehausungen leben, Gemsen halten und Jäger und Hirten vor Gefahren bewahren und zu Glück und Reichtum verhelfen - sofern sie jedenfalls ein »reines«, das heißt ein untadeliges Leben führen ${ }^{\text {I7}}$; schließlich die Engel (in Judentum, Christentum und Islam).

b) Ambivalente Geister: $\mathrm{Zu}$ ihnen zählen (in Europa) zum Beispiel die Elfen (die Vilen der Südslawen), die überwiegend weiblichen Geschlechts und mädchenhaft schön sind, langes Haar tragen, im Wald, auf Bäumen und Wiesen leben und sich in mondhellen Nächten auf einsamen Lichtungen mit Singen, Tanzen und Spielen unterhalten; an sich von gutmütigem Naturell, können sie sich aber auch boshaft und rachsüchtig zeigen und namentlich Menschen, die sie heimlich beobachten, Krankheit, Verderben und Tod bringen ${ }^{\text {I8 }}$; die Berggeister, gewöhnlich beiderlei Geschlechts, in Zwergengestalt mit großem Kopf, häufig geschickte Schmiede, die Hirten und vom Wege Abgekommenen helfen, Bergleute auf Erzvorkommen und verborgene Schätze hinweisen und so Glück, unter Umständen, wenn die Menschen ihre Hilfe mit Undank lohnen oder sie geringschätzig und schlecht behandeln, aber auch Unglück bringen können, indem sie das Vieh in Abgründe stürzen, Unwetter auslösen und Lawinen lostreten. ${ }^{\text {I9 }}$

c) Bösartige Geister: $\mathrm{Zu}$ ihnen zählt die weit überwiegende Mehrheit der »Naturgeister«, das heißt der Wald-, Busch-, Wasser-, Sumpf- und Wüsten-, auch vieler Berggeister (z.B. an Pässen); sie lieben es, Menschen, die unvorsichtigerweise weit draußen allein, und namentlich nachts, unterwegs sind, heimtückisch und plötzlich von hinten zu attakkieren, auf Abwege und sumpfiges Gelände zu locken, ihnen in furchterregender Gestalt zu erscheinen, um sie zu lähmen, in den Wahnsinn zu treiben und zu Tode zu erschrecken, oder sie auch in ihren Bann zu ziehen und sich gefügig zu machen. ${ }^{20}$ Besonders gefürchtet waren (in Europa, Asien und im Mittelmeerraum) die den Elfen verwandten Nixen, gleich diesen weiblichen Geschlechts und mit langem (meist grünem) Haar, das sie wieder gerne und sorgsam zu kämmen pflegten; nachts bei Mondschein entstiegen sie Teichen und Seen im Wald, sangen und tanzten und versuchten, Männer, die in ihre Nähe kamen, zu verführen, um sie anschließend ins Wasser zu ziehen, so daß sie ertranken. ${ }^{2 \mathrm{I}}$

\section{Individualgeister}

a) Gutartige Geister: Zu ihnen zählen Haus-, Schiffs- und Schutzgeister, sofern sie keiner Gruppe angehören, das heißt als Solitäre auftreten, spezifische, nur ihnen eigene Eigenschaften, manchmal auch einen Namen (wie z.B. der Klabautermann) besitzen und immer in derselben Gestalt auftreten; ferner Tierherrinnen bzw. Tierherren, die Verantwortung 
für Vermehrung und Fortbestand der einzelnen Fisch- und Tierarten tragen und entsprechend etwa Fisch-, Robben-, Elch-, Bären- oder Adlergestalt besitzen. $^{22}$

b) Bösartige Geister: $\mathrm{Zu}$ ihnen zählen in der Hauptsache die Oger, gewöhnlich in grobschlächtiger, menschenähnlicher Riesengestalt, manchmal mit spitzen (Amur-Tungusen), manchmal mit mehreren Köpfen (Armenier) gedacht, die in Berghöhlen, Schluchten oder Behausungen tief im Wald, allein, mit Ehefrau oder ihrer Mutter zusammen, gelegentlich auch in kleinen Gruppen (wie die Kyklopen) leben, immer Eigennamen tragen (z.B. Polyphem), meist dumm sind und eine besondere Vorliebe für Menschenfleisch besitzen. ${ }^{23}$

\section{Geister menschlichen URSPRUngs}

a) Gutartige Geister: Zu ihnen zählen die Ahnen (die Laren der Römer), die im Totendorf unter der Siedlung ihrer Nachfahren leben, allezeit intensiven Anteil an den Geschicken ihrer Hinterbliebenen nehmen, ihnen zu Gesundheit, Fruchtbarkeit und Erfolg verhelfen, im Traum erscheinen, um sie vor Fehlverhalten und Gefahren zu warnen oder ihnen in kritischen Situationen mit Rat und Tat zur Seite zu stehen, sie gleichwohl aber auch, wenn sie schwere Vergehen wider die Tradition begangen haben, mit Krankheit, Unfällen und Ernteeinbußen, ja dem Tod bestrafen, bis sie sich dann zu gegebener Zeit, gewöhnlich nach drei bis fünf Generationen, erneut unter den Ihren reinkarnieren.

b) Bösartige Geister: $\mathrm{Zu}$ ihnen zählt universaler Vorstellung nach das (ständig sich mehrende) Heer der eines Schlimmen Todes, das heißt vorzeitig aufgrund einer fluchwürdigen Verfehlung durch Tabubruch, schweren Schadenszauber, einen tödlichen Unfall oder Mord Verstorbenen (die Lemuren bzw. Larven der Römer und »Verdammten« oder »Verlorenen Seelen« des europäischen Volksglaubens), die niemals formell auf rituelle Weise bestattet, sondern flüchtig im Busch verscharrt oder lediglich abgelegt werden, daher nicht ins Totenreich finden und bevorzugt an lebensfeindlichen Orten, wie in Sümpfen (z.B. in Osteuropa) oder unter Gletschern (in den Alpen), das heißt in Grenzbereichen zwischen den Welten hausen, ruhelos umgetrieben und darauf aus, sich an den Lebenden für ihr unseliges Schicksal zu rächen. ${ }^{24}$ Einige bleiben auch über Jahrhunderte hin an den Ort ihres Verbrechens oder gewaltsamen Todes gebunden und gehen dann dort als Gespenster um. ${ }^{25}$

$\mathrm{Da}$ es Geister gab, daran zweifelte (früher) niemand. Nicht nur, daß dies die - heilvolle oder unheilvolle - Erfahrung ihrer Eingriffe in die Geschikke der Menschen lehrte; viele spürten, hörten oder sahen sie auch. Nicht wenigen erschienen sie im Traum, manchen draußen in Busch und Wald oder an bestimmten, dafür berüchtigten Stätten (sog. loca infesta ${ }^{26}$ ). An- 
dere, wie Kinder und Sterbende meist generell ${ }^{27}$, in Trance Befindliche (wie insbesondere Schamanen) und solche, die das »Zweite Gesicht« besaßen, das heißt während einer Wende- beziehungsweise Übergangszeit gezeugt oder geboren worden waren (z.B. Neujahrs- und Sonntagskin$\left.\operatorname{der}^{28}\right)$, konnten sie, wie schon erwähnt, allezeit schauen und davon berichten.

Geistigen Wesenheiten gegenüber, die zu segnen wie zu schaden, ja zu töten vermochten, konnte der Mensch nicht gleichgültig bleiben. Vor den übelsinnigen suchte man sich durch geeignete magische Vorsichtsund Abwehrmaßnahmen - Reinlichkeit, in kritischen Fällen strikte Askese, ferner Amulette, Feuer (Licht), Eisen (das Geister besonders schreckt) und Verhüllung der offenen Körperpartien (Geschlechtsorgane, Mund, Augen) - zu schützen, teils auch ihre unguten Neigungen durch Opfergaben zu destimulieren. Eine verläßliche Gewähr bot das allerdings nicht. Viele Geister hatten noch menschliche Wesensanteile genug, um so etwas wie Lüsternheit und Eßgier zu verspüren. Doch bedurften sie zur Befriedigung ihrer Leidenschaften menschlicher Leiber. Also setzten sie sich mit den Menschen zu Tisch und ließen jene, die es mit der Reinlichkeit nicht allzu genau nahmen und sich zum Beispiel vor der Mahlzeit nicht die Hände gewaschen hatten - denn an andere kamen sie nur schwerlich heran - für sich mitessen, so daß diese den Eindruck unziemlicher Gefräßigkeit erwecken mußten. ${ }^{29}$ Oder sie nutzten die Nacht, schlichen sich zu den Menschen aufs Lager und verkehrten mit ihnen - was entsprechend wollüstige Traumerlebnisse hervorrief. Andere wieder, namentlich Wassergeister, erschienen jungen Männern und Frauen, die allein unterwegs waren und ihr Gefallen fanden, in betörend schöner Gestalt, lockten sie vom Weg ab und verführten sie, ihnen beizuwohnen. Unter Umständen blieb der Genuß nicht ohne Reue. Oft waren die Opfer anschließend nicht mehr imstande, mit Menschen geschlechtlichen Umgang zu pflegen. Auch wurden sie ihre Geisterbuhlen kaum mehr los; brachten sie es dennoch zuwege, legten ihnen diese das als Untreue aus und schlugen sie mit Wahnsinn oder töteten sie. Manchmal trugen die unheiligen Beziehungen auch Früchte - auf Geister- wie auf Menschenseite; doch gerieten die Kinder selten gut; irgend etwas »stimmte nicht « mit ihnen. ${ }^{30}$ Noch bis ins I7. Jahrhundert waren Philosophen und Theologen in Europa der Meinung, daß Engel in der Lage seien, Scheinimitationen echter Körper herzustellen, denen sie zwar keine Seele zu verleihen vermochten, derer sich aber dann die Geister bedienten, so daß sie gleichwohl wie lebendig wirkten. Allerdings hielten weder ihre »Physis « noch ihr Funktions- und Leistungsvermögen den Vergleich mit ihren natürlichen Vorbildern aus »das stellen Menschen, die sich auf sexuellen Verkehr mit solchen Imitationen einlassen, nicht ohne Bedauern fest «. ${ }^{\text {I }}$ Schließlich nahmen überall auf der Welt Geister auch bei Tage gewaltsam Besitz von Menschen, drängten sich in ihre Seelen und drückten, wonach sie verlangte, durch deren Gestik, Mimik und Sprache aus. Solche Besessenheitszustände währ- 
ten gewöhnlich nur einige wenige Stunden, manchmal aber auch ein Leben lang. In diesen Fällen besaß der Mensch keinen eigenen Willen mehr; er war ganz zum Instrument, zum dienstbaren Geschöpf des Geistes geworden.

$\mathrm{Zu}$ guten und hilfreichen Geistern dagegen suchten die Menschen ihrerseits in Kontakt zu geraten und eine möglichst dauerhafte Beziehung herzustellen. Dazu boten sich verschiedene Möglichkeiten an, die in der Regel entsprechende vorbereitende Maßnahmen zur Voraussetzung hatten, die sich im Grunde nur konsequent aus den Bedingungen der gesuchten Kontaktaufnahme ergaben. Die Betreffenden mußten sich dazu nämlich in einen Übergangszustand versetzen. Das geschah, indem sie eine passende Zeit - die Nacht oder sonst eine Wendezeit - wählten, eine typische Grenz- oder Passageregion - eine Höhle, eine abgelegene Stelle im Wald, die Wüste oder eine einsame Berggegend - aufsuchten und sich dort dann auf verschiedenerlei Weise kasteiten, etwa den Schlaf mieden und fasteten, ferner heilige Texte rezitierten, beteten, meditierten und unter Umständen auch halluzinogene oder narkotisierende Drogen einnahmen, so daß sie zuletzt in eine Art Trancezustand gerieten und »hellsichtig « wurden, das heißt, wie die Runa im Osten Ekuadors den Prozeß beschrieben, »in den Bereich der mythischen Raumzeit überwechselten . $^{32}$

Diesen Weg gingen zum Beispiel Jugendliche - nicht nur, aber zur Hauptsache - bei nordamerikanischen Indianern vor allem des nördlichen Waldlands und der Great Plains, um Kontakt mit ihrem persönlichen Schutzgeist aufzunehmen. Sie zogen sich dazu bei Einsetzen der Pubertät an eine einsame Stelle in der Wildnis zurück, fasteten, beteten und meditierten, bis ihnen ihr Schutzgeist, überwiegend in der Gestalt eines bestimmten Tieres, erschien. Verging längere Zeit, ohne daß ihnen die erwartete Offenbarung zuteil wurde, verschärften sie ihre Bemühungen entsprechend, fügten sich schmerzhafte Verletzungen $\mathrm{zu}$, schleppten schwere Steine über größere Strecken, schliefen nicht und intensivierten ihre Konzentrationsübungen noch um einiges mehr. Physisch schließlich total erschöpft und in einem Zustand höchster nervlicher Überspannung und Sensibilität, empfingen sie eines Tages dann endlich die ersehnte Vision: Der Schutzgeist (guardian spirit) erschien ihnen, sprach sie an und begann sie in allem, was fortan für sie wichtig und von Bedeutung war, zu unterweisen. Das betraf sowohl die Herstellung bestimmter »Medizinen«, Zauberformeln, magische Praktiken, Gebete und Gesänge als auch Empfehlungen für Jagd, Ehe und Familienleben. Fortan stand er seinem Schutzbefohlenen unsichtbar zur Seite; nur in Gefahrenfällen erschien er ihm noch, warnte und beriet ihn. Kam er - wie auch immer - abhanden, erkrankte der Mensch und genas erst, wenn er ihn wiedergewonnen hatte. Kurz vor dem Tod seines Schützlings zog er sich dann endgültig zurück. ${ }^{33}$

In vielen Teilen der Welt, wie namentlich in Ostsibirien, im Kaukasus und im Hindukusch, suchten Jäger mit weiblichen Geistern (»Feen«), die 
über bestimmte Jagdwildarten (im Gebirge besonders Wildziegen, Gemsen und Steinböcke) geboten, längerfristige Liebesbeziehungen, ja regelrechte Ehen einzugehen, um sich ihres Jagdglücks zu versichern. Allerdings war das allein in der Traumwelt möglich und setzte voraus, daß die menschlichen Partner ein untadeliges, »reines « Leben führten. ${ }^{34}$ Menschen mit entsprechenden (»parapsychischen«) Gaben konnten sich Geister auch mit magischen Mitteln dienstbar machen, um sie entweder als »friends and allies«, wie bei den Jibaro in der Montaña von Ekuador, zu guten Zwecken, das heißt zum Wohle der Ihren, oder aber für eigensüchtige, schadensmagische Absichten einzusetzen. ${ }^{35}$

In beiden Fällen empfahl sich als probates Mittel geradezu, dienstbaren Geistern (auch Ahnen) entweder einen Gegenstand oder ein Idol gleichsam als »Absteige« oder Dauerquartier in Haus und Hof anzubieten oder sie in ein derartiges Behältnis zu bannen, so daß man jederzeit über sie verfügen konnte. Dabei handelte es sich teils um sogenannte »Fetische«, das heißt irgendwelche materiellen Objekte, neuerlich etwa auch Kopfwehtabletten, teils Masken, meist jedoch anthropomorphe Figürchen aus Tuch, Filz, trockenem Gras, Lehm, Stein, Holz und Metall, die oft, gleich Püppchen, bekleidet waren und regelmäßig gespeist, manchmal auch mit Öl oder Milch gesalbt wurden. ${ }^{36}$ Im Grunde verfuhr man bei ihrer Herstellung wie ehedem der Schöpfer bei der Erschaffung des Menschen - nur in der umgekehrten Reihenfolge, indem man den »Seelen« einen Leib gab. Dies und die Opfer verpflichteten sie. Streng nach der Reziprozitätsregel erwartete man von ihnen, daß sie den Menschen tatkräftig zur Hand gingen und ihnen bei der Krankenheilung, der Jagd, beim Feldbau und Geschäften zum Erfolg verhalfen, heute entsprechend bei Prüfungen, der Stellensuche, im Beruf und bei sportlichen Wettkämpfen glückbringend »mitmischen $\ll .37$

Derartige »Götzen « besaßen, trotz des Bilderverbots ${ }^{38}$, auch die alten Israeliten ${ }^{39}$; teils waren sie - so beispielsweise die Teraphim - aus kostbaren Materialien wie Elfenbein, Silber und Gold gearbeitet. ${ }^{\circ}{ }^{\circ} \mathrm{Da}$ die Praxis lange gängig blieb, lehren die harten Worte, mit denen sie noch die Weisheit Salomos (entstanden während des 2. oder I. Jahrhunderts v. Chr.) brandmarkt: »Aber des Fluches wert ist das, so mit Händen geschnitzt wird, sowohl als der, der es schnitzt: dieser darum, daß er's macht; jenes darum, daß es >Gott< genannt wird, so es doch ein vergänglich Ding ist. Denn Gott ist beiden gleich feind, dem Gottlosen und seinem gottlosen Geschäfte; und das Werk wird samt dem Meister gestraft werden [...] Denn Götzen aufrichten ist der Hurerei Anfang; und sie erdenken ist des Lebens Verderben« (I4:8-I2).

Die gottungefällige Praxis erhielt sich auch im Christentum. Die Bevölkerung mochte nur ungern von der Möglichkeit lassen, die Mächte, die vermeintlich so unmittelbar Einfluß auf ihre Geschicke besaßen, gleichsam im Griff zu haben. An die Stelle zumindest der Schutzgeister und Ressortgottheiten traten nunmehr die Heiligen, ja die Gottesmutter 
und der Gekreuzigte selbst. Der Kirche konnte das eigentlich nicht recht sein; hatte sie doch mit größerer Entschiedenheit die Idolatrie der Heiden als den Polytheismus bekämpft. ${ }^{4 \mathrm{I}}$ Doch beugte man sich der Frömmigkeit »von unten« und fand eine elegante Erklärung dafür in der These, daß die bildlichen Darstellungen Christi und der Heiligen als die »vollkommensten Verkörperungen des Unsichtbaren im Bereich der sichtbaren Welt« zu betrachten seien. Die Künstler kamen der Lehre entgegen, indem sie die an sich gemeinte transmaterielle Bedeutung der physischen Formen durch geometrische Schematisierung stärker zur Geltung zu bringen versuchten.

Allein, es blieb der Dissens und der immer wieder auflebende Vorwurf, die Abbildnerei widerstreite dem Gottesgebot und komme gefährlich dem Götzendienst nahe. Der »Bilderstreit« spitzte sich während des 8. und 9. Jahrhunderts gleichermaßen in der West- wie der Ostkirche (Byzanz) zu. Er beschäftigte zahllose Synoden. Teils wurden die Bilder verbrannt und die Gotteshäuser von aller Sinnfälligkeit "gereinig««. Die Kirchenoberen hatten vor allem Probleme mit dem verbreiteten Glauben, daß die Dargestellten bluten und sprechen, Wunder wirken und leibhaftig aus den Bildern heraustreten, Notleidenden helfen und Kranke heilen könnten. Doch letztendlich zogen die »Bilderstürmer« den kürzeren. Nunmehr lautete die Rechtfertigung, daß die heiligen Personen im Bild nicht einfach porträtiert, sondern tatsächlich anwesend seien und insofern auch die segnende und heilende Wirkung der Bilder ihre Erklärung finde. Ihnen, dem »Urbild«, nicht dem Abbild, komme daher - und ganz zu Recht - Verehrung und Kultdienst $\mathrm{zu}^{{ }^{42}}$ Konsequenter im Sinne des mosaischen Gebots verhielten sich, abgesehen vom - sunnitischen Islam, allein die reformierten Kirchen im Protestantismus. ${ }^{43}$

Der Glaube, daß bestimmten Gegenständen, mehr noch Bildern und Figuren, wie den Menschen die Seele ein spirituelles Agens innewohnen kann, ist im übrigen auch anderen »Hochreligionen « eigen; er besaß eine annähernd universale Verbreitung. Ihm lag erkennbar das Bedürfnis zugrunde, eine Geistmacht mit übermenschlichen Fähigkeiten nahe zur Hand und vor allem unter Kontrolle zu haben, die man im Bedarfsfall unmittelbar ansprechen, um etwas bitten, selbst nötigen, ja unter Umständen sogar erpressen konnte. Denn traditioneller Vorstellung nach gehört einem, was man erdacht, kreiert und eigenhändig geschaffen hat. Wer also ein Idol hergestellt und einen Geist darin eingeschlossen hatte, besa $\beta$ es, war sein »Herr « und vermochte sich seiner nach Gutdünken zu bedienen. Erledigte der Geist, was man ihn hieß, zur Zufriedenheit seines Besitzers, empfing er seinen gebührenden Lohn: Man speiste und beschenkte ihn entsprechend - Heilige mit Votivgaben, Geldspenden und frommen Stiftungen. Besonders Entgegenkommende und Erfolgreiche stiegen gewissermaßen im Wert. Rivalisierende Gruppen suchten sie etwa, wie Herodot (ca. 490-430 v. Chr.) von den Ägineten und Epidauriern im alten Griechenland ${ }^{44}$, der angloindische Ethnologe Verrier Elwin 
(I902-I964) von Hindus und Saora in Orissa (Indien) berichtet ${ }^{45}$, einander gewaltsam zu entwenden, oder man verpachtete, ja versteigerte sie auf öffentlichen Auktionen, wie die geschäftstüchtigen Römer taten; das bedeutete keinerlei Risiko und brachte zudem noch etwas ein. ${ }^{46}$

Auf der anderen Seite schloß das jedoch ebenso ein, daß jemand, dessen Idol seine Erwartungen bitter enttäuschte, sich - wie Ahnen und Götter unbotmäßigen Menschen gegenüber - legitimiert sah, den leistungsunwilligen Geist zur Rechenschaft $\mathrm{zu}$ ziehen und nötigenfalls Hand an ihn zu legen. Die Nanaj (Golden) am unteren Amur beschimpften und züchtigten ihre Idole, wenn sich eine Krankheit nicht bessern oder sonst ein erwünschter Erfolg nicht einstellen wollte; manche warfen sie auch einfach fort. ${ }^{47}$ Bengalische Bauern strafen ihre dörflichen Schutzgottheiten, wenn trotz aller Bitten und Opfer kein Regen fällt, indem sie ihr steinernes Abbild aus der schattenspendenden Hütte, in der es sonst seinen Platz hat, herauszerren und für eine Zeitlang der glühenden Sonne aussetzen, um ihnen die Konsequenzen ihrer Untätigkeit am eigenen »Leib« fühlbar $\mathrm{zu}$ machen. ${ }^{48}$ Entsprechende Beobachtungen machte der große Forschungsreisende Peter Simon Pallas (I74I-I8II) auch bei den Chanten (Ostjaken) in Westsibirien. Ihm erschien schier unglaublich, was er sah: »Kaum aber sollte man sich es vorstellen, daß ein Volk die Blindheit so weit treiben könne, die Hausgötzen, welche es sonst über alles verehrt, alsdenn, wenn es ihm unglücklich geht, und die Götzen nicht helfen wollen, von ihrer Stelle herunter zu werfen, zu zerhakken, und mit Schlägen oder sonst auf alle Art zu mißhandeln. «49 Des Gelehrten Verwunderung wäre gedämpfter ausgefallen, hätte er sich nur ein wenig mehr in der Kulturgeschichte seiner eigenen europäischen Heimat ausgekannt. Noch die staatstragenden Römer peitschten Statuen, die ihren Unwillen erregten, gnadenlos aus ${ }^{50}$ oder schleuderten ihre »Hausgötzen « beim Tod eines Kaisers erzürnt auf die Straße, weil sie das Schreckliche offensichtlich nicht hatten verhindern helfen können. ${ }^{\text {I }}$

Auch im Christentum blieb es nicht bei der Anbetung und Verehrung der Heiligen; man erwartete, daß sie sich ihrerseits erkenntlich zeigten. Führten Dürren oder Hagelschlag zu erheblichen Ernteeinbußen, rissen die Bauern im europäischen Mittelalter die Statuen der Heiligen, die man für das Wetter zuständig glaubte, ja selbst die Gottesmutter, bedenkenlos von ihren Sockeln, schleuderten sie auf den Boden, traten sie unter Flüchen, peitschten sie aus und beschmierten sie mit Kot. Aus dem Schweizer Kanton Wallis berichtet eine Überlieferung noch aus der jüngeren Zeit von einem Bauern, der vor einem Steinbild der Muttergottes niederkniete und sie um etwas bat. Als die Heilige indes seiner Bitte nicht umgehend entsprach, »wurde er unwillig und bewarf das Bild mit Kot. Das Bild fing an zu weinen. Er bewarf es noch einmal. Da hob es sich hoch hinauf in die Felsenwand, so daß kein Mensch mehr dahingelangen konnte.$^{52}$ Die Kirche mußte diese Art formlosen Umgangs mit ihren Heiligen mißbilligen. Das 2. Konzil von Lyon (I274) verurteilte - und 
bestätigte damit zugleich - den »verabscheuungswürdigen Mißbrauch, gemalte oder geschnitzte Bilder des Kreuzes [!], der seligen Jungfrau oder anderer Heiliger « derart schimpflich zu behandeln; als besondere Variante findet die Folter der Statuen mit Disteln und Dornen Erwähnung. ${ }^{53}$

Doch das fruchtete alles nicht viel; die Praxis war für den »naiven« Gläubigen unentbehrlich. In Sizilien kam es noch I893 zu einem Aufstand wider die Heiligen der Kirche insgesamt. Seit Monaten war kein Regen gefallen. St. Franziskus von Paola, verantwortlich für das jährliche »Regenwunder«, zeigte sich allen Bitten gegenüber taub. Man hielt Messen und Andachten, gab Konzerte und brannte Feuerwerke ab - doch es geschah absolut nichts. Da verloren die Bauern die Geduld. Aufgebracht übergaben sie zahlreiche Heiligenbilder den Flammen. In Palermo schleuderte man den heiligen Joseph in der gleichen Absicht wie die erwähnten bengalischen Bauern in einen verdorrten, sonnendurchglühten Garten. Man schwor, ihn solange dort liegen zu lassen, bis er sich einsichtig zeige und Regen schicke. Andere Heilige wurden wie ungezogene Kinder mit dem Gesicht zur Wand gekehrt - man wies einander den Rücken. Manchen riß man die kostbare Bekleidung herunter und bedrohte und beschimpfte sie auf das Gröblichste. In Licata schlug die Menge den Schutzpatron St. Angelo in Ketten und stellte ihn fäusteschüttelnd vor die Alternative: »Regen oder den Strick! « ${ }^{54}$ Letzten Endes rührte die Wut der Bauern wohl auch aus ihrem Ohnmachtsbewußtsein her. Die Heiden konnten ihre Idole durch neue ersetzen; die Christen blieben auf Gedeih und Verderb auf ihre Heiligen angewiesen.

Der gewisse zwanglose, allzu menschliche Umgang mit den Ikonen war möglich, weil sie der Konstitution nach den Menschen glichen: Das spirituelle Agens band in beiden Fällen eine physische Hülle, die seiner Entfaltungskraft Grenzen setzte. Abbilder konnten zwar untätig bleiben und dadurch indirekt schädigend wirken; sie vermochten in der Regel jedoch nicht zu töten. Anders dagegen lagen die Dinge, wenn es zu Kontakten zwischen Menschen und »unverhüllten« Geistern kam, also ungleiche Verhältnisse herrschten und die grundlegend antithetische Natur beider Existenzen zu vernichtenden Konsequenzen führen konnte.

Begegnungen mit gutartigen, den Menschen wohlgesonnenen Mächten bedeuteten dabei nur eine geringe Bedrohung, weil man sie entweder willentlich anstrebte oder vorauszusehen, das heißt sich entsprechend darauf vorzubereiten vermochte - wie Jugendliche bei der Schutzgeistsuche oder Schamanen vor der Séance durch Fasten, Konzentration und andere physische Deaktivierungsmaßnahmen, die zu Dämmer- und Trancezuständen führten und der Kommunikation zwischen Seele und Geist gleichsam den Verbindungsweg ebneten. Beim Sterben stellten sich die Bedingungen ohne eigenes Zutun durch den natürlichen Verfall des Körpers ein, so daß die Seele sich mühelos lösen, ihre verstorbenen Verwandten, die sie abholen kamen, sehen und gemeinsam mit ihnen, ohne Schaden zu nehmen, »heimgehen« konnte. $\mathrm{Zu}$ den großen Wendezeiten, 
wie während des Erntefestes und an Neujahr, wußte man die Toten immer zu Gast; seit alters standen daher Riten und Brauchtumsformen bereit (Wettspiele, Kleider- und Rollentausch, rituelle Anarchie und andere Inszenierungen inversen Verhaltens), die möglichen Risiken der Begegnung zu entschärfen, so daß weder die Lebenden noch die Verstorbenen zu Schaden kamen; denn der antithetische Seinszustand, der sie schied, war für beide gefährlich. ${ }^{55}$

Da Menschen und Geister, abgesehen von den genannten Grenzbedingungen, ihrer inversen Beschaffenheit wegen einander an sich nicht wahrzunehmen vermochten ${ }^{5}$, war allezeit möglich, daß sie unvorhergesehen aneinander gerieten - etwa, wenn ein Mensch im Wald mit dem Fuß auf einen schlafenden Geist trat. In derartigen Fällen löschten sie, wie schon früher erwähnt, entweder einander oder der Geist den Menschen aus. Auch die Erscheinung eines Verstorbenen würde, sollte man sie zu berühren versuchen, augenblicklich verschwinden ${ }^{57}$ : Lebende und Tote wie Menschen und Geister stellen inkompatible Seinsformen dar: Sie verhalten sich extrem unverträglich zueinander.

Nicht ganz so riskant waren sichtbare Begegnungen, bei denen beide eine gewisse Distanz voneinander schied. Doch löste selbst die Erscheinung eines harmlosen oder gutartigen Geistes zunächst Erschrecken und Verängstigung aus. ${ }^{5}$ Handelte es sich aber um eine Gottheit, vermochte der Mensch der Übermacht des »ganz anderen« nicht mehr zu widerstehen und bezahlte die Begegnung mit dem Tod - wie Jahwe einst Moses warnte, der ihn zu schauen begehrte: »Mein Angesicht kannst du nicht sehen; denn kein Mensch wird leben, der mich sieht« (2. Mose 33:20). Um so verheerender mußten die Folgen sein, wenn jemandem unversehens widerfuhr, einem bösartigen Geist von Angesicht zu Angesicht zu begegnen. Schon das Ungewöhnliche, Verzerrte, grob Widerwärtige seiner Erscheinung trafen den Unglücklichen bis ins Mark. Starb er nicht vor Schreck auf der Stelle, so erlitt er auf jeden Fall einen harten Schock, der ihn häufig für eine gewisse Zeit oder auch sein Leben lang lähmte, der Sprache beraubte, krankmachte oder in den Wahnsinn trieb. ${ }^{59}$ Im Sensler Oberland bei Fribourg in der Schweiz kehrte einst ein junger Mann beschwingt vom nächtlichen Kiltgang zurück. Als er ein Waldstück betrat, in dem damals ein Spukgeist umging, »erblickte er plötzlich die schwarze Gestalt des Unholdes. Und ehe er's gewahr wurde, packte ihn das Gespenst am Rücken. Schreckerfüllt wollte er die Flucht ergreifen, aber die Beine versagten ihm den Dienst. Er konnte keinen Schritt weiter setzen. Er wollte um Hilfe rufen, aber er brachte keinen Laut heraus. Zitternd und schlotternd vor Grausen mußte er auf demselben Platz stehen bleiben bis zum Morgengrauen.« Erst als das Angelus-Läuten einer benachbarten Kirche erklang, löste sich seine Erstarrung und er gewann die Gewalt über seinen Körper zurück. ${ }^{60}$

Heute hört man kaum mehr von derartigen Begegnungen, es sei denn aus dritter Hand und von entlegenen Gegenden, wo der »Aber- 
glaube« noch blüht. Die moderne, dem Anspruch nach streng empiriebestimmte, das heißt korrekter an einem einseitig materialistischen Erfahrungsverständnis orientierte Weltanschauung ließ keinen Raum mehr für Geister. Die Aufklärung hat sie buchstäblich ausgelöscht.

Doch neu ist das eigentlich nicht. Lebende und Ahnen (Totengeister) waren immer zwingend aufeinander angewiesen; beide verband ein komplementäres Verhältnis: Ohne die Fürsorge der Verstorbenen konnten die Lebenden nicht bestehen; ohne stetes Gedenken und Ahnenkult wäre es aus mit den Toten gewesen. Gängiger traditioneller Anschauung nach schwinden die Ahnen unter der Erde daher förmlich dahin, wenn niemand mehr ihrer gedenkt, Gebete und Opfer eingestellt werden und ihr Kult erlischt. ${ }^{6 \mathrm{r}}$ Mit den Geistern verhält es sich ähnlich: Je größer die Aufmerksamkeit, die man ihnen schenkt, so zum Beispiel die Auffassung der Kalabari im Süden Nigerias, desto mehr leben sie auf und gewinnen an Macht; begegnet man ihnen mit Gleichgültigkeit, zehrt sie das gleichsam aus, so daß sie zuletzt wie ausgestorben scheinen. ${ }^{62}$ Niels Braroe fragte einen betagten Cree in Kanada, ob es noch heute Geister gebe und sie unmittelbar in das Leben der Menschen eingriffen, wie das nach den Erzählungen der Alten früher gang und gäbe war. »Nein«, lautete die Antwort, »diese Dinge geschehen so gut wie nicht mehr, seit die Weißen kamen und wir ihnen unser Land überließen. « ${ }^{63}$ Auch die Zwerge im Sensler Oberland, die vormals den Almhirten so hilfreich zur Hand gingen, haben sich schließlich, weil ihnen niemand mehr weder Dank wußte noch sie überhaupt beachtete, tief unter die Erde zurückgezogen »und zeigen sich den Menschen nicht mehr « ${ }^{64}$

Den Geistern ist in der Neuzeit zum Verhängnis geworden, daß sie sich weder regelmäßig beobachten, noch messen oder wiegen lassen. Der "Zauberstab der Wissenschaft hat sie von Heim und Herd verbannt, von der verfallenen Klosterzelle und vom efeuumrankten Turm, von dem schaurigen Hain und dem einsamen Weiher ${ }^{6}{ }^{6}$ Kinder, die noch geneigt sind, an Geister zu glauben, klärt man beizeiten auf, daß es sich nur um Phantasiegebilde der Märchenwelt handelt. ${ }^{66}$ Doch ist das nicht eben aufrichtig. Viele, die so reden - Christen wie Muslime - sind nicht allein überzeugt, eine Seele zu besitzen, sondern glauben durchaus auch an Engel, ob gottnahe oder gefallene, ja selbst an »Dämonen«, die Geistliche denen, die sie »befallen« haben, nach dem Beispiel Jesu austreiben können. Offensichtlich sind dem »Zauberstab« der Wissenschaft Grenzen gesetzt. Der bekannte Soziologe Peter Berger gibt zu bedenken: »Unsere Vorfahren wußten nichts von der Teilchenphysik, sprachen aber mit Engeln. Nehmen wir an, daß wir durch unsere Kenntnis der Kernphysik tatsächlich eine neue Dimension von Wahrheit hinzugewonnen haben. Könnte es nicht sein, daß uns auch eine Wahrheit verlorenging, als unser Gespräch mit Engeln sein Ende fand? Können wir so sicher wissen, daß die Wahrheiten der modernen Physik notwendig die Unwirklichkeit von Engeln implizieren? Ich weiß es nicht nur nicht, sondern neige stark 
dazu, das Gegenteil für richtig zu halten. $\ll^{67}$ Vielleicht sollte man sagen, daß es sich weniger um ein Verdrängungsverhältnis als einen Perspektivenwechsel handelt, der zwar Neues ins Licht rückt, dafür aber Altes nicht aufhebt, sondern lediglich abschattet. Die Mittel der Naturwissenschaft sind de facto untauglich, Aussagen über die Existenz oder Nichtexistenz von - möglicherweise real existierenden - spirituellen Wesenheiten zu machen.

Insofern lebt, teils eingestandener-, häufiger uneingestandenermaßen, die Bereitschaft, an Geister zu glauben, fort, wie Umfragen das immer wieder in einem überraschend hohen Maß bestätigen. ${ }^{68}$ Die Überzeugungskraft des Rationalismus wird gemeinhin über-, genauer: fehleingeschätzt. Er taugt für »normale«, regelgeleitete, gewissermaßen berechenbare Situationen, aus denen er ja auch abgeleitet wurde. Greifen jedoch Unübersichtlichkeit, Desorientierung und Verwirrung um sich, sei es persönlich im Todesfall eines geliebten Kindes oder kulturell, wenn das Überleben an eine Fülle von Voraussetzungen geknüpft ist, die der einzelne, selbst Gruppen nicht, weder praktisch noch intellektuell kaum mehr zu erfüllen imstande sind, schießen alle möglichen Formen des Irrationalismus ins Kraut, wachsen, um es in Abwandlung eines bekannten Hölderlin-Wortes zu sagen, wo Gefahr droht, der vermeintlich rettende Aberglaube, Okkultismus und Spiritismus auch. Ja beide Bedingungen scheinen in einem komplementären Wechselverhältnis zu stehen. ${ }^{69}$ Die »Vernunftgläubigen«, die das verwundert, sehen sich dann um so mehr genötigt, nach einer plausiblen »Erklärung« dafür zu suchen. Man erwägt beispielsweise, daß sich besonders bei Menschen, zu denen Rationalismus und Bildung noch nicht so recht durchgedrungen scheinen, der uralte, auf naiv anthropomorpher Projektion beruhende Trugschluß erhalten haben könnte, wie man ihn ja auch bei Kindern kennt, daß alle möglichen unvorhergesehenen Ereignisse (wie »Zufälle« z.B.) auf Machenschaften menschenähnlicher, aber eben unsichtbarer, das heißt spiritueller Wesenheiten zurückzuführen seien. ${ }^{70}$ Die Vertreter der »Naturmythologie« des ausgehenden I9. und beginnenden 20. Jahrhunderts sahen die Ursache zu derartigen anthropomorphen Fehlkonzeptionen zur Hauptsache in bestimmten Naturerscheinungen wie Nebel (Erlkönig!), Windhosen, Böen, Wolken, Stromschnellen, steigenden und fallenden Wasserspiegeln, Lichterscheinungen, Sternschnuppen ${ }^{7 \mathrm{I}}$ und ungewöhnlichen Klangphänomenen, wie sie in der Wüste zum Beispiel sogenannte »dröhnende Dünen« auslösen, deren Geräuschbildung an Summen, Glockenläuten, Trompetenstöße, Trommelschlag, Dudelsackklänge und anderes erinnern soll und von den Beduinen denn auch Geistmächten zugeschrieben wird. ${ }^{72}$ Mir selbst wurde in Gilgit (Nordpakistan) ein Abendwind, der regelmäßig um dieselbe Zeit talabwärts durch einige Höhlungen in den Felswänden streicht und eine Art klagendes Wimmern hervorruft, als Geistergesang erklärt.

Besonders kompetent für eine Erklärung des Geisterglaubens fühlen 
sich schon von Berufs wegen vor allem Psychotherapeuten und Psychologen, da sie ja immer wieder bei ihren Patienten damit zu tun haben. ${ }^{73}$ Man sieht es so, daß es beim »Kranken« aufgrund psychischer Dissoziationsprozesse zur Ausbildung selbständiger, scheinbar ichfremder Subsysteme des Bewußtseins kommen kann, die dann personifiziert und als getrennte »Intelligenzen«, beziehungsweise Geistwesen begriffen werden. ${ }^{74} \mathrm{Zu}$ derartigen Entwicklungen können an sich bereits Streßbedingungen führen. Isoliert man Versuchspersonen und entzieht sie jeglichem Informationszufluß von außen, tritt wahrhaft »tödliche« Langeweile ein. Das Bewußtsein greift, um dem sichtlich unerträglichen Zustand zu entgehen, zunächst auf Gedächtnisinhalte zurück, entwickelt Gedanken und Vorstellungen - »doch bei längerem totalem Reizentzug treten (Tag-) Träume und schließlich Trugwahrnehmungen auf «.75 Derartige Befunde sind ethnologisch nicht uninteressant, da sie begründen könnten, warum sich Menschen, die auf Visionen und Offenbarungen aus sind oder auf Schutzgeistsuche gehen, bevorzugt absondern und in Seklusion begeben. Offenbar liegt hier lange Erfahrung zugrunde; den Geisterglauben allerdings erklärt das nicht.

Nach wie vor die überzeugendste Theorie lieferte bereits vor über hundert Jahren der englische Ethnologe Edward Burnett Tylor (I832-I9I7). Ihm zufolge liegt dem Geister- der Seelenglaube, das heißt die Konzeption einer leibunabhängigen »Freiseele«, zugrunde. Diese selbst dachte er sich aus zwei Erfahrungstatsachen entstanden: zum einen aus Träumen und Visionen (anderer), die den Eindruck vermittelen mußten, als besitze der Mensch ein »Etwas«, das sich unabhängig von seinem Körper und über beliebige Distanzen hinweg zu bewegen vermag, sowie zum zweiten Beobachtungen an Ohnmächtigen und Scheintoten, in die nach einer gewissen Zeit das »Leben« gleichsam wieder »zurückzukehren« scheint. Und da man im Traum auch Verstorbene sah, mußte dieses »Etwas«, die Seele, den Tod überdauern, das heißt unsterblich sein. In der Folge führte das konsequentermaßen zur Vorstellung einer jenseitigen Welt. Wie beim Menschen setzte man dann auch bei anderen Lebewesen und beweglichen Naturphänomenen eine Seele und schließlich objekt- und lokal ungebundene spirituelle Wesen im Diesseits, mehr aber noch im Jenseits voraus - Geister und Götter. ${ }^{76}$

Der Geisterglaube ist seit nunmehr Jahrzehntausenden und in den meisten Teilen der Welt so allgemein verbreitet und wird zudem in der weit überwiegenden Mehrheit der Fälle von »Gesunden« geteilt, die ein sozial absolut unauffälliges, ja glückliches und erfolgreiches Leben führen, daß es höchst unplausibel, wenn nicht absurd erschiene, ihn auf Epilepsie, Schizophrenie, Paranoia oder andere mentale Störungszustände zurückführen zu wollen..$^{77}$ Offensichtlich erfüllte er vitale Funktionen, bot Lösungen für Probleme an, die man sich anders nicht zu erklären vermochte, sicherte die Beziehungen zu den Toten und trug wesentlich 
zur Sinnhaftigkeit des Lebens, in dem ja auch das Unerquickliche, Unglück und Bösartigkeit ihren Platz haben, bei.

Die Frage, ob es Geister realiter gibt, stellt sich der Wissenschaft nicht - und läßt sich gleichwohl in gewissem Sinne bejahen: Sie existieren zweifelsfrei in den Köpfen der Menschen, die an sie glauben ${ }^{78}$, und bestimmen insofern deren Denken und Verhalten entscheidend mit; ohne sie bliebe es, nicht zuletzt der Wissenschaft, unverständlich. Wenn man so will, entsprechen Geister imaginären Zahlen: Es »gibt« sie zwar eigentlich nicht, aber es läßt sich vortrefflich mit ihnen rechnen. Wer weiß, vielleicht stellen Geister aber auch Ergebnisse der Verschränkung von nichtmaterieller und materieller, lokaler und nichtlokaler Welt dar, die zu »Ereignissen« führen, die der Mensch mit Hilfe der ihm eigenen nächststehenden, spontan sich einstellenden anthropomorphen Vorstellungsbildung deutet. 


\section{Telepathie}

\section{Von der Einigkeit, die empfindsam und stark macht*}

Im Zuge der kulturgeschichtlichen Entwicklung veränderte sich nicht nur die Umwelt des Menschen in drastischer Weise; auch Interessenorientierung, Wahrnehmung und Denken, Mentalität und Empfinden durchliefen mit dem Wechsel der kulturellen Milieus einen erheblichen Wandel. Schalter, Druckknopfbatterien, Armaturen und Displays haben die Sinne des modernen Menschen in spezifischer Weise geschärft, ja regelrecht zugespitzt. Das Leben vollzieht sich in Rhythmen, deren Takt sich nach den Schlägen von Uhren bemißt.

Das hatte, wie jeder Zugewinn, seinen Preis. Andere Empfindsamkeiten und Sinne stumpften mangels Inanspruchnahme ab. Sie wurden von den immer vielschichtiger einander überlagernden Schallpegeln mechanisierter Informationssignale mehr und mehr unterdrückt. Es blieb gewissermaßen ein Restrauschen, das konsequentermaßen für die Wahrnehmung, wie sie heute im Kurs steht, als »verunreinigend «, ja störend empfunden wird. Doch vordem spielten ebendiese ursprünglicheren Sensibilitäten und Sensorien im Leben der Menschen eine wichtige Rolle, da sie Impulse oder »Signale« zu registrieren vermochten, denen man damals große Bedeutsamkeit beimaß, als die Kommunikation zwischen Menschen, Tieren, Pflanzen und Geistwesen nur erst ansatzweise an »Apparate« delegiert war und der Informationsaustausch zwar vielleicht diffuser, aber unmittelbarer floß. Heute nimmt man dergleichen gerade noch im Umgang mit Haustieren oder Zimmerpflanzen wahr, bei Menschen gelegentlich in spezifischen, kritischen Lebenssituationen, wenn der »Panzer« gewissermaßen aufbricht und das »Hintergrundrauschen« deutlicher vernehmbar wird. Doch läßt die heutige Naturauffassung Telepathie nicht mehr zu. Man kann sie gegebenenfalls spüren, aber nicht

* Das folgende Kapitel stellt die überarbeitete Fassung eines Artikels dar, der unter dem Titel »Sympathie« bereits in der Zeitschrift für Parapsychologie und Grenzgebiete der Psychologie 37, 3-4 (I995): I3I-I44, erschienen ist. 
messen - etwa am Ausschlag eines »Zeigers«. Der Materialismus hat die Natur ihrer Seele beraubt. Der Mensch ist »vermessen« geworden.

»Ein paar Sekunden später ging er am Ufer entlang« - Cornelius, ein Verdächtiger, dem Maigret in Georges Simenons Roman Maigret und das Verbrechen in Holland (I93I) im Abstand von kaum hundert Metern folgt. Beide »gingen sie gleich nach den ersten Schritten im Takt, und das Knirschen des Schotters war eins. Maigret wurde sich dessen bewußt, als er einmal stolperte und für den Bruchteil einer Sekunde der Gleichklang ihrer Schritte unterbrochen wurde «. ${ }^{\mathrm{I}}$ Ebendort, in den Niederlanden, mußte rund 260 Jahre zuvor, im Februar I665, der Mathematiker und Physiker Christiaan Huygens (I629-I695) einer leichten Erkrankung wegen das Haus hüten. Müßig ruhte sein Auge auf zwei nebeneinander hängenden Exemplaren der von ihm entwickelten Pendeluhr. Und plötzlich belebte sich seine Aufmerksamkeit. Er bemerkte, daß sich beider Pendel absolut synchron bewegten. Huygens beobachtete die Uhren über Stunden hin, doch sie blieben im Takt. Daraufhin unterbrach er ihren Rhythmus - und gewahrte verblüfft, daß sie schon eine halbe Stunde später wieder gleichschwangen. Erst als er die Uhren getrennt an gegenüberliegenden Wänden aufgehängt hatte, gerieten die Pendel aus dem Gleichtakt. $^{2}$

Tatsächlich handelt es sich um ein offensichtlich fundamentales $\mathrm{Na}$ turprinzip. Benachbarte Elementarmagnete zeigen - bei normalen, »endlichen « Temperaturen - die Tendenz, in dieselbe Richtung, entweder nach »oben« oder »unten«, zu weisen; sie sind, wie man sagt, korreliert; mit zunehmender Entfernung schwächt sich der Effekt ab. ${ }^{3}$ Analoge Rhythmisierungsfunktionen besitzen etwa auch die Schrittmacherzellen des Herzens und die neuronalen Netzwerke oder »Oszillatoren« des Gehirns und Rückenmarks, die organische Verhaltensabläufe wie die Atmung, das Kauen und Schlucken oder Laufen steuern. ${ }^{4}$ Spirochätenbakterien beginnen in phasengleiche undulierende Bewegungen überzugehen, sobald sie zu mehreren an einer Nahrungsquelle zusammenkommen. ${ }^{5}$ Grillen zirpen bevorzugt unisono. Andere folgen dem Grundsatz: »vereint sind auch die Schwachen mächtig«, mit optischen Mitteln. An Flußmündungen Thailands, Malaysias und Neuguineas versammeln sich nachts auf den Bäumen oft Tausende männlicher Glühwürmchen, um blinkend um Weibchen zu werben. Die ersten treffen bei Eintritt der Dämmerung ein. Ihr Leuchten mutet noch matt an und ist vor allem noch unkoordiniert; es bleibt ohne ersichtlichen Erfolg. Dann jedoch bilden sich langsam Felder taktgleichen Blinkens heraus, die schließlich zusammenwachsen $\mathrm{zu}$ einem einzigen Funkchor synchron pulsierenden Sehnsuchtleuchtens. ${ }^{6}$ Weniger glutvoll, dafür gleichsam im Gleichschritt, geht es auf deutschen Waldböden zu. Dort führen Schleimpilzzellen, amöboide Mikroorganismen, ein wahrhaft unscheinbares Dasein als ungebundene Solitäre - doch nur, solange ihr Freßvorrat reicht. Geht er zur Neige, beginnen die Zellen, über den Austausch chemischer Signale, »die sich wie Wellen auf einem 
Teich ausbreiten«, gewissermaßen zum Sammeln zu blasen. Sie rücken zusammen und verwachsen schließlich zu einem einzigen vielzelligen Organismus, der sich alsbald schleichend in Marschbewegung versetzt. Ist ein strategisch günstiger Standort erreicht, zieht sich der schleimige »Truppenkörper « zusammen, reckt sich auf und bildet einen langen Stiel aus, der einen Kopf trägt, an dem Sporen heranreifen, die sich zuletzt nach einem quasi explosionsartigen Ausbruch niederregnend über den Waldboden verteilen, worauf der Prozeß aufs neue beginnt. ${ }^{7}$ Auf ähnliche Weise scheint die Kommunikation auch bei Insektensozietäten zu funktionieren, hier allerdings bereits nach Maßgabe eines dauergültigen Musters, das alles Verhalten der Einzeltiere über ihre gesamte Lebenszeit hin aufeinander abstimmt und bindend zu einer Art Superorganismus koordiniert, der ein entsprechend höheres, das heißt komplexer organisiertes Leistungsvermögen besitzt und vor allem dank seiner gesammelten »kollektiven Intelligenz« in der Lage ist, die »wahrhaft gigantischen ökonomischen Allokationsprobleme« solcher Systemsozietäten zu lösen. ${ }^{8}$

Menschliche Gesellschaften sind weit über das alles hinausgewachsen. Namentlich seit der Neuzeit setzten sie kritischer Zweifel, Vernunft und die geschliffenen Instrumentarien der Wissenschaft in den Stand, die Natur zu bemeistern. Zwar sitzt uns das alte Erbgut gewissermaßen noch tief in den Knochen - die neuronalen Oszillatoren oder »zentralen Mustergeneratoren «, die verantwortlich für die Steuerung der organischen Motorik sind, finden sich tief im entwicklungsgeschichtlich ältesten Teil des Gehirns, ganz unten im verlängerten Rückenmark, lokalisiert ${ }^{9}$; doch »wissen « wir, daß sie rein mechanisch wirken, das heißt sich, jeweils systemimmanent, sezieren und messen lassen. Allerdings schießt der tiefsitzende Mechanismus gelegentlich über seine biologischen Systemgrenzen hinaus und entzieht sich dann prompt exakter Bestimmung. Wenn Menschen sich in größeren Mengen versammeln und dicht beieinander stehen, entsteht da plötzlich, auf einen Ruf oder ein Geschehnis hin, gleich einer Woge sich fortpflanzend, ein einig Empfinden, recken sich Hände hoch und werden Fäuste rhythmisch gestoßen, skandieren, nach kurzem tastend-unkoordiniertem Suchen, Hunderte von Mündern eine Parole, die teils noch rhythmisches Klatschen begleitet ${ }^{\mathrm{IO}}$ : Alle Beteiligten sind »ein Herz und eine Seele«, wie die Schleimpilzzellen im Wald, die sich suchen, um gemeinsam zu wachsen. Oft auch fügt sich zusammen, was der Mensch lieber scheidet, weil er es nicht mit andern zu teilen wünscht. Untersuchungen ergaben zum Beispiel, daß die Regelzyklen von Frauen, die in Krankenhäusern, Studentenwohnheimen oder Gefängnissen in enger Vergemeinschaftung leben, zur Synchronisierung tendieren. ${ }^{\text {II }}$ Auch hier meldet sich altes Erbe zu Wort. Löwenweibchen werden an sich in unregelmäßigen Abständen von drei Wochen bis zu mehreren Monaten brünstig; leben sie jedoch längerfristig im selben Rudel zusammen, korreliert sich ihre Brunftzeit. ${ }^{\text {I2 }}$

Unsere wilden Altvorderen standen den Tieren bekanntlich noch 
näher. Sie hatten ein intimes Gespür für das Rauschen in der Natur und nahmen es nicht nur, unverderbt und naiv, wie sie waren, vollbewußt auf, sondern wußten seine Schwingungen auch für ihre Zwecke zu nutzen. Von der Erfahrung getragen, daß Einigkeit stark macht, pflegten die Ältesten strikt auf Traditionstreue zu dringen. Die sozialen Interaktionen standen in einem weithin ausgewogenen Resonanzverhältnis, dessen eherne Basis das Reziprozitätsgebot bildet. Alle hatten einander möglichst gleichzutun. Das schuf ein Höchstmaß an Gleichsinnigkeit, Solidarität und Kohärenz. Störungen fielen sofort ins Auge der allwachen Öffentlichkeit, die zugriff und $\mathrm{zu}$ neutralisieren, Streitereien $\mathrm{zu}$ schlichten, schwere Vergehen durch gemeinsame Bußübungen gleichsam »rückgängig $\mathrm{zu}$ machen« suchte. Andernfalls glaubte man die Kooperationsfähigkeit und Prosperität der Gruppe gefährdet.

Schon ungute Empfindungen waren gefürchtet. Namentlich Neid galt als eine Art Urkraft allen Übels. Er konnte den, gegen den er sich richtete, in jeder nur erdenklichen Weise schädigen, krankmachen, ja töten. ${ }^{\mathrm{I}}$ Eine Mutter, die ihrer Tochter grollte, weil sie das Haus verlassen hatte, mußte befürchten, sie um ihre Fruchtbarkeit zu bringen. ${ }^{\text {I4 }}$ Dachte man an den Tod eines andern, starb er, wie man auf Tahiti glaubte, über kurz oder lang. ${ }^{\text {I5 }}$ Beleidigungen eines einzelnen griffen gewissermaßen auch auf seine Familie, ja unter Umständen die gesamte Verwandtschaft über ${ }^{16}$, wie umgekehrt unehrenhaftes Verhalten und vor allem schwerwiegende Verfehlungen eines Familien- oder Gruppenmitglieds alle in »Mitleidenschaft « zogen. ${ }^{\mathrm{I}}$ Das Leid, das daraus erwuchs, übertrug sich auf die Gesamtgesellschaft: »If one member of the clan suffered , war man bei den Zulu in Südostafrika überzeugt, »all the members suffered, not in sentimental phraseology, but in real fact. ${ }^{\mathrm{I} 8}$ Böse Worte, Unehrlichkeit, Streitereien, die Vernachlässigung religiöser Pflichten, ein Tabubruch oder gar blutige Handgreiflichkeiten gefährdeten nicht nur den Jagderfolg ${ }^{\text {I9 }}$, sondern wirkten sich immer noch unmittelbarer auf Kulturpflanzen und Haustiere aus, mit denen man täglich in engem Kontakt stand: Sie konnten zu Mißernten und Viehsterben führen. ${ }^{20}$ Inzest, gewöhnlich das gravierendste aller Vergehen, das die Familie sprengte und so gleichsam einer gesellschaftlichen »Kernexplosion« entsprach, konnte den Untergang aller bedeuten. ${ }^{2 \mathrm{I}}$ Allein absolute Traditionstreue, also konfliktfreie Einigkeit, verbürgte das Wohlergehen, den Erfolg und die Überlebensfähigkeit der Gruppe.

Daher beschwor man geradezu den Frieden und die Harmonie aller immer wieder aufs neue, ganz besonders in der Familie und unter Verwandten. $^{22}$ Das bestimmte selbst den Duktus der alltäglichen Konversation: »Es wird ein Diskurs gepflegt, der aneinanderreiht und bestätigt, nicht aber zergliedert und kritisiert [...] Ganz selten wird im Dorf kontrovers diskutiert [...] Jeder tut so, als verleihe er nur der allgemeinen Norm Ausdruck [...] Das >Ich< des Individuums verschwindet hinter der Maske des generellen $>$ Man< [...] Wer anderer Meinung ist, schweigt [...] Die 
Gespräche vermitteln so den Eindruck eines weitgehenden Konsenses. « ${ }^{23}$ $\mathrm{Zu}$ gegebenem Anlaß versteift sich solche Rhetorik zu magischer Formelhaftigkeit. Die Ältesten der Iraqw in Tansania pflegten sich so zu Beginn ihrer Ratssitzungen unisono im Chor zu versichern: »Wir lieben einander«, »wir sind einer Meinung «, »wir sind eins«. ${ }^{24}$ Widerspruchsfreiheit zählt generell zu den Erhaltungsbedingungen von Systemen. ${ }^{25}$

Kommt etwas der Regelgeometrie in die Quere, droht gleich der Konsistenz des Ganzen Gefahr, springt unter Umständen eine Krise auf. Davon blieben auch alte Dorfgesellschaften, trotz allen Bemühens um Gleichklang, nicht verschont. Aber sie wußten, was tun. Prompt rückten ihre Mitglieder, wie die Schleimpilzzellen bei schwindendem Freßvorrat, noch enger zusammen, kam es zu verstärktem Schulterschluß.

Allerdings ist $\mathrm{zu}$ scheiden zwischen systeminhärenten, immer wiederkehrenden, und unerwarteten, exogen induzierten, das heißt traditionsinkonsistenten Verlaufsbrüchen. Zu ersteren zählten zum Beispiel Geburten, wenn eine Seele aus dem Totenreich sich erneut unter den Ihren inkarnierte, die Pubertät, wenn die Kinder gleichsam auf dem Sprung waren, ins Erwachsenendasein überzuwechseln, Hochzeiten, bei denen die Braut aus ihrem Verwandtschaftsverband in den ihres Zukünftigen integriert werden mußte, der Hiatus zwischen den Jahreszeiten oder gefahrträchtige Unternehmungen wie Jagd, Hochseefischfang, Handelsreisen und Krieg. Da man in diesen Fällen die Risiken kannte und abschätzen konnte, standen seit alters dafür erprobte und bewährte Verfahrensweisen parat. Bei Geburten synchronisierten die Eltern ihr Verhalten und verdichteten so die Frequenz seiner Schwingungen: Beide begaben sich, anfangs getrennt, in Seklusion; beide bewegten sich möglichst wenig, mieden ungute Gedanken, nahmen keinerlei scharfkantige oder spitze Geräte zur Hand und befolgten dieselben Enthaltsamkeitsvorschriften, aßen, wenn die Mutter aus der Geburtshütte ins Haus zurückgekehrt war, gemeinsam aus einer Schüssel - damit, wie die Jibaro in der Montaña von Ecuador zur Begründung anführten, »all three in one way form a single organism, a single personality «. ${ }^{26}$ Auch in den leiblichen Kontakt von Mutter und Neugeborenem wurde der Vater, wie in ländlichen Bereichen Europas noch bis vor kurzem, mit einbezogen, indem man den Säugling in ein Hemd, das er gerade getragen hatte, einwickelte ${ }^{27}$ oder mit Gebrauchsgegenständen von ihm in Berührung brachte. Mußte bei den Chewong im Innern von Malaya der Vater für einige Tage verreisen, trennte er ein Stück seiner Kleidung ab und wickelte es um den Hals des Säuglings. ${ }^{28}$ Die Dreieinigkeit von Eltern und Kind bildete so in dieser kritischen Übergangsphase einen einzigen, im Gleichtakt pulsierenden Überorganismus. Entsprechend beginnen Säuglinge auch zu weinen, wenn sie andere in ihrer unmittelbaren Umgebung weinen hören, und freuen sich sichtlich mit, wenn Heiterkeit aufkommt und Lachen ertönt. ${ }^{29}$ Stellt sich der erste Zahn ein, ist unter den Engstanverwandten oftmals üblich, das Ereignis scheinbar zu ignorieren; täte man seiner Erwähnung, 
das heißt würde man es »bereden«, liefe das Kind Gefahr, ein schlechtes Gebiß zu bekommen. ${ }^{30}$

Analog verfuhr man bei der Beschneidung auf dem Höhepunkt der Initiationszeremonien. Bei Aborigines im gebirgigen Nordwesten Australiens (Kimberley-Plateau) glaubte man den Erfolg der Operation nur gesichert, wenn den nächstangehörigen Frauen, die begleitend dazu einen bestimmten Tanz aufzuführen hatten, keinerlei Fehler unterlief. ${ }^{3 \mathrm{I}}$ Während der Rekonvaleszenzeit danach achtete man darauf, daß mögliche Unstimmigkeiten unter den beteiligten Verwandten geglättet und das Verhalten aller sozusagen auf gleichschwingende Perioden gebracht wurde. Bei den Kaguru in Tansania beobachtete Thomas O. Beidelman zum Beispiel, daß die Angehörigen sorgsam darauf bedacht waren, nichts zu tun, das die Initianden während der Erholungsphase nur irgend hätte gefährden können. Insbesondere mieden sie »Streit, Ehebruchsdelikte oder andere Formen von Fehlverhalten «.32

Vor allem Zwietracht mit ihrem dissoziierenden Sprengpotential war auch sonst in kritischen Situationen tabu. Flankierend konnte geboten sein, die Arbeit ruhen zu lassen, sich möglichst wenig zu bewegen und still zu verhalten, Enthaltsamkeit, namentlich bei der Nahrungsaufnahme, zu üben und insgesamt in nichts vom Herkommen abzuweichen. Das galt ganz besonders, wenn Teile der Gruppe fern vom Dorf einer riskanten Tätigkeit nachgingen, das heißt die Bande gewissermaßen stark »überdehnt« und auf die »Zerreißprobe« gestellt waren. Zum Gelingen des Unternehmens trug dann immer sehr wesentlich auch das Verhalten der Daheimgebliebenen bei: Erfolgreich konnte man nur gemeinsam sein, wenn die Bande hielten und gleichschwangen. Dafür wurde vielerlei unternommen; die Absicht aber blieb stets dieselbe. Bei den Lhota Naga pflegten die Frauen, deren Männer sich auf der Jagd befanden, nicht zu weben, damit die Gatten sich nicht in einer Schlingpflanze verfingen und einem Raubtier zum Opfer fielen. ${ }^{33}$ Das gleiche Tabu galt auch für die Ehefrauen der indigenen Bergbevölkerung Taiwans, wenn ihre Männer dem speziellen Weidwerk der Kopfjagd nachgingen. ${ }^{34}$ Besonders streng hatten sich die Frauen an das eheliche Treuegebot zu halten; brachen sie es, das heißt riß die Verbindung zwischen den Gatten, drohte den Männern ein tödlicher Unfall. Ein sambischer Bergmann kam so als einziger von Fünfen bei einem Steinschlag zu Tode, obwohl er einen Schutzhelm und eine Sicherheitskette trug; letztere wurde von einem Gesteinsbrocken glatt durchschlagen, so daß er in einen Schacht abstürzte. Seine Begleiter waren sich sicher, daß ihn zu ebender Zeit seine Frau über Tage betrogen hatte..$^{35}$

Um die Bande eigens zu straffen und beizutragen zum Erfolg ihrer Männer bei der Jagd auf hoher See, benutzten die Frauen der Iglulik-Eskimo die Urin-Schale des Gatten als Kopfunterlage beim Schlafen. ${ }^{36}$ Bei den Altaiern in Südsibirien durfte während der Jagd im Lager weder gespielt noch gelacht werden. ${ }^{37}$ Tschuktschinnen in Nordostsibirien spra- 
chen spezielle Monologe, die dem (magischen) Zweck dienten, den Jägern das Wild in die Arme zu treiben ${ }^{38}$; Giljaken am unteren Amur in Ostsibirien, die in der Siedlung zurückgeblieben waren, sangen bestimmte Lieder, um den Männern draußen - speziell bei der Bärenjagd - Mut zu verleihen. ${ }^{39}$

Genauso drohte der Gruppe und speziell den Frauen bei Kriegszügen und Handelsreisen die Gefahr, daß die Bindung eine gewaltsame Durchtrennung erfuhr. Frauen der Nor in Neuguinea, deren Männer sich auf dem Kriegspfad befanden, war untersagt, tagsüber zu schlafen, da dies, über den »Draht« der Beziehung, auch die Krieger müde gemacht und dem Risiko ausgesetzt hätte, von ihren Gegnern überrumpelt zu werden..$^{40}$ Jibaro-Frauen kamen, teils um den Schlaf zu meiden, teils um ihren Männern analogiemagisch beizustehen, Nacht für Nacht in einer Hütte zusammen, tanzten mit Rasseln und klappernden Schneckenhausketten und sangen Beschwörungsgesänge, die ihre Gatten und Söhne vor den feindlichen Waffen schützen und die Gegner regelrecht einlullen sollten, so daß sie der Gefahr nicht rechtzeitig gewahr wurden. ${ }^{4 \mathrm{I}}$ Oder man ließ, wie auf Formosa, auch nachts die Feuer hell lodern. ${ }^{42}$ Und wieder galt, wie in allen Trennungsfällen, das Treuegebot mehr denn je. ${ }^{43}$

Statt einer Lockerung der Beziehungen nur durch Meidungs- oder Korrespondenzverhalten entgegenzuwirken, konnte man auch aktiv etwas zu ihrer Festigung tun. Darum bemühten sich Frauen der Ao Naga in Assam, indem sie bei Mahlzeiten - dem zentralen Ausdrucksvollzug ehlicher und familiärer Bindung - so taten, als seien ihre Gatten zugegen. Sie sagten dann etwa laut und vernehmlich: »Der Reis ist heute ausgezeichnet. Nimm du zuerst, ich esse nach dir.« ${ }^{44}$ Vielfach wurden auch Tanz und Gesang schon vorbereitend zur stärkenden Verdichtung von Empfinden und Handlungsbereitschaft aufgewandt. Der deutsche Forschungsreisende Karl von den Steinen (1855-1929) gibt ein bezeichnendes Beispiel dafür. Er erlebte Ende des I9. Jahrhunderts mit, wie sich die Bororó im brasilianischen Bundesstaat Mato Grosso für einen bevorstehenden Überfall ihrer Feinde, der Kayapó, rüsteten: »Auch in der Nacht vom 2. auf den 3. April war alles wach. Unsere indianischen Freunde holten uns zum Ranchão [einer geräumigen Hütte] und luden uns ein, an einer Sitzung teilzunehmen, die den Zweck hatte, sich mit Musik in der Hoffnung auf einen Sieg über die bösen Kayapó zu stärken. Zu Anfang standen wir alle und tanzten auf der Stelle, während ein alter Häuptling in der Mitte sang und den Rasselkürbis wuchtig schüttelte. Wir andern hielten uns die Hände vor den Mund und brüllten ein dumpfes $u, u[\ldots]$ hinein und knickten taktmäßig in die Knie. Da wir merkten, wie sehr die Bororó dadurch getröstet wurden, ließen wir es an eifrigem Mittun nicht fehlen [...] Das Tanzen dauerte ein halbe Stunde [...] Nun waren wir aber auch alle mit frischem Mut erfüllt. ${ }^{45}$ Knapp 2000 Jahre zuvor erlebte Cornelius Tacitus (ca. 55-I20 n. Chr.), damals noch römischer Legionär am Rhein, ähnliche Ermutigungsmaßnahmen bei den Germanen. Sicht- 
lich beeindruckt, beschreibt er sie in der Germania (c. 3) wie folgt: »Es gibt bei ihnen auch noch Lieder, durch deren Wiedergabe, den sogenannten barditus, sie ihren Mut anfeuern und den Ausgang eines bevorstehenden Kampfes allein schon aus dem Klang deuten. Denn sie erregen Schrecken oder haben selber Angst [!], je nachdem der Gesang der Kämpferreihe war. Sie sehen hierin ja nicht lediglich Stimmen als vielmehr den Einklang ihres Mannesmuts. Sie haben es dabei vor allem auf ein rauhes Tönen und dumpfes Hervorstoßen abgesehen; darum halten sie ihre Schilde vor den Mund [vgl. oben die Bororó!], damit die Stimme durch den Widerhall voller und wuchtiger anschwillt.« Das »Hurrah!« späterer, quasi postgermanischer Krieger stellt da zwar eine ähnlich lautstarke Beschwörung einigen Mannesmuts, ethnographisch jedoch nur mehr eine weniger eindrucksvolle, schwache Abbreviatur des Vormaligen dar.

Vorgänge wie die beschriebenen kommen schon fast Kollektivritualen gleich, die im Grunde nur eine Formalisierung des Korrespondenzverhaltens bilden; denn auch deren Funktion ist es ja, in kritischen Situationen das Handeln der unmittelbar Betroffenen - oder ausgewählter Repräsentanten von ihnen - aus dem Alltagsgeschehen herauszulösen, in einen Zustand künstlicher Verstetigung zu versetzen und mittels strikter Synchronisation $\mathrm{zu}$ komprimieren, so daß alle gleichsam »wie an einem Strang ziehen« und das euphorisierende Hochgefühl übermächtigen Wirkvermögens teilen - wie bei Glühwürmchen, wenn sie die Liebessehnsucht treibt, und bei Schleimpilzzellen in Fällen würgenden Hungers.

Kontinuierlich indes verbürgt konsistente Solidarität allein die standhafte Treue zur Tradition, deren Frucht ein gefestigtes Identitätsbewußtsein ist, wie es typisch für die alten - »traditionellen« - Dorfgesellschaften war. Die setzten sich in der Regel aus Verbänden Abstammungsverwandter, das heißt aus Lineages oder Sippen (Klanen) zusammen, so daß Identität de facto besonders kennzeichnend für Verwandtschaft war. Das spiegelt sich oft auch in der Begrifflichkeit wider. In vielen Sprachen gehen die Bezeichnungen für »Verwandte « beziehungsweise »Verwandtschaft « teils auf Verbalstämme mit der Bedeutung »binden« zurück, teils bilden sie Synonyma für Begriffe wie »eigen«, »selbst«, »lieb« und »befreundet «. Gotisch frij, »lieben«, oder frijonds, »Freund«, hängt etymologisch mit freidjan, »schonen«, beziehungsweise althochdeutsch fridu, »Friede«, altschwedisch grith, norwegisch grid (gred), »Schonung«, »Sicherung des Lebens « und abermals »Friede « zusammen. Unter Blutsverwandten sind eben Streit und Feindschaft, dem ideologischen Soll nach zumindest, undenkbar. Gotisch unsibjis, »friedlos«, bedeutet wörtlich: »Der ohne Sippe ist ${ }^{46}$

Wer aber »versippt« blieb, war Teil eines Ganzen - auch in organischer Hinsicht. Die Leiber aller nämlich durchpulste, wenn auch in unterschiedlicher Verteilung, ein und dieselbe Vitalseele oder Lebenskraft. Es gab nicht eigentlich individualisierte einzelne; die von den Ahnen über- 
kommene eine seelische Energie, äußerten sich Informanten der Huli in Neuguinea Laurence Goldman gegenüber, »macht uns eins (makes us one) «. ${ }^{47}$ Der einzelne bildete, auch nach Auffassung der Jibaro in Ecuador, »einen untrennbaren Teil des Ganzen der Familie und Gruppe, zu der er gehörte«. Alle empfanden sich als »organically coherent with one another, so that one part stood for all and all for one $\kappa^{4} .^{8}$ Alle waren »members of one another«. ${ }^{49}$ Man verhielt sich, »als ob, was den Verwandten widerfährt, einem selbst geschähe«. Europäischen Beobachtern konnte sich so der Eindruck vermitteln, jeder sei gegen andere austauschbar. ${ }^{50}$ Befindet sich die Gruppenseele in »gutem « Zustand, »sind alle«, wie Oltscha am unteren Amur der russischen Ethnologin Anna Smoljak versicherten, "gesund, leben einmütig und wirtschaften erfolgreich «. Ja angeblich dachten dann auch alle einvernehmlich. Breiteten sich Krankheiten, Uneinigkeit und Mißerfolge aus, waren die Alten überzeugt, daß es hohe Zeit sei, das sichtlich geschwächte musu (die Gruppenseele) »wiederherzustellen«, was Aufgabe des Schamanen war. ${ }^{5 \mathrm{I}}$ Geschlossen siedelnd und verwandt, sprachen alle eine Sprache, bestritten ihren Unterhalt auf übereinstimmende Weise, benutzten dieselben Gerätschaften, verhielten sich weitgehend gleich, besaßen eine gemeinsame Weltanschauung - kurz: Die biologische setzte sich fort in der kulturellen Verwandtschaft; es herrschte Identität.

Das glich die Menschen untereinander an, rundete sie gewissermaßen nach außen hin ab. Ein Buschmann (Südafrika) betrachtete nach dem Zeugnis Lorna Marshalls »die Kinder seiner Eltern als ihren Eltern >gleich ( like), die Kinder seiner Kinder als diesen >gleichく, seine Vettern als ihm >gleich « - und so fort. ${ }^{52}$ Die stetig gelebte Gemeinsinnigkeit, das Reziprozitätsgebot und die Verpflichtung, einander beizustehen, wo immer es not tat, festigte die vermeintliche Ebenbildlichkeit von innen heraus immer wieder aufs neue. Verwandte standen, wie Einwohner der Insel Wogeo vor der Nordküste Neuguineas dem australischen Ethnologen Ian Hogbin beteuerten, »gemeinsam gegen die Welt«, waren »untereinander immer zur Nachsicht bereit, generös, fair, aufrecht, geradsinnig und ehrenhaft ${ }^{53}$ Daraus erwuchs nicht nur ein besonderes Vertrauensverhältnis und die feste Gewißheit, jederzeit aufeinander zählen zu können; die schöne Erfahrung, sich in jedem Nächsten gleichsam selber wiederzufinden, weckte auch aufrechte Liebe füreinander. Es stand außer Frage, daß »alle Verwandten«, wie George Silberbauer das selbst für die sammlerinnen- und jägerkulturlichen Buschmänner bestätigt, »einander zugetan sind und liebevoll miteinander umgehen «.54

Wo aber liebende Herzen einträchtig miteinander schlagen, wie die Pendel der Huygens-Uhren, da fließt auch die emotionale und verbale Kommunikation widerstandsfreier, herrscht in den Beziehungen sozusagen »Supraleitfähigkeit«. »Wahre Mitteilung findet«, wie Novalis sagt, »nur unter Gleichgesinnten, Gleichdenkenden statt. «55 Leid wie Freude »stecken an«, die Impulse greifen unmittelbarer. Engstverwandte bildeten 
allgemeiner Anschauung nach aufgrund ihres abstammungsbedingten gemeinsamen Vitalseelenbesitzes und langen Zusammenlebens, das ihre organischen wie sozialen Rhythmen aneinander angeglichen und korreliert hatte, eine sympathetische Empfindungsgemeinschaft, eine Art Überorganismus oder, wie Robert Thornton mit Blick auf die Iraqw in Tansania resümiert, einen »morally corporate body ${ }^{5}{ }^{6}$ Was einem Gruppenmitglied (»Organ«) widerfuhr, teilte sich instantan allen anderen mit, ja griff selbst auf Kulturpflanzen und Haustiere über. ${ }^{57}$

Dem trugen zahlreiche Verhaltensvorschriften Rechnung. In ländlichen Bereichen Rumäniens war zum Beispiel noch bis vor kurzem den Frauen verboten, das Haar aufgelöst zu tragen, weil das ihren Männern den Tod bringen konnte. ${ }^{5}$ Machten sich Eltern auf Mentawei (Indonesien), die der Geburt eines Kindes entgegensahen, eines Tabubruchs schuldig, mußten sie mit einer Totgeburt oder dem frühen Ableben des Säuglings rechnen. ${ }^{59}$ Mehr noch sah man - weltweit - Komplikationen bei der Niederkunft in Untreuedelikten der Mutter begründet. ${ }^{6 \circ}$ Erkrankte jemand, maß man stets dem Verhalten seiner Umgebung eine entscheidende Bedeutung für seine Genesung bei. Dazu war wichtig, daß die Angehörigen sich mit dem Kranken gewissermaßen »gleichschalteten«, um seinen Zustand mitzutragen, das heißt die Angriffsfläche gleichsam »auseinanderzuziehen«, so daß sie »dünner« und schwächer wurde und therapeutische Einflußnahmen leichter »durchschlagen« konnten. Bei den Gbeya in Zentralafrika versammelten sich die Angehörigen am Krankenlager, saßen nur da und schwiegen - ganz einfach, um ihr Mitleiden und ihre Solidarität zu bekunden und dem Kranken so Zuversicht und Kraft zu verleihen. ${ }^{6 \mathrm{I}}$ Ein Iglulik-Eskimo, dessen Kind erkrankt war, stellte sofort alle Arbeit ein; er litt mit ihm und widmete seine Kraft ganz seiner Genesung. ${ }^{62}$ In diesem Sinne vertrat noch der heilige Petrus Chrysologus (um 400), ein bedeutender Kirchenlehrer, Prediger und Bischof von Ravenna, die Ansicht: »Ein Arzt, der die Schwachheiten nicht trägt, kann nicht heilen; und wer nicht mit dem Kranken krank wird, kann dem Kranken nicht die Gesundheit bringen ${ }^{6_{3}}$ - ein Prinzip, dem sich im übrigen auch heutige christliche »Geistheiler« (spiritualist healers) noch verpflichtet fühlen. ${ }^{64}$ Oft teilten die Angehörigen auch die Diät mit dem Kranken. Andernfalls wäre es nach Überzeugung der Jibaro »dasselbe gewesen, als hätte der Patient die unpassende Nahrung zu sich genommen, was seinen Zustand verschlechtert hätte«. ${ }^{65}$ Curt Nimuendajù erlebte bei den Apinayé in Ostbrasilien, daß ein junger Mann, als seine Mutter an einem Augenleiden erkrankte, sofort den Verzehr von Geflügelfleisch einstellte; doch aß er noch Bohnen, die sich ebenfalls nicht mit der Krankheit der Mutter vertrugen, so daß sich ihr Zustand verschlimmerte, wofür sie ihn auch prompt verantwortlich machte. ${ }^{66}$ Schon bloße Gleichgültigkeit, die das verbindende Band sozusagen »durchhängen« ließ, konnte zu verheerenden Folgen führen. Eine Frau, die kaum Anteil am Schicksal ihres erkrankten Gatten nahm, riskierte nach Meinung der 
Yaruro in Venezuela, daß er starb. ${ }^{67}$ Besonders durchschlagend wirkten allerdings auch in diesen Fällen Streit, Tabubruch, Gewaltvergehen und vor allem Untreue. ${ }^{68}$

Auch Pflanzen und Bäume, deren Anbau und Pflege Sache einzelner Männer oder Frauen waren oder die man nahe beim Haus im Garten zog, Haustiere und selbst Gegenstände, die jemand mit seinen Händen hergestellt, in die er »seine Seele gelegt « hatte ${ }^{69}$, bildeten traditioneller Anschauung nach einen Teil des sympathetischen Beziehungs- und Schwingungsfeldes. Eine Frau, die Brot buk, durfte sich während des Vorgangs nicht setzen, da sonst der Teig nicht aufgegangen wäre. ${ }^{70}$ Erkrankte jemand im Haus, ließen die Pflanzen die Blätter hängen und welkten ${ }^{7 \mathrm{I}}$; starb er, wurden in weiten Teilen der Welt seine persönlichen Anbaupflanzen und Fruchtbäume (z.B. Taro und Yams, Sago- und Kokospalmen) vernichtet beziehungsweise gefällt. ${ }^{72}$ Sie hätten niemandem mehr gutgetan. Stand der Tod eines Bienenvaters bevor, überhängte man in Mittelmeerländern und Europa die Stöcke mit schwarzem Flor - damit die Tiere nicht fortzogen.

Am dichtesten schwang, »oszillierte« das sympathetische Wellenfeld unter Engstverwandten, also innerhalb der familiären Gemeinschaft zwischen - abstammungs- oder »blutsverwandten« - Vätern und Söhnen, Brüdern und Geschwistern sowie zwischen Gatten, sofern sie lange genug zusammengelebt und ihr Empfinden einander angepaßt hatten; die Wege waren kürzer, die Kommunikation floß rascher und unmittelbarer. Als Kinder schliefen die Geschwister zusammen, oft, wie bei den Sarakatsani in der Provinz Epirus in Griechenland, unter einer Decke, und aßen aus ein und demselben Topf. Ihr Verhältnis verwuchs und blieb: »Whatever, for good or ill, is suffered or achieved by one sibling is held to affect the other

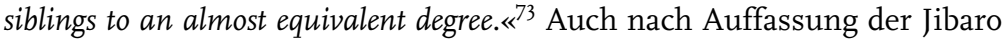
bildeten Geschwister »one organic whole«. ${ }^{74}$ Als besonders eng galten Brüder verbunden. Das klingt auch in Märchen oftmals noch an. Wenn etwa der eine fortzieht und sich in einem fernen wilden Wald mit tückischen Zauberern und kannibalischen Riesen mißt, »spürt« der Daheimgebliebene sofort, sobald jener in eine gefährliche Situation gerät. Er bricht auf der Stelle auf und »haut« den bedrohten Bruder sozusagen »heraus«.75 Bei Zwillingsbrüdern erreichen Dichte und Gleichmaß der sympathetischen Resonanz ihren Höchstwert. Bei den Bulsa in Ghana macht man, wenn einer stirbt, seine Grabstätte unkenntlich und sucht auch sonst alle Spuren seines Ablebens $\mathrm{zu}$ verwischen. Das tue man, berichtet ein Autor, weil man wisse, »daß Zwillinge nicht nur gleiche Anlagen haben, sondern auch stets das gleiche tun möchten, da ihre Seelen [...] gleich sind «. ${ }^{76}$ Das scheint durchaus plausibel, da auch in »westlichen « Gesellschaften telepathische Beziehungen unter - zumindest eineiigen - Zwillingen mit an Sicherheit grenzender Signifikanz dokumentiert werden konnten. ${ }^{77}$ Analoges gilt für das Alter ggo $^{78}-$ in der Regel 
ein Tier. Beide, Ego und Alter Ego, verbindet eine Art »Schicksalsgemeinschaft«: Verletzt sich einer oder stirbt, widerfährt dem andern dasselbe. ${ }^{79}$

Allen Fällen von Telekommunikation liegt ein und derselbe, offensichtlich typische Anlaß zugrunde: Ein Mitglied des sympathetischen Beziehungsfeldes, das sich $z u$ der Zeit in einiger Entfernung von den anderen oder einem engeren Angehörigen befindet, gerät in eine kritische Situation. Prompt schrillt gewissermaßen die »Teleglocke«. Der oder die Empfänger (im Fachjargon »Rezipienten«) »fühlen«, daß etwas »nicht in Ordnung « ist, hören vielleicht auch die Stimme des Betreffenden (des »Agenten«) oder nehmen ihn und was ihm gerade widerfährt kurzfristig in einer Art Vision wahr ${ }^{8 \circ}$ - typischerweise häufig im Traum ${ }^{8 \mathrm{I}}$, wenn das Wachbewußtsein so weit abgedämpft ist, daß robustere Impulse seitens der Außenwelt kaum mehr von den Sinnen zur Kenntnis genommen werden. Entsprechende Untersuchungen samt Reanalysen bestätigten stets, daß »spontane außersinnliche Wahrnehmung oder Erfahrung « zum einen unmittelbarer zwischen Personen mit »engen gefühlsmäßigen Beziehungen« sozusagen »wechselwirkt« und zum andern sichtlich im »Zusammenhang mit existentiellen Krisensituationen« steht. Daraus lasse sich, folgerte der Freiburger Psychologe und Parapsychologe Johannes Mischo (I930-200I), »wohl mit Recht die Hypothese ableiten, daß affektgeladene Informationen über eine gefühlsmäßig nahestehende Person, die sich in einer Krisensituation befindet, eine Auslösefunktion für spontane ASW-Erfahrungen ${ }^{82}$ darstellen ${ }^{83}{ }^{83}$ Ja man spricht dann auch geradezu von $»$ Krisentelepathie ${ }^{84}{ }^{8}$

Ethnologen sind derartige Fälle wohlvertraut. ${ }^{85}$ Hans-Joachim Heinz, der in den sechziger und siebziger Jahren des 20 . Jahrhunderts lange bei Buschmännern in Südafrika gelebt und gearbeitet hat, erfuhr beispielsweise von einem Gewährsmann: »Eines Tages, als ich Vieh nach Lobatse trieb, fühlte ich, daß meine Tochter erkrankt war. Als ich nach Hause kam, fand ich sie tatsächlich krank vor.« In einem zweiten Fall ging es um seinen Sohn. Hier reagierte er sofort. Der junge Mann befand sich in einiger Entfernung auf der Jagd, als seinen Vater ganz plötzlich die Empfindung überkam, daß er in Gefahr sei und Hilfe brauche. Auf der Stelle machte sich der Vater auf, folgte den Spuren seines Sohnes und traf ihn auch tatsächlich krank und bewegungsunfähig an. ${ }^{86}$

Eng fühlen sich, wie schon zur Sprache kam, auch langjährige Eheleute verbunden. Daher war auch ihnen in kritischen Situationen - bei Geburten, in Krankheitsfällen oder wenn der Mann weit außerhalb der Siedlung einer riskanten Tätigkeit nachging - ein ganz bestimmtes Korrespondenzverhalten vorgeschrieben. Auch Fälle von Telepathie unter Eheleuten werden immer wieder berichtet; bekanntlich nicht selten auch aus westlichen, »aufgeklärten « Gesellschaften. Im Zweiten Weltkrieg erlebten dergleichen häufig Frauen, deren Männer an der Front waren und schwer verwundet wurden oder fielen. 
In traditionellen Gesellschaften nahm man die Erfahrung nicht einfach als »übersinnliche« Informationsquelle hin; man wußte sie auch pragmatisch zu nutzen. Das taten zum Beispiel Ehemänner der Apinayé in Ostbrasilien, wenn sie auf Reisen gingen: Sie nahmen »am Tag vor der Abreise Asche aus der Feuerstelle, befeuchteten sie mit Wasser und formten einen dicken Klumpen daraus, den sie in Blätter wickelten und heimlich unter das Kopfende der Matte schoben, auf der die Gatten die letzte Nacht vor dem Aufbruch schliefen. Vor Morgengrauen nahmen sie den Klumpen wieder an sich und inspizierten ihn unterwegs dann regelmäßig. Brach er auseinander, galt dies als Zeichen dafür, daß ihre Frau ihnen untreu geworden war.« Bei einer Nachbargruppe bedienten sich die Männer als Informationsträger dieser Art drahtlosen Telekommunikation eines Holzstabs. Spaltete er sich an einem Ende auf, hatten sie ebenfalls die unangenehme Gewißheit, daß die eheliche Bindung gleichsam »geschlissen « war. ${ }^{87}$ Analoge Mittel scheinen im übrigen auch unseren eigenen Altvorderen nicht unbekannt gewesen zu sein. In dem Märchen Die drei Gürtel, in dem es allerdings andersherum zugeht, überreicht eine gute Fee einer Königin, deren Gemahl - ein notorischer Don Juan - auf Reisen ist, drei silberne Gürtel. Zerspränge der erste, erläutert sie ihr, bedeute dies, daß ihr Mann sie betrogen habe; dann solle sie den zweiten anlegen und schließlich, wenn auch dieser gesprungen sei, den dritten. Der letzte aber hält; die Gatten finden wieder zueinander - und »nie gab es nachher einen treuern Ehemann; sein Leichtsinn hatte ihn verlassen, und sie lebten bis ins hohe Alter glücklich «. ${ }^{88}$

Um es erst gar nicht zur Zerrütung der familiären Bande kommen zu lassen, konnte man schon im Vorfeld geeignete Maßnahmen treffen etwa durch die Wahl der Namen, die man seinen Kindern gab; denn Namen galten als Teil der Persönlichkeit; klangen sie ähnlich, band das ihre Träger. Mit besonderer Konsequenz kamen Turkvölker im Altai diesem Prinzip nach, indem sie die Namen von Eltern und Kindern (bzw. Geschwistern) durch Alliteration miteinander in Gleichklang brachten; im Falle von Vater und Sohn lauteten die Namen dann beispielsweise: Adnaj, Adybaj, Očybaj; bei Mutter und Sohn: Mandaš, ačaš; bei Vater und Tochter: ačaš, ajlaš; bei Brüdern wieder Artin, Adybaj, Očybaj, bei Schwestern Kujka, Kyznak. ${ }^{89}$ Aufgrund analoger Vorstellungen pflegte ein Buschmann Angehörige benachbarter Gruppen, die denselben Namen wie er trugen, als Verwandte $\mathrm{zu}$ betrachten und entsprechend $\mathrm{zu}$ behandeln..$^{\circ}$ Starb bei den Nanaj (Golden) in Ostsibirien einer von zwei oder mehreren Männern eines Dorfes, die denselben Namen trugen, wechselten die andern sofort den ihren, um nicht in den Tod mit »nachgezogen« $\mathrm{zu}$ werden. ${ }^{9^{\mathrm{I}}}$

Wer einen anderen mit seinem persönlichen Namen ansprach, was aus Gründen der Intimität gewöhnlich nur Engstangehörigen erlaubt war, löste bei diesem, je nach Ausdruck und Klangfarbe, mit der das geschah, eine bestimmte Empfindung - Freude, Betroffenheit, ein »schlechtes 
Gewissen« oder gar Angst - aus, weil er aufgrund ihrer beider gewachsenen dichten Beziehung verstand, welche Bedeutung sich mit der Namensnennung verbindet, daß ihr vielleicht ein Lob, ein Tadel oder eine Beileidsbekundung folgen werden.

Das Medium des emotionalen Informationsaustausches bildete traditioneller Anschauung nach die Vitalseele. Sie war Teil einer Art Allkraft, in Melanesien und Polynesien als Mana, bei den Irokesen als Orenda, bei Naga-Völkern in Assam als Aren (usw.) bezeichnet, die den gesamten Kosmos durchdrang - allerdings in ungleichmäßiger Verteilung: Bestimmte Stätten, Stoffe, Pflanzen, Tiere, Menschen, Organe und Naturerscheinungen enthielten sie mehr, andere weniger konzentriert. ${ }^{92}$ In stärker vereinheitlicht strukturierten Feldern, wie unter Verwandten oder Stoffen, Pflanzen und Tieren derselben Beschaffenheit oder Art, in denen Ähnlichkeiten und Übereinstimmungen überwogen, glichen sich die Schwingungen der Kraftverteilung ebenmäßiger aus, es kam weniger zu »störenden« Interferenzen; Empfindungen teilten sich rascher und ungebrochener mit; Verwandte verstanden sich auch ohne Worte.

Die Grundlage dafür bildete die Erfahrung, daß die Vitalseele vom Körper her über eine bestimmte mittlere Distanz, die etwa dem Lebensund Aktionsbereich der näheren Verwandten entspricht, spürbar ausstrahlte, in andere überging, Resonanz auslöste und mit ihnen gleichzuschwingen begann, gleich den Pendeln der Huygens-Uhren, den appetitgetriebenen Schleimpilzzellen und dem Liebesfeuer der Glühwürmchen. In Analogie zur Quantenfeldtheorie könnte man die Bewegung im »Feld « der Vitalkraftdiffusion bildlich als den steten Austausch virtueller (unbeobachtbarer), hier aber »massehaltiger« Teilchen verstehen ${ }^{93}$ : Die sich zersetzende Lebensseele Verstorbener verunreinigt zum Beispiel universalem Glauben nach konkret ihre engere Umgebung und gefährdet dadurch ebenso Stoffe und Materialien wie organisches Leben; die Diffusion entspräche gewissermaßen einer »Antischwingung«, die zerstörerische Wirkungen auszulösen vermag.

In Fällen ungestörter Schwingungsverhältnisse dagegen übertrüge sich die diffundierende Bewegungsenergie (wie bei Wärme z.B.) mittels »masseloser« Teilchen, »Psi-Quanten« gewissermaßen, also »ohne Materietransport «. ${ }^{94}$ Trifft sie auf das Feld eines nahestehenden, verwandten Partners, kommt es, wiederum in Analogie zu entsprechenden physikalischen Vorgängen, zur »Phasenkopplung« (phase locking), stellt sich zwischen beiden ein Schwingungsausgleich her, wie ihn die »Theorie gekoppelter Oszillatoren « beschreibt. ${ }^{95}$ Verschiedenartiges indes ließe sich nicht »verkoppeln«. Versuchte man es mit Gewalt, würden die ungleichen Partner »nach sehr kurzer Zeit außer Takt geraten, denn jede noch so kleine Differenz zwischen ihnen wüchse mit der Zeit an «. ${ }^{6}$

Analoge Vorstellungen hatten auch Philosophen der Stoa etwa ab dem zweiten Jahrhundert v. Chr., vermutlich aus den genannten traditionellen Anschauungen schöpfend, entwickelt. Sie nahmen an, daß die gesamte 
Natur von einer alles durchdringenden Kraft, dem pneuma (wörtlich »uft«, »Hauch«), zusammengehalten werde, die eine bestimmte Spannung, den tonos, besitze, deren Grad die physikalischen Eigenschaften der Körper bestimme. Ändert sie sich an einer Stelle, breitet dieser Impuls sich wellenförmig aus und verdichtet die Zusammenhänge zur »Sympathie « (sympatheia) zwischen den Dingen - eine Auffassung, die man, wie der Physiker Friedrich Hund (I896-I997) meint, durchaus als »eine Vorform der Feldtheorie der Kräfte« begreifen könne. ${ }^{97}$

Nun besitzt der Mensch aber neben der Vital- auch die leibunabhängige, rein spirituelle »Freiseele«, die seinem Bewußtsein entspricht und sein Denken, seine Entscheidungen und sein Handeln bestimmt. Nennt jemand den Namen eines anderen, so geschieht das in bestimmter Absicht. Er löst einen Impuls, den »Operator Psi « ${ }^{9}$, aus, der kurzfristig Unruhe ins Mana-Feld der beide verbindenden emotionalen Schwingungen bringt, das heißt eine spezifische Resonanz zur Folge hat - der Angesprochene reagiert; im Gespräch glätten sich unter Umständen die Wogen wieder. Gerät aber ein Mitglied eines sympathetischen Feldes in eine problematische, oder gar äußerst kritische Situation, gewinnt der Impuls, den sein verängstigtes Bewußtsein absetzt, derart an Bewegungsantrieb, daß er sich instantan dem »Perzipienten « mitteilt - wie laut Quantenfeldtheorie sogenannte »langreichweitige« Kräfte durch masselose, quasi »spirituelle« Teilchen vermittelt werden. ${ }^{99}$ Das stete sympathetische »Hintergrundrauschen« bauscht sich gewissermaßen zu einem verstärkten Signaleffekt auf. Die spezielle »Frequenz« der Schwingungen unter Engstangehörigen verändert sich spürbar und löst im Bewußtsein des »Perzipienten« das Bild des »Agenten« aus - es kommt zu »stochastischer Resonanz « ${ }^{100}$, bei Organismen zur »Krisentelepathie«!

Entfernung spielt dabei sichtlich keinerlei Rolle. Wie Quantenteilchen, die einmal in Wechselwirkung standen, stets, auch wenn sie sich längst an weit voneinander getrennten Orten befinden, korreliert bleiben, so daß Zustandsveränderungen an dem einen, quasi via »Telepathie«, entsprechende Reaktionen an dem anderen auslösen ${ }^{\text {Ior }}$ (das bekannte »Einstein-Podolsky-Rosen-Paradoxon«), teilt sich auch eine massive Krisenerfahrung über die »masselosen« spirituellen »Psi-Quanten« instantan über beliebige Distanzen hinweg dem oder den Engstangehörigen des Betroffenen mit. In beiden Fällen, im physikalischen wie im psychischen Bereich $^{\text {I02 }}$, besteht, wie die Physiker das nennen, eine »nichtlokale Korrelation « zwischen den einstmals verschränkten, also gleichsam verwandten, »identischen ${ }^{\mathrm{IO} 3}$ Teilchen, im letzteren sozusagen zwischen den »Quanten « der Freiseele. ${ }^{\text {I04 }}$ Es verdient der Erwähnung, daß bereits James George Frazer (I854-I94I), Anfang des 20. Jahrhunderts führender Vertreter der Ethnologie, das Phänomen in bezug auf die Magie als »law of contact or contagion « wie folgt formulierte: »Dinge, die einmal in Berührung miteinander standen, bleiben verbunden und wirken auch weiterhin, selbst über größere Distanzen hinweg, aufeinander ein.« ${ }^{\text {IO5 }}$ 
Erst in der Neuzeit, als die »Objektivität« der Welt, distanziert von »autonomen« Subjekten betrachtet, das Erkenntnisinteresse zu beherrschen begann $^{\text {Io6 }}$, wichen, wie zu Beginn des Kapitels angesprochen, weiche Korrelations- harten Kausalbezügen (der causa efficiens); vollends psychisch-sympathetische Resonanzphänomene sanken, diskreditiert zu okkultistischem Aberglauben, in hintergründiges Restrauschen ab. Heute lernen wir, gerade auch aufgrund neuerer Erkenntnisse in den Naturwissenschaften, ihre Realität und Bedeutung wieder wahrzunehmen. 


\section{Magie}

\section{Vom Willen, der durch Vorstellungskraft}

\section{die Welt bezwingt*}

»Nimm den Urin des Patienten«, empfahl einst der mittelalterliche $\mathrm{Na}$ turgelehrte und Philosoph Albertus Magnus (ca. II93-I280) als probates Mittel gegen Fieber, »mische ihn mit ein wenig Mehl, bis du einen guten Teig daraus gewinnst, und forme aus diesem 77 kleine Kuchen. Begib dich dann vor Sonnenaufgang zu einem Ameisenhügel und wirf die Kuchen hinein. Sobald sie die Insekten gefressen haben, wird das Fieber abklingen. ${ }^{\mathrm{I}}$

Heute würde wohl niemand mehr etwas auf eine derartige Verordnung geben. Offensichtlich handelt es sich um pure Magie. Wir bezweifeln daher ihre Wirksamkeit - wiewohl doch keiner von uns eine Probe aufs Exempel gemacht haben dürfte. Unsere Ablehnung wächst uns aus der Gewißheit zu, daß die albertinische Rezeptur aus vergangenen Tagen, einem »dunklen« Zeitalter stammt, ihre Parallelen in der Heilkunde wilder Völker hat und so rundum den Erkenntnissen der modernen wissenschaftlichen Medizin widerspricht. Eine gähnende Kluft hat sich aufgetan zwischen empiriegestütztem rationalem Räsonieren und dem sumpfigen Grund von Unwissenheit, Aberglauben, Zauberwahn und »Dreckapotheken«, die uns schaudern macht.

Grob analysiert, fußt die Medikation des Großen Albert auf den folgenden Annahmen:

- Kritische Situationen erfordern Maßnahmen übergewöhnlicher Art.

- Ihre Wirkung läßt sich verstärken durch die Vervielfältigung einzelner

* Das folgende Kapitel stellt die überarbeitete und erweiterte Fassung eines Vortragstextes dar, der unter dem Titel »Magie« demnächst in der Zeitschrift für Parapsychologie und Grenzgebiete der Psychologie erscheinen wird. 
Operationen, möglichst in Höhe einer bestimmten »magischen« Zahl (hier der 77).

- Die Wahl eines Interstadiums zwischen einer unheilschwangeren (dunklen) und einer heilverheißenden (hellen) Zeitphase, also wie hier zwischen Nacht und Tag, bietet eine besonders günstige Voraussetzung, etwas vom Bösen zum Guten zu wenden.

- Um etwas loszuwerden, daß sich nicht unmittelbar greifen läßt, kann man sich seiner nach dem pars pro toto-Prinzip entäußern, wobei der gewählte Teil (pars) nicht beliebiger, sondern hochwertiger Art sein sollte.

- In diesem Fall dient als Medium für die Fieberabfuhr der Urin des Kranken, der als Körpersekret vorneuzeitlichem Glauben zufolge die Lebenskraft und damit das Fieber, das sie beeinträchtigte, in hoher Konzentration enthielt.

- Die Wirkung wird durch die Intensität des Wünschens (Genesungswille) erzielt, dem das analogiemagische Verfahren sozusagen als mediales Ausdrucksvehikel dient: Durch Ameisenfraß gehen Teigklöße wie Temperatur in Nichts auf.

- Die Zuverlässigkeit der Therapie wird verbürgt durch die anerkannte Autorität des Arztes, der sie empfiehlt.

Das sind Kriterien, denen die anfängliche Belustigung bei der Lektüre der Verordnung doch nicht ganz standzuhalten vermag: Einiges ist uns nur allzu vertraut. In unsicheren Situationen empfinden wir das Bedürfnis, mehr zu tun, als die Vernunft geböte, und verdoppeln oder verdreifachen unsere Anstrengungen; Betroffenen spenden wir Zuversicht, indem wir ihnen die Hand auf die Schulter legen, Mut zusprechen und auf analoge Fälle mit gutem Ausgang verweisen; wir suchen ihnen eine Enttäuschung zu nehmen etwa dadurch, daß wir sie überreden, was gewesen ist, zu vergessen, Dinge, die daran erinnern, von sich zu tun, und ganz von vorn zu beginnen. Kritische Umstände veranlassen uns zu Reaktionen, die das Maß des Üblichen übersteigen.

Magie, nicht Rationalität, lieferte immer und überall die probaten Rezepte dazu. Nicht indes, wenn man Holz aufs Feuer legte, mit einem Kind spielte oder die Bierschale kreisen ließ, bediente man sich ihrer, sondern bei allem, was einem wichtig war oder prekär schien, in Situationen, in denen viel auf dem Spiel stand und der Ausgang unsicher war: bei der Jagd auf Großwild, der Eröffnung der Feldbausaison, in Fällen unerwiderter Liebe, bei Geburten, Heilmaßnahmen und zur Vorbereitung riskanter Unternehmungen - auch solchen mit unlauteren Zielen, wenn man andere zu schädigen, ja zu töten oder auch nur zu bestehlen gedachte. Im letzteren Fall konnten sich einem Dieb die Alternativen bieten, seine Opfer entweder in einen totenähnlichen Schlaf zu versetzen, indem er, worauf man zum Beispiel auf Java vertraute, Graberde um das Haus 
verstreute $^{2}$, oder sich unsichtbar zu machen. Dazu brachten sich noch vor gut hundert Jahren Diebe im Osten Deutschlands in den Besitz eines noch ungeborenen Kindes, trockneten es ein und führten es während des »Bruchs« in einem Holzkistchen bei sich. ${ }^{3}$

Die Lehren, die sich aus der Rezeptur Alberts des Großen ergeben, sind Teil eines allgemeineren Geltungsspektrums magischer Postulate. Um sich ihres Erfolgs zu versichern, mußten Handelnde, die magische Intentionen verfolgten, möglichst ganz bestimmte Voraussetzungen erfüllen. Das waren in der Regel die folgenden:

- Sie versetzten sich in einen übergewöhnlichen Zustand, der ihnen erlaubte, ein Mehr an magischer Wirkkraft mobilisieren zu können. Das geschah zum Beispiel durch Absonderung (Seklusion), rituelle Reinigung, sexuelle Enthaltsamkeit und Fasten, das heißt die gezielte Deaktivierung der Physis, um ihre spirituellen Potentiale uneingeschränkter zur Entfaltung kommen zu lassen, sowie die gedankliche Konzentration auf das Vorhaben; zur Verstärkung konnte man eine bestimmte Bemalung oder Tracht anlegen.

- Sie begaben sich an eine übergewöhnliche Örtlichkeit, bevorzugt eine Passagestelle zwischen Diesseits und Jenseits, etwa in eine Höhle, auf einen Berg, an eine Kreuzung, auf einen Friedhof oder in ein Heiligtum; denn überall dort, im Übergangsbereich mehrerer Möglichkeiten, befand sich das Geschehen gleichsam »im Fluß«, fluktuierte, war plastisch und leichter beeinflußbar.

- Sie wählten für ihr Handeln eine übergewöhnliche Zeit, das heißt bevorzugt wieder eine Übergangs- oder Scheitelphase, etwa die Abend- oder Morgendämmerung, Mitternacht, die Mittags- und Interimszeit »zwischen den Jahren« (»Zwölfnächte«, Neujahr, Neujahrsnacht), bestimmte Feiertage und überhaupt Initialphasen wie den Beginn einer Unternehmung, einen Amtsantritt, Geburten und Hochzeiten, an denen sich abermals die noch im Entstehen befindliche Entwicklung nach Wunsch »bewegen «, das heißt richten und formen ließ.

- Sie verwandten Mittel von übergewöhnlicher Art, denen man als solchen ein besonderes Wirkpotential zusprach. Das waren zum Beispiel Blut und bestimmte Organe (Herz, Nieren, Genitalien), Körpersekrete (Sperma, Schweiß, Speichel, Tränen, Blicke; auch Haar), spezifische Mineralien, pflanzliche und tierische Stoffe, bedeutungsvolle Erb- und Erinnerungsstücke (Gebrauchsgegenstände, Schmuck), Reliquien, Amulette und Talismane.

- Sie brachten die Intention der Handlung auf übergewöhnliche Weise, das heißt mittels altüberlieferter, sprachlich-»archaischer « Formeln, die gemurmelt rezitiert oder gesungen und pantomimisch verstärkt wurden, zum Ausdruck.

- Sie pflegten zentrale Passagen der Handlung mehrfach, gewöhnlich 
drei-, sieben- oder neunmal, zu wiederholen, um ihre »Schubkraft« entsprechend zu steigern.

- Sie bemühten sich, alles korrekt und fehllos auf die altüberlieferte, traditionsgemäße Weise durchzuführen, weil nur dann auch die volle Wirkung des Beabsichtigten verbürgt schien. Schon eine geringfügige Auslassung, erst recht ein Fehler, stellten den Erfolg des Ganzen in Frage. Man begann dann noch einmal von vorn.

Magisches Handeln bedient sich also, wie anderes auch, der gezielten Nutzung dynamischer Potentiale nach Maßgabe spezifischer Raum-, Zeitund Zustandsparameter - nur eben transponiert auf eine »höhere«, überalltägliche Ebene. Entsprechend kann es, wie anderes auch, nur funktionieren im Rahmen wohldefinierter regelgeleiteter Vorstellungs- und Verhaltenssysteme wie zum Beispiel der traditionellen Hydrologie, die Voraussetzung für den Regenzauber ist, oder des perinatalen Brauchtums. Während reines Routinehandeln am Ziel lediglich zu kurzfristigen Fluktuationen führt, die alsbald wieder einschwingen auf den Regelkurs des Systems, löst Magie, weil sie übergewöhnliche Wirkkräfte freisetzt, bei Erfolg qualitative - formative, deformative, transformative oder reformative - im Extremfall irreversible Veränderungsprozesse aus (wie den Tod z.B.).

Magie kann stärkend wie zerstörerisch wirken. Beides sollte aber allein dem Wohl und Erhalt der Gesellschaft dienen. In jedem Fall folgt das Handeln dabei lediglich einigen wenigen, universal einheitlichen Prinzipien. Grundlegende Bedeutung kommt dabei folgenden zu:

I. Dem Kontiguitätsprinzip, das heißt dem Bemühen, einander räumlich wie zeitlich Nahestehendes oder Ähnliches und insofern für verwandt und verträglich Gehaltenes durch Binden (Verknüpfen), Korrelieren oder komprimierende Kombination zu stärken. Familien- und Sippenangehörige siedeln geschlossen, Verstorbene werden unter Haus und Hof oder in einem gemeinsamen Dorffriedhof beigesetzt, Ahnenknochen aufbewahrt, teils am Körper getragen, wichtige Rituale kollektiv durchgeführt, Kräfte durch Korrespondenzverhalten gebündelt.

2. Dem Kontinuitätsprinzip, das heißt dem Bemühen, strikt traditionskonform zu leben, was meint, den Zusammenhalt durch bruchlose Ketten scheinbar kausaler Beziehungen und Beziehungsnetze, also durch Kontiguität in der Zeit, sicherzustellen.

3. Dem Okklusionsprinzip, das heißt dem Bemühen, unerwünschte Entwicklungen, wie etwa die bevorstehende Geburt eines wider die Regel gezeugten Kindes, durch Verschließen von Öffnungen (Türen) und Abdecken von Töpfen und anderen Behältern zum Stillstand zu bringen. ${ }^{4}$

4. Dem Relaxationsprinzip, das heißt dem Bemühen, durch Eigenver- 
schulden oder Zauber gebundene, beziehungsweise nur zögerlich voranschreitende Prozesse durch Öffnen von Türen, Behältern, Verschlüssen und Knoten zu lösen und wieder in Gang zu bringen. Das Verfahren findet weltweit vor allem bei Schwergeburten - die man gewöhnlich auf Untreue der Frau zurückführt - Anwendung. ${ }^{5}$

5. Dem Noninterpellationsprinzip, das heißt dem Bemühen, positive, kontiguitätsstärkende Prozesse, wie etwa die Herstellung eines Gebrauchsgegenstandes, das Heranreifen der Feldfrucht, die Fortpflanzung und Nahrungsaufnahme, das Wachstum der Kinder und die Mehrung des Besitztums, nicht zu stören, geschweige denn zu unterbrechen, gleichsam zu »durchkreuzen«.

6. Dem Nonantizipationsprinzip, das heißt dem Bemühen, positive, kontiguitätsstärkende und besitzmehrende Prozesse nicht im Ergebnis vorwegzunehmen, gleichsam durch »Berufen« zum Stillstand $\mathrm{zu}$ bringen. Man vermeidet zum Beispiel, anderen, namentlich Fremden, präzise Auskünfte über die Gesundheit und Anzahl der Kinder, den Umfang der Vorräte und die Stärke der Herden zu geben. Herrscher hüteten sich, Volkszählungen vorzunehmen. Als König David, dem Bösen Gehör schenkend (vgl. I. Chronik 2r:I), wider die Regel verstieß, wurde Israel mit der Pest geschlagen, der 70 oo० zum Opfer fielen (2. Samuel 24:I-I5). ${ }^{6}$ Wiegen sollten nicht vor der Geburt hergerichtet ${ }^{7}$, Gläser zu Neujahr nicht ausgetrunken ${ }^{8}$, künftige Ereignisse nicht »berufen« werden.

7. Dem Restituierungsprinzip, das heißt dem Bemühen, Geschädigtes oder Fehlgelaufenes durch Purifizieren, Korrigieren oder direkte Inversion rückgängig zu machen, indem etwa eine magische Formel mit der linken Hand oder von rechts nach links geschrieben ${ }^{9}$ oder ein nahezu leerer Vorratsbehälter als »voll« bezeichnet wird..$^{10}$ Ein Tiroler fand eines Tages, als er nach Hause kam, die Stube so gedrängt voller Geister, daß er kaum die Türe aufbrachte. Seine Kinder hatten nämlich während seiner Abwesenheit in seinem Zauberbuch gelesen. Er ließ sich die Stelle zeigen und las sie rückwärts, worauf die Geister auch prompt einer nach dem anderen wieder verschwanden. ${ }^{\text {II }}$

8. Dem Amplifikationsprinzip, das heißt dem Bemühen, die Effizienz des magischen Handelns generell durch Wiederholungen, Massierung der Aufwendungen und Exponieren besonders bedeutsamer Schritte (oder auch des Gesamtvorgangs) zu verstärken.

9. Dem Regenerationsprinzip, das heißt dem Bemühen, den ungestörten Verlauf kritischer Zustandswechselprozesse, wie Geburt (Niederkunft), Pubertät, Verehelichung, eine Amtsübernahme, die Genesung von einer schweren Krankheit, die Resozialisation nach einem Kardinalvergehen oder Tod, begleitend durch Transformations- beziehungsweise Wiedergeburtsriten, in den drei Schritten Abtötung, Umwandlung und Neugeburt nach der Strukturvorgabe der Rites de Passage sicherzustellen. 
Io. Dem Approximationsprinzip, das heißt dem Bemühen, Ähnlichkeit und insofern Quasi-Verwandtschaft über bestehende Distanzen hinweg durch räumliche, zeitliche und habituelle Annäherung, Angleichung oder auch Imitation zu stiften, indem man für seine Kinder einflußreiche Paten wählt oder sie angesehenen Familien zur Erziehung übergibt (engl. fosterage), die Nähe hochgestellter Persönlichkeiten und Autoritäten sucht, beziehungsweise sich nach seinem Tod im engeren Umfeld ihrer Gräber bestatten läßt (»ad sanctos« im Falle von Heiligen), große Vorgänger oder Vorbilder in Namenswahl (wie bei Päpsten z.B.), Sprache und Verhalten nachahmt und krafthaltige Stoffe (Knochen, Haare), Gegenstände, Reliquien, Kostbarkeiten und Überlieferungen (Gebete, Zauberformeln, Rezepte) sammelt und entweder bei sich selbst oder im »Schatzhaus« der Gruppe (Männerhaus, Heiligtum, Palast) magaziniert, beziehungsweise »thesauriert «.

II. Dem Seklusionsprinzip, das heißt dem Bemühen, sensible, einwirkungsanfällige Stellen und Zustände (Geburten, Initiationen, Hochzeiten, Krankheiten, wichtige Ritualhandlungen, Bestattungen) sowie Zusammengehöriges generell (Verwandtschaft, Gruppe, Dorf, Kultur) nach außen hin abzuschirmen durch Demarkierung (Zäune, Palisaden, Mauern), Kontakttabus (Berührungs- und Heiratsverbote) und Umschließen, indem man zum Beispiel Gelenke mit Bändern und Reifen, wie dem Leibriemen (Hüften), Fuß-, Armbändern und Halsketten, umringt oder sich zu bestimmten, hochsakralen Verrichtungen an eine magisch - etwa durch rituelles Umschreiten umzirkelte Stätte begibt. ${ }^{\text {I2 }}$

I2. Dem Distinktionsprinzip, das heißt dem Bemühen, einander Fernstehendes, Unähnliches und insofern für nicht verwandt, unzusammengehörig und daher unverträglich Gehaltenes striktest getrennt beziehungsweise auf Distanz zu halten, indem man zum Beispiel Obst und Gemüse oder Fleisch von Landtieren und Fisch nicht in ein und demselben Topf zusammenkocht, Hochstehenden nicht zu nahe kommt, keine sexuellen oder gar ehelichen Beziehungen mit Fremden eingeht und bei Entstehungs- und Wachstumsprozessen (Schwangerschaft, Aussaat, Nahrungszubereitung, Gerätefertigung, Hausbau) den Anblick und vor allem Kontakt mit Vergehendem, Verrottendem, Totem oder Zerstörerischem, wie einer Feuersbrunst, meidet. Anders würde man eine Kontiguitäts- und Kontinuitätsverletzung begehen, das heißt mindestens bedenkliche Kontaminationen, eher aber schwere Schädigungen, das heißt Kraftverluste riskieren.

13. Dem Interruptionsprinzip, das heißt dem Bemühen, Entwicklungen, die dazu führen könnten, daß Unvereinbares miteinander in Kontakt gerät, zu unterbrechen oder mißliebigen Personen zu schaden, indem man im ersteren Fall analogiemagisch Schnüre durchtrennt oder Schwellen und Wege kreuzt (im europäischen Volksglauben zu 
Abwehrzwecken auch sogenannte »Kreuzsteine« verwendet ${ }^{13}$ ), im letzteren etwa die Betreffenden im Schlaf quer überschreitet.

I4. Dem Eliminierungsprinzip, das heißt dem Bemühen, Verunreinigungen, Folgen von Fehlverhalten und Fremdgut, das irgendwie Eingang in die Gruppe fand, entweder auszutilgen oder aus der Endowelt $\mathrm{zu}$ entfernen, Personen also zu töten oder zu exkommunizieren.

Diesen handlungsleitenden liegt wiederum eine Reihe strukturierender formaler, die Orientierung sichernder Prinzipien zugrunde, wie sie auch aus der Gestaltpsychologie bekannt sind ${ }^{\mathrm{I} 4}$, und zwar in der Hauptsache die folgenden:

A) Das Reduktionsprinzip, das die Funktion hat, aus der Vielfalt des Wahrgenommenen einzelnes für relevant Gehaltenes herauszusondern und vereinfachend auf Punkte (Gegenstände, Lokalitäten, Personen), geradlinige Beziehungen (Reziprozität, Genealogie) und regelmäßige, quasi geometrische Figuren (Haus- und Siedlungsformen, Rangordnung, Rituale, Weltbild) zu reduzieren, um ihm mehr Prägnanz zu verleihen, das heißt es faßlicher und überschaubarer erscheinen $\mathrm{zu}$ lassen. ${ }^{\text {I5 }}$

B) Das Linearisierungsprinzip, das die Funktion hat, bestimmte Punkte, Ereignisse, Überlieferungen und Handlungsabfolgen durch gleichsam perlenschnurförmige Reihung in einen linearen, sequentiellen oder seriellen Zusammenhang zu bringen, um der Verbindung den Anschein einer kausalen Abhängigkeitsbeziehung zu verleihen.

C) Das Formalisierungsprinzip, das die Funktion hat, die durch Reduktion gewonnenen quasi-geometrischen Verbindungen, Zyklen und »Gestalten« durch Fixierung zu verstetigen, um ihnen Regelcharakter $\mathrm{zu}$ verleihen. Magische Redefiguren ${ }^{\mathrm{I} 6}$, festliche Aufmärsche und Rituale sind ebenso typische Beispiele dafür wie die Traditionspflege insgesamt.

D) Das Perfektionierungsprinzip, das die Funktion hat, Verhalten und Handeln so auszurichten, daß alles streng traditionsgetreu und möglichst fehllos geschieht - nach der Maxime etwa: Nur was genau nach Vorschrift, das heißt auf die alte, bestens bewährte Weise getan wird, kann auf sicheren Erfolg zählen. Magische Akte oder Rituale, bei denen ein Fehler unterläuft, werden gewöhnlich abgebrochen und aufs neue begonnen.

E) Das Exponierungsprinzip, das die Funktion hat, hochwertige Güter, wichtige Rituale und Veranstaltungen, ranghohe Würdenträger, Sakralbauten und heilige Überlieferungen durch topographische, temporale und soziographische Zentrierung, Ästhetisierung und Isolierung (Arkanisierung, Mystifizierung) als etwas Besonderes, unter Umständen Einzigartiges erscheinen zu lassen. 
Jedes Handeln wäre wirkungslos, ja es gäbe weder Bewegung noch gerichtetes Handeln, würden nicht Kräfte den Gliedmaßen und ihrer Verhaltenskoordination Antrieb verleihen. In den alten Kulturen herrschte die Auffassung, daß alles Geschehen in der Natur von - wenn man so will - drei »Grundkräften« bestimmt wird: der Lebenskraft oder Vitalseele, in Pflanzen, Tieren und Menschen verantwortlich für die organische Funktionsfähigkeit, im besonderen für Keimkraft, Fruchtbarkeit und Wachstum, den Naturkräften, wie sie sich beispielsweise in fließendem (oder fallendem) Wasser, im Wind, dem Feuer, harten und schweren Materialien, der Gestirnbewegung, der Wärme und Leuchtkraft der Sonne entfalten, und den spirituellen Kräften, die den Freiseelen, Geistern und Göttern entsprechen und allein über größere Entfernungen hin wirken können. Die ersteren beiden lassen sich dabei unmittelbar ineinander überführen: Krafthaltige Mineralien, organische Substanzen oder sakrale Örtlichkeiten (Heiligtümer, Heiligengräber) stärken die menschliche Lebens- und Widerstandskraft; Blut oder Knochenmehl lassen sich zu Düngungszwecken verwenden, der Liebesakt gesunder, vitaler Menschen auf frischeingesäten Äckern weckt und vermehrt die Fruchtbarkeit des Bodens; Handlungen und Rituale, die man bei aufgehender und hochstehender Sonne oder zunehmendem Mond vornimmt, besitzen ein verstärktes Wirkvermögen. Die spirituellen Kräfte dagegen sind der Stofflichkeit, wie der Schöpfer der Urmaterie vor der Entstehung der Welt, vorund übergeordnet, das heißt mehr oder weniger, je nach ihrem Vergeistigungsgrad, von ihr unabhängig - Freiseelen bleiben ihr, auch in Traum und Ekstase oder nach dem Tod, immer noch teilweise verhaftet; Götter sind vollends substanz- und »masselos«. Aufgrund dieses Verhältnisses unter den drei elementaren Kräften, bilden die ersten zwei ein einziges komplementäres Wirkfeld; ihre Trennung würde den »Tod« beider bedeuten (das Herz bleibt stehen, der Boden büßt seine Fruchtbarkeit ein, die Sonne erlischt usw.). Bewegung und Geschehen innerhalb dieses Feldganzen der Raumzeit aber werden allein von der dritten Kraft bestimmt und aufrechterhalten. Die Freiseele (mit Sitz im Bewußtsein) lenkt das Verhalten des Menschen und trägt so zum Erhalt der überkommenen Ordnung bei; die Ahnen überwachen das Tun und Lassen der Lebenden, die Götter den Gang der Welt. ${ }^{\text {I7 }}$

Die Kräfte, welcher Art auch immer, wirken an sich nicht regellos, oder gar »chaotisch«. Sie sind seit der Schöpfung in bestimmter Weise gebunden und dienen, sofern ihr Fluß nicht durch Zauber oder den Eingriff böswilliger Geister gehemmt und in »falsche« Bahnen gelenkt wird, allesamt dem Erhalt der vorzeiten geschaffenen Ordnung von Gesellschaft, Kultur, Natur und Kosmos - allerdings immer nur der endooptischen Anschauung nach: Spirituelle Impulse, die eine Gesellschaft von außen, von Göttern benachbarter Gruppen, von Buschgeistern oder Störenfrieden (Neidlingen, Streitsüchtigen, Schwarzmagiern) im eigenen Innern - gewissermaßen der »Fünften Kolonne« der Unheilsmächte in 
der exosphärischen Außenwelt - treffen, können nur Schaden anrichten und zerstörerisch wirken. Es bedarf daher stets einer gediegenen Kenntnis und wachen Kontrolle aller, der endo- wie der exogenen Kräfte, um sie $\mathrm{zu}$ seinen Gunsten einsetzen, beziehungsweise sich ihrer erwehren zu können.

Dabei ist zu beachten, daß die genannten drei Grundkräfte ihrer Natur nach unterschiedliche Wirkradien besitzen und sich insofern immer nur über bestimmte Entfernungen hin mobilisieren und nutzen lassen. Entsprechend orientiert sich alles Verhalten an der jeweils gegebenen Distanz zum Ziel und wird generell geschieden zwischen magischen Einflußnahmen durch unmittelbaren Kontakt, solchen über einen überschaubaren Nahbereich hin sowie Fernwirkungen. ${ }^{18}$ Erstere erfolgen durch Berühren oder Einverleibung, das heißt durch Essen und Trinken, Einatmen und Impfen. ${ }^{\text {I9 }}$ Als Kraftübermittlungsträger dienen dabei Dinge, Stoffe, Substanzen, Organe und Personen, denen man die Eigenschaften zuschreibt, die man zu übertragen, beziehungsweise zu gewinnen wünscht. Der Verzehr von Fischblasen erleichtert zum Beispiel das Schwimmen ${ }^{20}$; eine Schwangere, die zwei zusammengewachsene Äpfel ißt, kommt, wie man vormals auf Rügen glaubte, mit Zwillingen nieder. ${ }^{2 \mathrm{I}}$ Handauflegen durch einen Priester, Heiligen oder König segnet, heilt, tröstet und stärkt; ein Aphrodisiakum kräftigt das Liebesvermögen. Unmittelbar affiziert wird in diesen Fällen der Funktionsverbund von Leib und Lebenskraft (Vitalseele).

Einflußnahmen der zweiten Art, das heißt über einen überschaubaren Nahbereich hin, vollziehen sich über mittelbare Kontakte, etwa durch den - besänftigenden, liebevollen oder »bösen« - Blick, der im Sinne eines feinstofflichen, quasi ätherischen Lichtstrahls aufgefaßt wurde ${ }^{22}$, durch Sprache, Mimik und Gestik sowie die persönliche »Ausstrahlung«, teilweise spürbar als Wärme und Geruch. Menschen, die sich versündigt hatten und somit unrein waren, besaßen auch nach der Überzeugung des heiligen Thomas von Aquin (ca. I225-I274) noch »sengende Augen (oculos urentes), deren Blick über eine bestimmte Distanz des benachbarten Luftraums hin andere zu vergiften (inficiunt) vermag ${ }^{23}$. Große Sufi-Meister erziehen ihre Schüler, ja bekehren Ungläubige kraft ihres Blickes. ${ }^{24}$ Worte können Mut machen, herabsetzen und gebieten, Zauberformeln töten. Verschlossene Mienen »schrecken ab«, ein Lächeln »versöhnt«, eine Gebärde »schüchtert ein«. Könige und Heilige strahlen auf ihre Umgebung Segens- und Heilskraft ab. ${ }^{25}$ Als Übermittlungsmedium gilt in diesen Fällen sozusagen ein »Partikelstrom « der von der Physis abgesonderten Lebenskraft: Worte zum Beispiel werden im Mund mittels Kieferbewegung geformt und vom Atem, speicheldurchsetzt, getragen Unterkiefer, Speichel und Atem sind allesamt in hohem Maße vitalkrafthaltig, desgleichen auch Blick, Hände und Körpergeruch. ${ }^{26}$ Doch bleibt die Wirkung, wie bei allen akustischen, olfaktorischen und thermischen 
Diffusionsprozessen, begrenzt. An der Peripherie des Nahbereichsfeldes verklingen die Worte, lösen sich Blick- und Ausstrahlungsströme auf.

Unbegrenzt dagegen wirken Einflußnahmen der dritten Art; denn dabei bediente man sich rein spiritueller, »masseloser« Kraftübermittlungsträger, im Falle des Menschen der leibunabhängigen Freiseele. Hier stellte sich allerdings das Problem, daß die Ziele - abwesende Angehörige, Mitglieder benachbarter Gruppen, Regenwolken, die es erst heraufzubeschwören galt, Ahnen, Geister und Götter - zumeist außerhalb des Wahrnehmungsfeldes lagen, so daß Wirkung und Reaktionen nicht unmittelbar beobachtbar waren. Der Handelnde bedurfte, um die Kraft gerichtet in Gang zu setzen, der gedanklichen Konzentration und konnte, was er beabsichtigte, seinem fernen, unsichtbaren Gegenüber nur mimetisch signalisieren, das heißt mußte sich analoger, symbolischer Ausdrucksmittel bedienen.

Nach einer Überlieferung der Nez Percé im Nordwesten der USA warf einer ihrer Schamanen, als die Indianerkriege noch im Gange waren, einen amerikanischen Kavallerieoffizier über eine große Entfernung hinweg aus dem Sattel, indem er die Hand mit einem kleinen Röhrchen in seine Richtung stieß. ${ }^{27}$ De facto war es der wunschgetriebene Gedanke, der sich quasi projektilartig fortbewegt, den Gegner getroffen und vom Pferd gehoben hatte. In der Antike schmolz man Wachs, um das Herz einer (oder eines) erfolglos Begehrten $\mathrm{zu}$ »erweichen «. ${ }^{28}$ Weltweit suchte man andere, die man um ihr Liebesvermögen bringen wollte, durch das Verknüpfen von Schnüren (»Nestelknüpfen«) impotent beziehungsweise empfangsunfähig zu machen. Im Mittelalter stand noch die Todesstrafe durch Enthaupten darauf. ${ }^{29}$ Weit verbreitet waren auch die sogenannten »Defixionspuppen«, an denen man das, was man einem anderen ansann, mimetisch vorexerzierte; Wunsch und Wille trugen die Intention dann ins Ziel. Noch Paracelsus (I493-I54I) schwor auf die Praxis: »Wenn einer eine Figur macht gleich einem Menschen und diese an eine Wand malt, so wisset, daß alle Stiche, Schläge und Streiche, die das Bild treffen, auf den fallen, für den sie bestimmt sind. $\ll^{3 \circ}$

Auch zeitlich einander Fernes läßt sich um einer erwünschten Kontinuitätsstiftung willen analogiemagisch verknüpfen. Karl der Große (7478I4) liefert ein typisches Beispiel dafür. Er wollte sich als neuer David (König von Israel ca. I004-965 v. Chr.) verstanden wissen. Da dieser als Präfiguration des Heilands galt, beanspruchte er damit zugleich, in der Nachfolge Christi zu stehen. Entsprechend wurde auch die Heldensage vom Untergang seiner Nachhut in Ronceval gedeutet: In dem Verräter Ganelon erschienen Luzifer und Judas wiederverkörpert - was den König abermals dem Messias naherückte. ${ }^{\text {I }}$ Der Sieg der Sowjetunion über Deutschland schien im Vorgriff gesichert, als Stalin ihn in Analogie zum »Vaterländischen Krieg« gegen Napoleon offiziell zum »Großen Vaterländischen Krieg« deklarieren ließ. 
Entscheidend für die Fernwirkung der Analogiemagie blieb immer die Freisetzung und gezielte Fokussierung der »Geisteskraft « durch Wünschen, gedankliche Konzentration und Wille. ${ }^{32}$ Namentlich letzterer vermag bekanntermaßen Berge zu versetzen. »Der böse Wille«, charakterisiert ein Beobachter zum Beispiel die entsprechenden Anschauungen zentralafrikanischer Ethnien, »ist so gut wie die böse Tat. Er wirkt wie die Sonnenstrahlen wärmen, wie die Winde kühlen, wie Blumen riechen [...] wie Gifte von Pflanzen und Tieren. «33 Auch Goethe war dergleichen nicht fremd. »Ich habe«, bekannte er Eckermann gegenüber, »in meinen Jünglingsjahren Fälle genug erlebt, wo auf einsamen Spaziergängen ein mächtiges Verlangen nach einem geliebten Mädchen mich überfiel und ich so lange an sie dachte, bis sie mir wirklich entgegenkam. >Es wurde mir in meinem Stübchen unruhig «, sagte sie, >ich konnte mir nicht helfen, ich mußte hierher ¿ $^{34}$ Auch andere als der Dichterfürst waren von der Wirkkraft des Wünschens und Wollens überzeugt. Paracelsus, dem als Arzt romantische Empfindungen weniger nahelagen, schwebten eher martialische Möglichkeiten vor. Er hielt es für durchaus denkbar, daß der »Geist ohne des Leibes Hilfe, durch inbrünstiges Wollen allein und ohne Schwert, einen andern stechen oder verwunden « könne. ${ }^{35}$ Islamische Heilige vermochten durch pure Konzentrationskraft (tawağğuh) zu heilen. ${ }^{36}$ Arthur Schopenhauer (I788-I860), Verfechter einer strikt voluntaristischen Philosophie, äußerte sich nicht nur im gleichen Sinne, sondern setzte sich konsequentermaßen geradezu für eine Art Ehrenrettung der traditionellen Magie ein, wie sie zu seiner Zeit auf dem Land noch gang und gäbe war. Ihre Paraphernalien seien lediglich Beiwerk; zur Hauptsache komme es auf die Willenskraft an, die unter Umständen stark genug sei, selbst »leblose Körper « zu affizieren. ${ }^{37}$ »Ich bin daher der Meinung «, bekennt er unumwunden, »daß der Ursprung dieses, in der ganzen Menschheit so allgemeinen, ja, so vieler entgegenstehender Erfahrung und dem gemeinsamen Menschenverstande zum Trotz, unvertilgbaren Gedankens sehr tief zu suchen ist, nämlich in dem inneren Gefühl der Allmacht des Willens an sich [...] Dem dargelegten Grundgedanken gemäß finden wir, daß bei allen Versuchen zur Magie das angewandte physische Mittel immer nur als Vehikel eines Metaphysischen genommen wurde; indem es sonst offenbar kein Verhältnis zur beabsichtigten Wirkung haben konnte; dergleichen waren fremde Worte, symbolische Handlungen, gezeichnete Figuren, Wachsbilder u. dgl. m. [...] Denn bei jedem magischen Akt, sympathetischer Kur, oder was es sei, ist die äußere Handlung [...] eigentlich nicht das Wesentliche, sondern das Vehikel, das, wodurch der Wille, der allein das eigentliche Agens ist, seine Richtung und Fixation in der Körperwelt erhält und übertritt in die Realität; daher ist es, in der Regel, unerläßlich. « $^{8}$

Sigmund Freud (I856-1939) fand die Grundthese Schopenhauers wenig später in seinen eigenen Untersuchungen bestätigt. Statt von der Allmacht des Wollens bevorzugte er allerdings, von der »Allmacht des Ge- 
dankens« zu sprechen. ${ }^{39}$ Das konnte bei Parapsychologen nur auf $\mathrm{Zu}$ stimmung stoßen: Ihre Erfahrungen sprachen erst recht dafür. Einer ihrer größten, Hans Bender (I907-I99I), unterstrich: »Unsere Emotionalität, unsere Gefühle haben eine ungeheure Macht und Wirklichkeit. Was die Magie alter Zeiten annimmt, daß der Haßgedanke gegen den Nächsten diesem objektiv schadet, kann, so absurd es klingen mag, nach den Erfahrungen der Parapsychologie eine Realität sein, die natürlich nicht überall und immer sich auswirkt, aber von der wir annehmen müssen, daß sie untergründig doch häufig vorhanden ist. « ${ }^{\circ}$

Ob nun Emotionalität, Wille oder Gedanke - die Überzeugung von der Fernwirkung hinreichend starker mentaler Intentionen beruht offensichtlich auf Erfahrung und reicht überdies bis tief in die Geschichte zurück, ja besitzt neueren Erkenntnissen nach gediegene physiologische Grundlagen. Wohl nicht von ungefähr ist der »Gedankenzauber« ganz besonders charakteristisch für die typologisch ältesten, das heißt Sammlerinnen- und Jägerkulturen. Litten zum Beispiel die Selknam auf Feuerland allzusehr unter Schneefall, vollzogen sie einen bestimmten Ritus und rezitierten dazu mit konzentrierter Eindringlichkeit Formeln wie »Bald wird der Regen den Schnee vertreiben« oder »Jetzt muß der Regen kommen . $^{4 \mathrm{I}}$ Die Worte selbst waren Beiwerk im Sinne Schopenhauers; sie signalisierten verbal, was man wollte; mehr kam es auf die Intensität des Gedankens an. Begab sich ein Ultscha in Ostsibirien auf die Jagd, pflegte er sich auf dem Weg ins Revier voll auf den »Herrn der Tiere«, eine gottähnliche Geistmacht, die über das Wild gebot und den Jagderfolg entschied, zu konzentrieren. ${ }^{42}$ Nach Überzeugung der Paiute in Nevada »reisen« (travel) - in diesem Fall böse - Wünsche »mit dem Gedanken, dringen mit ihm in den Leib des Opfers ein und vollbringen dort ihr Zerstörungswerk «. ${ }^{43}$

Auf dem gleichen Weg lassen sich natürlich auch positivere Intentionen verwirklichen. Jüngsten Experimenten zufolge sind selbst - intelligentere - Tiere dazu imstande. Ratten können zum Beispiel lernen, einen Hebeldruck auszulösen, Affen, einen Roboterarm zu steuern, indem sie den Vorgang gedanklich imaginieren. Ihr Gehirn wurde dazu über ein spezielles »Interface« mit einem Computer verdrahtet. ${ }^{44}$ Auch für Menschen, selbst vollständig Gelähmte, ist inzwischen erwiesen, daß sie in der Lage sind, durch willentliche Beeinflussung ihrer cortikalen Potentiale mit Computern zu kommunizieren. ${ }^{45}$

Modellförmig ließe sich eine paradigmatische »Urszene« magischen Handelns etwa wie folgt vorstellen: Ein junger Mann wird auf das Weidwerk, die zentrale Tätigkeit seines künftigen Lebens, durch die »Jägerweihe« vorbereitet. Dazu reiben ihm die Älteren - wie bei den Buschmännern in Südafrika zum Beispiel - Pulver aus dem verkohlten Fleisch der Hauptjagdtiere in Einschnitte zwischen den Augen und am rechten Oberarm ein, damit er das Wild schon von weitem zu sehen und sicher zu treffen imstande ist. Oder sie salben seine Waffen - so bei den Pygmäen 
im Kongo - mit dem Blut des während der Probejagd von ihm erlegten Tieres, geben ihm von der Brühe des aus der Beute zubereiteten Festgerichts zu trinken und legen ihm zuletzt noch wichtige, lebenskrafthaltige Organe, wie das blutende Herz, in die Hand: Dadurch verfließen beider Vitalseelen ineinander und stellt sich eine sympathetische Beziehung und »Blutsbrüderschaft « zwischen Mensch und Wild her, die beide zu wechselseitigem Beistand verpflichtet. ${ }^{46}$ So gerüstet, richtet der nunmehr approbierte, das heißt zur Jagd offiziell autorisierte Jäger bei jedem Weidgang seine Gedanken vollkonzentriert auf seinen tierischen »Blutsbruder«, zieht ihn damit zu sich heran und signalisiert ihm wie dem »Herrn der Tiere in einer Jagdpantomime, wie sie rezent noch verschiedentlich vorkam und bereits auch auf jungpaläolithischen Höhlen- und Felsbildern dargestellt ist, was er zu tun gedenkt. Die Jagd selbst schließt das Ganze dann nur mehr ab.

Jahrzehntausende später gewann das Leben mit der Seßhaftigkeit feste Dauerstrukturen. Die Menschen rückten enger zusammen, ohne einander noch, wie in den Sammlerinnen- und Jägerkulturen, aus dem Wege gehen zu können. Das dörfliche Dasein warf verstärkt gesellschaftliche, namentlich besitz- und erbrechtliche Probleme auf. Der Entwicklung entsprechend differenzierte und formalisierte sich zunehmend auch die Magie. Die Versuchung wuchs, sich ihrer in Fällen von Konflikten zu bedienen, die man offen nur ungern austragen mochte. Mit dem Aufkommen städtischer Siedlungsformen und ihrer verwirrenden Unübersichtlichkeit erreichte der Prozeß seinen Höhepunkt. Die weiter fortschreitende Zergliederung der Gesellschaft, verbunden zur gleichen Zeit mit einer steten Verdichtung der sozialen Gruppierungen auf immer engerem Raum löste einen Schichtungsprozeß mit entsprechend komplexen Abhängigkeitsstrukturen und erhöhtem Konfliktpotential aus. In den Städten Altvorderasiens blühte das Zauberwesen. Bereits der sumerische König Gudea von Lagasch (ca. 2050-2000 v. Chr.) sah sich gezwungen, per Verordnung alle "Zauberer « des Landes zu verweisen. ${ }^{47}$ Aus dem westmittelmeerischen Altertum, vor allem der hellenistischen bis spätantiken Zeit, liegen in Fülle analoge Berichte vor. Die Enzyklopädisten, wie Plinius der Ältere (23-79 n. Chr.), liefern zahlreiche Proben davon. Auch die Christen wußten sich des drückenden Erbes nicht so recht zu erwehren. Immer wieder fordern die Kirchenväter, Gläubige, die der Zauberei überführt waren, unbedingt vom Abendmahl auszuschließen, ja, besser noch, zu exkommunizieren. Es geschieht »nicht selten «, klagt Hippolytos von Rom zu Anfang des 3. Jahrhunderts, »daß einige bis in das Alter darin verharren $\ll .^{4}$ Auch Priester taten gehörig mit. Manche empfahlen, wenn es darum ging, einem Mann zur Gnade der Keuschheit zu verhelfen, Riemen zusammenzubinden, $z u$ versiegeln und in einen tiefen Brunnen zu werfen. ${ }^{49}$ Im Mittelalter dasselbe Bild..$^{50}$ Nur tarnte sich der Zauber mit christlichen Formen, um nicht gleich der kirchlichen Justiz ins Netz zu gehen. »Rings um die Sakramente«, charakterisiert der be- 
kannte niederländische Mediävist Johan Huizinga (I872-I945) die Verhältnisse noch im Spätmittelalter, »blühten die Benediktionen; von den Reliquien kam man zu den Amuletten; die Kraft des Gebets wurde formalisiert in den Rosenkränzen, die bunte Galerie der Heiligen bekam immer mehr Farbe und Leben $\ll .{ }^{51}$ Strenggläubige Autoren sahen sich veranlaßt, ihre Stimme wider die wachsende Zahl von Kapellen und Kirchen, Festen und Heiligen, Gebeten und Hymnen, den zeremoniellen Aufwand und Übertreibungen bei Fasten und Enthaltsamkeitsübungen zu erheben. ${ }^{52}$ Selbst Päpste, wie Benedikt XIII. (I394-I4I7), standen im Ruch, des »Guten « $\mathrm{zu}$ viel $\mathrm{zu}$ tun, das heißt Magie zu betreiben. ${ }^{53}$ Noch nach Artikel Io9 der »Peinlichen Gerichtsordnung « Kaiser Karls V. von I532, die bis zum Ende des I8. Jahrhunderts formelle Gültigkeit behielt, drohte Schadenszauberern die Todesstrafe. ${ }^{54}$

In der Neuzeit hat weniger Aufklärung als Wohlstand, der dem Leben mehr Kalkulierbarkeit und Sicherheit verlieh, die Magie zwar nicht aufgehoben, aber doch ins Dunkel der Abseitigkeit verdrängt. In kritischen Situationen indes, in denen die scheinbar festgefügten Fassaden ins Wanken geraten, blüht sie sofort wieder auf - und zwar bei weniger wie Hochgebildeten gleichermaßen. ${ }^{55}$ Für Kinder und Jugendliche gilt das schon zustandsbedingt in besonderem Maße, da sie sich ständig vor neue Aufgaben gestellt sehen, mit denen sie erst lernen müssen, sich auseinanderzusetzen, die sie unsicher machen und ihnen daher per se problematisch erscheinen. Etwa vom dritten Lebensjahr an und teils noch bis zum Ende der Adoleszenz (bzw. Schulzeit) zählt Magie fast zum normalen Denken und Tun, um deutlicher jedoch wieder in besonders kritischen Situationen, das heißt während Initial- und Übergangsphasen, an Einfluß zu gewinnen. Typische Formen bilden ritualisiertes Verhalten beim $\mathrm{Zu}$ bettgehen und Aufstehen am Morgen ${ }^{56}$, auf dem Weg zur Schule und vor Klassenarbeiten ${ }^{57}$, intensives Wünschen und die Orakelbefragung (z.B. Abzählen und auf »Zeichen « achten). ${ }^{58}$ Später spielt Magie in den Liebesbeziehungen und vor Examina noch eine besondere Rolle. Anfang des 20. Jahrhunderts ging unter deutschen Studenten ein Sektkorken um, der in dem Ruf stand, sicher durchs Abschlußexamen zu führen. Er befand sich im Besitz einer Charlottenburger Akademiker-Gesellschaft. Wer davon wußte, bat ihn sich aus und trug ihn während der Prüfung bei sich. Wie es heißt, soll er sich stets bewährt haben. Natürlich wuchs die Kraft, die man ihm beimaß, mit jedem Erfolg. ${ }^{59}$

Während des Erwachsenenalters tritt die Tendenz zu magischem Verhalten ebenfalls wieder besonders im Zusammenhang mit Tätigkeiten (bzw. Berufen) und Situationen auf, die mit Risiken verbunden sind und deren Ausgang daher unsicher erscheint, wie bei Schwangerschaften und schweren Erkrankungen, im Bergbau, beim Entschärfen von Sprengkörpern (Minen, Bomben), bei sportlichen Wettkämpfen - oder beim Glücksspiel. ${ }^{60}$ In derartigen Fällen neigen viele Menschen beispielsweise dazu, besonders vorsichtig vorzugehen, im Glauben, dadurch möglichen 
Gefahren »aus dem Wege gehen « zu können, bei der Lösung schwieriger Aufgaben mehr auf konsequente Zielstrebigkeit, Hartnäckigkeit und Akribie als kühlrationales Kalkül zu setzen oder alles exakt »nach Vorschrift« zu machen (Perfektionierungsprinzip), etwa den Anweisungen der Ärzte genauestens Folge zu leisten, das heißt, ganz auf die Autorität des Experten zu bauen, dem man gern auch ein wenig mehr zahlt oder Geschenke macht, um sich vollends seiner Zuwendung zu versichern (Approximationsprinzip) ${ }^{6 \text { I }}$ Es wurde daher auch schon vorgeschlagen, Magie nicht einfach abzutun, sondern im Gegenteil therapeutisch zu nutzen. ${ }^{62}$ Andere vertrauen ihren persönlichen »Glückstagen«, tragen Talismane ${ }^{6_{3}}$ beziehungsweise ein Medaillon mit dem Bildnis ihres Schutzpatrons bei sich (Kontiguitätsprinzip), besuchen Heiligengräber und Wallfahrtsstätten mit wundertätigen Reliquien (Approximationsprinzip), bringen dort »Opfer« (Votivgaben) dar und legen Gelübde ab, das heißt gehen mit dem Heiligen eine spezielle Reziprozitätsverpflichtung ein, oder achten auf Vorzeichen, also einen »höheren«, wegweisenden »Wink«. Als im Herbst I997 in Nordkorea die Wahl Kim Jong-ils zum Nachfolger seines Vaters Kim Il-sung anstand, erblühten vorzeitig, wie die nationalen Medien berichteten, Hunderte von Birnen- und Aprikosenbäumen, ja einem Fischer ging eine seltene weiße Seegurke ins Netz, »um das Ereignis der Wahl des Genossen Kim Jong-il zum Generalsekretär der Partei zu begrüßen«. Eine Agenturmeldung faßte zusammen: »Angesichts der geheimnisvollen Naturerscheinungen sagen sich die Nordkoreaner, daß Genosse Kim Jong-il tatsächlich der größte der großen vom Himmel geschaffenen Männer ist und daß die Blumen zum Zeichen für dieses großartige Ereignis blühen« (Kontiguitätsprinzip). ${ }^{64}$ Bekanntermaßen zählen derartige magische Konnexionen auch sonst zu den probaten Mitteln der Indoktrination, Propaganda, Werbung und sogenannter »aggressiver Verkaufsstrategien«. Unter Sportlern bauen vor allem Boxer auf »Glücksbringer« zur Verstärkung ihrer physischen Schlagkraft. Manche tragen zum Beispiel beim Kampf immer die gleiche Hose, in der sie ihren ersten Sieg errangen, oder nehmen die Namen früherer, besonders erfolgreicher Vorgänger an (Amplifikationsprinzip). ${ }^{65}$

Auch »andere Umstände« erfordern zur Abwehr der Unwägbarkeiten, die sie begleiten, flankierende andere als die medizinisch gebotenen Maßnahmen. Untersuchungen in kalifornischen Geburtskliniken ergaben, daß werdende Mütter, unabhängig von Hautfarbe und Status, dieselben Vorstellungen über Zusammenhänge zwischen ihrem Verhalten, der Umwelt und dem heranreifenden neuen Leben in ihnen entwickeln, wie sie aus traditionellen Kulturen sattsam bekannt sind. Schwangere sollten zum Beispiel nichts sehen, geschweige denn berühren, was versehrt ist oder Zerstörung ausstrahlt (wie etwa eine Feuersbrunst), damit ihr Kind auch wohlbehalten zur Welt kommt (Distinktionsprinzip). Resümierend kam man zu dem Ergebnis, daß »diese Art Folklore nicht einfach ein Überbleibsel aus weniger aufgeklärten Zeiten ist«, sondern offensichtlich 
»auch in der heutigen Gesellschaft noch ihre Funktion erfüllt«. ${ }^{66}$ Andere Erhebungen in den USA ergaben, daß Mütter, deren Kinder an Tuberkulose, Masern oder Kinderlähmung erkrankt waren, entgegen ihrer sonstigen Gewohnheit, nicht nur häufig die Kirche besuchten, viel beteten und in der Bibel lasen, ja sich bestimmten religiösen Kasteiungsübungen unterzogen, sondern ihre Zuflucht auch zu gewissen »>magicak or ssuperstitious acts« nahmen, das heißt etwa die Wohnung wechselten, dem Kind ein Medaillon oder altes, vermeintlich heilkraftträchtiges Erbstück um den Hals hingen und zusätzlich Säfte, Kräuter und andere Arzneien aus den Arsenalen der Volksmedizin verabreichten (Amplifikationsprinzip). ${ }^{67}$

Doch nicht nur Angehörige oder die Patienten selbst, auch die behandelnden Ärzte greifen ergänzend schon mal, ob nun bewußt oder unbewußt, zu magischen Mitteln - sei es der »beschwörenden « Suggestivkraft ihrer Sprache, Mimik und Gestik, der Ritualisierung ihrer »Visiten« oder der Ausstrahlungskraft ihrer Autorität - die selbst Scheinmedikamenten Heilkraft zu verleihen vermag (wenn auch zumeist nur befristet). Solche »Placebos«, das heißt etwa Tabletten, die aus nichts als Stärke oder Zukker bestehen, Ampullen, die lediglich eine physiologische Kochsalzlösung enthalten, oder Zäpfchen aus reaktionsloser Suppositorienmasse, erzielen in der Tat oft eine erstaunliche therapeutische Wirkung. Dabei kommt gleich mehreres zusammen: Der Wille des Kranken, Erlösung von seinen Leiden zu finden, das Behandlungszimmer mit seiner zwar beunruhigenden, aber doch Heilung verheißenden Ausstattung, die rigorose Hygiene (»Reinheit«) und schließlich der Arzt in seinem berufsmäßigen Kittel, bestimmte Geräte immer zur Hand und mit ehrfurchtgebietendem Gefolge, das deutlich eine gewisse Distanz zu ihm, dem Hauptverantwortungsträger, wahrt, die ruhige, sichere Art, mit der er seine Anweisungen erteilt, vielleicht auch sein Ruf - das alles trägt häufig bereits so wesentlich zur Zuversicht des Patienten in die Heilkraft des Arztes bei, daß oft schon allein sein Besuch eine spürbare Besserung auslöst (Formalisierungsprinzip). Der Arzt, so der Kommentar eines Autors dazu, gebe dem Kranken durch die Art seines Auftretens gleichsam zu verstehen: »Ich will für dich sorgen! Es ist ein Versprechen, und die Tablette, die der Patient zu sich nimmt, gleichgültig, welcher Art sie ist, erwirbt die Kraft eines Symbols von Glaube, Wissen und Hilfe. ${ }^{68}$ Manche Ärzte erzielen mit Placebos sogar deutlich größere Erfolge als andere. Es sind das, wie entsprechende Untersuchungen zeigten, besonders liebenswürdige und gewinnende, gleichzeitig aber auch sicher auftretende, selbstbewußte, »starke« Naturen, die geradewegs auch als »Powerful Placebo Personalities« bezeichnet werden. Bei ihnen kann ein echtes Aspirin schon innerhalb weniger Minuten - sehr viel früher also, als die pharmakodynamische Wirkung tatsächlich einsetzt - selbst stärkste Kopfschmerzen beheben. ${ }^{69}$

Nennen ließen sich weiter auch als typische Ansatzsituationen magisch ritualisierten Verhaltens Amtseinführungen wie Beisetzungen hoher behördlicher Würdenträger, Gerichtsverhandlungen, Jubiläen, 
Gedenkfeiern und Staatsvisiten (Exponierungsprinzip)..$^{70}$ Auch Gelehrte, selbst Psychologen, sind alles andere als frei davon. Denn tatsächlich vermag niemand ununterbrochen und ausnahmslos rein rational $\mathrm{zu}$ denken und zu handeln; eher nur in mentalen Highlight-Situationen, wie bei der Suche nach der Lösung eines wissenschaftlichen Problems, sei es am Schreibtisch, im Labor oder Seminar. Kritiker der Psychoanalyse monierten, daß die »numerologischen Koinzidenzanalysen« Sigmund Freuds »praktisch nicht zu unterscheiden « seien von den »Beziehungsideen psychotischer Patienten $\ll^{7 \mathrm{I}}$ Geht man, wie Dieter Zimmer, die Psychoanalyse frontal an, fallen die Reaktionen teils kraß irrational aus ${ }^{72}$ - eine Erfahrung, die auch Vertretern der »harten« Naturwissenschaften nicht fremd zu sein scheint. »Bei vielen wissenschaftlichen Diskussionen«, klagt der Physiker Harald Atmanspacher, »wird man bei kritischer und unvoreingenommener Betrachtung feststellen, daß - abgesehen von erschreckenden Mängeln, was Grundregeln der Syntax betrifft - ein beachtlicher Teil der zu übermittelnden >Information< nichtverbal transferiert wird. Wesentliche Bestandteile dieser nicht-verbalen Kommunikation sind affektiven Ursprungs, z.B. Dominanzgestik, Einschüchterungsgehabe, bis hin zu mehr oder weniger subtilen Versuchen, die Gegner eigener Überzeugungen [...] in den Bereich der Lächerlichkeit zu ziehen. «73

Ideale Nährböden für eine Renaissance der Magie - oft fälschlicherweise auch als »Hexerei ${ }^{74}$ bezeichnet - liefern erst recht aber die heutigen Verhältnisse in vielen Ländern der Dritten Welt, in denen praktisch alles Tun und Geschehen von Risiken begleitet und unsicheren Ausgangs ist. Die ökonomischen Umwälzungen, Landflucht und Arbeitsemigration, der Zerfall der alten verwandtschaftlichen Strukturen, Nahrungsmangel, neuartige Seuchen, Bürgerkriege usw. mehr lassen den Menschen scheinbar nur noch die Wahl, ihre letzte Zuflucht in religiöser Sektiererei, Besessenheitskulten und eben vor allem der Magie zu suchen. Namentlich in den großen Städten, in denen die Verhältnisse ein teils exorbitantes Ausmaß erreichen, steht sie heute mehr denn je - wie analog in den alten Metropolen der Archaischen Hochkulturen - in vollem Flor, ja darf, wie die Meinung allgemein umgeht, noch mit beträchtlichen Zuwachsraten rechnen. ${ }^{75}$ Kenner der Situation im »dunklen « Erdteil »haben den Eindruck [...] daß diejenigen Afrikaner, die durch die Begegnung mit der europäischen Zivilisation aus einer für sie trotz Hexerei und Zauberei sinnvoll geordneten Welt herausgerissen wurden, jetzt noch intensiver als früher fürchten, der Hexerei [bzw. Schadensmagie] zum Opfer zu fallen [...] Autoren, die sich besonders mit Westafrika beschäftigt haben, berichten, daß überall neue, den Schutzgeistern gewidmete Schreine auftauchen, die ihre Anhänger vor Behexung bewahren sollen. Sie führen dies auf das Unbehagen der innerhalb weniger Jahre von einschneidenden sozialen Umwälzungen betroffenen Afrikaner zurück. « ${ }^{6}$

Magie ist ein ubiquitäres menschliches Verhaltensphänomen ${ }^{77}$ : Es setzt gewisse kognitive Operationen wie den Vergleich, die Herstellung 
von Analogie- und Abhängigkeitsbeziehungen, das Schlußfolgern, die Postulierung allgemeiner Zusammenhänge und die Annahme von »Kräften« voraus, die sich willentlich und nach Maßgabe bestimmter Prinzipien und Regeln nutzen lassen. Für Tiere konnte dergleichen - bestenfalls in schwachen Ansätzen bei einigen subhumanen Primaten - bislang nicht nachgewiesen werden.

Und allezeit spielte Magie im Leben des Menschen eine wichtige Rolle - angefangen mindestens von den Neandertalern (Homo sapiens primigenius; $200.000-30.000 \mathrm{v}$. Chr.) und ältesten Vertretern des anatomisch modernen Menschen (Homo sapiens sapiens; ab $200.000 \mathrm{v}$. Chr.), den Trägern der jungpaläolithischen Kulturen (36.00o - 8.00o v. Chr.), für die uns die ersten gesicherten Zeugnisse vorliegen (u.a. Bestreuen der Toten mit Ocker zur Erhaltung der Lebenskraft, Verwendung von Fruchtbarkeitsidolen, Darstellung jagdmagischer Szenen auf Höhlen- und Felsbildern). Verständlich daher, daß diese offenbar elementare und doch so besondere Verhaltensuniversalie des Menschen bereits seit der Antike das Interesse der Gelehrten, zunächst der Philosophen, später der Theologen, Psychologen, Soziologen, Religionswissenschaftler und Ethnologen auf sich zog. Mustert man die diversen Erklärungsversuche durch, stellt sich alsbald heraus, daß sie sich im Grunde allesamt um lediglich zwei Thesen bewegen:

I. Die Magie erfüllt psychische und soziale Entlastungsfunktionen. In kritischen, das heißt potentiell bedrohlichen Situationen hilft sie den Zagenden auf, suggeriert ihnen eine Lösungsmöglichkeit, stärkt so ihr Vertrauen in die eigenen Kräfte, stiftet Optimismus und Hoffnung. Der Wunsch ist dabei der Vater der Zuversicht. Für »Wilde« wie Zwangsneurotiker, so auch die Überzeugung Freuds, ist »nicht die Realität des Erlebens, sondern die des Denkens « ausschlaggebend. ${ }^{78}$ In der Ethnologie verfocht am nachhaltigsten Bronislaw Malinowski (I884-I942) diesen seiner Kulturtheorie nach »funktionalistischen« Erklärungsansatz. »Der Liebende«, erläuterte er etwa, »der sich in Schmerz verzehrt angesichts einer unerreichbaren oder gleichgültigen Schönen, sieht sie in seinen Visionen vor sich, spricht $\mathrm{zu}$ ihr, fleht sie an, gebietet ihren Gefühlen, glaubt sich erhört und drückt sie, träumend, an seine Brust.« Magie basiere auf einem »universalen psycho-physiologischen Mechanismus«, der Risiken abzumildern, Spannungen aufzulösen und, so ergänzend sein Nachtreter Edward E. Evans-Pritchard (I902-I973) und andere angelsächssische Autoren in der Nachfolge Malinowskis, sozialen Unmut und Aggressionen symbolisch abzureagieren gestatte. ${ }^{79}$ Sie besitzt die Funktion, »den Optimismus des Menschen zu ritualisieren und seinen Glauben an den Sieg der Hoffnung über die Furcht zu stärken «. ${ }^{\circ \circ} \mathrm{Daß}$ man in bedrängten Lagen, sofern man den Kopf nicht verliert, mehr tut als unter »normalen« Voraussetzungen, ist fraglos plausibel - bis an die Grenze zur Trivialität. Doch sagt das lediglich etwas über die Zwecke (»Funktionen«), aber so gut wie nichts über die Prinzipien und Formen magischen 
Denkens und Handelns, geschweige denn die »Theorien«, die ihnen zugrunde liegen, aus.

2. Die Magie stellt ein Relikt aus der Frühzeit der menschlichen Geistesgeschichte dar. Dies war vor allem die These der Evolutionisten des I9. und beginnenden 20 . Jahrhunderts. Sie lebte entsprechend bei den orthodoxmarxistischen Sowjetethnologen fort ${ }^{8 \mathrm{I}}$ und wurde auch von Nichtmarxisten noch bis in die jüngere Vergangenheit von manchen geteilt. Der »Kulturpsychologe« Jean Gebser (I905-I973) bestimmte sie als zweite der - wie er annahm - noch unbewußten Strukturebenen in der stammesgeschichtlichen Entwicklung der Psyche, der eine »archaische« vorausging und die »mythische folgte, die selbst endlich in die »mentale intellektuellen Geistigkeit einmündete. ${ }^{82}$ Der (katholische) Theologe Alfons Kirchgässner sah sie »als Kontrapost gegen Aufklärung« wirksam, »wie unter der Erdkruste das vulkanische Element «. ${ }^{83}$ Der »archaische« Mensch, so die Quersumme aller Erfunde dieser Art, war noch nicht imstande, weder die Zusammenhänge in der Natur noch sich selbst korrekt $\mathrm{zu}$ begreifen, und bildete alles daher durch »symbolische Verknüpfungen « ab, die in kontraponierendem Widerspruch zur sogenannten »naturalistischen Weltsicht« der Moderne stehen ${ }^{84}$, die so ganz, usuellem Vermeinen nach, von streng rationalistischem, kausal-logischem Denken beherrscht ist. ${ }^{85}$

Dieser Sicht der Dinge sekundierten auch prominente Psychologen, so allen voran der Däne Alfred Lehmann (I858-I921) ${ }^{86}$ und Sigmund Freud $^{87}$, deren Auffassung teils heute noch von Autoren wie etwa Leonard Zusne und Warren Jones geteilt wird. ${ }^{88}$ Schwerer wiegen indes die Befunde der Entwicklungspsychologie, da sie eine empirische Bestätigung der These zu liefern scheinen. Gelehrte wie Heinz Werner (I890-I964), Jean Piaget (I896-I980), Willy Krogmann, Karl Zeininger und andere sahen die Magie ontogenetisch vorangelegt im magischen Denken und Verhalten von Kindern, wie es besonders für Sechs- bis Zwölfjährige typisch ist. ${ }^{89}$ Zwar darf dies als gesichert gelten, doch begegnet die Supposition, daß es zulässig sei, kindliche Vorstellungen und Verhaltensweisen mit denen ausgereifter Erwachsener in traditionellen wie modernen Gesellschaften schlankweg gleichsetzen zu können, grundsätzlichen Bedenken. In der letzteren Hinsicht »erklärt« man die Magie abermals als Reliktphänomen, nur diesmal aus den Frühphasen kindlicher Geistigkeit.

James George Frazer (I854-I94I), der letzte große Vertreter des klassisch-ethnologischen Evolutionismus, teilte zwar die Überzeugung von der Reliktnatur und Rückständigkeit der Magie, suchte sie aber erstmals streng systematisch als ehernes Regelwerk zu fassen. Er schied die geistesgeschichtliche Entwicklung der Menschheit in die drei Stadien der »Magie«, »Religion « und »Wissenschaft« (science). Im ersten, dem »Zeitalter der Magie « (the age of magic) herrschte insgesamt noch »a lower intellectual stratum ${ }^{9 \circ}$; die Menschen glaubten alle Vorgänge in der Natur von dem mechanischen Walten unveränderlicher Gesetze bestimmt (»by the opera- 
tion of immutable laws acting mechanically«)..$^{9 \mathrm{I}}$ Diesem lagen seinen Überlegungen nach zwei elementare Prinzipien der Wahrnehmungsassoziation zugrunde:

I. Ähnliches bewirkt Ähnliches, beziehungweise: eine Wirkung ähnelt ihrer Ursache. Dem entspreche das law of similarity, das die imitative (oder »homöopathische«), das heißt die Analogiemagie bestimmt.

2. Dinge, die einmal in Berührung miteinander standen, bleiben verbunden und wirken auch weiterhin, selbst über größere Distanzen hinweg, aufeinander ein; dem entspreche das law of contact or contagion, das die Kontakt- und Übertragungsmagie bestimmt. Hier griff Frazer, wenn man so will, dem quantenphysikalischen Prinzip der »nichtlokalen Korrelation« vor!

Beider Basis bildet die allgemeinere Grundlage der »sympathetischen Magie«, die vom law of sympathy bestimmt wird. ${ }^{92}$ Fraglos profitierte Frazer hier von der strengen gedanklichen Schulung durch seinen Lehrer und Freund, den Physiker William Thomson (I824-1907, Nobelpreis I906), später Lord Kelvin of Largs, der ihn, wie ein langjähriger Mitarbeiter bezeugt, das Universum verstehen gelehrt hatte »als regiert von exakten und absolut invarianten Naturgesetzen «. ${ }^{93}$ In seiner Prinzipiensystematik dagegen knüpfte er unstreitig an seinen großen schottischen Landsmann David Hume (I7II-I776) an ${ }^{94}$, den er zwar nicht eigens erwähnt, aber wohl nur, weil er die Kenntnis seiner Schriften, die damals zur Pflichtlektüre für Gymnasialschüler und erst recht Studenten zählten, ohne weiteres bei seinen Lesern voraussetzen durfte. In An inquiry concerning human understanding hatte Hume beide Prinzipien Frazers bereits gleichlautend benannt und als universale »Prinzipien der Vorstellungsverknüpfung « bestimmt. ${ }^{95}$ Trotz ihrer systematischen Schlüssigkeit blieb die Magie für Frazer jedoch immer Teil der ältesten Entwicklungsstufe der Menschheit, eine Schöpfung aus der »Kindheit der menschlichen Gesellschaft « (infancy and childhood of human society), der dann später das Zeitalter der Religion und krönend schließlich die Lichtära der Wissenschaft folgten. ${ }^{96}$

Magie, Religion und Wissenschaft wurden auch sonst immer wieder, als schiede sie eine essentielle Unvereinbarkeit, kontrastierend gegeneinander aufgewogen. Im Falle der Religion flößten manchen die nicht zu ignorierenden Übereinstimmungen und die teils dichte Verschränkung mit der Magie ein deutliches Unbehagen ein. ${ }^{97}$ Zum Rückweis strich man verstärkt die Unterschiede heraus: Magie diene rein individuellen, persönlichen, nicht gemeinschaftlichen sozialen Zielen; sie erzwinge, statt gebeugten Haupts zu erbitten ${ }^{98}$; sie bilde den Bodensatz überholten Glaubensguts, den die Religion noch am Saum ihres Sternenmantels gleichsam mitschleife.

Und wenig anders stellte sich auch das Verhältnis zur Wissenschaft 
dar. Einerseits gaben das Regelwerk der Magie und der Feldcharakter ihrer dynamischen Relationen zu denken; es schien, als habe sie Geburtshilfe bei der Entstehung der Wissenschaft geleistet. ${ }^{99}$ Andererseits gründeten sich ihre Konklusionen unbestreitbar auf »falsche« Prämissen. Edward B. Tylor (I832-I9I7), der neben Frazer bedeutendste Vertreter des ethnologischen Evolutionismus, sprach in dem Sinne von einer »sorgfäl-

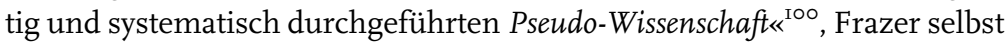
von »false science«. ${ }^{\text {IOI }}$ Die Wilden hatten zwar systematisch gedacht, doch, so auch noch die Überzeugung von Leonard Zusne und Warren Jones, die »wahren« Zusammenhänge zwischen Ursache und Wirkung in der Natur nicht verstanden. ${ }^{\text {Iо2 }}$

Kühne Behauptungen, darf man wohl sagen, die sich jedoch erklären (und abweisen) lassen, wenn man sie als Konsequenzen der allgängigen eurozentrisch-identitätsideologischen Optik versteht. In dem Falle wäre der Syllogismus der folgende: Wir haben den wahren, höchstentwickelten Glauben; was ihm räumlich und zeitlich vorgelagert erscheint und lediglich noch im Untergrund oder in Randlagen der Gesellschaft fortlebt, kann ihm nicht angehören, ist - magiegespeister - »Aberglaube«. Es steht, wie der deutsche Ethnologe und katholische Geistliche Wilhelm Schmidt (I868-I954) deklarierte, »im schärfsten Gegensatz zur Religion« «. ${ }^{\text {103 }}$ Der bekannte evangelische Theologe und »Religionspsychologe« Karl Beth (1872-I959) senkte gar alle vorchristlichen Religionen kurzerhand ins Reich der Magie ab - in den Orkus der Verdammten gewissermaßen. ${ }^{\text {I04 }}$ Und analog dazu, auf die jüngste Hochebene europäischer Geistigkeit transponiert: Wir haben die bislang höchste Stufe menschenmöglicher Erkenntnis erklommen; unsere Theorien sind empirisch bestens bestätigt, sie bilden daher die Wirklichkeit zutreffend ab. Was davon abweicht oder im Widerspruch dazu steht, muß atavistisches Sperrgut aus den dunklen Tiefenschichten frühzeitlich magischen, »prälogischen« Naturverständnisses sein, wie es heute nur mehr bei rudimentär zivilisierten Völkern, Kindern, Ungebildeten und Geistesgestörten fortlebt, oder ist schlichtweg falsch, ein Schattengewächs des Irrationalismus. Die schon mehrfach genannten Psychologen Leonard Zusne und Warren Jones setzen zum Beispiel, im Abhub zur Wissenschaft, Magie, Okkultismus, Spiritismus und »Anomalistik « ineins ${ }^{105}$ - tertium non datur, wie es die aristotelischboolesche Logik gebietet. ${ }^{\text {I06 }}$ Die Welt, so Max Weber (I864-I920), wurde durch den Prozeß der »intellektualistischen Rationalisierung «, der sich der Wissenschaft danke, gründlich »entzaubert«. An die Stelle der Magie sei die Technik getreten. ${ }^{\text {I07 }}$ Ludwig Wittgenstein (I889-I95I) war sich weniger sicher. In seinem Kommentar zu Frazers Monumentalwerk The Golden Bough kritisiert er, »daß alle diese Gebräuche [...] sozusagen als Dummheiten dargestellt werden « und die »Anschauungen als Irrtümer erscheinen «; das mute nicht eigentlich plausibel an und bleibe letztendlich unbefriedigend. ${ }^{\text {I08 }}$ Ja er argwöhnt, in ethnologisch ansprechender 
Weise: »Das Ausschalten der Magie hat hier den Charakter der Magie selbst.« ${ }^{\mathrm{IO} 9}$ Resümierend bleibt alledem gegenüber festzuhalten:

I. Der Glaube an die Wirkkraft magischen Handelns hat über die Jahrzehntausende hin überlebt - bis in die Gegenwart; er erscheint also doch in gewisser Weise bewährt. Nicht nur Kinder und andere mit vermeintlich rudimentärem oder defizientem Einsichtsvermögen, auch Erwachsene, die sich als »bekennende Rationalisten« verstehen, bedienen sich ihrer, wenn auch, sobald sie sich dabei gleichsam »ertappt« sehen, nicht ohne Verlegenheit, die sie dann häufig mit einem verschämten oder verschwörerischen Lächeln zu überspielen suchen.

2. Offensichtlich stellt die Magie so etwas wie den verschatteten Unterboden des im öffentlichen Approbationsbereich konventionalisierten »normalen« Vorstellungs- und Verhaltensduktus dar, von dem sich rationales Denken und Handeln eher als spezielle Besonderung gleichsam schaumkronenartig abhebt. Ihre Beständigkeit könnte ebensogut neurologisch bedingt sein wie auf immer wieder bewährter Erfahrung beruhen. Sie mit Dummheit oder Devianz zu assoziieren, wäre kaum plausibel, wissenschaftlich nicht zu begründen und hätte zudem wenig erfreuliche Konsequenzen: Es würde uns allesamt zu »Patienten« machen!

3. In jedem Fall erfüllt Magie vitale Funktionen, und zwar in Gesellschaften jedweden Typs. Auf ihr basieren die sogenannten »Alltagstheorien«, die auch in Situationen Erklärungen bereitstellen, in denen Religion und Wissenschaft entweder verdammen, vertrösten, kopfschüttelnd reagieren oder »vor einem Rätsel stehen«. Magische Vorstellungen stiften eine starke Weltbildkonsistenz von besonderer Symmetrie und Regelförmigkeit, in dem es keine Zufälle gibt und auch ein Stuhlbein, an dem man sich stößt, noch seinen Platz hat. ${ }^{\text {IIO }}$ Insofern liefert Magie ein umfassendes Orientierungssystem, das sich gerade in flexiblen, kritischen Situationen bewährt.

4. Magische Operationen erscheinen nur unter der Präsupposition eines »Kraftfeldes« - des »Mana-Feldes«, wie ich es nenne und schon andernorts näher beschrieben habe ${ }^{\text {III }}$ - schlüssig, das im zentralen Beziehungsbereich der unmittelbar Beteiligten durchsetzt ist von der Dichtetextur sympathetischer Korrelationen, analog den »Kraftlinien« elektromagnetischer Felder im Sinne Michael Faradays (I79I-I867), die für diesen, wiewohl immateriell, doch »die eigentliche Realität« darstellten. ${ }^{\text {II2 }}$ Impulse, angeregt durch gedankliche Konzentration, den »Operator Psi «I3 ${ }^{\mathrm{II}}$, können dabei unter spezifischen - physischen, psychischen oder konstellationsbedingten - Voraussetzungen in Gang gesetzt und geleitet werden. Würde man Schlösser oder Töpfe öffnen, ohne dabei gezielt an die bestimmte Frau mit den akuten Geburtskomplikationen zu denken, liefe man beispielsweise Gefahr, daß alle 
Verschlüsse aufsprängen, Anwesende unangenehm gesprächig würden oder, einen selbst eingeschlossen, unter Inkontinenz zu leiden begännen. Im Zentrum des Aktionsradius ließe Magie sich als praktische Sympathie verstehen.

5. Unverkennbar besteht ein Zusammenhang zwischen Magie und Psi-Phänomenen, die ja gleichfalls an handelnde Personen geknüpft sind. Im sympathetischen »Mana-Feld « rühren kritische Situationen an einem »Punkt« an bestimmten anderen Momente telepathischer Hellsicht auf. ${ }^{\text {II }}$ Noch eher aber scheint Psychokinese betroffen: die magische Einflußnahme auf organische und mentale, möglicherweise auch physikalische Systeme durch gedankliche Konzentration, beziehungsweise die Aktivierung psychozerebraler Prozesse durch den »Operator Psi«. ${ }^{\mathrm{II} 5}$ »Mens agitat molem « waren unter anderen bereits Vergil ${ }^{\mathrm{II} 6}$ und Thomas von Aquin überzeugt, der meinte, daß der Mensch - und namentlich beim Wirken von Wundern - durchaus imstande sei, »den körperlichen Stoff (corporalem materiam) durch die Kraft der Seele (per virtutem animae) $\mathrm{zu}$ verändern «. ${ }^{\mathrm{II} 7}$ Geburten können, wie erwähnt, durch Öffnen von Verschlüssen erleichtert, Menschen durch Blicke, Worte und Gesten »gelähmt« oder »bewegt« werden. Unbestritten ist zwar, daß die Umwelt Einfluß auf den Menschen nimmt; doch warum, fragt Heine in den Reisebildern, »nicht auch der Mensch auf die Natur, die ihn umgibt?« Er meinte das nicht im gängigen Sinne mit den Mitteln der Technik, sondern so wie einst Orpheus, der »Bäume und Steine nach begeisterten Rhythmen bewegen konnte ${ }^{\text {II } 8}$ Tatsächlich übten ja Menschen jahrtausendelang auf diese »orphische« Weise Einfluß auf Jagdwild und Wachstum der Pflanzen aus, riefen Regen herbei und wehrten Unwetter und Sonnenfinsternisse ab. Tabus stellten sicher, daß es in der Natur nicht zu irrläufigen Entwicklungen und Katastrophen kam. Uns sind nur mehr Garten oder Balkon geblieben. Wir glauben, daß unsere Blumen besser gedeihen, wenn wir sie »biodynamisch « düngen, einen »grünen Finger« haben und ihnen bewußte Zuwendung schenken.

6. Magie und Wissenschaft schließen einander nicht aus. Eher ließen sie sich mit Claude Lévi-Strauss als zwei zwar qualitativ verschiedenartige, immer aber einander durchdringende »strategische Ebenen« der Erkenntnis begreifen. ${ }^{\text {II }}$ »Ich wollte zeigen«, sagte er noch vor wenigen Jahren, rückblickend auf sein Lebenswerk, »daß sich zwischen dem Denken der sogenannten primitiven Völker und dem unsrigen kein Graben auftut. Als man in unseren eigenen Gesellschaften Bräuche und Glaubensinhalte, die fremd waren und den gesunden Menschenverstand irritierten, aufzuzeichnen begann, erklärte man sie als $\mathrm{Spu}$ renelemente oder Überreste von Formen archaischen Denkens. Für mich hatte es im Gegenteil den Anschein, daß diese Denkformen bei uns noch immer gegenwärtig, lebendig sind. Sie koexistieren mit anderen Denkformen, die sich auf die Wissenschaft berufen; sie sind 
mit gleichem Recht zeitgemäß.« ${ }^{\text {I20 }}$ Und, wie man hinzufügen darf, trotz ihres so viel höheren Alters noch kaum erforscht und verstanden. Zeit also, sich ihrer ernsthafter wissenschaftlich, in Kooperation etwa von Ethnologie, Psychologie, Parapsychologie, Neurologie und Physik, und zwar unvoreingenommen, anzunehmen. Wir könnten dabei viel auch über uns selbst erfahren. 


\title{
9. Schafe und Ziegen
}

\section{Von der Mißhandlung der Unvernunft durch die Vernunft*}

\author{
„Der Glaube ist zum Ruhen gut, \\ Doch bringt er nichts von der Stelle. \\ Der Zweifel in ehrlicher Männerfaust \\ Der sprengt die Pforten der Hölle.॥ \\ Theodor Storm
}

Die martialischen Verse Theodor Storms verraten einen gewissen Gemütsaufruhr. Ähnlich bewegt zeigte sich Henry Sidgwick (I838-I900), als Moralphilosoph eher ein mutmaßlich Gemäßigter, als er am I7. Juli ı882 in seiner ersten Ansprache als Gründungspräsident der gerade ans Licht der Öffentlichkeit getretenen Society for Psychical Research in London seinem Publikum zurief: »Ich sage, es ist ein Skandal, daß der Streit um die Realität dieser Phänomene immer noch weitergeht. « ${ }^{\mathrm{I}}$ Er schien, im stormschen Sinne, eher zum Ruhen im Glauben geneigt. Doch standen ihm und seinem Gefolge turbulente Zeiten bevor. Denn schon traten nichts Gutes ahnende Skeptiker auf den Plan, entschlossen, die Höllenfeuer, die Sidgwick und die Seinen zu schüren schienen, mit ehrlichen Männerfersen auszutreten.

* In der Parapsychologie pflegt man mit »Schafen« Menschen zu bezeichnen, die fest an die Existenz von Psi-Phänomenen glauben, mit »Ziegen« dagegen jene, die schon ihre Möglichkeit entschieden bestreiten oder ihnen zumindest skeptisch gegenüberstehen. Das Kapitel entspricht der nur geringfügig modifizierten Fassung eines Textes, der demnächst unter dem Titel »A cloddish controversy. Andrew Lang und Edward Clodd im Streit um die Frage, ob Psi-Phänomene anachronistische Eruptionen barbarischer Unwissenheit oder seriöser Forschung würdig sind « in der Zeitschrift für Parapsychologie und Grenzgebiete der Psychologie ercheinen wird. Ich danke Herrn Dipl.-Psych. Eberhard Bauer vom Institut für Grenzgebiete der Psychologie und Psychohygiene in Freiburg im Breisgau für wertvolle Literaturhinweise. 
Der Streit um die Realität von Erfahrungsphänomenen hob mit Sicherheit bereits an, als die ersten Archanthropinen aus dem Formenkreis des Homo erectus vor gut I, 5 Millionen Jahren sich sprachlich zu verständigen begannen. Seitdem salzt und pfeffert er nahezu jedes Gespräch, jeden Rechtsstreit und Glaubensdisput, jede realwissenschaftliche Diskussion - in den »Idealwissenschaften « Mathematik und Logik stellt sich das Problem bekanntlich nicht. Nach den Prinzipien des Kritischen Rationalismus kann es einen Erkenntnisfortschritt nur geben, wenn man einander des Irrtums oder gar der Täuschung entlarvt, zurückhaltender ausgedrückt: durch »Falsifizierung«. Insofern wäre es eher ein Skandal gewesen, in der Realitätsfrage eins zu sein. Erfahrene Schäfer lassen Schafe und Ziegen gemeinsam weiden, wohl wissend, daß sie ihrer Nahrungssuche auf unterschiedlichen Niveaus nachgehen. Doch Menschen sind Omnivoren. Sie neiden einander die Kost, führen kritische Argumente für ihre Präferenzen ins Feld, sind überzeugt, im Recht zu sein, und streiten darüber, wobei sich, nunmehr nach den Kriterien der Evolutionären Erkenntnistheorie, die Besserwissenden durchsetzen. Dawider erhob in der Kontroverse, um die es im folgenden geht, der Poet, glänzende Feuilletonist, Schriftsteller, anerkannte Altertums- wie Literaturwissenschaftler und Ethnologe Andrew Lang (I844-I9I2) seine Stimme.

Ihm stand an der Ziegenfront ganz vorn der Londoner Bankier ohne Furcht und Tadel Edward Clodd (I840-I930) gegenüber, dessen Herz fest für den damals in vollem Flor stehenden Evolutionismus schlug. Der wirkte nicht zuletzt so befeuernd, weil er seinen Vertretern, mehr noch der »Rasse«, der sie angehörten, die schöne Gewißheit gab, $z u$ Recht die führende Rolle in der Welt zu spielen. Und nicht, weil Gott ihnen das verheißen, sondern die Wissenschaft den untrüglichen Beweis dafür geliefert hatte - die Biologie, aber auch die Ethnologie, die ihr nachzog. Die europäischen »Herrenvölker«, das lehrten die vergleichenden Kulturwissenschaften, hatten sich nicht allein physisch durchgesetzt, sie standen auch an der Spitze des zivilisatorischen Fortschritts. Clodds Verehrung galt neben Charles Darwin (I809-I882), Herbert Spencer (I820-I903), Charles Lyell (I797-I875), Thomas Henry Huxley (I825-I895) und anderen prominenten Naturgelehrten seiner Zeit, deren einige ihm freundschaftlich verbunden waren, auch Edward Burnett Tylor (I832-I9I7), dem großen Alten der englischen Ethnologie. Sie alle einte das Bekenntnis zum Rationalismus, der auch Clodds Überzeugungen Flügel verlieh.

Doch war der Sieg noch längst nicht erfochten. Zäh leisteten die minder Tüchtigen den Erleseneren Widerstand. Allein letztere besaßen in der Wissenschaft das überlegene Waffensystem. Ihr kamen indes nicht nur agonische, sondern mehr noch aufklärerische Aufgaben zu. Clodd focht in der vordersten Frontlinie mit. Er belehrte die Öffentlichkeit mit Werken über den Ursprung des Menschengeschlechts, der Religion und Mythologie, die bewußt schlicht gehalten waren, damit sie jedermann, auch Kin- 
der, verstehen konnten, schrieb über Mana und Magie und führte vor allem einen wahren publizistischen Feldzug wider Aberglaube, Spiritismus und Okkultismus - jene fauligen Altlasten der Evolution, die es endgültig auszutilgen galt. ${ }^{2}$ Wenn wir, verhieß er, kraft wissenschaftlicher Analyse »einen Aberglauben erledigen (if we kill a superstition)«, zeigt das nicht nur seine Hinfälligkeit, der jeder Irrtum ausgesetzt ist, es heißt auch, sich entschlossen und aufrecht in den Dienst »der vitalen Kraft des menschlichen Fortschritts zu stellen «. ${ }^{3}$

Diesem achtbaren Ziel hatte sich auch die Folk-Lore Society verschrieben. Von einem anfangs noch kleinen Kreis Gleichbewegter, zu denen auch Clodd und Lang gehörten, 1878 in London gegründet, vereinigte sie schon bald die führenden Köpfe der - damals noch ungeschiedenen Volks- und Völkerkunde. Zu ihrem zehnjährigen Jubiläum widerfuhr Lang die Ehre, ins Präsidentenamt gewählt zu werden, während Clodd, seinen genuinen Gaben gemäß, zunächst noch die Funktionen des Kassenwarts und Treuhänders wahrnahm. ${ }^{4}$ Als er dann seinerseits I895 und noch einmal I896 das Amt des Präsidenten bekleidete, zählte die Gesellschaft unter anderen so renommierte Ethnologen wie den Sehr Ehrenwerten Sir John Lubbock (1834-19I3), General-Leutnant Augustus Henry Lane Fox Pitt-Rivers (1827-I900), den schon genannten Tylor, Edwin Sidney Hartland (I848-I927), Alfred Cort Haddon (I855-I940) und James George Frazer (1854-I9I4) zu ihren Mitgliedern. ${ }^{5}$

Es war ein respektabler Verein. Und dem entsprachen auch die Aufgaben, die er sich setzte. Mit Befremden mußte man konstatieren, daß etliche magische Praktiken, absonderliche Brauchtümer und verquere Vorstellungen, wie man sie an sich bei den Wilden vorzufinden gewohnt war, auch unter Zivilisierten noch anstanden. Die Lösung des Rätsels gab der Evolutionismus vor. Man begriff sie als lebende Fossilien oder, wie Tylor sie nannte, «survivals«, die in abgelegenen Nischen den Vormarsch des Fortschritts überdauert hatten. Verglich man sie mit den analogen, unter Wilden noch voll florierenden Formen, besaß man zum einen die Möglichkeit herauszufinden, welch krauser Sinn ihnen innewohnte, das heißt vermochte sie zu entlarven und $\mathrm{zu}$ »erledigen«, und hatte zum andern ein Mittel, die ältesten Stadien der seelischen und kulturellen Entwicklung der Menschheit zu rekonstruieren ${ }^{6}$ - wie die Astronomen aus dem Studium der fernsten Himmelskörper Einblick in die Entstehungsgeschichte des Universums gewinnen.

Clodd machte begeistert mit. Man hatte den Schlüssel gefunden, der alles erklärte. Die Wilden waren ihrer animalischen Vergangenheit noch kaum entwachsen. »The lowest savage of to-daץ«, so der gelehrte Bankier, »is not on a much higher plane than the most intelligent animals«. ${ }^{7}$ Insofern ließ sich auch von ihren kognitiven Kompetenzen nur wenig erwarten. Zum Beispiel vermochten sie subjektive noch nicht von objektiven Wahrnehmungen zu scheiden. ${ }^{8}$ Traumgesichte - hier folgte Clodd der Animismus-Theorie Tylors - hatten in ihnen den Glauben geweckt, daß der 
Mensch eine leibunabhängige Seele besitze, die nach seinem Dahinscheiden fortexistiert, während rätselhafte Naturphänomene wie Echo, Wind, Gewitter und dergleichen, aber auch die Erfahrung mit eigenen hysterischen Leiden, Ohnmachten, epileptischen Anfällen, Schizophrenie, Paranoia usw. sie zu der Überzeugung verleiteten, daß es, analog zur Seele, noch andere spirituelle Wesenheiten gebe, allezeit bereit, den Menschen zu narren wie zu quälen - beispielsweise durch Mißerfolge, Unfälle, Besessenheit, Träume und Halluzinationen. ${ }^{9}$ Der Urmensch lebte in der bekannten »Heidenangst« vor den ihn ständig umlauernden Dämonen, gefangen im Dunkel seiner geistigen Schwerfälligkeit. »Remember«, rückt Clodd seinen Lesern in The Childhood of Religions vor, ein manichäisches Szenario im Rembrandtschen Chiaroscuro entfaltend, »that where ignorance is, there is darkness; but that where knowledge dwells, light abides«. ${ }^{\text {IO }}$

Angst stand am Beginn der religiösen Vorstellungsbildung - die Angst vor dem Unsichtbaren, dem der Wilde mit allerhand Imaginationen Gestalt zu verleihen suchte. So hatte auch Thomas Hobbes (I588-I679) im Leviathan gelehrt, auf den sich Clodd immer wieder beruft. Zunächst allerdings reichten die zerebralen Kapazitäten natürlich nicht aus, sich spirituelle Wesen nach dem Bilde des Menschen vorzustellen. Wie der Hund - ein beliebtes Vergleichsbild Clodds für den frühen Menschen sich vor dem Knochen ängstigt, der sich plötzlich, von seinem Besitzer versuchsweise an einem unsichtbaren Faden gezogen, wie aus eigener Kraft fortzubewegen scheint, glaubten die Menschen ursprünglich, daß allen Dingen und Naturerscheinungen unpersönliche Kräfte innewohnten. Clodds Zeitgenossen, die der gleichen Auffassung waren, schöpften dabei aus Beobachtungen von Reisenden und Missionaren, wie namentlich denen Robert Henry Codringtons (I830-I922), die von derartigen Vorstellungen bei Südsee-Insulanern berichtet hatten. ${ }^{\text {II }}$ Clodd bezeichnete diese Entwicklungsphase als Stufe des »Naturalismus«, andere, die mehr Gewicht auf den Umgang mit den ominösen Kräften - dem mana der Melanesier und Polynesier zum Beispiel, dem wakan der Sioux oder dem orenda der Irokesen - legten, sahen in der Magie die Leitvorstellung jener Zeit. Frazer bevorzugte daher die Bezeichnung »The Age of Magic«, das auch seinem Dafürhalten nach bestimmt war von geistigen Defiziten, die dementsprechend nur $\mathrm{zu} »$ Fehlkonzeptionen« (misconceptions) führen konnten. ${ }^{\mathrm{I} 2}$ Tylor hatte, wie schon im letzten Kapitel erwähnt, die ersten tastenden Bemühungen des Menschen, sich in seiner Horrorwelt zu orientieren, konzilianter immerhin als »eine sorgfältig und systematisch

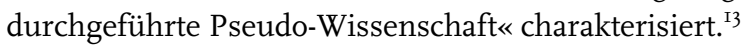

Auf den »Naturalismus« folgte dann, ebenfalls Hobbes zufolge und zuzeiten Clodds vor allem von Tylor, eigentlich aber allgemein geteilter Auffassung nach, der »Animismus«: Der Seelenglaube bildete sich aus, einzelne Tote stiegen zu Naturgeistern und Ressortgöttern auf, bis die Entwicklung schließlich, übergangslos in kontinuierlicher Geradlinigkeit fortschreitend, wie Clodd sich ausdrückt, »vom Bellen des Hundes bis zu 
den Reden des Demosthenes oder dem Vibrieren einer Amöbe bis zu den Ekstasen der Heiligen ${ }^{\mathrm{I}}{ }^{4}$, streng den Gesetzen der »evolutionistischen Lehre « folgend ${ }^{15}$, ihren Höhepunkt im Monotheismus fand. ${ }^{16}$ Clodd kommentiert den Vervollkommnungsprozeß im Geiste der Frohen Botschaft: »Sunnier views of Him made glad the heart, chasing away the false ideas about Him that frightened poor timid, tender souls. $\ll^{\mathrm{T}}$ An anderer Stelle führt er zum Beweis das schlagende - und durch die bemannte Raumfahrt so glänzend bestätigte - Argument ins Feld: »Unsere Teleskope haben den Himmel abgefegt und keinerlei auf- oder absteigende Engel gefunden. $\ll^{18}$

Doch weder die Strahlen der güldenen Sonne noch der Besen »in ehrlicher Männerfaust« hatten die Risse und Lücken im verfallenden Altgemäuer aus vergangenen Tagen erfaßt. Dort nebelten nicht nur die Schwaden des alten Aberglaubens fort und trieben die Blumen des Bösen ins Kraut; in den Ruinen gingen auch Menschen um, die Tische schweben und klopfen ließen, mit anderen nonverbal Empfindungen und Gedanken austauschten, Geister sahen, die Toten heraufbeschworen und sich aus dem Sitzen heraus in die Luft erhoben. Für Clodd und Kombattanten war die Sachlage klar. Es handelte sich um Relikte aus grauer Vorzeit oder Rückfälle in die Wahnwelt jener Frühphase der Unwissenheit. ${ }^{\text {I9 }}$ Der Beweis lag auf der Hand: Die Betroffenen gehörten überwiegend den niederen, illiteraten Bevölkerungsklassen an. ${ }^{20}$ Sie standen insofern den Wilden nahe. Beiden, so Clodd, mangelt es an kritischer Urteilskraft, so daß sie nicht zwischen Wahn und Wirklichkeit zu scheiden vermögen. ${ }^{2 \mathrm{I}}$ Dummheit und Unwissenheit seien der Nährmix für Aberglauben wie Psi-Manie. Doch Clodd, den die Nöte des Nächsten nicht unberührt ließen, empfahl auch, den Armen im Geiste das Mitgefühl nicht zu versagen. Denn so sei es leider nun mal: » Where the corrective of knowledge is absent, we see that it could not be otherwise. ${ }^{22}$

Andrew Lang, der ihm gewissermaßen als »Schafskopf« gegenüberstand, entsprach zwar den Bildungsansprüchen Clodds, blieb aber dennoch verstockt. Vielleicht weil sein sanfteres, weiches Gemüt mehr Raum auch für akademisch Anstößiges bot. Die Gabe dazu schien ihm bereits in die Wiege gelegt. Er wuchs im ländlichen Süden Schottlands auf, wo der alte Volksglaube noch in Blüte stand. Die Vorsehung bescherte ihm eine Amme, die den heidnischen Überlieferungen offenbar mehr ergeben war, als sich mit der Würde der Kirche vertrug. Winterabends pflegten Andrew und seine Geschwister, um das Küchenfeuer versammelt, »verzaubert« ihren Liedern und Geschichten von Feen, Elfen und Kobolden, Gespenstern, Ungeheuern in einsamen Seen und verborgenen Schätzen zu lauschen. Die Kinder gewannen den Eindruck, daß es draußen im Hügelland kaum einen alten Stein gab, unter dem nicht Gold vergraben lag. ${ }^{23}$ Als Lang, etwa ab dem fünften Lebensjahr, lesen konnte, verschlang er alles, was ihm an Märchenbüchern, Gespenster- und Heldengeschichten unterkam. Er hatte die Angewohnheit, sechs Bücher geöffnet auf ebenso- 
vielen Stühlen zu verteilen und ihnen dann reihum seine Aufmerksamkeit zu widmen. ${ }^{24}$ Eine Dame, die damals in seinem Elternhaus verkehrte, erinnert sich an ihn als »einen Knaben, der, vertieft in ein Buch, nichts von seiner Umgebung wahrnahm und sichtlich keinerlei Interesse an kleinen Mädchen hatte ${ }^{25}$ Mit siebzehn besuchte er die Universität von St. Andrews, mit zwanzig das Balliol College in Oxford - in beiden Fällen mit so gutem Erfolg, daß ihm vier Jahre später am renommierten Merton College in Oxford ein Stipendium zugesprochen wurde ${ }^{26}$, dem er, später auch als Lehrer und Ehrenfellow, sein Leben lang verbunden blieb.

Lang schlug jedoch nicht den Gelehrtenweg ein, vielleicht weil er fürchtete, daß ihn dann die Feen geflohen hätten. Er wandte sich der Literatur zu, schrieb zahllose Artikel, Essays und Buchrezensionen für Zeitungen und Magazine, fiktionale Erzählungen, Märchen und Gespenstergeschichten, machte sich einen Namen als Lyriker, übersetzte die Ilias und Odyssee sowie ein altfranzösisches Epos und tat sich mit gelehrten Schriften über das homerische Griechenland, Jeanne d'Arc, die Entstehung und Entwicklung der Religion, über Mythologie, Brauchtum, Magie und Totemismus hervor, um sich in den letzten zwanzig Jahren seines Lebens schließlich verstärkt mit Fragen der Parapsychologie auseinanderzusetzen. Auch hier zeigte er sich äußerst produktiv. Neben etlichen Zeitungsbeiträgen und einschlägigen Artikeln für die Encyclopaedia Britanni$c a$ von 1902 sind vor allem die beiden Bücher Cock Lane and Common Sense (1894) und The Book of Dreams and Ghosts zu nennen, in denen er neuzeitliche Belege für Fälle von außersinnlicher Wahrnehmung (ASW) mit Befunden aus Ethnologie und Geschichte verglich. Als er I9I2 die Feder für immer aus der Hand gelegt hatte, füllten allein seine Buchtitel I6 Seiten im British Museum Catalogue aus. Insgesamt wird sein Euvre auf einige hundert Bände geschätzt. Er besaß eine ebenso breite wie solide Bildung, argumentierte mit kritischer Präzision, sparte auch nicht mit Selbstkritik, ließ sich gleichwohl nicht von gewagten, teils kühnen Kombinationen abschrecken und schrieb bei alledem einen Stil von gediegener literarischer Eleganz. ${ }^{27}$ Persönlich wird er als schüchtern und zurückhaltend, melancholisch und doch auch humorvoll, gelegentlich leicht herablassend beschrieben. ${ }^{28}$ Von der Tochter Lord Stairs, der Gräfin von Dumfries, berichtet er in Cock Lane and Common Sense, sie habe unter einer absonderlichen Unpäßlichkeit gelitten, das heißt die Gewohnheit gehabt, von einem Ende des Raums zum anderen sowie quer über den Garten zu fliegen. Dies sei sicher verbürgt. »Für ein Gartenfest«, so sein Kommentar dazu, »wäre diese Fähigkeit eine unschätzbare Attraktion. $\ll^{29}$

Lang zählte zu den führenden Literaten seiner Zeit, was seiner Stimme Gewicht verlieh. Er entdeckte und förderte - unter anderen - Robert Louis Stevenson (1850-1894) und Rudyard Kipling (1865-1936), war eng mit ersterem, mehr noch mit Henry Rider Haggard (1856-1925) und nicht zuletzt selbst mit Edward Clodd befreundet. Bei allem Erfolg vergaß er 
auch weniger Glückliche nicht. Notleidende Schriftsteller unterstützte er ebenso diskret und unauffällig wie generös, so daß er gelegentlich selbst in finanzielle Verlegenheit geriet. ${ }^{30}$ Neben der Ethnologie und Parapsychologie, für deren Anerkennung er publizistisch energisch focht, gehörte seine Liebe dem Cricket, Angeln, Schottland, Kindern und Katzen. ${ }^{3 \mathrm{I}}$

In manchem dachte er quer zum Trend seiner Zeit. In der Ethnologie flößte ihm ein penibles Quellenstudium die Überzeugung ein, daß am Anfang der religiösen Vorstellungsbildung, wie gerade der Befund bei den »most backward races« lehre, der Glaube an einen, und zwar schöpferisch tätigen Gott (einen »maker«) stand, der eher menschliche Züge trug und jedenfalls keinerlei Gemeinsamkeiten mit den üblichen Geistervorstellungen aufwies. ${ }^{32}$ Der Animismus konnte demnach nur später entstanden sein. ${ }^{33} \mathrm{Ihm}$ folgte der Polytheismus - und mit der weiteren sozialen Entwicklung ein steter Niedergang der religiösen Lebens- und Weltanschauung! $!^{34}$

Damit stellte er den Evolutionismus geradewegs auf den Kopf und legte sich prompt mit dessen führenden Repräsentanten an. Hartland goß die Schale des Hohnes über ihm aus ${ }^{35}$, Frazer, den er besonders attakkierte $^{36}$, strafte ihn mit beharrlicher Mißachtung. Langs Versuche, ihn aus der Reserve zu locken, gingen ins Leere. ${ }^{37}$ Bei dem schon genannten deutschen Ethnologen Pater Wilhelm Schmidt (I868-I954) dagegen, der seine Auffassung teilte, den »Urmonotheismus « jedoch - wie Stoiker und Kirchenväter schon Jahrhunderte vor ihm - in einer göttlichen »Uroffenbarung « begründet sah, fand er freundliche Anerkennung. Lang selbst hatte den Erfund nur konstatiert, nicht aber zu erklären versucht.

In seinen parapsychologischen Studien vertrat er die Meinung, daß es sich in den rezenten Fällen kaum, wie etwa bei gewissen Formen des Geburts- oder Hochzeitsbrauchtums, um anachronistische »Überlebsel« (survivals) aus versunkenen Tagen handeln könne, da Hellsehen, Gedankenübertragung, Levitationen und dergleichen lebendiger Bestandteil heutiger Erfahrungs- und Kulturwirklichkeit seien und immerhin durchaus gesunde und achtbare Personen zu Zeugen hätten. ${ }^{38}$ Und seine nächste querschlägige Folgerung: Man müsse die ethnographischen und historischen Berichte wissenschaftlich ernstnehmen und als mögliche Quelle der religiösen Vorstellungsbildung, etwa des Geisterglaubens, in Betracht ziehen. Selbst wenn sich alles als Blendwerk trickreichen Trugs herausstellen sollte, wäre damit immer noch viel für Volks- und Völkerkunde gewonnen. ${ }^{39}$ Dazu aber müsse gesammelt und verglichen werden, was immer erreichbar sei - wobei Lang selbst mit bestem Beispiel voranging. ${ }^{40}$ Freilich war ihm bewußt, daß er damit schwankenden Boden betrat. Seine Kollegen in der Folk-Lore Society zogen irritiert die Brauen hoch; nahm er doch die Phantasmagorien der Wilden, »condemned by modern science«, ernst. ${ }^{4 \mathrm{I}}$ Unter den Ethnologen trug ihm das lediglich posthum bei William Halse Rivers (I864-I922) Achtung ein, der ihn unerschrocken als »Pionier einer Forschungsrichtung« pries, »von der 
noch viel zu erwarten steht.« « ${ }^{22}$ Er selbst plädierte für nichts mehr und nichts weniger, als die Dinge unvoreingenommen, rational und mit »fairness« anzugehen. ${ }^{43}$ Vertrauenswürdigen und ehrenhaften Zeugen mit Mißtrauen, ja Verdächtigungen zu begegnen, sei wenig sportlich und überdies unbritisch. ${ }^{44}$ Es gehe zudem nicht um »übernatürliche« (supernatural), sondern lediglich »ungewöhnliche (unusual) Vorkommnisse. ${ }^{45}$

Seine Untersuchungen erbrachten, daß Psi-Phänomene sowohl weltweit als auch zu allen Zeiten mit großer formaler Übereinstimmung auftreten ${ }^{46}$; auch das widerlegte den Evolutionismus. Schon die erdrückende Masse der Belege besitze ein Gewicht, das sich nicht leichthin abschütteln lasse. ${ }^{47}$ Allerdings sei damit noch keine Erklärung gewonnen. Es fehle noch an einer » round < and satisfactory hypothesis«, die allen Fakten gerecht werde und ihre Kontinuität begründen könne. ${ }^{48}$ Mit der gebotenen Vorsicht deutete er immerhin denkbare Möglichkeiten an. Wie, wenn der Wilde nicht, wie ihm allgemein unterstellt werde, seine Erfahrungen generell fehlinterpretiert, sondern tatsächlich wiedergibt, was er erlebt? In dem Falle wäre die Folgerung unausweichlich, daß ihm lediglich Ungewöhnliches widerfuhr, das er konsequent seinem Weltbild integrierte, um sich gerade nicht von ihm schrecken zu lassen. Das wiederum würde voraussetzen, daß Menschen allezeit Psi-Gaben besaßen. »Similar conditions of mind«, so die These Langs, »produce similar practices, apart from identity of race, or borrowing of ideas and manners. ${ }^{49}$ Früher habe man das akzeptiert, heute werde es von der Wissenschaft für Humbug erklärt. Vermutlich liege aber gerade hier die Ursache für übereinstimmende Vorstellungs- und Brauchtumsformen und könne es sich insofern um »an important element of rejected truth « handeln..$^{\circ}$

Lang war gewonnen. 1904 trat er der Society for Psychical Research bei, um bereits I9II, ein Jahr vor seinem Tod, zu ihrem Präsidenten gewählt zu werden. Er befand sich hier in bester, teils nobler Gesellschaft. Zu den Vorstands-, Ehren-, korrespondierenden und gewöhnlichen Mitgliedern zählten zum Beispiel zwei Bischöfe, ein ehemaliger Premierminister (Arthur Balfour), der Zoologe und Mitstreiter Darwins Alfred Russell Wallace (I823-I9I3), die Physiker und Chemiker Sir William Crookes (I832-I9I9), Marie Curie (I867-I934, Nobelpreis I9II), John William Strutt, der spätere Lord Rayleigh (I842-I9I9, Nobelpreis I904), und Sir Joseph John Thomson (I856-1940, Nobelpreis I906), die Philosophen Henri Bergson (I859-I94I, Nobelpreis I927) und Hans Driesch (I867I94I), die Psychologen William James (I842-I9I0), Sigmund Freud (I856I939) und Carl Gustav Jung (I875-196r), die Maler John Ruskin (I8I9I900) und George Frederick Watts (I8I7-I904) sowie der Dichter Alfred Lord Tennyson (1809-1892) und der schriftstellernde Mathematiker Lewis Carroll (I832-1898) ${ }^{5 \mathrm{I}}$ - eine Galerie der besten Köpfe jener Zeit und zugleich, in scharfem Kontrast dazu, ein beklemmendes Zeugnis für die geistige Enge, teils bornierte Voreingenommenheit und mangelnde Neugier heutiger Gelehrter, die sichtlich nur kaum mehr die Bereitschaft und 
den Mut der damaligen großen Pioniere aufbringen, sich mit Fragen auseinanderzusetzen, die nun mal nicht ins eigene wissenschaftliche home and castle zu passen scheinen.

Das erklärte Ziel der Gesellschaft, »ohne Voreingenommenheit oder Vorurteile und im Geiste der Wissenschaft jene menschlichen Gaben, seien sie nun real oder bloß vermutet, zu untersuchen, die mit allgemein anerkannten Hypothesen nicht explikabel erscheinen ${ }^{52}$, entsprach ganz der Einstellung Andrew Langs. Und zudem fußte seine Affinität zu den »Psycho-Forschern « in seiner tiefsitzenden Inklination für alles Geheimnisvolle und Mysteriöse. ${ }^{53}$ Nicht von ungefähr hatten Feen an seiner Wiege gestanden. Er bekannte, Erscheinungen, Erfolge beim Tischrücken und Automatischem Schreiben gehabt zu haben, und sah, wie in seiner Familie seit Generationen üblich, kurz vor seinem Tod eine »schreckliche, gespenstische Katze ${ }^{54}$

Diese typisch schottischen Schattenseiten ließen ihn den Mitgliedern der Folk-Lore Society in London als schwarzes Schaf erscheinen. Als Clodd I895 den Präsidentensessel der Gesellschaft bestieg, schlug er gnadenlos zu. Am Ende seiner Presidential Address listete er, kurz und bündig, die Verfehlungen Langs und seiner Gesinnungsgenossen auf. Es begann eine Auseinandersetzung, die ein Autor erst kürzlich - und wohl ein wenig über Gebühr - »als die berühmteste Debatte zwischen dem rationalistischen und dem supernaturalistischen Lager in den Annalen der Volksund Völkerkunde « bezeichnete. ${ }^{55}$ Clodd selbst sprach in seinem Nachruf auf den Freund, sichtlich nicht ohne spätes Bedauern, von »our bloodless duel.$^{5}{ }^{6}$ Im Grunde ging es um nur wenige Punkte, wie sie im übrigen unverändert auch heute noch die Gemüter erhitzen.

I. Clodd rückte den »Schafen« von der Society for Psychical Research $(S P R)$ vor, sich entgegen ihren gediegenen Grundsätzen von ebenso eingefleischten wie intolerablen Vorurteilen leiten zu lassen. Der »wahre« Brauchtumsforscher dagegen »dringt, gleich dem Biologen, unvoreingenommen [...] bis zu den Ursprüngen vor, sortiert die Varietäten, vergleicht, klassifiziert und vereint die verschiedenen Familien zu einer Ordnungsgruppe $\ll .57$

Lang erwiderte: Unsere Gegner behaupten, sie selbst seien bar aller Vorurteile. Doch eben hierin liegt ihr erstes. Gerade Gelehrte sollten wissen, daß kein Mensch tatsächlich frei davon ist. ${ }^{5}$ Ich, outet sich Lang nicht ohne Hintersinn, stehe dazu - ich bin durch und durch »Romantiker«. Wäre ich ohne jedes Vorurteil, hätte ich meinen Humor verloren; würde ich meinen Bias verbergen, ginge ich meiner Gelehrtenehre verlustig. Ich gestehe, »ich würde selbst einen Poltergeist, sofern seine Existenz außer Zweifel stünde, mit Vergnügen willkommen heißen; nicht, daß ich in ihm einen angenehmen Zeitgenossen sähe - weit gefehlt! Wenn ich Poltergeist sage, meine ich eine gesicherte Instanz, die verantwortlich für die absonderlichen Bewandtnisse und Bewegungen von Objekten ist ${ }^{59}$ Eine zweite Voreingenommenheit diagnostizierte Lang 
im »napoleonischen Selbstvertrauen« gewissermaßen der »Leitziegen « in ihre intellektuelle Überlegenheit. ${ }^{60}$ Man überschätze den Rationalismus ${ }^{6 \mathrm{I}}$ und sei überzeugt, alle Aspekte der menschlichen Natur befriedigend in Begriffen der Chemie und Biologie erklären zu können. Die Mitglieder der SPR seien sich da weniger sicher und würden immerhin der Möglichkeit Raum geben, daß in der Hinsicht noch mehr und anderes zu entdekken sei. ${ }^{62}$ Ein drittes Vorurteil machte Lang in Clodds Überzeugung aus, alles, womit sich die SPR beschäftige, sei »verseucht vom alten Animismus « und insofern »dummes Zeug und Aberglaube«. Das wäre zumindest nicht sonderlich originell, da es ganz den Erklärungen der Wilden und unserer Altvorderen entspräche. ${ }^{6}$ Viertens schließlich handle es sich dabei um einen typisch evolutionistischen Bias im Sinne der Aussage »Mr. Tylor's«, Überlebtes könne getrost als wertlos abgelegt werden. »Distinguo!« hält Lang dagegen: Es gelte zu scheiden; manche Phänomene, die noch heute lebendigen aufs Haar entsprechen, könnten doch durchaus wichtige Aufschlüsse zu einem besseren beiderseitigen Verständnis liefern. Sie achtlos beiseite zu schieben, würde die Wissenschaft unter Umständen wertvoller Erkenntnisquellen berauben. ${ }^{64}$

2. Clodd legte nach. Nein, es sei mit den Idealen eines seriösen Gelehrten ganz und gar unvereinbar, sich mit den Schrullen der »barbaric spiritual philosophy $\mathrm{zu}$ beschäftigen ${ }^{65}$ und in ernsthafte Diskussionen über »das Gewäsch (twaddle) von närrischen Geistern « einzutreten. ${ }^{66}$ Die $S P R$ würde lediglich den »guten alten Animismus« mit ebenso vagen wie hochtönenden Phrasen wie »subliminales Bewußtsein«, »telepathische Energie« oder der »Unsterblichkeit des psychischen Prinzips« überschäumen. ${ }^{67}$ Die Folk-Lore Society, stellte er klar, habe an derlei Hirngespinsten keinerlei Bedarf. ${ }^{68}$ Sie sehe sich im Gegenteil verpflichtet, »truth from trance« zu trennen. ${ }^{69}$ Er empfahl den »Schafsköpfen« auf der Gegenseite, sich einmal kompromißlos der Frage zu stellen, ob Psi-Phänomene nicht »Effekte krankhafter Dispositionen « sein könnten und ihre wahre Ursache in Übermüdung, Hunger, Psychosen oder Störungen der Leberfunktion und des Verdauungstraktes hätten ${ }^{70}$, wofür die Ernährungsgewohnheiten der Wilden wie der rezenten ländlichen Bevölkerungen doch gute Voraussetzungen böten..$^{7 \mathrm{I}}$ Die SPR jedenfalls habe diesem Gesichtspunkt noch viel zu wenig Rechnung getragen. ${ }^{72}$ Neuere Kritiker, weniger gentlemanlike, belassen es nicht bei wohlmeinenden Ratschlägen. Sie behaupten herausgefunden zu haben, daß Psi-Gläubigkeit generell mit »schizotypischen Verhaltensstörungen« einhergehe. Allerdings scheinen die Untersuchungen, aus denen sie ihre Befunde schöpfen, methodisch nicht eben astrein zu sein.73

Lang erwiderte, Clodd habe, wenngleich bedingtermaßen, Recht. Selbstverständlich könnten organische oder mentale Störungen und überhaupt die Konfusionen im Denken der Wilden auch an der Entstehung der Phänomene beteiligt sein. ${ }^{74}$ Schließlich trug auch er noch am Erbe des Evolutionismus. Doch sah er den Wilden immerhin differenzierter. 
Sein Schüler, der große englische Religionsethnologe Robert Ranulph Marett (I866-I943), hörte ihn einmal sagen: »The savage is an absurd fellow, but on the whole a sportsman. ${ }^{75}$ Clodds Invektiven gründeten jedoch, so rückte er ihm vor, auf unzulässigen Generalisierungen. Die Erfahrung zeige untrüglich, daß es, und gerade auch heute noch, Menschen von bester Gesundheit und untadeliger Vertrauenswürdigkeit gebe, die fraglos über Fähigkeiten verfügten, die mit den materialistischen Kriterien der Wissenschaft unvereinbar, also inexplikabel seien. ${ }^{76}$ Er dachte dabei vor allem an die unerwartet auftretenden, sogenannten »spontanen« Phänomene wie namentlich die Krisentelepathie. Sie widerlegten nun mal die Annahme, daß es sich immer und nur um animistische survivals handle. ${ }^{77}$ Dergleichen komme häufiger vor, als Vernunftapostel vom Schlage Clodds sich träumen ließen. Viele Menschen, die Psi-Erfahrungen machten, getrauten sich nicht, sie einzugestehen, aus der begründeten Befürchtung, von Leuten wie Clodd gleich des Aberglaubens und der Rückständigkeit bezichtigt zu werden. ${ }^{78}$ Die »Psycho-Folkloristen «, wie Lang einmal sich und seinesgleichen etikettierte, beschäftigten sich nicht, wie Mr. Clodd ihnen unterstelle, mit der »Geister-Welt«; sie interessierten sich vielmehr für faktisch durchaus beobachtbare Phänomene, die aber in der Hauptsache mentaler Natur seien. Wenn Menschen zum Beispiel halluzinierten, begreife er nicht, warum in aller Welt das nicht Gegenstand wissenschaftlicher Forschung sein solle?79 Wir widmen uns, erklärt und wiederholt er schon nachgerade mit Engelsgeduld, nicht mit dem »Übersinnlichen«; wir beschäftigen uns lediglich mit besonders ungewöhnlichen Vorkommnissen. »Eine Geistererscheinung«, hält er Clodd und seiner »Ziegensuite« vor, »ist, gesetzt, ihre Existenz unterliegt keinem Zweifel, ein ebenso >natürliches $>$ Phänomen wie die Verdauung « ${ }^{80}$ (die Sorge um eine komplikationsfreie Digestion spielt in der viktorianischen Literatur eine merkwürdig hervortretende Rolle). Lang schloß für seine Person allerdings die Möglichkeit eines Fortlebens nach dem Tod - und je älter er wurde, um so mehr - davon aus. In der SPR verfocht sie vor allem der bedeutende Althistoriker und Mitbegründer der Gesellschaft Frederic Henry Myers (I843-I90I). »I cannot march with him«, bekannte Lang I903 in seinem Artikel Human Personality after Death für die Märzausgabe der Monthly Review, um schließlich in seiner Presidential Address I9ı hinzuzufügen: »I believe in nothing of the sort. « ${ }^{8 \mathrm{I}}$

3. Clodd warf der SPR-Garde des weiteren vor, sie ließe sich allzu bereitwillig von Scharlatanen hinters Licht führen. ${ }^{82}$ Ihr Bias narkotisiere offensichtlich ihr Urteilsvermögen. Gelehrsamkeit scheine nicht wirksam davor zu schützen. Wenn es um ein chemisches Element wie Thallium, das Radiometer oder eine der anderen wundervollen Entdeckungen von Mr. Crookes gehe, hege er keinerlei Zweifel. Doch sobald die Herren »in dunklen Räumen mit Medien zusammensitzen, die zu abnormen ekto-

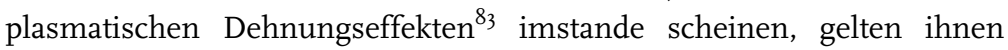
weder Zeit und Raum noch die Gesetze der Schwerkraft mehr etwas«. Des 
Menschen Sinne, so das Credo Clodds, »sind seine Erzbetrüger (archdeceivers), denen die Vorurteile hilfreich zur Hand gehen«. Dagegen immunisiere allein intellektuelle Selbstdisziplin. ${ }^{84}$ Und sichtlich nicht ohne Triumphgefühl führt er zum Beweis den Fall des seinerzeit international hochrenommierten Mediums Eusapia Paladino (I854-I9I8) an, dessen Demonstrationen, wie namentlich Tischrücken und Materialisationen, allenthalben Furore machten. Auch Lang zeigte sich so beeindruckt, daß er bekannte, »praktisch überzeugt« zu sein. Doch es blieben Zweifel. Eusapia wurde wiederholt getestet, beziehungsweise »durchgemangelt« (busted up), wie Lang es ausdrückte, um dann tatsächlich des Trickbetrugs überführt zu werden. »Daß eine illiterate, wenn auch schlaue neapolitanische Taschenspielerin Männer von hoher Intelligenz zu Narren halten konnte, bestätigt«, so Clodds genüßliches Resümee, »meine Vorbehalte voll und ganz. $\ll^{85}$ Klüger hätten sich hinterher allerdings nur einige wenige gezeigt, andere dagegen ein trotziges »e pur si muove« gemurmelt. Mr. Lang habe immerhin, halb scherzend, in einem Brief, »where one hears him whistling to keep up his courage«, freimütig eingeräumt, er hoffe, Eusapia werde nunmehr der SPR die Gelegenheit geben, ihr Geld für bessere Zwecke aufzuwenden. ${ }^{86}$

Lang erwiderte, Irrtümer müßten, wie die Geschichte der Wissenschaft sattsam belege, keinesfalls eine Katastrophe darstellen; man könne lernen aus ihnen. Im besagten Fall wisse man jetzt, wie der Trick funktioniere, und das sei insofern ein wichtiger Wissensgewinn, als er transkulturell und über Jahrhunderte hin angewandt worden sei. ${ }^{87}$ Denn rein erkenntnispragmatisch erscheine ihm sinnvoller $\mathrm{zu}$ fragen, warum etwas immer wieder gemacht oder erzählt werde, statt, ob es »wahr « sei. ${ }^{88}$ Und überdies dürfe man nicht übersehen, daß die Trickhypothese nur eine begrenzte Reichweite besitze. Sie könne schwerlich weder Suggestion und Hypnose noch etwa durch Drogengenuß induzierte Halluzinationen erklären. Ihm sei durchaus begreiflich, daß die SPR sich für derartige Phänomene interessiere, nicht aber, warum sie die Volks- und Völkerkunde kalt lasse. ${ }^{89}$ Sollten denn alle, die jemals Psi-Erlebnisse hatten, und nicht zuletzt die besonders kritischen und vertrauenswürdigen unter ihnen, »Sklaven angeborener Instinkte und Opfer gerade der untauglichsten (unfittest) Reliktvorstellungen « sein? Und müsse es nicht überhaupt sehr merkwürdig erscheinen, daß ausgerechnet die am wenigsten tauglichen Traditionen mit einer derartig kraftvollen Beharrlichkeit überleben? ${ }^{90}$ Lang benannte hier zu Recht einen Widerspruch, den die in ihrem »napoleonischen Überlegenheitsdünkel« hochhinwandelnden Cloddschen »Ziegen« großzügig ihrer Aufmerksamkeit zu entschlagen beliebten.

4. Clodd wich einen Schritt zurück und dämpfte ab, er werfe den Psychoforschern nicht so sehr vor, daß die Phänomene, denen ihr Interesse gelte, von Geistwesen verursacht seien. Von mir aus, räumte er großmütig ein, »können sie glauben, was sie wollen«. Seine Vorbehalte bezögen sich weniger auf ihre Untersuchungen als die dabei angewand- 
ten Methoden. Zum Beispiel habe sich eine ihrer Kommissionen mit Halluzinationsphänomenen beschäftigt und dabei nahezu doppelt soviel Frauen wie Männer befragt. Ein Zehntel der Befunde sei von Angehörigen der »ungebildeten Klassen«, wie Besitzern kleiner Läden und Küstenwächtern, erhoben worden. Zudem hätten neben den Herren Sidgwick, Myers und Podmore den Hauptpart in der fünfköpfigen Kommission offenbar die beiden weiblichen Mitglieder, nämlich die Gattin des Erstgenannten und Fräulein Alice Johnson, innegehabt, was sein Mißtrauen zusätzlich nähre. Denn wen könne es ernstlich wundern, daß da die Ergebnisse positiv ausfielen. Geistig Minderbemittelte und Frauen neigten natürlich eher zu Halluzinationen. Zwölf der Befragten hätten sogar vorgegeben, »Engel« gesehen zu haben! Tröstlich sei immerhin, daß England deutlich besser als Brasilien und Rußland abgeschnitten habe. ${ }^{9 \mathrm{I}}$ Er perhorresziere derartige Untersuchungsmethoden; sie seien wertlos, weil inkorrekt und von Vorurteilen geleitet. »The psychical researcher«, beschied er zum Schluß seiner so absolut vorurteilsfreien Abrechnung, »represents a state of feeling, the folklorist represents an order of thought. "92 $^{2}$

Lang ließ die Blöße, die ihm sein Kontrahent hier allzu unbedacht bot, nicht ungenutzt. In seiner Presidential Address I9II vor der Society for Psychical Research würdigte er den Anwurf nur weniger Worte und drückte den Finger dabei sanft, aber mit Nachdruck auf die weiche Stelle. »Ein Freund von mir«, sagte er, »den ich nicht namentlich nennen will, hat unsere Halluzinationsstudie kritisiert [...] Von den Befragten, die bestätigende Antworten gaben, waren I85 keine Briten und daher, natürlich, geistig minderbemittelt. Soweit ich also sehe, sind Nichtengländer allesamt Hohlköpfe.« Er habe seinen Freund vor derartigen Verstiegenheiten gewarnt. Doch, durchdrungen von seiner intellektuellen Überlegenheit, habe er sich, wie Napoleon bei Waterloo, in sein Verhängnis gestürzt und seine halsbrecherische Statistik publiziert. ${ }^{93}$ Mehr bedurfte es nicht. Mit der Offenlegung des krassen Vorurteils Clodds war auch seine Kritik erledigt.

Manche, wie Gillian Bennett, meinen, es sei nicht möglich zu entscheiden, wer bei dem Disput letztlich die Oberhand behalten habe. Die Standpunkte hätten $\mathrm{zu}$ weit auseinandergelegen, um einen Ausgleich auch nur denkbar erscheinen zu lassen. ${ }^{94}$ Ich sehe es anders. Clodd war es, der seine Ansichten mit Schafsvertrauen verfocht, das heißt sich selbst zu keinem Augenblick in Frage zu stellen vermochte. Wo die Schwierigkeiten erst eigentlich anfangen, lagen für ihn die Lösungen bereits wohlfeil bereit. Bei allem Argumentieren stand das evolutionistische Credo immerzu schon gleichsam als Koeffizient vor der Klammer. Lang dagegen blieb unsicher und skeptisch, auch seinen eigenen Auffassungen gegenüber. Bereits in Cock Lane and Common Sense bekannte er, alles andere als überzeugt zu sein, daß den Phänomenen, von denen er berichte, auch tatsächlich Realität zukomme; er sehe sich außerstande, eine Entschei- 
dung pro oder contra zu treffen. ${ }^{95}$ Insofern nahm er es mit den Prinzipien der wisenschaftlichen Redlichkeit und des kritischen Rationalismus ernster als die »Ziegen«, die ihm allzuhoch erhobenen Hauptes meinten, die Hörner zeigen zu müssen.

Und nicht zuletzt behielt er Recht. Psi-Phänomene sind weder Relikte aus grauer Vorzeit noch - beziehungsweise allein - die verquere Ausgeburt zurückgebliebener, unterernährter oder morbider Hirne. Das von Lang wiederholt geltend gemachte Argument, für ihre Realität spräche vor allem, daß sie zu jeder Zeit, unabhängig von den jeweils gegebenen kulturellen Voraussetzungen, von Stand und Intelligenz der Personen immer wieder unter formal und strukturell übereinstimmenden Bedingungen in Erscheinung treten könnten, hat durch die stetig wachsende Zahl von Belegen, zu denen nicht zuletzt die Ethnologie einen erheblichen Teil beitrug, eine schwerlich abweisbare Bestätigung erfahren. Zumal Telepathie, Hellsehen und Psychokinese, das heißt die mentale Einflußnahme auf physische Körper und Zustände, dürften inzwischen als gesicherte Tatbestände gelten. Dem gab unter den renommierteren Ethnologen, wie schon erwähnt, als erster William H. Rivers in seinem Nachruf auf Lang ungeschminkt Ausdruck. Seinem Wirken sei es vor allem zu danken, daß nunmehr die Zeit, in der es für einen Wissenschaftler noch als unziemlich galt, sich mit der Parapsychologie zu befassen, endgültig der Vergangenheit angehöre ${ }^{96}$ - eine Einschätzung, die allerdings, wie die Folgezeit lehrte, an verfrühtem Optimismus litt. Viele haben zwar sogar selbst entsprechende Erfahrungen gemacht, mochten sich aber nicht dazu bekennen, bis zum heutigen Tag, weil sie noch immer meinen, um ihre Reputation fürchten zu müssen. ${ }^{97}$ Rühmliche Ausnahmen bildeten da zum Beispiel, beide aufgrund einschlägiger Erfahrungen während ihrer Feldforschungsarbeit, der seinerzeit führende australische Ethnologe Adolphus Peter Elkin (I89-1979) und der schwedische Amerikanist und Religionsethnologe Åke Hultkrantz, Mitglied der Königlichen Akademie der Wissenschaften zu Stockholm. Elkin gestand: »Viele von uns neigten dazu, die Mitglieder der Society for Psychical Research für absonderliche Typen (queer beings) zu halten. Indes kann es nur Aufgabe der Wissenschaft sein, alle Phänomene zu untersuchen, geduldig, objektiv und, falls notwendig, mit Hilfe neuer Zugangsweisen. $\aleph^{98}$ Hultkrantz rang sich zu dem Bekenntnis durch: »Kurzum, ich bin geneigt, die Behauptung zu akzeptieren, daß es sogenannte paranormale Phänomene gibt, die Teil unserer Realität sind.«99

Zuletzt rückte auch Clodd seinem unbequemen Freund um einiges näher. Widerstrebend erkannte er an, daß er sein Pulver wohl nicht so reichlich verschossen hätte, wenn nicht der Gegner ein Mann vom Range Langs gewesen wäre. »De mortuis«, mahnt er versöhnlich, und nicht zuletzt an die eigene Adresse gerichtet, in seinem Nachruf auf den Freund, »nil nisi verum «. ${ }^{100}$ Vor einigen Jahren, berichtet er, hätten sie die Dinge im Club noch einmal diskutiert. »Ich zitierte den Vers $>$ the devils 
also believe and tremble««, worauf Lang augenzwinkernd erwidert habe: »I don't believe, but I tremble ${ }^{\text {IOI }}$

Andrew Lang war, was auch immer ihn sonst noch auszeichnete, auf jeden Fall ein außergewöhnlicher Ethnologe - universal gebildet, originell, kreativ, dabei kritisch und »fair« im besten britischen Sinne. Dank seiner kunstvollen Feder und großen öffentlichen Reputation trug er zu seiner Zeit wie kein anderer zur Popularisierung der Parapsychologie bei. ${ }^{\text {I02 }}$ Requiescat in pace domini. 


\section{0. Die Zweifaltigkeit der Welt}

\section{Von der Spiegelung des Festen im Flüssigen}

Gibt es Gespenster? Oder, anspruchsvoller formuliert: Gibt es Götter? Letztere zeigen sich in der Regel nicht. Selbst Moses mußte sich mit der Stimme Gottes begnügen, der aus einem brennenden Busch, in der Wüste, hoch auf dem Sinai oder aus der Stiftshütte heraus zu ihm sprach. Geister dagegen treten hier und da in Erscheinung - in tierlicher wie menschlicher Gestalt, als Windhose, Strudel oder wandernde Lichter über sumpfigem Grund. Da sie in Erdnähe leben, entspricht es ihrer Natur schon eher, sich $\mathrm{zu} »$ materialisieren«. Totengeister, dem Menschen am engsten verbunden, kehren periodisch zurück; sie verkörpern sich immer wieder aufs neue.

Allgemein aber ziehen auch Geister es vor, gemäß ihrer Beschaffenheit ungesehen zu bleiben. Sie sind, gleich den Göttern, nicht von dieser, sondern einer anderen, mit den leiblichen Sinnen daher nicht unmittelbar wahrnehmbaren Welt, die dort beginnt, wo die unsere, erfahrungsgesättigt vertraute aufhört. Der Umschlag vollzieht sich nicht abrupt; die Übergänge sind fließend, die Konturen verschwimmen oder verschränken sich und durchfalten einander. So kommt es schon in Grenzbereichen, mehr dann aber noch darüber hinaus, zu ungewöhnlichen, verwirrenden, »exotischen« und häufig erschreckenden Erscheinungen. Denn was anders ist, hebt sich ab von der eigenen binnenweltlichen Ordnung, steht, je ferner man ihr entrückt ist, in teils kaum noch erträglichem Widerspruch zu ihr, schlägt zuletzt um in absolute Inversion, die gewöhnliche Menschen, die sich ihr aussetzen, tötet, das heißt sich $z u$ eigen macht.

Jenseits der Feldflur dehnen sich, wenig bekannt und unvertraut, Steppe, Busch, Wald, Dschungel, Sumpfland und karstige Höhenregionen aus, in denen es »unheimlich « ist, unberechenbare, meist bösartige Geister hausen, überall Gefahren lauern, Ungeheuer ihr Unwesen treiben und nur wenigen Begnadeten sich einmal eine Gottheit offenbart. Wer beherzt genug ist und die Schrecken nicht scheut, kann dort auch viel Neues erfahren und, wie die Märchenhelden im Zauberwald, in den Besitz 
übergewöhnlich wirksamer, magischer Mittel und Medizinen gelangen, Schätze heben - und eine Prinzessin zur Frau gewinnen.

Geht der Tag zur Neige, kriecht aus dem Wald, aus Mulden, Höhlen, Schluchten und Dickicht das Dunkel hervor, das dort nie vollends von Sonne und Taglicht ausgetilgt wird, wirft immer längere Schatten und überzieht zuletzt die Erde mit Nacht. Und mit ihm kommen die Geister bis ins Dorf. Fenster und Türen werden fest verschlossen gehalten. Sie geöffnet zu lassen, könnte tödliche Konsequenzen nach sich ziehen, weil dann, einem rumänischen Volksglauben nach, die Gefahr besteht, daß »der Teufel ins Haus kommt «. ${ }^{\mathrm{I}}$ Erst recht drohte draußen Gefahr. Niemand, den nicht eine dringende Verpflichtung dazu zwang, verließ in traditionellen Gesellschaften nachts das Haus. Die Kaguru in Tansania verrichteten dann, um keinerlei Risiko einzugehen, selbst ihre Notdurft im Innern der Hütte. ${ }^{2}$ Vor allem Schwangere, Wöchnerinnen und Kranke waren gefährdet. Zum Schutz unterhielt man an ihrem Lager ein helloderndes Feuer, das die Nacht gleichsam ausschloß. Frauen, die sich bei Nacht außer Hauses begaben, setzten sich verbreiteter Auffassung nach der Gefahr aus, von Geistern geschwängert zu werden, das heißt mit Wechselbälgern, also verunstalteten Kindern niederzukommen. ${ }^{3}$

In der Nacht rückten beide Welten, wie zu Anbeginn, als das Dunkel noch nicht vom Hellen geschieden war, bedrohlich dicht aneinander; die Binnen- wurde von der Außenwelt überschattet; Unheil und Chaos standen gewissermaßen vor der Tür. Doch wiederum taten sich damit auch übergewöhnliche Wahrnehmungs- und Erkenntnismöglichkeiten auf. Die Menschen schliefen und träumten. Ihre Seele verließ den Leib und vermochte weiter, »hell« zu sehen, was ihr bei Tag durch die Einkörperung verschlossen, »unsichtbar«, blieb; unter Umständen Dinge, die ihr noch unbekannt und neu waren oder zukünftiges Geschehen betrafen.

Je nach den gegebenen mundanen Raumzeitbedingungen bestanden in manchen Fällen günstigere Möglichkeiten zur Transzendierung der Immanenz; denn beide Welten gingen, wie gesagt, teils ineinander über, so daß sich die Grenzen verwischten und die Stofflichkeit mal dichter und undurchdringlicher, mal dünner verteilt und gleichsam gelichtet war, ja an einzelnen Stellen gewissermaßen »Vakuumverhältnisse« herrschten. Solche Bedingungen boten zum Beispiel »Löcher« und »Spalten« im materialen Mantel der irdischen Welt wie Höhlen, Quellen, Teiche, Bergspitzen (oft zugleich auch sakrale Stätten!), Heiligtümer, Tempel und Wendezeiten, etwa zwischen Tag und Nacht, den Jahren und während biographischer Seinswechselzustände (Geburt, Initiation, Hochzeit, Tod). Unter derartigen Umständen hatten die Seelen leichter Zugang zum Jenseits und konnten Informationen (»Botschaften«) von »drüben« annähernd widerstandsfrei durchströmen ins Diesseits, mußten sich hier allerdings den Gegebenheiten fügen und »materialisieren«, sozusagen von der Wellennatur umspringen in die Korpuskularität: Sie gerannen zu außergewöhnlichen Vorkommnissen, $\mathrm{zu}$ »Zeichen«, die sich entsprechend 
denn auch um die genannten Passage- und Sakralstätten herum besonders verdichten, beziehungsweise häufiger während der Übergangszeiten (z.B. in der Neujahrsnacht) auftreten. Wenn ein Einwohner der Insel Tikopia (Melanesien) durch den Wald geht und einen von Natur aus scheuen Vogel stracks auf sich zu laufen sieht, muß er davon ausgehen, daß eine Gottheit zugegen ist - das Außergewöhnliche, »Verkehrte«, des Geschehens weist dies untrüglich aus. ${ }^{4}$

Der Mensch vermag sie zu erkennen und zu deuten, weil er selbst dank seiner psychophysischen Doppelnatur nicht nur der Verschränkung beider Welten gleichsam eingefaltet ist, sondern mehr noch die zentrale Schnittstelle zwischen Geist und Materie darstellt - seine Leibwelt beherbergt die unsterbliche Freiseele. Um in der Durchmengung nicht zu versinken und die Orientierung im Lebensstrom zu verlieren, bedurfte es der bewußten, artifiziellen Scheidung zwischen Immanentem und Transzendentem durch den Menschen selbst: Die Kultur ist auf Distinktion zwischen Binnen- und Außenwelt, Zugehörigem und Unzugehörigem, Materiellem und Immateriellem, Realem und Irrealem, Diesseits und Jenseits hin angelegt. Anders wäre ein intelligentes, selbstreflexives Dasein nicht möglich. Der kosmologische Dualismus ist ebenso ein notwendiges Konstrukt wie eine fundamentale Eigenschaft der Welt - weil der Mensch Bewußtsein und Denkvermögen besitzt. Entsprechend läßt er sich auch soweit in der Geschichte zurückverfolgen, wie archäologische Zeugnisse für das Bestehen von Verwandtschaftsverbänden und, dies vor allem, für rituelle Bestattungen vorliegen; denn beides basiert auf dem Seelenglauben. Ersteres ist bereits für den späten Homo erectus um 400.000 v. Chr. (Mehrfamilienhäuser von bis zu I7 $\mathrm{m}$ Länge) ${ }^{5}$, letzteres mindestens seit den Neandertalern um 70.000 v. Chr. belegt. ${ }^{6}$

Der Dualismus setzt, formal auf seine Elementarstruktur reduziert, zwei unterschiedliche Systeme voraus, die einander benachbart sind. Infolgedessen bildet ihr Grenzbereich eine genuin kritische Zone, in der, fern vom Gleichgewicht und der Regelkonsistenz der Zentralareale, Widerstreitendes in Berührung gerät, erodierende Destabilisierung einsetzt und Unerwartetes möglich wird. Übergangszonen kennzeichnet daher ein kreatives, das heißt dynamisches Potential.7 Was hier geschieht, entzieht sich eindeutiger Zuordnung, erscheint polypossibel, oszillierend zwischen vielerlei Möglichkeiten, läßt wechselnde Bestimmungen $\mathrm{zu}$, ist offen für Innovationsansätze. Wer Neues sucht und den Wandel will, muß »bis an die Grenze gehen«.

Dort sieht er sich den »Gezeitenkräften« ausgesetzt, wie sie aus der Umdrehung zweier (oder mehrerer) unterschiedlich strukturierter benachbarter Systeme, ihrer schleifenden Berührung und - mal leichteren, mal massiven - Wechselwirkung entstehen. In der Endowelt ist alles auf das Bemühen hin angelegt, die Schöpfung, die hier ihren höchsten Vollkommenheitsgrad erreichte, vermöge strikter Traditionstreue zu perpetuieren. Das Geschehen wiederholt sich, kurzfristig auf linearen oder bo- 
genförmigen, letztendlich auf zyklischen Bahnen. Die Kräfte sind vektoriell gebunden; sie wirken auf gleichförmige, bestandserhaltende Weise. Draußen in der Exosphäre jedoch, wo das Schöpfungswerk unvollendet blieb, das heißt der Trennungsprozeß von Flüssigem und Festem, Dunkel und Hell, Geformtem und Ungeformtem gleichsam auf halbem Weg zum Stehen kam, wirken die Kräfte ungeordnet, widereinander, teils strudelförmig, explosiv und immer zerstörerisch für alles, was sie berühren. Wer sich dorthin begibt, läuft Gefahr, entsprechend der Verzerrung der räumlichen Strukturen, des Geschehens und selbst der Zeit ${ }^{8}$ »verkrümmt«, wenn nicht »zerrissen«, oder verwandelt zu werden - zum »Zauberer«, der auf die Schädigung anderer sinnt, zum Wegelagerer, Räuber, Werwolf und Untoten oder, wenn ihm gutartige Jenseitsmächte beistehen, zum Schamanen, Helden, Heiligen und Erlöser. Häufig verlieren Menschen wie Geister beim Grenzübertritt - vom Totenreich zurück ins Leben, wenn eine Fee einen Sterblichen heiratet, jemand, der eine Seelenreise unternimmt - die Erinnerung an die verlassene Welt. ${ }^{9}$ Machen sie sich eines schwerwiegenden Fehlverhaltens schuldig, geraten sie ab vom Weg, der ihnen in der Fremdwelt die Richtung wies, auf die »schiefe Bahn«; die Entwicklung ist in diesem Fall irreversibel; sie zieht sie in die exosphärische Abgründigkeit: die Fee stirbt den Tod eines Menschen, ohne ins Geisterreich zurückkehren zu können, Zauberer und Kriminelle fallen einem »Schlimmen Tod« zum Opfer, der sie zu Untoten ohne Wiederkehr macht, sie bleiben auf ewig »Verzerrte«, absolute Unzugehörige zwischen den Welten.

Besser also, man geht lediglich bis an die Grenze. Denn auch dort tritt vermöge der Wechselwirkung Ungewöhnliches und Neuartiges auf, freilich in abgemilderter Form, weil es bereits dem Einfluß der Endowelt ausgesetzt ist und vertrautere Züge anzunehmen beginnt, das heißt »zurechtgebogen« wird nach Maßgabe der hier herrschenden Anschauungskriterien. Gleichwohl stellt es allemal eine »Information« dar, die nur, um ihr das potentiell Bedrohliche der Neuartigkeit zu nehmen, entweder abgestoßen, eliminiert, oder eben dem endoweltlichen Vorstellungszusammenhang integriert, also gedeutet und »eingestuft« wird.

Damit ist ihr Gehalt sinnhafter Teil der determinierten Regelwelt des Binnensystems geworden. Er zählt nunmehr - um einen terminologischen Vorschlag des Pädagogen Alfred K. Treml aufzugreifen - zu dem, was eine Kultur »markiert«. Jenseits dieser Welt des »Bezeichneten« erstreckt sich, bis ins Unendliche, »alles andere «, die Sphäre des indeterminierten $\gg$ Nichtmarkierten «, die »Transzendenz $\aleph^{\mathrm{IO}}$, oder, wenn man so will, der Carl Gustav Jungsche »Welthintergrund «. ${ }^{\text {II }}$ Ohne diese unsichtbare »dunkle« Welt, aus der uns ständig unerwartete und neuartige Informationen zufließen, wäre die helle sichtbare nicht zu denken, ja erstere stellt für die letztere "geradezu die Bedingung ihrer Möglichkeit« dar. Denn erst der »Kontrast der Differenz von markierter und nichtmar-

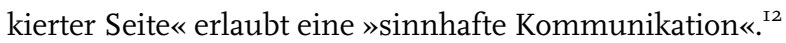


Beide verbindet offenbar ein unauflösliches Komplementaritätsverhältnis. ${ }^{{ }^{3} 3}$ »Wir spielen nämlich oft «, stellte der scharfsinnige Kant in seiner quasi-ethnologischen Schrift Anthropologie in pragmatischer Hinsicht bereits fest, »mit dunkelen Vorstellungen, und haben ein Interesse, beliebte oder unbeliebte Gegenstände vor der Einbildungskraft in Schatten zu stellen; öfter aber noch sind wir selbst ein Spiel dunkeler Vorstellungen, und unser Verstand vermag nicht, sich wider die Ungereimtheiten zu retten, in die ihn der Einfluß derselben versetzt, ob er sie gleich als Täuschung anerkennt « ${ }^{I 4}$ - natürlich! Wiewohl Kant doch andererseits sicher ist, »unbezweifelt schließen zu können«, daß wir derartige »dunkele Vorstellungen« nicht nur haben, sondern ihr »Feld [...] im Menschen unermeßlich sei ${ }^{\text {I5 }}{ }^{15}$

Das Komplementaritätspostulat besagt, daß man die »helle« wie die »dunkle«, die »markierte« wie die »unmarkierte« Welt im Bezug zueinander als Ganzes zu verstehen versuchen muß. Dies wurde auch von neueren Physikern, wie namentlich Wolfgang Pauli (I900-I958; Nobelpreis I945), gefordert. Ihm zufolge ist Naturwissenschaft ohne Irrationalität gar nicht denkbar, wobei man das Irrationale indes weder als das noch nicht Verstandene noch das Widervernünftige, sondern als Außervernünftiges zu begreifen habe, das rational nicht zu begründen sei. Ein ganzheitliches Naturverständnis müsse »die irrationalen Aspekte des Außervernünftigen als gleichberechtigtes Gegenüber des Vernünftigen anerkennen «. ${ }^{\mathrm{I}}$ Paulis Postulat, resümiert Hans Primas, der es ebenso sieht, laufe auf eine neue, umfassendere »Idee der Wirklichkeit« hinaus; sie »schließt Bilder und Symbole ein und erfordert eine Konjunktion komplementärer Aspekte«. ${ }^{\mathrm{I}}$

Doch bleibt auch bei dieser, gleichsam gerundeten Anschauung der Bereich, in dem komplementär verschränkte Systeme unmittelbarer aneinander geraten und sich ihre Wechselwirkungsprozesse verdichten, die kritische Schnittzone des Ganzen, gleichzeitig aber auch der analytisch fruchtbarste Ansatzbereich für das Verständnis der Komplementarität selbst.

Gilt in der Endowelt des vernünftig Markierten, die Irrationales und Dunkles »als nicht dazu gehörend [...] ausschließt ${ }^{18}{ }^{8}$, die Rationalität der aristotelisch-booleschen Logik (nach dem britischen Mathematiker George Boole, I8I5-I864), die nur wahre oder falsche Aussagen anerkennt (tertium non datur), und wird ihre Gegenwelt von Antikriterien des unmarkierten »Außervernünftigen«, in extremis dem kosmologischen Inversionsprinzip beherrscht, kann weder das eine noch das andere die Vorgänge in den Grenzbereichen bestimmen. Entweder schlagen hier, wie weiland während der Schöpfung und dereinst am Ende der Welt, Ordnung und Chaos, Form und Formlosigkeit, Festes (Teilchen) und Flüssiges (Welle), Leben und Tod oder »Geist« und »Materie« unmittelbar ineinander um, oder es stellen sich korrelationale, also Korrespondenzbeziehungen her, die weder dem Satz vom ausgeschlossenen Dritten noch 
vollends der Inversion unterworfen sind, sondern den Regeln der komplementären Wechselwirkung gehorchen: Sie können sowohl das eine als auch das andere sein - je nach Situation und Zugriff. ${ }^{19}$ Es herrschen in diesen "gleichgewichtsfernen« Bereichen genuin instabile, mehrdeutige Verhältnisse.

Und ebenhier treten Ereignisse auf, die wir als kontingent oder paranormal erfahren, dringt Transzendenz in den Vordergrund der materialisierten Endowelt durch. Gedankliche Impulse (der »Operator Psi«) erreichen über das Mana-Feld die Dunkelseite unseres Bewußtseins. Die meisten nehmen wir vermutlich nicht wahr; sie lösen kein Echo aus, »leuchten « nicht »auf « bis in die Noosphäre, da sie uns nicht betreffen. Stammt das Signal jedoch von einem Menschen, der uns nahesteht, mit dem uns aufgrund eines langen, intensiven Zusammenlebens »Sympathie« verbindet, ruft es eine spürbare Reaktion hervor, die ins Bewußtsein tritt und über die anthropomorphe Vorstellungsbildung Gestalt gewinnt: Wir »sehen« (Hellsehen, »Wahrträume«) oder »empfinden« (Telepahie), je nach der Stärke des Impulses, daß der Betreffende in Gefahr schwebt, oder mutmaßen aus den Umständen der Wahrnehmung heraus, daß ihm eine ganz bestimmte Bedrohung bevorsteht (Präkognition) ${ }^{20}$; sind die Gesichte »echt«, das heißt der Beziehungspartner befindet sich auf der Jagd, auf einer Autofahrt oder im Krankenhaus, trifft die Vorausschau mit annähernd fünfzigprozentiger Wahrscheinlichkeit zu, da die möglichen Alternativen begrenzt sind. Nach den Kriterien der aristotelisch-booleschen Aussagenlogik, wie sie für die Zentralareale der Endowelt gelten, wäre Präkognition ein Unding. Darauf wies schon Aristoteles (384-322 v. Chr.), der Schöpfer des Satzes vom ausgeschlossenen Dritten $^{21}$, selbst hin. Er meinte nämlich, daß dieser schwerlich auch Geltung für Aussagen über künftige Ereignisse haben könne. Denn das würde bedeuten, daß alles Geschehen determiniert sei, weil etwa die Aussage: »Morgen wird eine Seeschlacht stattfinden «, bereits heute notwendig wahr oder falsch sein müsse - ein Drittes wäre ja nicht möglich. ${ }^{22}$

Dafür, daß der Operator Psi (der »Geist«) die Physis zu beeinflussen vermag, liegen hinreichende Beweise vor. Die Befunde der Neurowissenschaften, namentlich der Elektrophysiologie, lassen heute kaum mehr einen Zweifel daran, daß zwischen Hirn und Psyche eine stete Wechselwirkung, ein »psychozerebraler Korrelationismus«, besteht - der wiederum auch die Grundlage der Psychokinese bildet. ${ }^{23}$

Überdies scheint die neurophysiologische Basis der telepathischen Suggestibilität auch genetisch bedingt zu sein, das heißt sich über die Jahrhunderttausende hin durch Auslese evolutiv entwickelt zu haben. ${ }^{24}$ Dies würde nicht zuletzt auch die universalen und kultur- wie zeitunabhängigen Übereinstimmungen paranormaler Wahrnehmungen und Phänomene erklären. ${ }^{25}$

Heute allerdings ist diese Empfindsamkeit von grobsinnlicher »Reizüberflutung« und der Dominanz der Apparate überdeckt. Im Islam wird 
der Umstand, daß sich in der neueren Zeit keine Wunder mehr ereignen, entsprechend auf die zunehmende Säkularisierung zurückgeführt. ${ }^{26}$ Tiere indes besitzen die ursprüngliche, wahrhaft »feinsinnige« Empfindsamkeit noch, die uns oft geradezu ans »Wunderbare« zu grenzen scheint. Bakterien, Bienen, Vögel oder Wale nutzen zur Orientierung das Magnetfeld der Erde; Rochen und Haie registrieren Impulse in der Dimension von millionstel Volt im Nervensystem und Muskelgewebe der von ihnen gejagten Tiere; Robben können mit Hilfe ihrer Barthaare die »hydrodynamischen" Spuren »lesen«, die ihre Beutetiere im Wasser hinterlassen haben. ${ }^{27}$ Beim Menschen legen erst persönliche oder auch gesellschaftliche Krisensituationen, wenn die Panzer der modernen Medienwelt Risse erhalten und aufbrechen, den alten »Spürsinn« bloß. Im Zweiten Weltkrieg hörte man, wie schon gesagt, in Deutschland häufig von Frauen, die "gewußt« hatten, daß ihre Söhne oder Ehemänner gefallen waren, noch ehe sie die offizielle Todesnachricht erhielten. Derartige sensitive Sonderbedingungen machen außersinnliche Wahrnehmung immer wieder möglich. Eine Erklärung jedoch liefern auch hier weder indianisches Naturverständnis, keltische Mystik oder meditative Versenkung, sondern allein der systematische interkulturelle Vergleich und Befundanalysen nach den Kriterien wissenschaftlicher Methodik und epistemologischer Rationalität. Außersinnliche Wahrnehmung und Szientismus stehen nicht in einem booleschen Verdrängungsverhältnis; ihre Beziehung sollte vielmehr, entsprechend den Vorgaben der Natur, im Sinne eines komplementären Wechselwirkungsprozesses verstanden werden. Letzten Endes behalten »Schafe« und »Ziegen« Recht - doch nur, sofern sie bereit sind, gemeinsam zu grasen. 


\section{Anmerkungen}

\section{Kapitel I}

I. Stevenson 2000: 274 .

2. Davis \& Hersh i986: 167f.

3. Adler ig84: 269 .

4. Mischo I984: 39 .

5. Primas i996: 7I.

6. Koestler i972: 26 .

7. Prigogine \& Stengers I98I: I7I.

8. Prigogine \& Stengers I98I: I75.

9. Prigogine \& Stengers I98I: I99. Robert 200I: 68.

I0. Monod i97I: I43.

II. H. Schmidt I993: 29.

12. Primas i996: 73. Robert 2001: 68, 70.

13. Prigogine \& Stengers I98I: $202 \mathrm{f}$. Robert 200I: 68.

14. Neuser I996: 9. Robert 200I: 70.

I5. Luhmann I978: 422.

I6. E. von Weizsäcker I974: 93ff.

I7. Kaspar ı983: 132.

I8. E. von Weizsäcker I974: 95 (Hervorhebung im Original).

19. Liebeck i928: 83f. Vgl. Pervin I963: 57I, 585f. Schaal i959: 332.

20. Vgl. z.B. Sell I955: 86 (Andamaner).

2 I. Silberbauer i98ı: iıо.

22. Vgl. z.B. Muller i97I: 8I (Rukuba, Nigeria). Harwood I970: 49 (Safwa, Tansania). Ghurye I963: 78f. (Mahadev Koli, Indien: Maharashtra).
23. H. Hartmann I952: I3I.

24. Vgl. Lucadou i989: IIo.

25. Schuetz I944: 507.

26. Vgl. z.B. Evans-Pritchard I929: I79f. Hogbin I970: I45.

27. Hasenfratz 2002: 10.

28. Vgl. z.B. Downs ig66: 55. Jones \& Jones i976: I9.

29. Lachmann 2002: I40f.

30. Lachmann 2002: I37 (Hervorhebung von mir, KEM).

3I. Pervin ig63: 570f., $585 \mathrm{f}$.

32. Hund i996: 27.

33. Nach Vaihinger I922: $73 \mathrm{f}$.

34. Vollmer i986: 67 .

35. L. M. Krauss I987.

36. Linton I952. Kluckhohn I94I.

\section{Kapitel 2}

I. Müller 2000.

2. Genz: 1992: 44I.

3. Linton I952: inff., 80.

4. Hogbin I970: I45.

5. Sell I955: 9.

6. Krige \& Krige I947: 270. Vgl. das analoge Beispiel bei Clausen I969: I4I, bei dem ein einziger von fünf sambischen Bergleuten durch Steinschlag den Tod fand.

7. Wilson I959: 8 . 
8. Silberbauer I98I: 58 .

9. Vgl. Goody I962: 208f. Faron I967: 228. Popov i976: 34f. Silberbauer i98I: 53. Fischer I987: 87.

10. Wilson 1957: 23 I.

II. Bailey I97I: $23 f$.

12. Silberbauer I98I: II4.

13. Sundermeier I980: 256 .

14. Heeschen I994: I8I.

15. Kenner I970: 95 f.

16. Vgl. z.B. Grimms Märchen Nr. 182, Die Geschenke des kleinen Volkes.

17. Goldenweiser I932: $365 \mathrm{f}$.

18. Arsdale i98I: II3.

19. Vgl. z.B. Rivers 1920: 51. Fuchs I950: IOI, 22I. Paulson I960: 94. Baer I969: 285. Popov I976: 3 I.

20. Smoljak ı99ı: ıо8.

21. Mensching 1926: $76 f$.

22. Elkin I945: I2.

23. Elkin I945: $\mathrm{I2}$.

24. Wilson I957: 49, 72f.

25. Vgl. z.B. Wilson I957: I7, 63.

26. Just I99ı: 91. Vgl. Hetmann I984: 60.

27. Mischo I984: 20.

28. Timm I983: 234, 238.

29. Mischo I984: 35 .

30. Mischo I984: 20. Vgl. Mischo $1_{9} 83$ : I68f., I74. Timm I983: 234. Bonin I983: 77.

3I. Näheres dazu unten, Kap. 7 .

32. Büchel I $983: 89 f$. Briggs \& Peat I990: 38 .

33. Mischo I984: 20.

34. Vgl. unten S. $78 \mathrm{ff}$.

35. Müller 200I: 54ff. Vgl. Zelenin I932: 22. Elkin I945: 59. Howell I984: I66.

36. Vgl. z.B. Tradicionnoe mirovozzrenie tjurkov I989: 92f.

37. Fehrle o.J.: $59 \mathrm{ff}$.

38. Müller 1987 : 65 f., $76 f$. Puhvel I989: 84 .

39. Puhvel ig89: 93ff.
40. Turner I968: I35-150. Traube I989: 323.

4I. Douglas i974: I25ff.

42. Vgl. z.B. Habermas i99I: $70 f$.

43. Aristoteles: Metaphysik VI 3. IO27a, $20 f f$.

44. Kaspar I983: 132 (Hervorhebungen im Original).

45. Nach Vollmer i986: 53 (Hervorhebung im Original).

46. Simpson 1969: $27 f$.

47. Nach Popper in Popper \& Eccles I982: 44 .

48. Sachsse bei Jaroschek I979: 63f., 66.

49. Monod I97I: I54. Vgl. Simpson I969: $23 f$.

50. Simpson: aaO, $27 f f$.

5I. C. F. von Weizsäcker 1994: 28 (Hervorhebung von mir, KEM).

52. C. F. von Weizsäcker I994: 23.

53. Vgl. Prigogine \& Stengers I98I: I99ff. Halliwell I992: 54.

54. Halliwell I992: 54.

55. Vgl. Halliwell I992: 58.

56. Spergel \& Turok I992: 76 .

57. Rüsen I998: 22. 2003: $26 \mathrm{ff}$., IIof.

58. Luckmann I99I: 79, 8I, 85ff., io8.

59. Assmann I996: I7ff.

60. Vaihinger I922: $73 \mathrm{f}$.

6I. Nach Quadbeck-Seeger I988: I36.

\section{Kapitel 3}

I. Vgl. z.B. Friederici I906: 82. Mörner I924: I36f. Serpenti I968: I23f. Kirk I972: 378 .

2. Vgl. z.B. Rivers I920: 60. Nachtigall I952: I93.

3. Beninger I931: 772, 776ff. Tackenberg 1955: 102. Narr 1961: 194. MüllerKarpe I968: 349 . 
4. Vgl. z.B. Man I883: 86. Knortz I909: 20. Mörner 1924: I36. Malinowski 1927: 107. Buchbinder \& Rappaport I976: $23 f$.

5. Briggs \& Peat I990: $42 f$.

6. Briggs \& Peat I990: 15,30 . Ditto \& Pecora I993: 46 .

7. Briggs \& Peat I990: 45 .

8. Ditto \& Pecora I993: 47.

9. Bauer I992: 253 f. H. Schmidt I993: 30.

10. Vgl. Amann 1992: 232f., 237.

I I. Vollmer I986: I03.

12. Amann I992: 254.

13. Vgl. Genz I992: 353 .

14. Genz I992: 39.

15. Abbott I990: 76 .

16. Müller I987a: II4ff. 2000: $328 \mathrm{ff}$.

17. Müller i987b: 38 .

18. Vgl. z.B. Bogoras I925: 23If. Mensching I926: 70. Straubergs I957: 79.

Doerfer I983: Nr. 16, 22, 24, 25. Hetmann I984: 56f., 59f. Just I99I: 9Iff. Illi I99г: II6, Fußn. 3. Moody I994: 44.

19. Müller 200га: I89.

20. Battaglia I990: 62 .

21. Schouten I991: 232.

22. Genz I992: 39.

23. Vgl. Amann I992: 233 f., 253.

24. Genz I992: 39ff.

25. Müller 2002: 95f., I57f., I76.

26. Briggs \& Peat I990: 25 (Hervorhebung von mir, KEM).

27. Primas 1992-93: I08 (Hervorhebungen im Original).

28. Vgl. Gernert I994: I29.

29. Maruyama I974. Vgl. Gernert I994: I23.

30. H. Albert I972: 4 f.

31. Vgl. Bringmann et al. I990: Igf.

32. Atmanspacher I993: 5 .

\section{Kapitel 4}

I. Nadel I947: 268 .

2. Müller ı987a: 120.

3. Preuß I936: 139 .

4. Vgl. z.B. Mills I926: I00. Parry I932: 488. Baumann 1936: 306ff. Elwin I950: I35f. Inan I954: 20, 22. LéviStrauss I97I: 243. Eliade I98I: I46. Iordanskkij I982: I2.

5. Harva I938: II8, I22ff.

6. Müller 2002a: 2I7. Vgl. Reimbold I970: 8I.

7. Biezais I983: 283. Vgl. Gahs I928: $236 f$.

8. Bürkle I968: 249 .

9. Ritz-Müller I990: 6If.

10. Röhrich I980: I69.

II. Schröter-Kunhardt I993: 66.

12. Moody I994. Schröter-Kunhardt I995: I33, I37. Kasten 2000: 72. Müller 2002: I32f.

13. Vgl. z.B. Die Märchen der Brüder Grimm, Nr. 186, Die wahre Braut, oder Nr. I93, Der Trommler.

14. Assmann 1993: 344. Vgl. z.B. Die Märchen der Brüder Grimm, Nr. I93, Der Trommler.

15. Capelle I940: I50.

16. Vgl. Homer: Ilias XIV 23I; XVI 672. Hesiod: Theogonie 2IIff., $758 \mathrm{ff}$. Staudacher I968: $77 f f$.

17. Kasten 2000: 72

18. Müller I987: 66f. Vgl. z.B. die Schilderung von Thiel 200I: 2Iof.

19. Vgl. z.B. Lienhardt I970: 284 . Helander I988: I2I. Thiel 200I: 2II.

20. Lienhardt I970: 284 .

2I. Thiel 200I: 2II.

22. Tremearne I9I2: I58f. H. Hartmann I952: 79f. Wilson I957: 60, 21of. Ortiz I969: 52. Mbiti I974: 32. Sibeth I992: 5I. Moody I994: 8. Thiel 200I: 2IO.

23. Cipolletti ı983: гзг. 
24. Haraldsson I992: 470. SchröterKunhardt I995: 133 .

25. Vgl. z.B. Cipolletti I983: 73 f.

26. Paracelsus I926: 47 .

27. Vgl. z.B. Barnes I974: I04.

28. Müller i996: Igf. Vgl. Radin ig26: 385, Anm. 4. Huber i965: 94. Beidelman I97I: 35, I00. I986: II5. Ritz-Müller I997: 28.

29. Spindler $1962:$ i7.

30. Ploss $1876: 264 f f$.

3I. Vgl. z.B. Smoljak ı99ı: I70.

32. Eilers $1927: 76$.

33. Müller I997: 39ff. Ritz-Müller I997: 28.

34. Müller I996: 40. I997: 4I.

35. Vgl. z.B. Smoljak I99I: I70.

36. Junod I9I2: 56 . Vgl. Middleton I960: 270 (Lugbara, Uganda).

37. Gossen I974: 24.

38. Huber i965: 94. Müller I996: $20 f$.

39. Müller I973-74: $96 \mathrm{ff}$.

40. Sundermeier I980: 252

41. Müller 1987: $70 f$.

42. Scheftelowitz I9I2: 2If.

43. Thiel 200I: $2 \mathrm{I} 3$.

44. Müller I987: 72. Ovsyannikov \& Terebikhin I994: 54, 56 .

45. Mörner I924: I23ff.

46. Müller I987: 69 .

47. Havers I946: Ioo. Müller 200Ib: 76.

48. Müller 200ıb: 69. Vgl. a. Ludwig Bechstein: Das Tränenkrüglein. Kröger I978: 59. Röhrich I980: I78f. Loux I980: 232.

49. Vgl. Goody I962: 208f. Popov I976: 34f. Fischer 1987: 87.

50. Sell I955: I2.

51. Vgl. Fischer 1987: 86.

52. Haraldsson $1992: 477-483$.

53. Vgl. z.B. Guntern I998: 328f., 330336 (Wallis).

\section{Kapitel 5}

I. Ritz I988: 67, I93.

2. Vgl. z.B. Luk'janov i904: 33 (Abchasen, Westkaukasien). Elwin I947: 475 (Muria Gond, Bastar, Indien).

3. Vgl. z.B. Schebesta I95I: 572 (Pygmäen, Zentralafrika). Endicott I979: 95 (Batek Dè, Malaysia).

4. Paulus Diaconus: Historia Langobardorum III 34. C. Meyer I884: 363f. Luk'janov I904: 33. Elwin I947: 475. Rudolph I982: 62 .

5. Ritz I988: I33, I43. Vgl. Karsten I935: 242, 444f. Elwin I947: 479. Beidelman I963: 47, Fußn. 7.

6. Vgl. z.B. Elwin I947: 480.

7. Köngäs Maranda I974: I95f.

8. Ritz I988: 68.

9. Snow i994: I39f.

10. Vgl. z.B. Ritz I988: I42f. (Naga, Assam). Beidelman I963: 47, Fußn. 7 (Kaguru, Tansania).

I I. Vgl. Hutton I92I: 247f. Parry I932: 35I. Karsten I935: 445. Beidelman I963: 47, Fußn. 7.

12. Shukla i959: 6r.

13. Parry I932: 77,480 .

14. Karsten I935: 445 .

15. Mills I926: 293. Ritz I988: I55.

16. Ghurye 1963: 54. Popov 1976: 31 . Ritz I988: I44.

17. Rasmussen I929: 93.

18. Elwin I947: 476 .

19. Parry I932: 48I, Fußn. 2. Ghurye I963: 54 .

20. Parry I932: 48I.

21. Mills I926: 293. Erste Versuche, die verschiedenen Typen von Träumen und Traumgesichten systematisch zu klassifizieren, wurden bereits in der Antike unternommen. Erwähnt seien hier vor allem die Schriften des Artemidoros von Ephesos (2. Jh. n. Chr.): Oneirokritika (»Traumdeututng«), des Macrobius (um 
400 n. Chr.): Commentum ad Ciceronis somnium Scipionis (»Kommentar zu Ciceros Somnium Scipionis«, nach Cicero: De re publica VI I9-20), insbesondere Buch

I. Kap. 3, und des armenischen Gelehrten Eznik von Kolb (5. Jh. n. Chr.): Wider die Sekten. Übersetzt und kommentiert von J. M. Schmid. Wien I900, S. I34. Im Grunde referieren die genannten Autoren jedoch lediglich die oben aufgeführten Typen der in traditionellen Gesellschaften gängigen Traumdeutungsweisen, ohne wesentlich Neues zu bieten. Homer (9. Jh. v. Chr.) schied kurz und lapidar zwischen falschen, »lügenhaften«, und wahren Träumen (Odyssee XIX 559ff.).

22. Ritz I988: 144 .

23. Vgl. Schurtz I902: 3. Ritz I988: 68.

24. Endicott I979: 95.

25. Karsten I935: 444.

26. Karsten I $935: 445$.

27. Parry I932: 35 If. Müller I987b: $245 \mathrm{f}$. Smoljak I99ı: I83. Vgl. a. Rasmussen I929: 93.

28. Bogoras I925: 260 .

29. Müller 2002: I2off., I28ff.

30. Müller i996: 20. Vgl. z.B. Eilers I927: 76. Smoljak I99I: I70.

3I. Landes I938: I4O.

32. Anonymus iو2I: iıgf.

33. Guntern I998: I47.

34. Reeve I988: 26.

35. Nimuendajú I939: I33, I38.

36. Nimuendajú I939: I36; vgl. I35.

37. Nimuendajú I939: I37.

38. Müller I996a: 8If.

39. I. Samuel 9:9.

40. Vgl. 5. Mose I8:I5. Jeremia 7:25; 35: I3. Hosea I2:II. Amos 2:II.

4I. Schmökel I957: I04f. Batto I974: II9-I23. I. Samuel I9:20ff. I. Könige I8: 2off.; 20:35; 22:6, I2. 2. Könige 2:3ff.; 4:I, 38; 5:22; 6:Iff.; 9:I. Amos 7:I4

42. Müller ig83: $332 \mathrm{ff}$.
43. Censorinus: De die natali, c. II. Ammianus Marcellinus XXI i; XXIII 5.

44. Cicero: De divinatione I 2.

45. Cicero: De divinatione I $2 \mathrm{ff}$. De oratore III 66. Vgl. Lachmann 2002: I03.

46. Herodot I 46, 52. II $54 \mathrm{ff} . \mathrm{V} 59 \mathrm{ff}$. VIII 33, I35. Pausanias II 24, I. IX 10, 6; 23, 3. Iamblichos: De mysteriis Aegyptiorum III II. Stengel I898: 67f. Rohde I96ı: 63ff.

47. Iamblichos: De mysteriis Aegyptiorum III II.

48. Pausanias II 24, I.

49. Stengel $1898: 65$.

50. Stengel $1898: 65 f$.

5I. Plutarch: De defectu oraculorum, c. 38-40.

52. Plutarch: De defectu oraculorum, c. 40-42.

53. Vgl. z.B. I. Samuel 28. Batchelor I892: I97f. Smith I925: 9Iff. Karsten I935: 447. Nadel I947: 4I7f. Die Belege ließen sich auch hier beliebig vermehren.

54. Vgl. z.B. Elwin I947: 205 (Muria Gond, Bastar, Indien).

55. Heers I986: $164 \mathrm{f}$

56. Wilson I957: 68 .

57. Vgl. z.B. Fuller I96r: 27.

58. Augustinus: De civitate dei VII 32.

59. Vgl. z.B. 2. Korinther I2:2-4.

60. Vgl. Apostelgeschichte Ir:27ff.; I3: Iff.; I5:32; 2I:9ff. Epheser 2:20; 4:II.

61. Probst i87i: I98f.

62. Obst 2000: 148,457 ; vgl. I3, 167 , 23I, $462 \mathrm{ff}$.

63. Ritz I988: I25.

64. Petrullo I939: 237.

65. Beidelman I963: $52 \mathrm{f}$.

66. Ausführlich dazu Lagercrantz 1964 .

67. Min'ko I975: 24.

68. Downs I966: 55 .

69. Hays I966: 34. Parry I932: 479.

70. Vgl. z.B. Middleton i960: 24I (Lugbara, Uganda). Firth I958: I76 (Tikopia, Salomonen, Melanesien).

7I. Smoljak I99I: 35. 
72. Vgl. z.B. Lidzbarski I9I5: 75f., 77. Thurnwald 1951: 377. Widengren i960: 66f., 69. Bin Gorion I962: I82ff. Reinach I895: 42 f.

73. Vgl. z.B. Hillner I876-77: 37 .

74. Maple I97I: 25.

75. Beidelman $1986: 99$.

76. Vgl. z.B. Nicolaisen I963: I7I. Hultkrantz I982: 167.

77. Ritz I988: 134 .

78. Müller ı987b: $168 f$.

79. Civ'jan $1985: 160$.

80. Civ'jan $1985: 162$.

8I. Elwin I947: 7 I.

82. Ritz I988: 50.

83. Dittmer I96r: $87 a$.

84. Ritz I988: 52, 56. Vgl. z. B. Middleton I960: 24I. Hoenerbach I984: 23 f.

85. Ritz I988: 134.

86. Ritz I988: I34. Vgl. z.B. Parry I932: 479. Hoenerbach I984: 23f.

87. Civ'jan I985: I6r.

88. Sinha i966: гог.

89. Hays I966: 34. Vgl. Beidelman I97I: 40.

90. Ritz I988: 52, 53, 6I, 98, I3If.

9l. H. Hartmann I952: 132.

92. Beidelman I963: 47. Ritz I988: 98. Vgl. Roy I925: 385. Srinivas I952: I05. Smith I925: 95 .

93. Ritz I988: 52, 53.

94. Beidelman $1963: 40,53$.

95. Silberbauer I98I: 55 f.

96. Vgl. z.B. Obst 2000: $363 \mathrm{ff}$.

97. Vgl. z.B. Eckert I940: 35 f.

98. Elkin 1945: 27ff. Cowan 1992: 36 , 82ff. Vgl. a. Haaf ig67: $38 \mathrm{ff}$. (Kusasi, NO-Ghana).

99. Müller I987b: 299. I996: 27f. Ritz I988: $46 f .$, I27.

100. Sartori I935-36: 531. Müller I990: I46. 1996: 28.

101. Müller i967: 256f., 263, Anm. I5. I973-74: гог. I990: I45f.
102. Reitzenstein I904: I75ff. Boll I9I4: I36ff. Haberland i965: I52.

103. H. Krauss 2000: II, I5.

104. Schimmel 200I: 27.

105. Vgl. z.B. Ritter I846: 33 (Altarabien).

106. H. Krauss 2000: 15 .

107. Rattray I955: I78. I969: 77, 8If., 9I, 95f., I02. Haberland I965: I67, 304.

Hecht I969: 65. Thiel 200I: 253.

108. Firth I975: 35 .

109. 2. Petrus I:20-21. Müller I999: 73. 200Ib: II2f. Vgl. Bourdieu I963: 6o. Eliade i963: 8. Lienhardt i967: ıा6. Lukesch i969: I6. Hallowell I969: 57. I 10. Eliade I963: 8ff. Hallowell I969: 56f. Hogbin I970: 28f. Müller I999: 73ff. II I. D’Azevedo I962: 2I, 26f. Müller 200Ib: 109. Vgl. Buxton 1963: 77. Scharbert I979: 346 (alte Israeliten). Dzobo I98г: 98.

II2. Fuller I96r: 28.

I 13. D’Azevedo I962: 27. Vgl. Engelbrektsson I978: 36. Keen I994: 5I.

II4. Zwernemann I984: 375 .

II5. Buxton I963: 77.

I I6. Meek I93I: $539 f$.

I 17. Dürr I938: 97. Vgl. Assmann I992: $4 \circ$.

I 8. 2. Samuel I4:20. Dürr I938: Io8f.

I19. D'Azevedo I962: 27.

I20. Karsten I935: 444.

I2I. Kopytoff ig8r: 7I2f.

\section{Kapitel 6}

I. Baer 1987: 7I.

2. Frazer 1963: 73 .

3. Zit. nach Frazer 1963: Io5f.

4. Rasmussen I929: II9.

5. Vgl. z.B. Caratini I989: 105.

6. Bogoras 1925: 250.

7. Wiener I992: 243.

8. Zitiert nach Peat I992: 2I.

9. Vgl. etwa Ohnuki-Tierney I980: I39. 
10. Müller I996b: $203 \mathrm{ff}$.

II. Widengren I96r: 26.

12. Marcus Minucius Felix: Octavius, c. 26. Fehrle o.J.: 59f. Scheftelowitz I9I4: 386f. Frazer I963: I04. Caratini I989: I05. Battaglia I990: 59. 13. Vgl. z.B. Boddy I982: 693. Novik I989: 38 .

14. Müller i997a: 6f. Vgl. z.B. Karsten I935: 382. Petersdorff I957: 2I2. Fuller I961: 3, 83. Henninger 1963: 30of. Franke I982: 74. Puhvel I989: I5ff. Theodoratus \& LaPena I994: 23. Moody I994: 189. I5. Vgl. z.B. F. S. Krauss I888: 944. Christensen I933: 226f. Barnes I974: 2I4f. P. Meyer I98I: 2I-40. Smoljak I99I: 50.

16. Vgl. z.B. Buch I882: 604. C. Meyer I884: 34I. E. D. Morgan I888: 39of. Roskoschny I888: 732f. Haekel I946: I04. Runeberg I947: I25, I42ff. Ränk I948: I53f. Krader I954: 345. Johansons I964. Smoljak I99I: 82. Bongard I992: 243. I7. Vgl. z.B. E. D. Morgan I888: 39 of. Ufer I930: 2of. Haekel I946: I05f., I08, I42ff. Krader I954: 344f. Strathern I972: I3of. Hauser-Schäublin 1997: 422. Thiel 200I: I47.

18. Vgl. z.B. Runeberg I947: II7, II8, I40. Gadžieva I96I: 326. Müller-Stellrecht I983: 394 .

19. Vgl. z.B. F. S. Krauss I888: $942 f$. Wuttke I900: 46. Weinberg I904: 260, Fußn. 8. Runeberg I947: I24f., I39.

20. Vgl. z.B. Runeberg I947: II3, II4, II6. Niederberger I978: I7f. Militzer I992: I45.

2I. Müller I996b: I46ff. Vgl. z.B. Runeberg I947: I27-I32. Thiel 200I: I45.

22. Vgl. z.B. Roskoschny I888: 745 . Runeberg I947: I20, I23. F. Albert I956: 252.

23. Vgl. z.B. Métraux I963: $565 f$. Müller 200I: 4I.
24. Vgl. z.B. Abeghian I899: IIIff. Mills I926: 223. Armstrong I928: I24f.

Runeberg I947: II6, I20. Smoljak I991: 29.

25. Vgl. z.B. Augustinus: De civitate dei IX II. Preisendanz I926: 6f., gf. Runeberg I947: I24. Sell I955: 20f. Bhattacharyya I955: 24f. Hopfner I965: 313. Maloney I974: 173. Swanson 1985: 150.

26. Moody I994: I89.

27. Petersdorff I957: 212.

28. Müller I996: 20. I997a: Iof. Bajburin \& Toporkov I990: 154 .

29. Müller I987b: 299. I996: 27f. Vgl. F. S. Krauss I888: 942. E. D. Morgan I888: 390. Bongard I992: 243.

30. Bajburin \& Toporkov I990: 155 .

3I. Vgl. z.B. Ritter I846: I83. Palgrave I867: 26. F. S. Krauss I888: 942. Abeghian I899: II9. Wuttke I900: 47. Roy I925: 293f. Runeberg I947: II7, I22, I4O. Swanson I985: 155 .

32. Specht 2002: I43f.

33. Reeve i988: 26. Vgl. Müller i997a: IIf.

34. Müler iو96a: 8If.

35. Müller 2003: 27. Vgl. ferner auch Palgrave i867: 26. Oldenberg I9I7: 255f. Gadžieva I96r: 326. Métraux I963: 568. Anesaki I964: 263f. Goodale I97I: I74f. Taksami i976: 205. Smoljak I99I: 29f.

36. Karsten I935: 430. Bor I955: 33 .

37. Kraschenninikow I766: 215. Haekel I946: I03f., ıо7ff., I42ff. Ränk I948: I54. Métraux I963: 572f.Smoljak I99I: 32, 68. Thiel 200I: I47ff.

38. Vgl. Thiel 200I: I49.

39. 2. Mose 20:4-5; vgl. Jesaja 44: IO-I5.

40. Gerstenberger I995: I6. Vgl. Richter I7:I-5.

41. Grüneisen I900: I92ff. Bin Gorion I962: 327f., 547 .

42. Müller ig80: $308 \mathrm{f}$., $376 \mathrm{ff}$.

43. Hauskeller 2000: 25 . Hasenfratz 2002: 22f. 
44. Hasenfratz 2002: 22.

45. Herodot V 82-85.

46. Elwin I955: I8I.

47. Gladigow I995: $257 f$.

48. Smoljak I99i: 46 .

49. Bhattacharyya I955: 23.

50. Pallas $1778: 59$. Vgl. a. Kohn \& Andree I876: 37. Haekel i946: I04.

51. Geffcken I9i6-ig: 287. Lethen I992: I6o.

52. Price I987: 62 .

53. Guntern I998: I8If.

54. Hasenfratz 2002: $27 f$.

55. Frazer I932: $274 \mathrm{f}$.

56. Müller i997a: I3.

57. Müller I992: 40.

58. Müller i997a: $9 f$.

59. Vgl. Lukesch i969: I85.

60. Müller i997a: 9, I6. Vgl. etwa Karsten I935: 455. Campbell I964: 333. AbuLughod I986: II5. Caratini I989: Io6. Thiel 200I: I44ff.

6I. Bongard I992: $94 f$.

62. Müller I999: 78. Vgl. z.B. Thiel I990: I43. Stöhr I992: 6I.

63. Horton $1962: 204$.

64. Braroe I975: 67 .

65. Bongard I992: $2 \mathrm{I} 8$.

66. Frazer $1963: 72 f$.

67. Vgl. Bettelheim I977: I3.

68. Berger I994: I9 (Hervorhebungen im Original).

69. Helmers 1989: 254 .

70. Diskussionsbeitrag Hasenfratz bei Kerber I997: 51 .

7I. Vgl. Saliba 1983: 19.

72. Wundt I920: 18-23. Vries I961: 202253. Zusne \& Jones I989: 77. Schneider I990: I40. Müller 2000a: $78 f$.

73. Nori et al. 1998: 68.

74. Gleichwohl sucht man in einschlägigen Lexika nach einem Eintrag »Geister« vergebens!

75. Bender I966: 6oIf. Bauer I990: 28.

76. Kasten 2000: 73 .
77. Tylor i87i.

78. Vgl. Müller: Schamanismus, Io2Io8. Vgl. a. Frazer: The scapegoat, ıo6. 79. Vgl. Wundt I920: I29f. Schneider I990: I40.

\section{Kapitel 7}

I. Simenon I980: $54 \mathrm{f}$.

2. Strogatz \& Stewart 1994: 74.

3. Genz I992: I98f.

4. Strogatz \& Stewart 1994: 74. Grillner: 1996: 50. Eberhard-Metzger 2003: 60.

5. Briggs \& Peat I990: 283 .

6. Strogatz \& Stewart I994: 76 .

7. Peat I992: 82 .

8. Wehner I992: I49, I54ff. Peat I992: 83.

9. Grillner I996: 50.

10. Vgl. M. S. I995: I7.

II. Briggs \& Peat I990: 283 .

12. Wickler \& Seibt I977: 88.

13. Müller i987b: I96f.

14. Krige \& Krige I947: 240.

15. Levy I973: 257.

16. Vgl. z.B. Schiffauer I987: $23 \mathrm{ff}$.

17. Vgl. z.B. Wilson I957: I73f. Berndt I965: 202f. Peinsipp I985: 55.

Thornton i980: I40f. Abu-Lughod I986: 65f. Rousseau I990: II7.

18. Kidd I906: 75 .

19. Vgl. Douglas 1963: 208.

20. Vgl. z.B. Fortune i932: 108f. Wilson I957: 2I4f. Hoenerbach I984: I, 48.

2I. Vgl. Thiel I990: 142.

22. Vgl. z.B. Mills I926: I75. Middleton I960: 100. Douglas 1965: I4.

23. Schiffauer i987: $220 f$.

24. Thornton I980: 62ff.

25. Riedl I988: 7 I.

26. Karsten I923: I2. Vgl. Ch. Wagley \& E. Galvão I949: 68ff. Müller I996: I6ff. 27. Vgl. z.B. Loux I980: II2. 
28. Howell I984: I45.

29. Damon I999: 63 .

30. Thurnwald I927: 293.

3I. Kaberry I939: 80.

32. Beidelman I97I: 106 .

33. Mills i922: 40.

34. McGovern I923: 54. Vgl. zu analogen Tabus bei Tschuktschen und Giljaken in Nordost- und Ostsibirien Frazer I963a: I22, und Novik I989: I6o.

35. Clausen i969: I4I.

36. Rasmussen I929: 26, I86f.

37. Tradicionnoe mirovozzrenie tjurkov I989: 201

38. Novik I989: I59f.

39. Obayashi \& Paproth I966: 2I4.

40. Henning I936: 104.

4I. Karsten I923: 24.

42. McGovern I923: $54 \mathrm{f}$.

43. Vgl. z.B. Malinowski I929: 339.

44. Mills i926: 207. Vgl. Müller I987b: $238 f$.

45. Von den Steinen I894: 459f.

46. Güntert I923: 72, 79f. Mühlmann I940: $49 f$.

47. Goldman I983: 67 .

48. Karsten I923: I2.

49. Davis I991: 6

50. Abu-Lughod ig86: 65f.

5I. Smoljak I99I: I73.

52. Marshall $1976: 208$.

53. Hogbin I970: 22.

54. Silberbauer I972: 3II

55. Nach Quadbeck-Seeger I988: 95.

56. Thornton I980: 139.

57. Karsten I923: I2. Witherspoon I98I: II2.

58. Civ'jan I985: I6I.

59. Sell I955: 9 .

60. Vgl. z.B. Haaf ig67: 8off.

61. Samarin I965: II $8 \mathrm{f}$.

62. Rasmussen I929: 197.

63. Kirchgässner I959: I 84 .

64. Westley i980: $39 f$.

65. Karsten I923: I2.
66. Nimuendajù I939: 226 .

67. Petrullo I939: 226.

68. Vgl. z.B. Douglas I963: I22f. Beidelman I963: 48 .

69. Vgl. Karsten I923: I2. Müller I987b: 204.

70. Szromba-Rysowa I98I: 270 (Polen).

7I. Bonin I983: 77.

72. Lévy-Bruhl I930: $265 \mathrm{ff}$.

73. Campbell ig64: I72f. Vgl. Biernoff 1978: 95

74. Karsten I923: I2.

75. Vgl. Bettelheim I977: 88.

76. Kröger $1978: 56$.

77. Reuter I992: 23I.

78. Kröger I978: 56 .

79. Bonin $1983: 77$.

80. Bauer I984: 62f.; vgl. I992: $265 f$.

8I. Mischo I983: I67ff.

82. $\mathrm{ASW}=$ Kürzel für $» A u ß e r s i n n l i c h e$ Wahrnehmung«.

83. Mischo I984: 20, 42.

84. Bauer I992: $265 f$.

85. Ernesto Bozzano hat eine Sammlung davon - überwiegend nach älteren Quellen - zusammengestellt: Bozzano I989: $39 \mathrm{ff}$.

86. Heinz I975: 24

87. Nimuendajù I939: 84 .

88. Wesselski I942: I58-I75

89. Tradicionnoe mirovozzrenie tjurkov južnoj Sibiri I989: I72.

90. Marshall I976: 200; vgl. 203

91. Lopatin I960: 105.

92. Müller i987b: I84ff.; vgl. I23ff., I70ff., 2I6ff., 233ff., $247 \mathrm{ff}$.

93. Vgl. Freedman \& van Nieuwenhuizen I987: 51.

94. Vgl. Springer 2000: $22 \mathrm{f}$.

95. Strogatz \& Stewart 1994

96. Ditto \& Pecora I993: 48.

97. Hund I996: 27.

98. Müller 2002: I72.

99. Freedman \& van Nieuwenhuizn I987: 5I. 
100. Moss \& Wiesenfeld I995.

I0I. Büchel I983: 89 f. Briggs \& Peat I990: 282. Pesic 2003: 57.

102. Vgl. Lucadou I99I: 244.

103. Vgl. Pesic 2003: 57.

104. Müller 2002: I70.

105. Frazer I963a: 52 .

106. Amann: Das Gestaltproblem in der Chemie, 253. Vgl. Jordan: Verdrängung und Komplementarität, 77.

\section{Kapitel 8}

I. Friend I96r: I54f.

2. Knebel I898: 506.

3. Strack I900: 7 I.

4. Vgl. z.B. Hauser-Schäublin I977: II7.

5. Die Belege dazu sind Legion. Vgl. z.B. Hillner I877: 15. Roy I925: 2Igf. Mills I926: 266. Drower 1938: II2. Hogbin I943: 289ff. Elwin I943: II6, I29. Loux I980: 60.

6. Vgl. Müller I998: 57 .

7. Loux I980: 6I.

8. Havers i946: 133.

9. Versnel I996: 283 .

10. Havers I946: I34.

II. Fehrle i926: $59 f$.

12. Vgl. Müller I997b.

13. Seligmann I927: 258. Jacoby I93233: 516.

14. Müller i987b: 136.

15. Müller I987b: I32ff. Vgl. Rock \& Palmer I991: 7of.

16. Todorov \& Ducrot 1975: 317f.

17. Müller i987b: I70-ı9I.

18. Müller I987b: 216 .

19. Müller: aaO, $2 \mathrm{I} 7$.

20. Karsten I935: 453; vgl. I42.

21. Aigremont I9Io: 6r; vgl. a. 66.

22. Müller I987b: 223 .

23. Thomas von Aquin: Summa theologica I II7, 3. Vgl. Stemplinger I9I9: 64, 68 .
24. Gramlich I987: I73ff.

25. Müller I987b: $220 f f$.

26. Müller i $987 b: 233 f f$.

27. Walker i967: 74 .

28. Frazer i963a: 77.

29. Seligmann I922: 34I. Nemec I976:

9I.

30. Paracelsus I926: 52.

31. Haug I987: I8of. Vgl. Graus I987:

I58. Zusne \& Jones I989: I6.

32. Müller I987b: І9I-I98.

33. Pechuël-Loesche I907: 335 .

34. Eckermann o.J.: I43f. Vgl. Müller I987b: 245 f.

35. Seligmann I922: $462 f$.

36. Gramlich I987: I7Iff.

37. Schopenhauer: o.J.: 327 .

38. Schopenhauer o.J.: $335 \mathrm{f}$.

39. Freud I974: 364-386. Vgl. H. Werner I933: $358 \mathrm{f}$.

40. Bender I959: 165 .

41. Gusinde I93г: 684f.

42. Smoljak i966: I24.

43. Whiting I977: 2I2b. Vgl. Speck I935: I84. Webster I948: 83.

44. Nicolelis \& Chapin 2003.

45. Wolf i999.

46. Vgl. Müller I996a: $78 \mathrm{f}$.

47. Schmökel I956: I40f.

48. Probst i87i: I47f.

49. Kayser I886: 22ff. Th. Werner I996: 8.

50. Vgl. Huizinga I969: I, 21off. Kieckhefer i994: 835 .

5I. Huizinga I969: 2II; vgl. 2Ioff.

52. Huizinga: aaO, 2IIf.

53. Th. Werner: aaO, 5 .

54. Ahrendt-Schulte \& Hoffmann 1996 :

I9.

55. Schäfer I958: 44. Blumberg I96263: $52 \mathrm{ff}$.

56. H. Werner $1928: 467 f$. Zeininger I929: 82ff. 
57. H. Werner 1928: 469, 473. Vorwahl I929: II3. Zeininger I929: 87. Remplein I966: 249 .

58. Zeininger I929: 47, 95f. Vgl. Krogmann I926: 560 .

59. Tidemann I935: 53 .

60. Blumberg I962-63: 52ff. Vgl. Spamer I958: 52.

6I. Greeley I96I-62: 23f.

62. Zusne \& Jones I989: 272.

63. $\mathrm{Zu}$ deutsch »Glücksbringer«. Das

Wort stammt - wie italienisch talismano, französisch und spanisch talisman - vom arabischen tilasm, Plural tilismā, ab, das seinerseits eine Übernahme aus dem altgriechischen telesma ( $\tau \varepsilon \lambda \varepsilon \sigma \mu \alpha)$, "geweihter Gegenstand «, darstellt, dem Nomen zum Verbum lismā, ab, das seinerseits eine Übernahme aus dem altgriechischen telesma ( $\tau \varepsilon \lambda \varepsilon \sigma \mu \alpha)$, »geweihter Gegenstand «, darstellt, dem Nomen zum Verbum telein ( $\tau \varepsilon \lambda \varepsilon \iota v)$, »vollbringen«, »bewirken«. Auch Kinder besitzen oft derartige »Glücksbringer « (Steine, Glasscherben, Lesezeichen, bestimmte Schreibstifte usw.), von denen sie sich in der Schule Erfolg versprechen. A. Hartmann I996: 30.

64. Paul Eckert: »Mutter Natur unterstützt Kim Jong-il«, in: Frankfurter Allgemeine Zeitung vom 30. 09. I997.

65. Blumberg $1_{9} 62-63: 52 \mathrm{ff}$.

66. Newman 1969: 122, sowie passim.

67. Lewis I963: 9ff.

68. Schindel I967: 895 .

69. Schindel I967: $892 \mathrm{ff}$. Vgl. Brown I998: 68ff.

70. Jaffé I958: Iо. Kirchgässner I959: 325. Shils I975: I56f. A. Hartmann I996: $27 \mathrm{ff}$.

7I. Brugger I994: 222.

72. Zimmer I990, insbes. 7ff., $4 \mathrm{I} 6 \mathrm{ff}$.

73. Atmanspacher I993a: 34 , Fußn. 48.

74. Unter Hexen sind korrekt bestimmte (erwachsene) Personen - überwiegend soll es sich um Frauen handeln - zu verstehen, deren Freiseele sich nachts, ohne daß sie bei Tag davon wüßten, von ihrem Körper löst, über andere Schlafende hermacht und ihnen langsam, über einen längeren Zeitraum hin, die Lebenskraft »aussaugt«, so daß sie zuletzt an Entkräftung (oder »Schwindsucht«) sterben. Im Gegensatz zur Magie (Zauberei), deren Techniken und Rezepturen im Prinzip jedermann erlernen kann, ist die »Hexenkraft« eine angeborene, oft in bestimmten Familien erbliche Gabe, die nur von Spezialisten, den sogenannten »Hexendoktoren«, erkannt, beziehungsweise nach dem Tod durch Obduktion diagnostiziert werden kann.

75. Packard I980: 248 ff. Müller I987b: I70 und die dortigen Belege. Thiel 200r: 72.

76. Mair I969: I6If. Vgl. Beattie I963:

53. Marwick 1970: 97.

77. Zusne \& Jones I989: I3.

78. Freud I974: 375 ; vgl. $367 f f$. Fromm I966: 42. Birk I970: 2If. Dongier I97I: 68.

79. Malinowski I954: 79ff. Evans-Pritchard I937: 63, I0off., 39I.

80. Malinowski ı954: 90. Vgl. Homans I94I: I64. Lewis I963: 7f. Beattie I965: 207f. Zusne \& Jones I989: I5.

8I. Vgl. z.B. Ugrinovič I973: 44; vgl. 60.

82. Gebser I953: Kap. III 4-5. Vgl. Atmanspacher i993a: 8f.

83. Kirchgässner I959: 325 .

84. Zusne \& Jones I989: 32; vgl. II, I4, 3If.

85. A. Hartmann $1996: 27$.

86. Lehmann i9o8: I5ff., 649 .

87. Freud I974: 379 .

88. Zusne \& Jones I989: 32.

89. Vgl. insbes. Krogmann I926. H.

Werner I928 und I933. Zeininger I929. Piaget I980.

90. Frazer i963a: XX. 
91. Frazer 1963a: 224.

92. Frazer i963a: 52-54 (Kap. III r: The principles of magic).

93. Downie I940: 6.

94. Vgl. Frazer I9I3: IIff.

95. Hume I809: 24.

96. Frazer i963a: 237; vgl. XX, $233 \mathrm{ff}$.

97. Vgl. Zusne \& Jones I989: 246.

Kieckhefer I994: 829, 832.

98. Homans I94I: I66f. Jensen I948 und I950. Tokarev I959: Io. Titiev I960: 294f. Mauss i972: 23f. Vgl. Zusne \& Jones 1989: 246 .

99. Vgl. Tambiah I993: 2I. Kieckhefer I994: 8I3.

100. Tylor I873: I34.

101. Frazer 1963a: 53 .

102. Zusne \& Jones I989: 19, 20.

103. W. Schmidt I9I2: 5 .

104. Beth I927: 80, I27f. Vgl. Pettersson I957: IIoff. Kieckhefer I994: 8I4f., 830.

105. Zusne \& Jones 1989: 2.

106. Vgl. Primas I992-93: $84,86,93$.

107. Weber I985: 593 f.

108. Wittgenstein I979: I; vgl. 8.

109. Wittgenstein I979: V.

I 10. Meran I985: 64. Vgl. Hahn I977: 63. Iordanskij I982: Io.

III. Müller 2002: I6gf.

II2. Pesic 2003: 57.

I 13. Müller 2002: I7I.

II4. Müller 2002: I72f.

II5. Müller 2002: I73f. Vgl. Reuter et al. I990: 301.

I 16. Vergil: Aeneis VI 727.

II7. Thomas von Aquin: Summa theologica I II7, 3 .

II8. Heine I980: 43I.

I 19. Lévi-Strauss i962: 21, 23f., 289f., 354f. Vgl. Tambiah I993: I05ff.

120. Lévi-Strauß \& Eribon 1989: I60.

\section{Kapitel 9}

I. Bauer: 1984:52.

2. Vgl. Hardy I929.

3. Clodd I896: 42.

4. Green I946: 7I, 20I. Hardy I929: I83. Gauld I983: I62.

5. Vgl. Folk-Lore 7 (1896): 34 .

6. Vgl. Gauld I983: I62f.

7. Clodd i905: เ8.

8. Clodd I905: $26 \mathrm{f}$.

9. Clodd I905: 27, 59 .

10. Clodd I883: 3 .

I I. Vgl. Codrington I89I.

12. Frazer i963a: XX, 222; vgl. 52ff., $220 f f$.

2

13. Tylor 1873: 134 .

14. Clodd I905: I4.

15. Clodd I905: 96

16. Clodd I905.

17. Clodd I883: 3 .

18. Clodd i905: 49 .

19. Gould I99I: 134 .

20. Clodd i895: $57 f$.

21. Hardy I929: 185 .

22. Clodd I895: 78.

23. Green $1946: 6 f$.

24. Green I946: 80. Gauld I983: I6r.

25. Green I946: I2.

26. Gauld I983: I6I.

27. Vgl. Green i946: VIIff., I, 54ff., 69ff., I24. Gauld I983: I62, I72f. Clodd I9I2: 359 .

28. Clodd I9I2: 362. Gauld I983: I62, I73.

29. Lang I894: $295 f$.

30. Green I946: I75. Gauld I983: I62.

31. Green I946: 74. Gauld I983: I73.

32. Lang I900: I60-288. I894: 336 .

33. Lang I900: VII, I.

34. Lang I9or: $\mathrm{V}$.

35. Clodd I9I2: 362 .

36. Vgl. Gauld I983: I62.

37. W. Schmidt igi2a: $372 \mathrm{f}$.

38. Lang I894: 6. Vgl.Gauld I983: I69. 
39. Lang I900: 2, 65-159. Vgl. Gauld I983: I64f.

40. Lang I894: 83. I900: 2f. I908: I2. Vgl. Gauld I983: I67. Clodd I9I2: 360.

4I. Lang I900: 2. Gauld I983: I64.

42. Rivers I9I2: 370.

43. Lang I894: IX, XIII, XIV.

44. Gauld I983: I72. Vgl. Lang I9II: 369,370 .

45. Lang I894: XII.

46. Lang I894: 7, 22f., 33ff. I9II: 368. Vgl. Green I946: 72. Gauld I983: I66.

47. Lang I894: X, 355. І9Іі: 368 .

48. Lang I894: $82 \mathrm{f}$.

49. Lang I908: I2.

50. Lang I894: $338 \mathrm{ff}$. I893.I895: 247.

Vgl. Gauld I983: I64f.

5I. Salter I948: IO, 31. Bauer I984: 52, 60, 68. Beloff i993: 70f.

52. Beloff I993: 64. Vgl. Bauer I984: $52 \mathrm{ff}$.

53. Gauld I983: I65, I67. Vgl. Lang I9II: 370.

54. Gauld I983: I74. Vgl. Green I946: 2I, 7I.

55. Bennett I999: I50.

56. Clodd I9ı2: 36 I.

57. Clodd I896: 4I.

58. Lang I9Іі: 366 .

59. Lang I9II: 370.

60. Lang I9Іі: 37 I.

6I. Lang I894: XIII.

62. Lang I9II: 369 .

63. Lang $1895: 237 f$.

64. Lang I900: $5 f$. Vgl. W. Schmidt I9I2a: 373 .

65. Clodd I895: 79; vgl. $78 \mathrm{ff}$.

66. Bennett I999: I5I.

67. Clodd I895: 79.

68. Clodd ı895a: 252f. г9ı2: 36 г.

69. Clodd I895a: 252.

70. Clodd I895a: 253. I905: 27; vgl. 59.

7I. Vgl. Lang I894: XIVf., 6.

72. Clodd I895a: 253.

73. Mischo I994: I858ff.
74. Lang I894: $338 \mathrm{ff}$.

75. Marett I9I2: 364 .

76. Lang I9II: 374 .

77. Lang I894: XV, 7 .

78. Lang I894: XIII.

79. Lang $1895: 236 \mathrm{f}$

80. Lang I894: XII.

81. Lang I9II: 374 .

82. Vgl. Gould I99I: I35.

83. Unter Ektoplasma wird eine feinstoffliche Substanz verstanden, die während der Trance in verschiedenen Formen (Fäden, schleierartigen Gebilden) aus dem Medium austritt.

84. Clodd I895: 80. I895a: 255 f.

85. Clodd I896: 38 .

86. Clodd $1896: 39$

87. Lang I894: XII. I895: 239.

88. Lang I894: 8 .

89. Lang I895: $239 \mathrm{ff}$.

90. Lang I895: 24If.

91. Clodd I895a: 248-250.

92. Clodd I895a: 258.

93. Lang I9II: 37 I.

94. Bennett I999: I59.

95. Lang: Cock Lane, 22. Vgl. Presidential address, 371, 375 .

96. Rivers I9I2: 370 .

97. Hultkrantz I98г: 74f.; vgl. 76 f., 79ff., 90. McClenon \& Nooney 2002: $49 f$.

98. Elkin I945: 77 (Hervorhebungen von mir, KEM).

99. Hultkrantz I98r: 94.

100. Clodd I9I2: 362 .

I0I. Clodd I9I2: 361 .

102. Rivers I9I2: 370. Gauld I983: I72.

\section{Kapitel 10}

I. Civ'jan ı985: ı6ı. Vgl. Müller ı987b: I5

2. Beidelman I986: $55 \mathrm{f}$.

3. Müller 2002a: 213f.

4. Firth $1967: 26$. 
5. Lüning I983: 3. Klotz I997: I3ff.

6. Smolla I967: 60. Fajnberg I975: 5off. Müller ı987: 49f. (Langhäuser für mehrere Familien).

7. Turner i968: I35-150. Traube I989: 323.

8. Ich erinnere an die mehrfach erwähnte Inversions- und Dilatationserfahrung Jenseitsreisender; vgl. o. S. 26ff., 49, 6If., 69.

9. Vgl. o. S. $57 \mathrm{f}$.

10. Treml 2003: 8f.

II. Vgl. Franz I983: 95ff.

12. Treml 2003: 8.

13. Vgl. Prigogine \& Stengers I98r: I99ff. Halliwell I992: 54 .

14. Kant 1968: 4I9.

15. Kant I968: 4I8.

16. Primas 1992-93: 108f.

17. Primas 1992-93: Io9 (Hervorhebung im Original).

18. Primas 1992-93: 108.

19. Vgl. Primas 1992-93: 84ff.

20. Müller 2002: I73.

2I. Aristoteles: Metaphysik IV 7.

22. Aristoteles: De interpretatione, c. 9 .

23. Reuter et al. I990.

24. McClenon 1997 und 2002. McClenon \& Nooney 2002: 47. Vgl. A. H. Morgan 1973 .

25. McClenon \& Nooney 2002: $47 \mathrm{f}$.

26. Einzmann I977: 108.

27. Prasch 2003: I04. 


\section{Literatur}

Abbott, Larry, I990: Das Rätsel der kosmologischen Konstanten, in: Kosmologie und Teilchenphysik. Heidelberg, S. 70-77.

Abeghian, Manuk, I899: Der armenische Volksglaube. Leipzig.

Abu-Lughod, Lila, I986: Veiled sentiments: honor and poetry in a Bedouin society. Los Angeles, London.

Adler, Meinhard, I984: Tod als Notwendigkeit, Töten als Alltäglichkeit, in: Rolf Winau/Hans Peter Rosemeier (Hg.), Tod und Sterben. Berlin, New York, S. 262-288.

Ahrendt-Schulte, Ingrid/Hoffmann, Barbara, I996: »Von falscher Lehr und bösen unchristlichen Leben«. Zur Verfolgung von Zauberei und Pietisterey in der Frühen Neuzeit, in: Sowi 25 (I), S. I9-26.

Aigremont [Schultze-Galléra, S.], I9ıо: Volkserotik und Pflanzenwelt: eine Darstellung alter wie moderner erotischer und sexueller Gebräuche, Vergleiche, Benennungen, Sprichwörter, Redewendungen, Rätsel, Volkslieder, erotischen Zaubers und Aberglaubens, sexueller Heilkunde, die sich auf Pflanzen beziehen. Leipzig.

Albert, Friedrich, I956: Die Waldmenschen Udehe: Forschungsreisen im Amur- und Ussurigebiet. Darmstadt.

Albert, Hans, ${ }^{2}$ I972: Theorien in den Sozialwissenschaften, in: Hans Albert (Hg.), Theorie und Realität: ausgewählte Aufsätze zur Wissenschaftslehre der Sozialwissenschaften. Tübingen, S. 3-25.

Amann, Anton, I992: Das Gestaltproblem in der Chemie. Die Entstehung molekularer Form unter dem Einfluß der Umgebung, in: Gestalt Theory I4 (4), S. 228-265.

Anesaki, Masaharu, I964: Japanese mythology. New York.

Anonymus, I921: Clairvoyance among the Polynesian, in: The Journal of the Polynesian Society 30, S. II9-I20.

Armstrong, W. E., I928: Rossel Island: an ethnological study. Cambridge.

Arsdale, Peter W. van, I98I: The elderly Asmat of New Guinea, in: Pamela T. Amoss/Stevan Harrell (Hg.), Other ways of growing old: anthropological perspectives. Stanford, S. III-I23. 
Assmann, Jan, I992: Politische Theologie zwischen Ägypten und Israel. München.

- I993: Die Katastrophe des Vergessens. Das Deuteronomium als Paradigma kultureller Mnemotechnik, in: Aleida Assmann/Dietrich Harth (Hg.), Mnemosyne: Formen und Funktionen der kulturellen Erinnerung. Frankfurt/Main, S. 337-355.

— I996: Ägypten: eine Sinngeschichte. München, Wien.

Atmanspacher, Harald, I993: Wolfgang Pauli und die Alchemie. Teil III: Impulse für die modernen Naturwissenschaften, in: Zeitschrift für Parapsychologie und Grenzgebiete der Psychologie 35, S. I-27.

- I993a: Die Vernunft der Metis: Theorie und Praxis einer integralen Wirklichkeit. Stuttgart, Weimar.

Baer, Gerhard, I969: Ein besonderes Merkmal des südamerikanischen Schamanen, in: Zeitschrift für Ethnologie 94, S. 284-292.

- I987: Peruanische ayahuasca-Sitzungen - Schamanen und Heilbehandlungen, in: Adolf Dittrich/Christian Scharfetter (Hg.), Ethnopsychotherapie: Psychotherapie mittels außergewöhnlicher Bewußtseinszustände in westlichen und indigenen Kulturen. Stuttgart, S. 70-80.

Bailey, F. G., I97I: Gifts and poison, in: F. G. Bailey (Hg.), Gifts and poison: the politics of reputation. Oxford, S. I-25.

Bajburin, Al’bert K./Toporkov, Andrej L., I990: U istokov etiketa: étnografičeskie očerki. Leningrad.

Barnes, Robert H., I974: Kédang: a study of the collective thought of an eastern Indonesian people. Oxford.

Batchelor, John, I892: The Ainu of Japan: the religion, superstitions, and general history of the hairy aborigines of Japan. London.

Battaglia, Debbora, I990: On the bones of the serpent: person, memory, and mortality in Sabarl Island society. Chicago.

Batto, Bernard F., I974: Studies on women at Mari. Baltimore, London.

Bauer, Eberhard, I984: Ioo Jahre parapsychologische Forschung - die Society for Psychical Research, in: Eberhard Bauer/Walter von Lucadou (Hg.), Psi - was verbirgt sich dahinter? Wissenschaftler untersuchen parapsychologische Erscheinungen. Freiburg im Breisgau, S. 5I-75.

- I990: Zum gegenwärtigen Stand der Okkultismus-Debatte, in: Albert Götz von Olenhusen (Hg.), Wege und Abwege: Beiträge zur europäischen Geistesgeschichte der Neuzeit; Festschrift für Ellic Howe zum 20. September1990. Freiburg im Breisgau, S. 23-32.

- 1992: Die Welt des Paranormalen und ihre wissenschaftliche Erforschung, in: Andreas Resch (Hg.), Aspekte der Paranormologie: die Welt des Außergewöhnlichen. Innsbruck, S. 243-284.

Baumann, Hermann, I936: Schöpfung und Urzeit der Menschen im Mythus der afrikanischen Völker. Berlin.

Beattie, John, I963: Sorcery in Bunyoro, in: John Middleton/E. H. Winter (Hg.), Witchcraft and sorcery in East Africa. London, S. 27-55. 
- ${ }^{2}$ I965: Other cultures: aims, methods and achievements in Social Anthropology. London.

Beidelman, Thomas O., I963: Kaguru omens. An East African people's concepts of the unusual, unnatural and supernormal, in: Anthropological Quarterly 36, S. 43-59.

- I97I: The Kaguru: a matrilineal people of East Africa. New York.

- I986: Moral imagination in Kaguru modes of thought. Bloomington.

Beloff, John, I993: Parapsychology: a concise history. London.

Bender, Hans, I959: Glaubensheilung und Parapsychologie, in: Wilhelm Bitter (Hg.), Magie und Wunder in der Heilkunde. Stuttgart, S. I4O-I59.

- I966: Mediumistische Psychosen. Ein Beitrag zur Pathologie spiritistischer Praktiken, in: Hans Bender (Hg.), Parapsychologie: Entwicklung, Ergebnisse, Probleme. Darmstadt, S. 574-604.

Beninger, Eduard, I93I: Die Leichenzerstückelung als vor- und frühgeschichtliche Bestattungssitte, in: Anthropos 26, S. 768-78I.

Bennett, Gillian, I999: »Alas, poor ghost«: traditions of belief in story and discourse. Logan, Utah.

Berger, Peter L., I994: Sehnsucht nach Sinn: Glauben in einer Zeit der Leichtgläubigkeit. Frankfurt/Main, New York.

Berndt, Ronald M., I965: Law and order in Aboriginal Australia, in: Ronald M. Berndt/Catherine H. Berndt (Hg.), Aboriginal man in Australia: essays in honour of emeritus professor A. P. Elkin. London, Sydney, S. $167-206$.

Beth, Karl, ${ }^{3}$ I927: Religion und Magie: ein religionsgeschichtlicher Beitrag zur psychologischen Grundlegung der religiösen Prinzipienlehre. Leipzig.

Bettelheim, Bruno, I977: Kinder brauchen Märchen. Stuttgart.

Bhattacharyya, Asutosh, I955: The cult of the village gods of West Bengal, in: Man in India 35 (I), S. I9-30.

Biernoff, David, I978: Safe and dangerous places, in: L. R. Hiatt (Hg.), Australian Aboriginal concepts. Canberra, S. 93-I05.

Biezais, Haralds, I983: Der Gegengott als Grundelement religiöser Strukturen, in: Saeculum 34 (3-4), S. 280-291.

Bin Gorion, Micha J., I962: Die Sagen der Juden. Frankfurt/Main.

Birk, Kasimir, I970: Sigmund Freud und die Religion. Münsterschwarzach. Blumberg, P., I962-63: Magic in the modern world, in: Sociology and Social Research 47, S. I47-I60.

Boddy, Janice, I982: Womb as oasis. The symbolic context of Pharaonic circumcision in rural northern Sudan, in: American Ethnologist 9 (4), S. 682-698.

Bogoras, Waldemar, I925: Ideas of space and time in the conception of primitive religion, in: American Anthropologist 27 (2), S. 205-266.

Boll, Franz, I9I4: Aus der Offenbarung Johannis: hellenistische Studien zum Weltbild der Apokalypse. Leipzig, Berlin.

Bongard, Nikolaus, I992: Sensler Sagen. Freiburg Schweiz. 
Bonin, Werner F., I983: Über Doppelgänger, Spiegelbilder und Masken, in: Eberhard Bauer/Walter von Lucadou (Hg.), Spektrum der Parapsychologie:Hans Bender zum 75. Geburtstag. Freiburg im Breisgau, S. 7I85 .

Bor, Elizabeth, I955: Adventures of a botanist's wife. London.

Bourdieu, Pierre, I963: The attitude of the Algerian peasant toward time, in: Julian Pitt-Rivers (Hg.), Mediterranean countrymen: essays in the social anthropology of the Mediterranean. Paris, S. 55-72.

Bozzano, Ernesto, ${ }^{3}$ I989: Übersinnliche Erscheinungen bei Naturvölkern. Freiburg im Breisgau.

Braroe, Niels W., I975: Indian and White: self-image and interaction in a Canadian Plains community. Stanford.

Briggs, John/Peat, F. David, I990: Die Entdeckung des Chaos: eine Reise durch die Chaos-Theorie. München.

Bringmann, Wolfgang et al., I990: Fechner und die Parapsychologie, in: Zeitschrift für Parapsychologie und Grenzgebiete der Psychologie 32, S. I943.

Brown, Walter A., I998: Der Placebo-Effekt, in: Spektrum der Wissenschaft I998 (3), S. 68-74.

Brugger, Peter, I994: Die althergebrachte Art von Verhältnis zum Zufall. Zeitlosigkeit und Ausbildungsresistenz okkulten Denkens, in: Zeitschrift für Parapsychologie und Grenzgebiete der Psychologie 36 (3-4), S. $22 \mathrm{I}-226$.

Buch, Max, I882: Die Wotjäken: eine ethnologische Studie. Stuttgart.

Buchbinder, Georgeda/Rappaport, Roy A., I976: Fertility and death among the Maring, in: Paula Brown/Georgeda Buchbinder (Hg.), Man and woman in the New Guinea highlands. Washington, S. 13-35.

Büchel, Wolfgang, I983: Naturauffassung und Parapsychologie, in: Eberhard Bauer/Walter von Lucadou (Hg.), Spektrum der Parapsychologie: Hans Bende zum 75. Geburtstag. Freiburg im Breisgau, S. 86-93.

Bürkle, Horst, I968: Der Tod in den afrikanischen Gemeinschaften. Zur Frage theologisch relevanter Aspekte im afrikanischen Denken, in: Leben angesichts des Todes: Helmut Thielicke zum 6o. Geburtstag. Tübingen, S. 243-267.

Buxton, J. C., I963: Chiefs and strangers: a study of political assimilation among the Mandari. Oxford.

Campbell, John K., I964: Honour, family and patronage: a study of institutions and moral values in a Greek mountain community. Oxford.

Capelle, Wilhelm, I940: Die Vorsokratiker. Stuttgart.

Caratini, Sophie, 1989: Les Rgaybāt (1610-1934). Bd. 2. Paris.

Christensen, Arthur, I933: Die Iranier. München.

Cipolletti, Maria S., I983: Jenseitsvorstellungen bei den Indianern Südamerikas. Berlin. 
Civ'jan, T. V., I985: Mifologičeskoe programmirovanie povsednevnoj žizii, in: Al'bert K. Bajburin (Hg.), Etničeskie stereotipy povedenija. Leningrad, S. I54-I78.

Clausen, Lars, I969: Behauptung der Magie, in: Internationales Jahrbuch für Religionssoziologie 5, S. I4I-I55.

Clodd, Edward, i883: The childhood of religion. New York.

— I895: Presidential address, in: Folk-Lore 6, S. 54-8I.

— I895a: A reply to the foregoing »protest«, in: Folk-Lore 6, S. 248-258.

- I896: Presidential address, in: Folk-Lore 7, S. 35-60.

- I905: Animism: the seed of religion. London.

- I9I2: In memoriam: Andrew Lang (I844-I9I2), in: Folk-Lore 23, S. 358362 .

Codrington, Robert H., I891: The Melanesians: studies in their anthropology and folk-lore. Oxford.

Cowan, James G., I992: The Aborigine tradition. Shaftesbury.

Damon, William, I999: Die Moralentwicklung von Kindern, in: Spektrum der Wissenschaft I999 (10), S. 62-70.

Davis, John, I99I: Times and identities: an inaugural lecture delivered before the University of Oxford on 1 May 1991. Oxford,

Davis, Philip J./Hersh, Reuben, I986: Erfahrung Mathematik. Basel.

D'Azevedo, W. L., I962: Uses of the past in Gola discourse, in: The Journal of African History 3, S. II-34.

Dittmer, Kunz, I96r: Die sakralen Häuptlinge der Gurunsi im Obervolta-Gebiet. Hamburg.

Ditto, W. L./Peccora, L. M., I993: Das Chaos meistern, in: Spektrum der Wissenschaft I993 (II), S. 46-53.

Doerfer, Gerhard (Hg.), I983: Sibirische Märchen. Bd. 2. Düsseldorf, Köln.

Dongier, Maurice, I97I: Neurosen: Erscheinungsformen und Beispiele aus der psychotherapeutischen Praxis. Freiburg im Breisgau.

Douglas, Mary, I963: The Lele of the Kasai. London.

- I965: The Lele of Kasai, in: Daryll Forde (Hg.), African worlds: studies in the cosmological ideas and social values of African peoples. London, S. I26.

- I974: Ritual, Tabu und Körpersymbolik. Frankfurt/Main.

Downie, R. Angus, I940: James George Frazer: the portrait of a scholar. London.

Downs, James F., I966: The two worlds of the Washo: an Indian tribe of California and Nevada. New York.

Drower, E. S., I938: Woman and taboo in Iraq, in: Iraq 5, S. I05-II7.

Dürr, Lorenz, I938: Die Wertung des göttlichen Wortes im Alten Testament und im antiken Orient; zugleich ein Beitrag zur Vorgeschichte des neutestamentlichen Logosbegriffes. Leipzig.

Dzobo, N. K., I98I: The indigenous African theory of knowledge and truth. Example of the Ewe and Akan of Ghana, in: Conch I3 (I-2), S. 85IO2. 
Eberhard-Metzger, Claudia, 2003: Stammzell-Therapie nach Herzinfarkt, in: Spektrum der Wissenschaft 2003 (10), S. 60-6I.

Eckermann, Johann P., o.J.: Gespräche mit Goethe in den letzten Jahren seines Lebens. 3 Bde. in I. Leipzig.

Eckert, Georg, I940: Prophetentum und Kulturwandel in Melanesien, in: Baessler-Archiv 23, S. 26-4I.

Eilers, Anneliese, I927: Die sozialen Beziehungen des Kindes bei den Bantunegern. Hamburg.

Einzmann, Harald, I977: Religiöses Volksbrauchtum in Afghanistan: islamische Heiligenverehrung und Wallfahrtswesen im Raum Kabul. Wiesbaden.

Eliade, Mircea, I963: Myth and reality. New York, Evanston.

- I981: Die Sehnsucht nach dem Ursprung: von den Quellen der Humanität. Frankfurt/Main.

Elkin, Adolphus P., I945: Aboriginal men of high degree. Sydney.

Elwin, Verrier, I943: Conception, pregnancy and birth among the tribesmen of the Maikal Hills, in: The Journal of the Royal Asiatic Society of Bengal 9, S. 99-I48.

- I947: The Muria and their ghotul. London.

- I950: Bondo highlander. Bombay.

- I955: The religion of an Indian tribe. London.

Endicott, Kirk M., I979: Batek Negrito religion: the world-view and rituals of a hunting and gathering people of peninsular Malaysia. Oxford.

Engelbrektsson, Ulla-Britt, I978: The force of tradition: Turkish migrants at home and abroad. Göteborg.

Evans-Pritchard, Edward E., I929: Witchcraft (mangu) amongst the AZande, in: Sudan Notes and Records I2 (2), S. I63-249.

- I937: Witchcraft, oracles and magic among the Azande. Oxford.

Fajnberg, Lev A., I975: Vozniknovenie i razvitie rodovogo stroja, in: Pervobytnoe obščestvo: osnovnye problemy razvitija. Moskva, S. 49-87.

Faron, Louis C., I967: Death and fertility rites of the Mapuche (Araucanian) Indians of central Chile, in: John Middleton (Hg.), Gods and rituals: readingsin religious beliefs and practices. Garden City, S. 227-254.

Fehrle, Eugen, o.J.: Geisterhafte Wesen im Kehricht, in: Joseph M. Ritz (Hg.), Festschrift für Marie Andree-Eysn: Beiträge zur Volks- und Völkerkunde. München, S. 59-63.

- I926: Zauber und Segen. Jena.

Firth, Raymond, ${ }^{9}$ I958: Human types: an introduction to social anthropo$\log$. London.

- I967: Tikopia ritual and belief. London.

- I975: Speech-making and authority in Tikopia, in: Maurice Bloch (Hg.), Political language and oratory in traditional society. London, S. 2943.

Fischer, Hans, I987: Heilserwartung: Geister, Medien und Träumer in Neuguinea. Frankfurt/Main, New York. 
Fortune, Reo F., I932: Sorcerers of Dobu: The social anthropology of the Dobuislanders of the western Pacific. London.

Franke, Herbert, I982: Archäologie und Geschichtsbewußtsein in China, in: Hermann Müller-Karpe (Hg.), Archäologie und Geschichtsbewußtsein. München, S. 69-83.

Franz, Marie-Louise von, I983: Ein Beitrag zur Diskussion der Synchronizitätshypothese C. G. Jungs, in: Eberhard Bauer/Walter von Lucadou (Hg.), Spektrum der Parapsychologie: Hans Bender zum 75. Geburtstag. Freiburg im Breisgau, S. 94-I04.

Frazer, James G., I913: The belief in immortality. Bd. I. London.

- I932: Mensch, Gott und Unsterblichkeit: Gedanken über den menschlichen Fortschritt. Leipzig.

- I963: The scapegoat. London.

- I963a: The magic art and the evolution of kings. Bd. I. London.

Freedman, Daniel Z./Nieuwenhuizen, Pieter van, I987: Supergravitation und die Einheit der Naturgesetze, in: Gravitation: Raum-Zeit-Struktur und Wechselwirkung. Heidelberg, S. 46-6I.

Freud, Sigmund, I974: Totem und Tabu: einige Übereinstimmungen im Seelenleben der Wilden und der Neurotiker. Frankfurt/Main. (Sigmund Freud-Studienausgabe, Bd. 9).

Friederici, Georg, I906: Skalpieren und ähnliche Kriegsgebräuche in Amerika. Braunschweig.

Friend, John A. N., I96r: Demonology, sympathetic magic and witchcraft: a study of superstition as it persists in man and affects him in a scientific age. London.

Fromm, Erich, I966: Psychoanalyse und Religion. Konstanz, Zürich.

Fuchs, Stephen, I950: The Children of Hari: a study of the Nimar Balahis in the central provinces of India. Wien.

Fuller, Anne H., I96r: Buarij: portrait of a Lebanese Muslim village. Cambridge, Mass.

Gadžieva, Sakinat Š., I96r: Kumүki: istoriko-ètnografičeskoe issledovanie. Moskva.

Gahs, Alexander, I928: Kopf-, Schädel- und Langknochenopfer bei Rentiervölkern, in: Festschrift P. W. Schmidt. Wien, S. 23I-268.

Gebser, Jean, I953: Ursprung und Gegenwart. Bd. I. Stuttgart.

Gauld, Alan, I983: Andrew Lang as psychical researcher, in: Journal of the Society for Psychical Research 52 (794), S. I6I-I76.

Geffcken, Johannes, I9I6-I9: Der Bilderstreit des heidnischen Altertums, in: Archiv für Religionswissenschaft I9, S. 286-315.

Genz, Henning, ${ }^{2}$ I992: Symmetrie - Bauplan der Natur. München.

Gernert, Dieter, I994: What can we learn from internal observers?, in: Harald Atmanspacher/G. J. Dalenoort (Hg.), Inside versus outside. Berlin, S. I2I-I33.

Gerstenberger, Erhard S., I995: Warum hast du mich verlassen? Die Klage um die Gerechtigkeit Gottes im Alten Testament, in: Michael 
Nüchtern (Hg.), Warum läßt Gott das zu? Kritik der Allmacht Gottes in Religion und Philosophie. Frankfurt/Main, S. I2-32.

Ghurye, Govind S., ${ }^{2}$ I963: The Mahadev Kolis. Bombay.

Gladigow, Burkhard, I995: Religionsökonomie. Zur Einführung in eine Subdisziplin der Religionswissenschaft, in: Hans G. Kippenberg/ Brigitte Luchesi (Hg.), Lokale Religionsgeschichte. Marburg, S. 253-258.

Goldenweiser, Alexander A., I932: Early civilization: an introduction to anthropology. New York.

Goldman, Laurence, I983: Talk never dies: the language of Huli disputes. London.

Goodale, Jane C., I971: Tiwi wives: a study of the women of Melville Island, North Australia. London.

Goody, Jack, I962: Death, property and the ancestors: a study of the mortuary customs of the LoDagaa of West Africa. London.

Gossen, Gary H., I974: Chamulas in the world of the sun: time and space in a Maya oral tradition. Cambridge, Mass.

Gould, Warwick, I99I: Frazer, Yeats and the reconstruction of folklore, in: Robert Fraser (Hg.), Sir James Frazer and the literary imagination: essays in affinity and influence. New York, S. I2I-I53.

Gramlich, Richard, I987: Die Wunder der Freunde Gottes: Theologien und Erscheinungsformen des islamischen Heiligenwunders. Wiesbaden.

Graus, František, I987: Epochenbewußtsein im Spätmittelalter, in: Reinhart Herzog/Reinhart Koselleck (Hg.), Epochenschwelle und Epochenbewußtsein. München, S. 153-166.

Greeley, Andrew, I96I-62: Myths, symbols and rituals in the modern world, in: Critic 20 (3), S. I8-25.

Green, Roger L., I946: Andrew Lang: a critical biography. Leicester.

Grillner, Sten, I996: Bewegungssteuerung im Wirbeltier-Rückenmark, in: Spektrum der Wissenschaft I996 (3), S. 50-56.

Grüneisen, Carl, I9००: Der Ahnenkultus und die Urreligion Israels. Halle.

Güntert, Hermann, I923: Der arische Weltkönig und Heiland: bedeutungsgeschichtliche Untersuchungen zur indo-iranischen Religionsgeschichte und Altertumskunde. Halle.

Guntern, Josef (Hg.), ${ }^{9}$ I998: Walliser Sagen. Zürich, Düsseldorf.

Gusinde, Martin, I93I: Die Selk'nam: vom Leben und Denken eines Jägervolkes auf der großen Feuerlandinsel. Mödling bei Wien.

Haaf, Ernst, I967: Die Kusase: eine medizinisch-ethnologische Studie über einen Stamm in Nordghana. Stuttgart.

Haberland, Eike, I965: Untersuchungen zum äthiopischen Königtum. Wiesbaden.

Habermas, Rebekka, I99I: Wallfahrt und Aufruhr: zur Geschichte des Wunderglaubens in der frühen Neuzeit. Frankfurt/Main.

Haekel, Josef, I946: Idolkult und Dualsystem bei den Ugriern. (Zum Problem des eurasiatischen Totemismus), in: Archiv für Völkerkunde I, S. 95-163. 
Hahn, Alois, I977: Kultische und säkulare Riten und Zeremonien in soziologischer Sicht, in: Anthropologie des Kults. Freiburg im Breisgau, S. 5I-8I.

Halliwell, J. J., I992: Quantenkosmologie und die Entstehung des Universums, in: Spektrum der Wissenschaft 1992 (2), S. 50-58.

Hallowell, A. Irving, ${ }^{2}$ I969: Ojibwa ontology, behavior, and world view, in: Stanley Diamond (Hg.), Primitive views of the world. New York, London, S. 49-82.

Haraldsson, Erlendur, I992: Erscheinungen von und Berichte über Begegnungen mit Verstorbenen. Eine Analyse von 357 aktuellen Berichten, in: Andreas Resch (Hg.), Aspekte der Paranormologie: die Welt des Außergewöhnlichen. Innsbruck, S. 469-484.

Hardy, Thomas, I929: In memoriam Edward Clodd (I840-1930), in: Folk-Lore 40, S. I83-I86.

Hartmann, Andreas, I996: Private Magie im Deutschland des 20. Jahrhunderts. Forschungsgeschichtliche und aktuelle Perspektiven, in: Sowi 25 (I), S. 27-34.

Hartmann, Hans, I952: Der Totenkult in Irland: ein Beitrag zur Religion der Indogermanen. Heidelberg.

Harva, Uno, I938: Die religiösen Vorstellungen der altaischen Völker. Porvoo, Helsinki.

Harwood, Alan, I970: Witchcraft, sorcery, and social categories among the Safwa. Glasgow.

Hasenfratz, Hans-Peter, 2002: Religion - was ist das? Lebensorientierung und Andere Wirklichkeit. Freiburg im Breisgau.

Haug, Walter, I987: Die Zwerge auf den Schultern der Riesen. Epochales und typologisches Geschichtsdenken und das Problem der Interferenzen, in: Reinhart Herzog/Reinhart Koselleck (Hg.), Epochenschwelle und Epochenbewußtsein. München, S. I67-194.

Hauser-Schäublin, Brigitta: I977: Frauen in Kararau: zur Rolle der Frauen bei den Iatmul am Mittelsepik, Papua New Guinea. Basel.

- I997: Die Vergangenheit in der Gegenwart. Zeitkonzeptionen und ihre Handlungskontexte bei den Abelam in Papua-Neuguinea, in: Baessler-Archiv 70, S. 409-429.

Hauskeller, Michael, ${ }^{5}$ 2000: Was ist Kunst? Positionen der Ästhetik von Platon bis Danto. München.

Havers, Wilhelm, I946: Neuere Literatur zum Sprachtabu. Wien.

Hays, Hoffmann R., I966: The dangerous sex: the myth of feminine evil. London.

Heers, Jacques, I986: Vom Mummenschanz zum Machttheater: europäische Festkultur im Mittelalter. Frankfurt/Main.

Heeschen, Volker, I994: Mythen und Wandergeschichten der Mek-Leute im Bergland von West-Neuguinea (Irian Jaya, Indonesien), in: Brigitta Hauser-Schäublin (Hg.), Geschichte und mündliche Überlieferung in Ozeanien. Basel, S. I6I-I84. 
Heine, Heinrich, ${ }^{2}$ I980: Reisebilder. Frankfurt/Main.

Heinz, Hans-Joachim, I975: Elements of !ko Bushmen religious beliefs, in: Anthropos 70, S. I7-4I.

Helander, Bernhard, I988: Death and the end of society. Official ideology and ritual communication in the southern Somali funeral, in: S. Cederroth et al. (Hg.), On the meaning of death: essays on mortuary rituals and eschatological beliefs. Uppsala, S. II3-I35.

Helmers, Sabine, 1989: Tabu und Faszination: über die Ambivalenz der Einstellung zu Toten. Berlin.

Henning, Joachim, I936: Die Frau im öffentlichen Leben in Melanesien. Leipzig.

Henninger, Joseph, 1963: Geisterglaube bei den vorislamischen Arabern, in: Festschrift Paul Schebesta: zum 75. Geburtstag gewidmet von Mitbrüdern, Freunden und Schülern. Wien-Mödling, S. 279-3I6.

Hetmann, Frederik, I984: Die Reise in die Anderswelt: Feengeschichten und Feenglaube in Irland. Frankfurt/Main.

Hillner, Johann, I876-77: Volksthümlicher Glaube und Brauch bei Geburt und Taufe im Siebenbürger Sachsenlande, in: Programm des evangelischen Gymnasiums in Schäßburg und der damit verbundenen Lehr-Anstalten I876-77, S. 3-52.

Hoenerbach, Wilhelm, I984: Agrarische Vorstellungen in Nordafrika: Protokolle. Wiesbaden.

Hogbin, H. Ian, I943: A New Guinea infancy. From conception to weaning in Wogeo, in: Oceania I3 (4), S. 285-309.

- I970: The island of menstruating men: religion in Wogeo, New Guinea. Scranton, London, Toronto.

Homans, George C., I94I: Anxiety and ritual. The theories of Malinowski and Radcliffe-Brown, in: American Anthropologist 43, S. I64-I72.

Hopfner, Theodor, I965: Artikel »Mageia«, in: Pauly-Wissowa: Realencyclopädie der Classischen Altertumswissenschaft. Bd. XIV I. Stuttgart, Sp. 3OI-393.

Horton, Robin, I962: The Kalabari world-view. An outline and interpretation, in: Africa 32 (3), S. 197-219.

Howell, Signe, I984: Society and cosmos: Chewong of peninsular Malaysia. Singapore, Oxford, New York.

Huber, Hugo, I965: Tod und Leben. Weltanschauliche Problematik bei Andangme- und Ewe-Gruppen am Unteren Volta, in: Réincarnation et vie mystique en Afrique Noire: Colloque de Strasbourg (16-18 mai 1963). Paris, S. 87-99.

Huizinga, Johan, ${ }^{\text {I० }}$ I969: Herbst des Mittelalters: Studien über Lebens- und Geistesformen des 14. und 15. Jahrhunderts in Frankreich und in den Niederlanden. Stuttgart.

Hultkrantz, Åke, I98I: Ritual und Geheimnis. Über die Kunst der Medizinmänner, oder: Was der Herr Professor verschwieg, in: Hans Peter 
Duerr (Hg.), Der Wissenschaftler und das Irrationale. Bd. I. Frankfurt/ Main, S. 73-97.

- I982: Religion and experience of nature among North American hunting Indians, in: Åke Hultkrantz/Ørnulf Vorren (Hg.), The hunters: their culture and way of life. Tromsø, Oslo, Bergen, S. I63-I86.

Hume, David, I809: Essays and treatises on several subjects. Bd. 2. Edinburgh.

Hund, Friedrich, I996: Geschichte der physikalischen Begriffe. Heidelberg.

Hutton, John H., I92I: The Sema Nagas. London.

Illi, Dieter W., I991: Das Hindukush-Haus: zum symbolischen Prinzip der Sonderstellung von Raummitte und Raumhintergrund. Stuttgart.

Inan, Abdülkadir, I954: Tarihte ve bugün şamanizm: materyaller ve Araştırmalar. Ankara.

Iordanskij, Vladimir B., I982: Chaos i garmonija. Moskva.

Jacoby, I932-33: Artikel »Kreuzstein«, in: Handwörterbuch des deutschen Aberglaubens. Bd. 5. Berlin, Leipzig, Sp. 516.

Jaffé, Aniela, I958: Geistererscheinungen und Vorzeichen: eine psychologische Deutung. Zürich, Stuttgart.

Jaroschek, Kurt, I979: Gespräche mit Freunden über den Glauben der Naturwissenschaftler. Reinheim.

Jensen, Adolf E., I948: Magie. Bemerkungen zu drei neuen Veröffentlichungen, in: Studium Generale I (4), S. 226-236.

- I950: Gibt es Zauberhandlungen?, in: Zeitschrift für Ethnologie 75, S. 3I2.

Johansons, Andreja, I964: Der Schirmherr des Hofes im Volksglauben der Letten. Stockholm.

Jones, Rex L./Jones, Shirley K., I976: The Himalayan woman: a study of Limbuwomen in marriage and divorce. Palo Alto.

Jordan, Pascual, I947: Verdrängung und Komplementarität: eine philosophische Untersuchung. Hamburg-Bergedorf.

Junod, H. A., I9I2: The life of a South African tribe. Bd. I. Neuchatel.

Just, Gisela, I991: Magische Musik im Märchen: Untersuchungen zur Funktion magischen Singens und Spielens in Volkserzählungen. Frankfurt/ Main.

Kaberry, Phyllis M., I939: Aboriginal women sacred and profane. London.

Kant, Immanuel, I968: Anthropologie in pragmatischer Hinsicht, in: Wilhelm Weischedel (Hg.), Immanuel Kant: Werke in zehn Bänden. Bd. Io (2). Darmstadt, S. 399-69o.

Karsten, Rafael, I923: Blood revenge, war, and victory feasts among the Jibaro Indians of eastern Ecuador. Washington.

- I935: The head-hunters of western Amazonas: the life and culture of the Jibaro Indians of eastern Ecuador and Peru. Helsingfors.

Kaspar, Robert, I983: Die biologischen Grundlagen der evolutionären Erkenntnistheorie, in: Konrad Lorenz/Franz M. Wuketits (Hg.), Die Evolutiondes Denkens. München, Zürich, S. I25-I45. 
Kasten, Erich, 2000: Wenn das Gehirn aus der Balance gerät: Halluzinationen, in: Spektrum der Wissenschaft 2000 (I2), S. 64-73.

Kayser, C., I886: Die Canones Jacob's von Edessa. Leipzig.

Keen, Ian, I994: Knowledge and secrecy in an Aboriginal religion. Oxford.

Kenner, Hedwig, I970: Das Phänomen der verkehrten Welt in der griechischrömischen Antike. Klagenfurt.

Kerber, Walter (Hg.), I997: Personenkult und Heiligenverehrung. München.

Kidd, Dudley, I906: Savage childhood: a study of Kafir children. London.

Kieckhefer, Richard, I994: The specific rationality of medieval magic, in: The American Historical Review 99 (3), S. 813-836.

Kirchgässner, Alfons, I959: Die mächtigen Zeichen: Ursprünge, Formen und Gesetze des Kultes. Basel.

Kirk, Malcolm S., I972: Headhunters in today's world. The Asmat of New Guinea, in: National Geographic I4I (3), S. 376-408.

Kluckhohn, Clyde, I94I: Patterning as exemplified in Navaho culture, in: Leslie Spier et al. (Hg.), Language, culture, and personality: essays in memory of Edward Sapir. Menasha, S. Io9-130.

Klotz, Heinrich, I997: Die Entdeckung von Çatal Höyük: der archäologische Jahrhundertfund. München.

Knebel, J., I898: Amulettes javanaises, in: Tijdschrift voor Indische Taal-, Land-en Volkenkunde 40, S. 497-507.

Knortz, Karl, I909: Der menschliche Körper in Sage, Brauch und Sprichwort. Würzburg.

Köngäs-Maranda, Elli, I974: Lau, Malaita: »A woman is an alien spirit«, in: Carolyn J. Matthiasson (Hg.), Many sisters: women in cross-cultural perspective. New York, London, S. I77-202.

Koestler, Arthur, I972: Die Wurzeln des Zufalls. München, Wien.

Kohn, Albin/Andree, Richard, ${ }^{2}$ I876: Sibirien und das Amurgebiet: Geschichte und Reisen, Landschaften und Völker zwischen Ural und Beringstraße. Bd. I.Leipzig.

Kopytoff, Igor, I98I: Knowledge and belief in Suku thought, in: Africa 5I (3), S. 709-723.

Krader, Lawrence, I954: Buryat religion and society, in: Southwestern Journal of Anthropology Io, S. 322-35I.

Krascheninnikow, Stepan, I766: Beschreibung des Landes Kamtschatka. Lemgo.

Krauss, Friedrich S., I888: Vilenglauben in Slawonien, in: Das Ausland 6I, S. $94 \mathrm{I}-946$.

Krauss, Heinrich, 2000: Die Engel: Überlieferung, Gestalt, Deutung. München.

Krauss, Lawrence M., I987: Dunkle Materie im Universum, in: Gravitation: Raum-Zeit-Struktur und Wechselwirkung. Heidelberg, S. I6o-I7I.

Krige, Eileen J./Krige, Jacob D., ${ }^{3}$ I947: The realm of a rain-queen: a study of the pattern of Lovedu society. London. 
Kröger, Franz, I978: Übergangsriten im Wandel: Kindheit, Reife und Heirat bei den Bulsa in Nord-Ghana. Hohenschäftlarn.

Krogmann, Willy, I926: Das »magische« Denken der Kinder, in: Zeitschrift für Pädagogische Psychologie 27, S. 556-562.

Lachmann, Renate, 2002: Erzählte Phantastik: zu Phantasiegeschichte und Semantik phantastischer Texte. Frankfurt/Main.

Lagercrantz, Sture, I964: Traditional beliefs in Africa concerning meteors, comets, and shooting stars, in: Eike Haberland et al. (Hg.), Festschrift für Ad. E. Jensen. Bd. I. München, S. 319-329.

Landes, Ruth, I938: The Ojibwa woman. New York.

Lang, Andrew, I893: Superstition and fact, in: The Contemporary Review 64, S. $882-892$.

- I894: Cock Lane and common-sense. London.

- I895: Protest of a psycho-folklorist, in: Folk-Lore 6, S. 236-248.

— ${ }^{2}$ I900: The making of religion. New York.

- I901: Magic and religion. New York.

- I908: The origins of religion and other essays. London.

- I9ır: Presidential address, in: Proceedings of the Society for Psychical Research 25, S. 364-376.

Lehmann, Alfred, ${ }^{2}$ I908: Aberglaube und Zauberei: von den ältesten Zeiten an bis in die Gegenwart. Stuttgart.

Lethen, Helmut, I992: Damnatio Memoriae und die Rhetorik des Vergessens, in: Dietmar Kamper/Christoph Wulf (Hg.), Schweigen: Unterbrechung und Grenze der menschlichen Wirklichkeit. Berlin, S. I59-168.

Lévi-Strauss, Claude, I962: La pensée sauvage. Paris.

- I97I: Das Rohe und das Gekochte. Frankfurt/Main.

Lévi-Strauss, Claude/Eribon, Didier, I989: Das Nahe und das Ferne: eine Autobiographie in Gesprächen. Frankfurt/Main.

Levy, Robert I., I973: Tahitians: mind and experience in the Society Islands. Chicago.

Lévy-Bruhl, Lucien, I930: Die Seele der Primitiven. Wien, Leipzig.

Lewis, Lionel S., I963: Knowledge, danger, certainty, and the theory of magic, in: American Journal of Sociology 69, S. 7-I2.

Lidzbarski, Mark, I9I5: Das Johannesbuch der Mandäer. Gießen.

Liebeck, Oskar, I928: Das Unbekannte und die Angst. Leipzig.

Lienhardt, Godfrey, I967: Denkformen, in: Institutionen in primitiven Gesellschaften. Frankfurt/Main, S. I07-II9.

- I970: The situation of death. An aspect of Anuak philosophy, in: Mary Douglas (Hg.), Witchcraft confessions and accusations. London, S. 27929 I.

Linton, Ralph, ${ }^{3}$ I952: The cultural background of personality. London.

Lopatin, Ivan A., I960: The cult of the dead among the natives of the Amur Basin. 's-Gravenhage.

Loux, Françoise, I980: Das Kind und sein Körper: Volksmedizin, Hausmittel, Bräuche. Frankfurt/Main. 
Lucadou, Walter von, I989: Psyche und Chaos: neue Ergebnisse der Psychokinese-Forschung. Freiburg im Breisgau.

— I99I: Wie »hell« sehen Hellseher?, in: Zeitschrift für Parapsychologie und Grenzgebiete der Psychologie 33 (3-4), S. 237-249.

Luckmann, Thomas, I991: Die unsichtbare Religion. Frankfurt/Main.

Lüning, Jens, I983: Mensch und Umwelt in der Steinzeit, in: Forschung Frankfurt I, S. 2-5.

Luhmann, Niklas, I978: Geschichte als Prozeß und die Theorie soziokultureller Evolution, in: Karl-Georg Faber/Christian Meier (Hg.), Historische Prozesse. München, S. 413-440.

Lukesch, Anton, I969: Mythos und Leben der Kayapo. Wien.

Luk'janov, T. I., I904: Iz kosmogoničeskich poverij abchazcev, in: Sbornik Materialov dlja Opisanija Mestnostej i Plemen Kavkaza 34 (3), S. I66-I89.

Mair, Lucy, I969: Magie im Schwarzen Erdteil. München.

Malinowski, Bronislaw, I927: Das Geschlechtsleben der Wilden in NordwestMelanesien: Liebe, Ehe und Familienleben bei den Eingeborenen der Trobriand-Inseln, Britisch-Neu-Guinea. Leipzig, Zürich.

- I954: Magic, science and religion and other essays. New York.

Maloney, Clarence, I974: Peoples of South Asia. New York.

Man, E. H., I883: On the aboriginal inhabitants of the Andaman Islands, in: The Journal of the Anthropological Institute of Great Britain and Ireland $\mathrm{I2}$, S. 69-175, 327-434.

Maple, Eric, I971: Superstition and the superstitious. London, New York.

Marett, Robert R., I9I2: Andrew Lang. Folklorist and critic, in: Folk-Lore 23, S. 363-366.

Marshall, Lorna, I976: The !Kung of Nyae Nyae: the !Kung Bushmen of the Kalahari Desert in South West Africa. Cambridge.

Maruyama, Magoroh, I974: Endogenous research versus delusions of relevanceand expertise among exogenous academics, in: Human Organization 33 (3), S.318-322.

Marwick, M. G., I970: Sorcery in its social setting: a study of the northern Rhodesian Cewa. Manchester.

Mauss, Marcel, I972: A general theory of magic. Londo, Boston.

Mbiti, John S., I974: Afrikanische Religion und Weltanschauung. Berlin.

McClenon, James, I997: Shamanic healing, human evolution, and the origin of religion, in: Journal for the Scientific Study of Religion 36, S. 323-337.

- 2002: Wondrous healing: shamanism, human evolution, and the origin of religion. DeKalb.

McClenon, James/Nooney, Jennifer, 2002: Anomalous experiences reported by field anthropologists. Evaluating theories regarding religion, in: Anthropology of Consciousness I3, S. 46-60.

McGovern, Janet B. M., I923: Unter den Kopfjägern auf Formosa. Stuttgart. Meek, Charles K., I93I: Tribal studies in northern Nigeria. Bd. 2. London. 
Mensching, Gustav, I926: Das heilige Schweigen: eine religionsgeschichtliche Untersuchung. Gießen.

Meran, Josef, I985: Theorien in der Geschichtswissenschaft: die Diskussion über die Wissenschaftlichkeit der Geschichte. Göttingen.

Métraux, Alfred, I963: Religion and shamanism, in: Julian H. Steward (Hg.), Handbook of South American Indians. Bd. 5. New York, S. 559599 .

Meyer, Carl, I884: Der Aberglaube des Mittelalters und der nächstfolgenden Jahrhunderte. Basel.

Meyer, Piet, I981: Kunst und Religion der Lobi. Zürich.

Middleton, John, I960: Lugbara religion: ritual and authority among an East African people. London.

Militzer, Heinz, I992: Suche und Erkundung von Rohstoff-Lagerstätten. Gibt es Alternativen zu geowissenschaftlichen Methoden?, in: Hans Binder (Hg.), Macht und Ohnmacht des Aberglaubens: Magie, Wissenschaft, Pseudowissenschaft. Pähl, S. I43-I6I.

Mills, James P., I922: The Lhota Nagas. London.

- I926: The Ao Nagas. London.

Min'ko, Leonid I., I975: Sueverija i primety (istoki i suščnost'). Minsk.

Mischo, Johannes, I983: Parapsychische Erfahrungen und Psychodiagnostik im »affektiven Feld«, in: Eberhard Bauer/Walter von Lucadou (Hg.), Spektrum der Parapsychologie: Hans Bender zum 75. Geburtstag. Freiburg im Breisgau, S. I67-192.

- I984: Außersinnliche Wahrnehmung. Methoden, Ergebnisse, Probleme, in: Eberhard Bauer/Walter von Lucadou (Hg.), Psi - was verbirgt sich dahinter? Freiburg im Breisgau, S. 9-50.

- I994: Schizotypische Muster im Denken und Verhalten?, in: Therapiewoche 44 (32), S. I858-1863.

Mörner, Birger, I924: Tinara: die Vorstellungen der Naturvölker vom Jenseits. Jena.

Monod, Jacques, I971: Zufall und Notwendigkeit: philosophische Fragen der modernen Biologie. München.

Moody, Raymond A., ${ }^{2}$ I994: Blick hinter den Spiegel: Botschaften aus der anderen Welt. München.

Morgan, Arlene H., I973: The heritability o hypnotic susceptibility in twins, in: Journal of Abnormal and Social Psychology 82, S. 55-6r.

Morgan, E. D., I888: The customs of the Ossetes and the light they throw on the evolution of law, in: The Journal of the Royal Asiatic Society of Great Britain and Ireland 20, S. 2I-48.

Moss, Frank/Wiesenfeld, Kurt, I995: Signalverstärkung durch Rauschen, in: Spektrum der Wissenschaft I995 (Iо), S. 92-96.

M. S., I995: Der Ein-Atom-Mikrolaser, in: Spektrum der Wissenschaft I995 (5), S. I7-I8. 
Mühlmann, Wilhelm E., I940: Krieg und Frieden: ein Leitfaden der politischen Ethnologie; mit Berücksichtigung völkerkundlichen und geschichtlichen Stoffes. Heidelberg.

Müller, Klaus E., I967: Kulturhistorische Studien zur Genese pseudo-islamischer Sektengebilde in Vorderasien. Wiesbaden.

- I973-74: Grundzüge der agrarischen Lebens- und Weltanschauung, in: Paideuma I9-20, S. 54-I24.

- I980: Geschichte der antiken Ethnographie und ethnologischen Theoriebildung: von den Anfängen bis auf die byzantinischen Historiographen. Bd. 2. Wiesbaden.

- I983: Vorderasien, in: Klaus E. Müller (Hg.), Menschenbilder früher Gesellschaften: ethnologische Studien zum Verhältnis von Mensch und Natur; Gedächtnisschrift für Hermann Baumann. Frankfurt/Main, New York, S. 297-339.

- I987: Sterben und Tod in Naturvolkkulturen, in: Hansjakob Becker et al. (Hg.), Im Angesicht des Todes: ein interdisziplinäres Kompendium. Bd. I. St. Ottilien, S. 49-90.

- I987a: Vom Ursprung der Anfänglichkeit, in: Mark Münzel (Hg.), Ursprung: Vortragszyklus 1986/87 über die Entstehung des Menschen und der Welt in den Mythen der Völker. Frankfurt/Main, S. II3-I23.

- I987b: Das magische Universum der Identität: Elementarformen des sozialen Verhaltens; ein ethnologischer Grundriß. Frankfurt/Main, New York.

- I990: Epistemologische Grenzfälle. »Höhere« Erkenntnis in traditionellen Gesellschaften, in: Zeitschrift für Parapsychologie und Grenzgebiete der Psychologie 32 (3-4), S. I37-I52.

- I992: Reguläre Anomalien im Schnittbereich zweier Welten, in: Zeitschrift fürParapsychologie und Grenzgebiete der Psychologie 34 (I-2), S. 3350.

— ${ }^{2}$ I996: Kindheitsvorstellungen, in: Klaus E. Müller/Alfred K. Treml (Hg.), Ethnopädagogik: Sozialisation und Erziehung in traditionellen Gesellschaften; eine Einführung. Berlin, S. 13-34.

- ${ }^{2}$ I996a: Initiationen, in: Klaus E. Müller/Alfred K. Treml (Hg.), Ethnopädagogik: Sozialisation und Erziehung in traditionellen Gesellschaften; eine Einführung. Berlin, S. 69-9I.

- I996b: Der Krüppel: Ethnologia passionis humanae. München.

- I997: Der gesprungene Ring: wie man die Seele gewinnt und verliert. Frankfurt/Main.

- I997a: Jenseitskontakte, in: Zeitschrift für Parapsychologie und Grenzgebieteder Psychologie 39 (I-2), S. I-I9.

- I997b: Der magische Kreis, in: Paul Michel (Hg.), Symbolik von Ort und Raum. Bern, S. 45I-468.

- I998: Das Geheimnis in traditionellen Gesellschaften, in: Albert Spitznagel (Hg.), Geheimnis und Geheimhaltung: Erscheinungsformen - Funktionen - Konsequenzen. Göttingen, S. 55-66. 
- I999: Die fünfte Dimension: soziale Raumzeit und Geschichtsverständnis in primordialen Kulturen. Göttingen.

- 2000: Ethnicity, Ethnozentrismus und Essentialismus, in: Wolfgang Eßbach (Hg.), Wir/ihr/sie: Identität und Alterität in Theorie und Methode. Würzburg, S. 317-343.

- 2000a: Der Drache im Garten der Sinnhaftigkeit. Können Echsen, Drachen oder gar Frösche Wesentliches zur Begründung von Sinnkonzepten beitragen?, in: Kulturwissenschaftliches Instiut. Jahrbuch 1999/2000. Essen, S. 75-86.

- ${ }^{2}$ 200I: Schamanismus: Heiler - Geister - Rituale. München.

- 200Ia: Das Geschehen im Netz der Zeit, in: Moritz Csáky/Peter Stachel (Hg.), Speicher des Gedächtnisses: Bibliotheken, Museen, Archive. Bd. 2. Wien, S. I77-I95.

- 200Ib: Wortzauber: eine Ethnologie der Eloquenz. Frankfurt/Main.

- 2002: Die gespenstische Ordnung: Psi im Getriebe der Wissenschaft. Frankfurt/Main.

- 2002a: Zwischen Tag und Nacht. Vom Schatten des Todes im Leben traditioneller Gesellschaften, in: Jan Assmann/Rolf Trauzettel (Hg.), Tod, Jenseits und Identität: Perspektiven einer kulturwissenschaftlichen Thanatologie. Freiburg im Breisgau, München, S. 204-222.

- 2003: Mfumu José und der heilige Joseph, in: Dieter Kramer et al. (Hg.), Missio, Message und Museum: Festschrift für Josef Franz Thiel zum 70. Geburtstag. Frankfurt/Main, S. 23-34.

Müller-Karpe, Hermann, ı968: Jungsteinzeit. München.

Müller-Stellrecht, Irmtraud, I983: Hunza, in: Klaus E. Müller (Hg.), Menschenbilder früher Gesellschaften: ethnologische Studien zum Verhältnis von Mensch und Natur; Gedächtnisschrift für Hermann Baumann. Frankfurt/Main, New York, S. 388-4I5.

Muller, Jean-Claude, I97I: Pouvoir mystique, sorcellerie et structure sociale chez les Rukuba (Benue-Plateau State, Nigeria), in: L'Homme II, S. 7I-III.

Nachtigall, Horst, I952: Die kulturhistorische Wurzel der Schamanenskelettierung, in: Zeitschrift für Ethnologie 77, S. I88-197.

Nadel, Siegfried F., I947: The Nuba: an anthropological study of the hill tribes in Kordofan. London.

Narr, Karl J., I96r: Urgeschichte der Kultur. Stuttgart.

Nemec, Helmut, I976: Zauberzeichen: Magie im volkstümlichen Bereich. Wien, München.

Newman, Lucile F., I969: Folklore of pregnancy. Wives' tales in Contra Costa County, California, in: Western Folklore 28, S. II2-I35.

Neuser, Wolfgang, I996: Einführung, in: Wolfgang Neuser/Katharina Neuser-von Oettingen (Hg.), Quantenphilosophie. Heidelberg, S. 7-II.

Nicolaisen, Johannes, I963: Ecology and culture of the pastoral Tuareg: with particular reference to the Tuareg of Ahaggar and Ayr. Copenhagen. 
Nicolelis, Miguel A./Chapin, John K., 2003: Roboter steuern von Geistes Hand, in: Spektrum der Wissenschaft 2003 (I), S. 74-82.

Niderberger, Franz, I978: Sagen und Gebräuche aus Unterwalden. Zürich.

Nimuendajù, Curt, I939: The Apinayé. Washington.

Nori, Franco et al., I998: Singender Sand, in: Spektrum der Wissenschaft I998 (8), S. 68-73.

Novik, E. S., I989: Ritual und Folklore im sibirischen Schamanismus: eine vergleichende Strukturanalyse. Hamburg.

Obayashi, Taryo/Paproth. Rüdiger, ı966: Das Bärenfest der Oroken auf Sachalin, in: Zeitschrift für Ethnologie 9I, S. 2II-236.

Obst, Helmut, ${ }^{4}$ 2000: Apostel und Propheten der Neuzeit: Gründer christlicher Religionsgemeinschaften des 19. und 20. Jahrhunderts. Göttingen.

Ohnuki-Tierney, Emiko, I980: Ainu illness and healing. A symbolic interpretation, in: American Ethnologist 7, S. I32-I5I.

Oldenberg, Hermann, ${ }^{2}$ I9I7: Die Religion des Veda. Stuttgart, Berlin.

Ortiz, Alfonso, I969: The Tewa world: space, time, being, and becoming in a Pueblo society. Chicago, London.

Ovsyannikov, O. V./Terebikhin, N. M., I994: Sacred space in the culture of the Arctic regions, in: David L. Carmichael et al. (Hg.), Sacred sites, sacred places. London, S. 44-8I.

Packard, Randall M., I980: Social change and the history of misfortune among the Bashu of eastern Zaire, in: Ivan Karp/Charles S. Bird (Hg.), Explorations in African systems of thought. Bloomington, S. 237-267.

Palgrave, William G., I867: Reise in Arabien. Bd. I. Leipzig.

Pallas, Peter S., I778: Reise durch verschiedene Provinzen des Russischen Reichs in einem ausführlichen Auszuge. Bd. 3. Frankfurt/Main, Leipzig.

Paracelsus, I926: Über das Ens der Geister, in: Sämtliche Werke. Bd. I. Jena, S. 46-54.

Parry, Nevill E., I932: The Lakhers. London.

Paulson, Ivar, I960: Seelenvorstellungen und Totenglaube bei nordeurasischen Völkern, in: Ethnos 25 (I-2), S. 84-II8.

Peat, F. David, I992: Synchronizität: die verborgene Ordnung. München.

Pechuël-Loesche, Eduard, I907: Volkskunde von Loango. Stuttgart.

Peinsipp, Walther, I985: Das Volk der Shkypetaren: Geschichte, Gesellschaftsund Verhaltensordnung; ein Beitrag zur Rechtsarchäologie und zur soziologischen Anthropologie des Balkan. Wien, Köln, Graz.

Pervin, Lawrence A., I963: The need to predict and control under conditions of threat, in: Journal of Personality 3I, S. 570-587.

Pesic, Peter, 2003: Die Identität der Quanten, in: Spektrum der Wissenschaft 2003 (I), S. 56-62.

Petersdorff, Egon von, 1957: Daemonologie. Bd. 2. München.

Petrullo, Vincenzo, I939: The Yaruros of the Capanaparo River, Venezuela. Washington.

Pettersson, Olof, I957: Magic - religion. Some marginal notes to an old Problem, in: Ethnos 22, S. Iog-II9. 
Piaget, Jean, I980: Das Weltbild des Kindes. Frankfurt/Main.

Ploss, Hermann H., I876: Das Kind in Brauch und Sitte der Völker: anthropologische Studien. Bd. 2. Stuttgart.

Popov, A. A., I976: Duša i smert' po vozzrenijam nganasanov, in: Innokentij S. Vdovin (Hg.), Priroda $i$ čelovek $v$ religioznych predstavlenijach narodov Sibiri i severa (vtoroja polovina XIX - načalo XX v.). Leningrad, S. 3I-43.

Popper, Karl R./Eccles, John C., I982: Das Ich und sein Gehirn. München, Zürich.

Prasch, Pia, 2003: Tierischer Scharfsinn, in: Spektrum der Wissenschaft 2003 (7), S. I04.

Preisendanz, Karl, ı926: Akephalos, der kopflose Gott. Leipzig.

Preuß, Konrad Th., I936: Die religiöse Bedeutung der Paradiesmythen, in: Custom is king: essays presented to $R$. $R$. Marett on his seventieth birthday, June 13, 1936. London, S. II9-I39.

Price, Simon, I987: From noble funerals to divine cult. The consecration of Roman emperors, in: David Cannadine/Simon Price (Hg.), Rituals of royalty: power and ceremonial in traditional societies. Cambridge, S. 56I05.

Prigogine, Ilya/Stengers, Isabelle, ${ }^{2}$ I98I: Dialog mit der Natur: neue Wege naturwissenschaftlichen Denkens. München, Zürich.

Primas, Hans, I992-93: Ein Ganzes, das nicht aus Teilen besteht. Komplementarität in den exakten Naturwissenschaften, in: Neue Horizonte I992-93, S. 8I-III.

- I996: Synchronizität und Zufall, in: Zeitschrift für Parapsychologie und Grenzgebiete der Psychologie 38 (I-2), S. 6I-9I.

Probst, Ferdinand, I87I: Lehre und Gebet in den drei ersten christlichen Jahrhunderten. Tübingen.

Puhvel, Martin, I989: The crossroads in folklore and myth. New York.

Quadbeck-Seeger, Hans-Jürgen, I988: Zwischen den Zeichen: Aphorismen über und aus Natur und Wissenschaft. Weinheim.

Radin, Paul, I926: Crashing Thunder: the autobiography of a Winnebago Indian. New York.

Ränk, Gustav, I948: Die Hausgottheiten der Frauen und das Geschlechtstabu bei den nordeurasischen Völkern, in: Ethnos I3, S. I53-I70.

Rasmussen, Knud, I929: Intellectual culture of the Iglulik Eskimos. Copenhagen.

Rattray, Robert S., ${ }^{2}$ I955: Ashanti. London.

- ${ }^{2}$ I969: Ashanti law and constitution. Oxford.

Reeve, Mary-Elizabeth, I988: Cauchu Uras. Lowland Quichua histories of the Amazon rubber boom, in: Jonathan D. Hill (Hg.), Rethinking history and myth: indigenous South American perspectives on the past. Urbana, S. 19-34. 
Reimbold, Ernst Th., I970: Die Nacht in Mythos, Kultus, Volksglauben und in der transpersonalen Erfahrung: eine religionsphänomenologische Untersuchung. Köln.

Reinach, Théodore, I895: Mithradates Eupator, König von Pontos. Leipzig.

Reitzenstein, Richard A., I904: Poimandres: Studien zur griechisch-ägyptischen und frühchristlichen Literatur. Leipzig.

Remplein, Heinz, I966: Die seelische Entwicklung des Menschen im Kindesund Jugendalter: Grundlagen, Erkenntnisse und pädagogische Folgerungender Kindes- und Jugendpsychologie. München, Basel.

Reuter, Bernhard M., I992: Psyche, Gehirn und Synchronizität, in: Andreas Resch (Hg.), Aspekte der Paranormologie: die Welt des Außergewöhnlichen. Innsbruck. S, 2I7-24I.

Reuter, Bernhard M. et al., I990: Kausalität und Synchronizität. Zum psychophysischen Problem, in: Analytische Psychologie 2I, S. 286-308.

Riedl, Rupert, I988: Über die Realitätsformen von Natur- und Denkgesetzen; oder die Biologie von Korrespondenz und Kohärenz, in: Erhard Oeser/ElfriedeM. Bonet (Hg.), Das Realismusproblem. Wien, S. 55-74.

Ritter, Carl, I846: Die Erdkunde von Asien. Bd. 8, I. Berlin.

Ritz, Ute, I988: Das Bedeutsame in den Erscheinungen: Divinationspraktiken in traditionellen Gesellschaften. Frankfurt/Main, New York.

Ritz-Müller, Ute, I990: Würde Gott sterblich sein, wären es auch die Menschen (Akan-Sprichwort), in: Josef F. Thiel (Hg.), Der Tod: Ende oder Tor zum Leben? Tod und Jenseitsvorstellungen der Völker. Frankfurt/Main, S. 57-69.

- I997: Divination im Raum Tenkodogo (Burkina Faso), in: Zeitschrift für Parapsychologie und Grenzgebiete der Psychologie 39 (I-2), S. 20-34.

Rivers, William H. R., ı9ı2: Andrew Lang. Folklorist and critic, in: FolkLore 23, S. 369-371.

- I920: The concept of »soul-substance« in New Guinea and Melanesia, in: Folk-Lore 31, S. 48-86.

Robert, Raoul, 200I: Das Ende des Schmetterlingseffekts, in: Spektrum der Wissenschaft 200I (II), S. 66-75.

Rock, Irvin/Palmer, Stephen, I99I: Das Vermächtnis der Gestaltpsychologie, in: Spektrum der Wissenschaft I99I (2), S. 68-75.

Röhrich, Lutz, I980: Der Tod in Sage und Märchen, in: Gunther Stephenson (Hg.), Leben und Tod in den Religionen: Symbol und Wirklichkeit. Darmstadt, S. 165-183.

Rohde, Erwin, I96r: Psyche: Seelencult und Unsterblichkeitsglaube der Griechen. Bd. 2. Darmstadt.

Roskoschny, Hermann, I888: Vom Aberglauben der Großrussen, in: Das Ausland 6I, S. 66I-666, 695-697, 704-708, 732-734, 743-747.

Rousseau, Jérôme, I990: Central Borneo: ethnic identity and social life in a stratified society. Oxford.

Roy, Sarat C., I925: The Birhors: a little known jungle tribe of Chota Nagpur. Ranchi. 
Rudolph, Ebermut, I982: Das »Andere Ich« des Menschen im Tiere. Ein Beitrag zur Frage des »Lebensgleichlaufes« und anderer psychologischer wie paranormaler Phänomene in der Mensch-Tier-Beziehung, in: Zeitschrift für Ethnologie I07, S. 23-68.

Rüsen, Jörn, I998: Einleitung. Für eine interkulturelle Kommunikation in der Geschichte. Die Herausforderung des Ethnozentrismus in der Moderne und dieAntwort der Kulturwissenschaften, in: Jörn Rüsen et al. (Hg.), Die Vielfalt derKulturen. Frankfurt/Main, S. I2-36.

- 2003: Kann gestern besser werden? Essays zum Bedenken der Geschichte. Berlin.

Runeberg, Arne, 1947: Witches, demons and fertility magic: analysis of their significance and mutual relations in West-European folk religion. Helsingfors.

Saliba, John A., I983: Die Zukunft des »Homo Religiosus«. Einige anthropologische Gedanken zu Mircea Eliade, in: Hans Peter Duerr (Hg.), Sehnsucht nach dem Ursprung: zu Mircea Eliade. Frankfurt/Main, S. 9-3I.

Salter, W. H., I948: The Society for Psychical Research: an outline of its histo$r y$. London.

Samarin, William J., I965: Language of silence, in: Practical Anthropology I2 (3), S. II5-II8.

Sartori, Paul, I935-36: Artikel »Rauchnächte«, in: Handwörterbuch des deutschen Aberglaubens. Bd. 7. Berlin, Leipzig, Sp. 529-532.

Schaal, Rudolf, I959: Das Mitleben mit dem Lebendigen, in: Westermanns Pädagogische Beiträge II (8), S. 330-335.

Schäfer, Herbert, I958: Der Okkulttäter. (Hexenbanner, magische Heiler, Erdenstrahler). Bonn.

Scharbert, Josef, I979: Das Alter und die Alten in der Bibel, in: Saeculum 30 (4), S. 338-354.

Schebesta, Paul, I95I: Die Religion der Primitiven, in: Franz König (Hg.), Christus und die Religionen der Erde: Handbuch der Religionsgeschichte. Bd. I. Freiburg im Breisgau, S. 539-578.

Scheftelowitz, Isidor, I9I2: Das Schlingen- und Netzmotiv im Glauben und Brauch der Völker. Gießen.

- I9I4: Die Sündentilgung durch Wasser, in: Archiv für Religionswissenschaft I7, S. 353-412.

Schiffauer, Werner, I987: Die Bauern von Subay: das Leben in einem türkischen Dorf. Stuttgart.

Schimmel, Annemarie, 200I: Zeitvorstellungen im Islam, in: Landeshauptstadt München (Hg.), Jede Kultur hat ihre Zeit: Dokumentation der gleichnamigen Veranstaltungsreihe vom November 1999 bis Februar 2000. München, S. I8-3I.

Schindel, Leo, I967: Placebo und Placebo-Effekte in Klinik und Forschung, in: Arzneimittel-Forschung I7 (7), S. 892-9I8. 
Schmidt, Helmut, I993: Fortschritte und Probleme der PsychokineseForschung, in: Zeitschrift für Parapsychologie und Grenzgebiete der Psychologie 35 (I-2), S. 28-40.

Schmidt, Wilhelm, I9I2: Der Ursprung der Gottesidee: eine historisch-kritische und positive Studie. Bd. I. Münster in Westfalen.

- I9I2a: Andrew Lang. Folklorist and critic, in: Folk-Lore 23, S. 37I-375.

Schmökel, Hartmut, I956: Das Land Sumer. Stuttgart.

- I957: Geschichte des alten Vorderasien. Leiden.

Schneider, Christina M., I990: Wilhelm Wundts Völkerpsychologie: Entstehung und Entwicklung eines in Vergessenheit geratenen, wissenschaftshistorisch relevanten Fachgebietes. Bonn.

Schopenhauer, Arthur, o.J.: Animalischer Magnetismus und Magie, in: Arthur Schopenhauers sämtliche Werke in zwölf Bänden. Bd. 6. Stuttgart, Berlin, S. 323-350.

Schouten, Sybo A., I99I: Quantitativ ausgewertete Experimente mit Medien und Paragnosten - eine Übersicht, in: Zeitschrift für Parapsychologie und Grenzgebiete der Psychologie 33 (3-4), S. 203-236.

Schröter-Kunhardt, Michael, I993: Das Jenseits in uns, in: Psychologie heute I993 (6), S. 64-69.

- I995: Erfahrungen Sterbender während des klinischen Todes, in: TW Neurologie Psychiatrie 9, S. I32-I40.

Schuetz, Alfred, I944: The strangers. An essay in social psychology, in: The American Journal of Sociology 49 (6), S. 499-507.

Schurtz, Heinrich, I902: Altersklassen und Männerbünde: eine Darstellung der Grundformen der Gesellschaft. Berlin.

Seligmann, Siegfried, I922: Die Zauberkraft des Auges und das Berufen: ein Kapitel aus der Geschichte des Aberglaubens. Hamburg.

- I927: Die magischen Heil- und Schutzmittel aus der unbelebten Natur, mit besonderer Berücksichtigung der Mittel gegen den bösen Blick: eine Geschichte des Amulettwesens. Stuttgart.

Sell, Hans Joachim, I955: Der schlimme Tod bei den Völkern Indonesiens. 's-Gravenhage.

Serpenti, L. M., I968: Headhunting and magic on Kolepom (FrederikHendrik Island, Irian Barat), in: Tropical Man I, S. II6-I39.

Shils, Edward, I975: Center and periphery: essays in macrosociology. Chicago, London.

Shukla, Brahma K., I959: The Daflas of the Subansiri region. Shillong.

Sibeth, Achim, I992: Masken in krisenhaften Situationen an Beispielen aus Indonesien, in: Eva Ch. Raabe (Hg.), Mythos Maske: Ideen, Menschen, Weltbilder. Frankfurt/Main, S. 47-88.

Silberbauer, George B., I972: The G/wi Bushmen, in: Marco G. Bicchieri (Hg.), Hunters and gatherers today: a socioeconomic study of eleven such cultures in the twentieth century. New York, S. 27I-326.

- I98I: Hunter and habitat in the central Kalahari Desert. Cambridge.

Simenon, Georges, I980: Maigret und das Verbrechen in Holland. Zürich. 
Simpson, George G., I969: Evolution. Methoden und derzeitiger Stand der Theorie, in: Anne Roe/George G. Simpson (Hg.), Evolution und Verhalten. Frankfurt/Main, S. 7-35.

Sinha, Tarunchandra, I966: The psyche of the Garos. Calcutta.

Smith, William C., I925: The Ao Naga tribe of Assam. London.

Smoljak, Anna V., I966: Ul'či: chozjajstvo, kul'tura i byt v prošlom i nastojaščem. Moskva.

- I99I: Šaman: ličnost', funkcii, mirovozzrenie (narody Nižnego Amura). Moskva.

Smolla, Günter, I967: Epochen der menschlichen Frühzeit. Freiburg im Breisgau, München.

Snow, Dean R., I994: The Iroquois. Oxford, Cambridge, Mass.

Spamer, Adolf, I958: Romanusbüchlein: historisch-philologischer Kommentar $z$ u einem deutschen Zauberbuch. Berlin.

Specht, Rainer, 2002: Schulphilosophische Meinungen über angenommene Engelleiber, in: Hans-Jürgen Horn (Hg.), Jakobs Traum: zur Bedeutung der Zwischenwelt in der Tradition des Platonismus. St. Katharinen, S. I39-I52.

Speck, Frank G., I935: Naskapi: the savage hunters of the Labrador Peninsula. Norman.

Spergel, David N./Turok, Neil G., I992: Texturen - Ursache der kosmischen Grobstruktur?, in: Spektrum der Wissenschaft I992 (5), S. 72-8I.

Spindler, Louise S., I962: Menomini women and culture change. Menasha.

Springer, Michael, 2000: Dünne Leiter quanteln Wärme, in: Spektrum der Wissenschaft 2000 (8), S. 22-24.

Srinivas, M. N., I952: Religion and society among the Coorgs of South India. Oxford.

Staudacher, Willibald, I968: Die Trennung von Himmel und Erde: ein vorgriechischer Schöpfungsmythus bei Hesiod und den Orphikern. Darmstadt.

Stemplinger, Eduard, I9I9: Sympathieglaube und Sympathiekuren in Altertum und Neuzeit. München.

Stengel, Paul, I898: Die griechischen Kultusaltertümer. München.

Stevenson, Robert Louis, ${ }^{2}$ 2000: Der Ausschlachter: ein Criminalroman. München.

Stöhr, Waldemar, I992: Leben und Töten in der Vorstellung altindonesischer Völker, in: Bernhard Mensen SVD (Hg.), Recht auf Leben - Recht auf Töten: ein Kulturvergleich. Nettetal, S. 59-78.

Strack, Hermann L., I900: Das Blut im Glauben und Aberglauben der Menschheit: mit besonderer Berücksichtigung der »Volksmedizin « und des »jüdischen Blutritus«. München.

Strathern, Marilyn, I972: Women in between: female roles in a male world; Mount Hagen, New Guinea. London, New York.

Straubergs, Karlis, I957: Zur Jenseitstopographie, in: ARV Journal of Scandinavian Folklore I3, S. 56-IIo. 
Strogatz, Steven H./Stewart, Ian, I994: Gekoppelte Oszillatoren und biologische Synchronisation, in: Spektrum der Wissenschaft I994 (2), S. 74-8I.

Sundermeier, Theo, I980: Todesriten und Lebenssymbole in den afrikanischen Religionen, in: Gunther Stephenson (Hg.), Leben und Tod in den Religionen: Symbol und Wirklichkeit. Darmstadt, S. 250-259.

Swanson, Richard A., I985: Gourmantché ethnoanthropology: a theory of human being. Lanham.

Szromba-Rysowa, Zofia, I98I: The social aspect of the popular diet in Poland, with special consideration of eating customs and nutritional prescriptions and proscriptions, in: Alexander Fenton/Trefor M. Owen (Hg.), Food in perspective. Edinburgh, S. 267-275.

Tackenberg, Kurt, I955: Zum Problem der Teilbestattungen und der Totenfurchtin prähistorischer Zeit, in: W. Lang et al. (Hg.), Von fremden Völkern und Kulturen. Düsseldorf, S. 97-I03.

Taksami, uner M., I976: Predstavlenija o prirode i čeloveke u nivchov, in: Innokentij S. Vdovin (Hg.), Priroda $i$ čelovek $v$ religioznych predstavlenijach narodov Sibiri i severa (vtoraja polovina XIX - načalo XX v.). Leningrad, S. 203-216.

Tambiah, Stanley J., ${ }^{3}$ I993: Magic, science, religion, and the scope of rationality. Cambridge.

Theodoratus, Dorothea J./LaPena, Frank, I994: Wintu sacred geography of northern California, in: David L. Carmichael et al. (Hg.), Sacred sites, sacred places. London, S. 20-3I.

Thiel, Josef F., I990: Der Inzest bei den Yansi. Eine Feldstudie, in: KarlHeinz Kohl et al. (Hg.), Die Vielfalt der Kultur: ethnologische Aspekte von Verwandtschaft, Kunst und Weltauffassung; Ernst Wilhelm Müller zum 65. Geburtstag. Berlin, S. I29-I43.

- 200I: Jahre im Kongo: Missionar und Ethnologe bei den Bayansi. Frankfurt/Main.

Thornton, Robert J., I980: Space, time, and culture among the Iraqw of Tanzania. New York.

Thurnwald, Richard, I951: Des Menschengeistes Erwachen, Wachsen und Irren: Versuch einer Paläopsychologie von Naturvölkern mit Einschlu $\beta$ der archaischen Stufe und der allgemein menschlichen Züge. Berlin.

— I927: Artikel »Moral«, in: Reallexikon der Vorgeschichte. Bd. 8. Berlin, Sp. 289-3II.

Tidemann, H., I935: Der glückbringende Sektpfropfen, in: Niederdeutsche Zeitschrift für Volkskunde 13, S. 53.

Timm, Ulrich, I983: Was wissen wir wirklich über Psi-Phänomene? Ein kritisches Resümee, in: Eberhard Bauer/Walter von Lucadou (Hg.), Spektrum der Parapsychologie: Hans Bender zum 75. Geburtstag. Freiburg im Breisgau, S. 224-242.

Titiev, Mischa, I960: A fresh approach to the problem of magic and religion, in: Southwestern Journal of Anthropology I6 (3), S. 292-298. 
Todorov, Tzvetan/Ducrot, Oswald, I975: Enzyklopädisches Wörterbuch der Sprachwissenschaften. Frankfurt/Main.

Tokarev, Sergej A., I959: Suščnost' i proizchoždenie magii, in: Issledovanija i materialy po voprosam pervobytnych religioznych verovanij. Moskva, S. 7-75.

Tradicionnoe mirovozzrenie, I989: Tradicionnoe mirovozzrenie tjurkov južnojSibiri: čelovek, obščestvo. Novosibirsk.

Traube, Elizabeth G., I989: Obligations to the source. Complementary and hierarchy in an eastern Indonesian society, in: David MayburyLewis/Uri Almagor (Hg.), The attraction of opposites: thought and society in the dualistic mode. Ann Arbor, S. 32I-344.

Tremearne, A. J. N., I9I2: Notes on the Kagoro and other Nigerian headhunters, in: The Journal of the Royal Anthropological Institute of Great Britain and Ireland 42, S. I36-I99.

Treml, Alfred K., 2003: Religion aus systemtheoretischer Sicht, in: Annette Scheunpflug/Alfred K. Treml (Hg.), In Gottes Namen: Religion. Velber, S. 6-I2.

Turner, Victor W., I968: The drums of affliction: a study of religious processesamong the Ndembu of Zambia. Oxford.

Tylor, Edward B., I87I: Primitive culture: researches into the development of mythology, philosophy, religion, language, art and custom. 2 Bde. New York.

— I873: Die Anfünge der Cultur: Untersuchungen über die Entwicklung der Mythologie, Philosophie, Religion, Kunst und Sitte. Bd. I. Leipzig.

Ufer, Heinrich, I930: Religion und religiöse Sitte bei den Samojeden. Erlangen.

Ugrinovič, Dmitrij M., I973: Vvedenie v teoretičeskoe religiovedenie. Moskva.

Vaihinger, Hans, ${ }^{8}$ I922: Die Philosophie des Als Ob: System der theoretischen, praktischen und religiösen Fiktionen der Menschheit auf Grund eines idealistischen Positivismus. Leipzig.

Versnel, Hendrik S., Die Poetik der Zaubersprüche, in: Tilo Schabert/ Rémi Brague (Hg.), Die Macht des Wortes. München, S. 233-297.

Vollmer, Gerhard, I986: Was können wir wissen? Bd. 2. Stuttgart.

Von den Steinen, Karl, ı894: Unter den Naturvölkern Zentral-Brasiliens: Reiseschilderung und Ergebnisse der Zweiten Schingú-Expedition 1887-1888. Berlin.

Vorwahl, H., I929: Psychologie der Vorpubertät: eine Einführung in das Eigenleben der Halbwüchsigen. Bonn.

Vries, Jan de, I96r: Forschungsgeschichte der Mythologie. Freiburg im Breisgau, München.

Wagley, Charles/Galvão, Eduardo, I949: The Tenetehara Indians of Brazil: a culture in transition. New York.

Walker, Deward E. Jr., I967: Nez Perce sorcery, in: Ethnology 6, S. 66-96. Weber, Max, ${ }^{6}{ }_{19} 85$ : Wissenschaft als Beruf, in: Max Weber, Gesammelte Aufsätze zur Wissenschaftslehre. Tübingen, S. 582-613. 
Webster, Hutton, I948: Magic: a sociological study. Stanford.

Wehner, Rüdiger, I992: Kollektive Intelligenz sozialer Insekten, in: Christian Thomas (Hg.), »Auf der Suche nach dem ganzheitlichen Augenblick«: der Aspekt Ganzheit in den Wissenschaften. Zürich, S. I49-I62.

Weinberg, Richard, I904: Der syrjänische Pam-Kultus, in: Globus 86, S. 259-26I.

Weizsäcker, Carl Friedrich von, ${ }^{3}$ I994: Aufbau der Physik. München.

Weizsäcker, Ernst von, I974: Erstmaligkeit und Bestätigung als Komponenten der pragmatischen Information, in: Ernst von Weizsäcker (Hg.), Offene Systeme I: Beiträge zur Zeitstruktur von Information, Entropie und Evolution. Stuttgart, S. 82-II3.

Werner, Heinz, I928: Über magische Verhaltungsweisen im Kindesalter, in: Zeitschrift für Pädagogische Psychologie 29, S. 465-476.

- ${ }^{2}$ I933: Einführung in die Entwicklungspsychologie. Leipzig.

Werner, Thomas, I996: Die den Teufel zwingen. Schwarze Magie im Mittelalter, in: Sowi 25 (I), S. 5-II.

Wesselski, Albert (Hg.), I942: Deutsche Märchen vor Grimm. Brünn, München, Wien.

Westley, F. R., I980: Purification and healing rituals in new religious movements, in: Ray B. Browne (Hg.), Rituals and ceremonies in popular culture. Bowling Green, S. 36-47.

Whiting, Beatrice B., I977: Paiute sorcery. Sickness and social control, in: David Landy (Hg.), Culture, disease, and healing: studies in medical anthropology. New York, S. 210-218.

Wickler, Wolfgang/Seibt, Uta, I977: Das Prinzip Eigennutz: Ursachen und Konsequenzen sozialen Verhaltens. Hamburg.

Widengren, Geo, I960: Iranisch-semitische Kulturbegegnung in parthischer Zeit. Köln, Opladen.

- I96r: Das Prinzip des Bösen in den östlichen Religionen, in: Das Böse. Zürich, Stuttgart, S. 25-6r.

Wiener, Michael, I992: Maskierte Männer - besessene Frauen?, in: Eva Ch. Raabe (Hg.), Mythos Maske: Ideen, Menschen, Weltbilder. Frankfurt/Main, S.243-264.

Wilson, Monica, I957: Rituals of kinship among the Nyakyusa. London.

- I959: Divine kings and the » breath of men «. Cambridge.

Witherspoon, Gary, I98I: Relativismus in der ethnographischen Theorie und Praxis, in: Hans Peter Duerr (Hg.), Der Wissenschaftler und das Irrationale. Bd. I. Frankfurt/Main, S. 98-I25.

Wittgenstein, Ludwig, I979: Bemerkungen über Frazers »Golden Bough«. Atlantic Highlands.

Wolf, Ulrich, I999: Die Kraft der Gedanken, in: Spektrum der Wissenschaft I999 (8), S. I5-I7.

Wundt, Wilhelm, ${ }^{3}$ I920: Völkerpsychologie: eine Untersuchung der Entwicklungsgesetze von Sprache, Mythus und Sitte. Bd. 4, I. Leipzig.

Wuttke, Adolf, ${ }^{3}$ I9००: Der deutsche Volksaberglaube der Gegenwart. Berlin. 
Zeininger, Karl, I929: Magische Geisteshaltung im Kindesalter und ihre Bedeutung für die religiöse Entwicklung. Leipzig.

Zelenin, Dmitrij, I932: Die religiöse Funktion der Volksmärchen, in: Internationales Archiv für Ethnographie 3I, S. 2I-3I.

Zimmer, Dieter E., ${ }^{2}$ I990: Tiefenschwindel: die endlose und die beendbare Psychoanalyse. Reinbek.

Zusne, Leonhard/Jones, Warren H., ${ }^{2}$ I989: Anomalistic psychology: a study of magical thinking. Hillsdale.

Zwernemann, Jürgen, I984: Essen und Trinken bei den Moba in NordTogo, in: Matreier Gespräche: Otto Koenig 70 Jahre. Wien, Heidelberg, S. 37I-376. 


\section{Die Titel dieser Reihe:}

Klaus E. Müller

\section{Der sechste Sinn}

Ethnologische Studien zu

Phänomenen der

außersinnlichen Wahrnehmung

Mai 2004, 214 Seiten,

kart., $20,80 €$,

ISBN: 3-89942-203-1

Gunter Gebauer, Thomas

Alkemeyer, Bernhard Boschert,

Uwe Flick, Robert Schmidt

\section{Treue zum Stil}

Die aufgeführte Gesellschaft

Mai 2004, 150 Seiten,

kart., $12,80 €$,

ISBN: 3-89942-205-8

Thomas Lemke

\section{Veranlagung und}

Verantwortung

Genetische Diagnostik

zwischen Selbstbestimmung

und Schicksal

Februar 2004, 140 Seiten,

kart., mit Glossar, 14,80 €,

ISBN: 3-89942-202-3

Karl-Heinrich Bette

\section{$\mathrm{X}$-treme}

Zur Soziologie des Abenteuer-

und Risikosports

Februar 2004, 158 Seiten,

kart., $14,80 €$,

ISBN: 3-89942-204-X
Volkhard Krech

\section{Götterdämmerung}

Auf der Suche nach Religion 2003, 112 Seiten,

kart., $12,80 €$,

ISBN: 3-89942-100-O

Volker Heins

Das Andere der Zivilgesellschaft

Zur Archäologie eines Begriffs 2002, 102 Seiten,

kart., $12,80 €$,

ISBN: 3-933127-88-2

Stefan Weber

Medien - Systeme - Netze

Elemente einer Theorie der

Cyber-Netzwerke

2001, 128 Seiten,

kart., $13,80 €$,

ISBN: 3-933127-77-7

Leseproben und weitere Informationen finden Sie unter: www.transcript-verlag.de 


\section{Zeitschrift für Parapsychologie und Grenzgebiete der Psychologie}

Die Zeitschrift für Parapsychologie und Grenzgebiete der Psychologie ist das renommierteste Fachorgan für die Parapsychologie und verwandte Gebiete der engeren Nachbarwissenschaften im deutschsprachigen Raum. Sie wird getragen von der "Wissenschaftlichen Gesellschaft zur Förderung der Parapsychologie« (WGFP) und dem »Institut für Grenzgebiete der Psychologie und Psychohygiene" (IGPP).

Die Zeitschrift verfolgt interdisziplinäre Forschungs- und Erkenntnisinteressen zum Gesamtspektrum der verhaltensund kognitionswissenschaftlichen »Grenzbereichsphänomene«.

Sie bietet Beiträge zu Fragen der Außersinnlichen Wahrnehmung und Psychokinese, der Diagnostischen und Klinischen
Psychologie, der Sozialpsychologie und Psychohygiene, der Physik (Quantenphysik) und Neurowissenschaften, außerschulmäßiger Heilverfahren (»Geistheilen«) und verwandter Phänomengruppen der Volkskunde und Ethnologie (Besessenheit, Ekstatik, Schamanismus, Magie, Hexerei, Wiedergeburtsglaube). Darüber hinaus informiert sie über neueste Forschungsergebnisse, berichtet über Fachkongresse und bespricht einschlägige Neuerscheinungen.

Die Zeitschrift erscheint halbjährlich in je zwei Doppelheften. Sie ist im Buchhandel oder direkt bei der »Wissenschaftlichen Gesellschaft zur Förderung der Parapsychologie", Hildastraße 64, D-79102 Freiburg i. Br. (Tel./ Fax: 0761/77202) erhältlich (Einzelhefte oder Abonnement). 